\title{
Quantitative Analysis of the Performance of Center-of-Pressure Measures in Static Posturography
}

\author{
by
}

Shabana Baig

A thesis submitted to the Faculty of Graduate and Postdoctoral Affairs in partial fulfillment of the requirements for the degree of

\author{
Master of Applied Science \\ in Biomedical Engineering
}

Ottawa-Carleton Institute for Biomedical Engineering

Department of Systems and Computer Engineering

Carleton University

Ottawa, Ontario, Canada

March 2013 
Library and Archives

Canada

Published Heritage

Branch

395 Wellington Street

Ottawa ON K1A ON4

Canada
Bibliothèque et

Archives Canada

Direction du

Patrimoine de l'édition

395 , rue Wellington

Ottawa ON K1A ON4

Canada
Your file Votre référence

ISBN: 978-0-494-94662-6

Our file Notre référence

ISBN: $978-0-494-94662-6$
NOTICE:

The author has granted a nonexclusive license allowing Library and Archives Canada to reproduce, publish, archive, preserve, conserve, communicate to the public by telecommunication or on the Internet, loan, distrbute and sell theses worldwide, for commercial or noncommercial purposes, in microform, paper, electronic and/or any other formats.

The author retains copyright ownership and moral rights in this thesis. Neither the thesis nor substantial extracts from it may be printed or otherwise reproduced without the author's permission.
AVIS:

L'auteur a accordé une licence non exclusive permettant à la Bibliothèque et Archives Canada de reproduire, publier, archiver, sauvegarder, conserver, transmettre au public par télécommunication ou par l'Internet, prêter, distribuer et vendre des thèses partout dans le monde, à des fins commerciales ou autres, sur support microforme, papier, électronique et/ou autres formats.

L'auteur conserve la propriété du droit d'auteur et des droits moraux qui protege cette thèse. $\mathrm{Ni}$ la thèse ni des extraits substantiels de celle-ci ne doivent être imprimés ou autrement reproduits sans son autorisation.
In compliance with the Canadian Privacy Act some supporting forms may have been removed from this thesis.

While these forms may be included in the document page count, their removal does not represent any loss of content from the thesis.
Conformément à la loi canadienne sur la protection de la vie privée, quelques formulaires secondaires ont été enlevés de cette thèse.

Bien que ces formulaires aient inclus dans la pagination, il n'y aura aucun contenu manquant. 


\begin{abstract}
Static posturography analyses center-of-pressure (COP) variations during a static standing posture to quantify postural stability. The objective of this thesis is to investigate the performance of six conventional COP measures, including the effects of analysis window length. These COP measures were compared during four different stability conditions for both simulated and experimental data. Performance was quantified by cluster analysis using the silhouette coefficient. Better performance was associated with parameter(s) that maximize the inter-cluster distances (increased discernability between stability conditions) and minimize the intra-clusters distances (increased repeatability within a given stability condition). Results suggest that average velocity is the best measure to assess postural stability amongst the investigated measures. The results suggest that the performance of COP measures increase with the increase of analysis window size.
\end{abstract}




\section{Acknowledgements}

I would like to say special thanks to my supervisor Dr. Adrian Chan for his excellent expertise and guidance and also for helping me get through my stressful moments. I would also like to say thanks to my co-supervisor Richard Dansereau for his excellent expertise. I am also thankful to my colleagues Anas Al-Bulbul, Graham D. Fraser, Varsha Chaugai, and Shermeen Nizami for their motivational support in the lab and friendship outside, Shazia Mirza for her delicious food and hot cups of tea.

I am thankful to my husband Tariq Baig for his help and positive attitude to encourage me to keep going. I am also thankful to my kids Abdullah Baig, Aiman Baig, Hasan Baig and Ibrahim Baig for their understanding and moral support.

I am thankful to my parents for their prayers and coming to Canada to help me in taking care of my children while I was at the University for long hours. I am thankful to my God that I have wonderful people around me. It would not have been possible without their help.

I would also like to thanks School of Rehabilitation Sciences, Faculty of Health Sciences, University of Ottawa; and Bruyère Continuing Care Élisabeth Bruyère Research Institute for providing data for this research. 


\section{Statement of Originality}

The purpose of Statement of Originality is to certify that to my best knowledge, the research work presented in the thesis is conducted by the author at Carleton University in partial fulfillment of the requirements for the degree of M.A.Sc. in Biomedical Engineering and has not been submitted for any other degree. The methodology for the study was designed by the author with her supervisors. The data collection for this study was conducted at Élisabeth Bruyère Research Centre by Research Associate Anthony Remaud in the supervision of Professor Martin Bilodeau, University of Ottawa. Results of this research have been disseminated in publications other than this thesis. A summary of these publications and a description of the author's contributions are provided in this statement.

The results presented in the following conference paper appear in Chapter 4. The first author performed all the analysis and developed a novel methodology to investigate performance of center-of-pressure conventional measures with the feedback from coauthors. The data were collected by one of the co-authors at the School of Rehabilitation Sciences, Faculty of Health Sciences, University of Ottawa. The manuscript was written and revised with feedback from co-authors. The first paper was presented as an oral presentation by the first author at the 2012 International Conference on Electrical and Computer Systems in Ottawa.

1. Baig, S., Chan, A. D. C., Dansereau, R. M., Remaud, A., \& Bilodeau, M. (2012). Performance of center-of-pressure measures. Proceedings of the International Conference on Electrical and Computer Systems (pp. 22-24). Ottawa. 
The results presented in journal paper appear in Chapters 3 and 4 . The author performed all data analyses. The manuscript was prepared by the author with the revisions by the coauthors. The paper was submitted for publication in the International Journal of Electrical and Computer Systems (IJECS). The data were collected by one of the co-authors at the School of Rehabilitation Sciences, Faculty of Health Sciences, University of Ottawa and Bruyère Continuing Care, Élisabeth Bruyère Research Institute.

1. Baig, S., Dansereau, R. M., Chan, A. D. C., Remaud, A., \& Bilodeau, M. (submitted 2012). Cluster Analysis of Center-of-Pressure Measures. International Journal of Electrical and Computer Systems (IJECS). 


\section{Table of Contents}

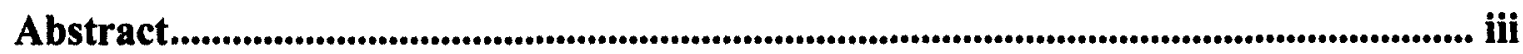

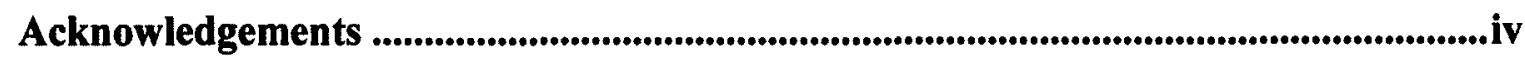

Statement of Originality .........................................................................................................................v

Table of Contents ..............................................................................................................................vii

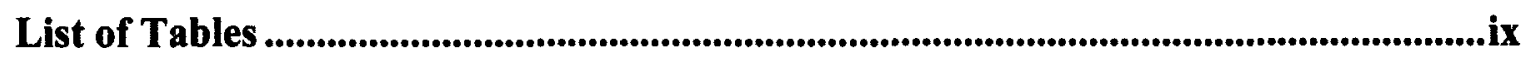

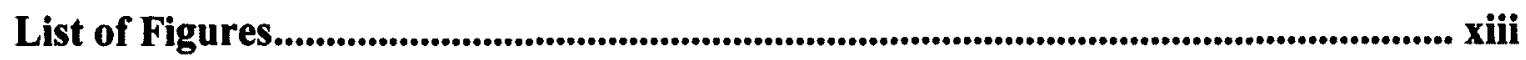

List of Abbreviations ..................................................................................................... xviii

List of Symbols ................................................................................................................xix

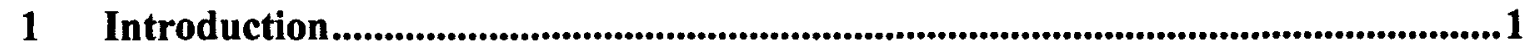

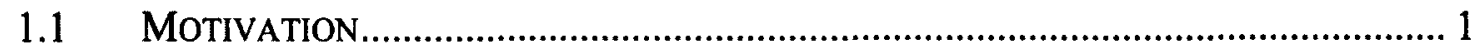

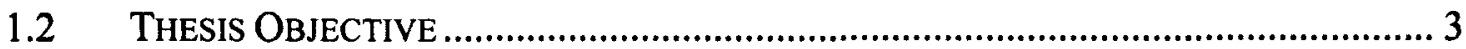

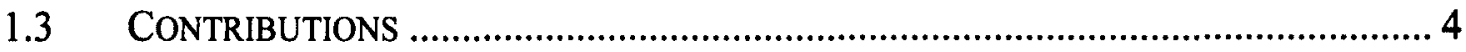

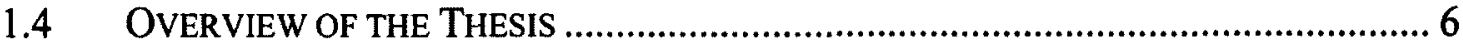

2 Literature Review .............................................................................................................

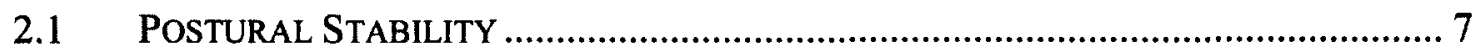

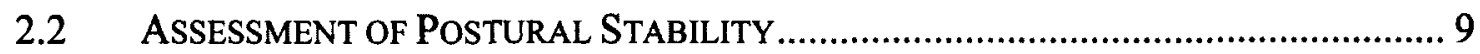

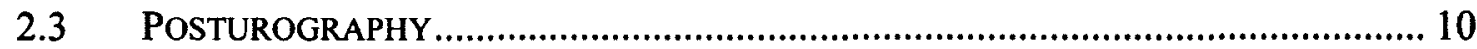

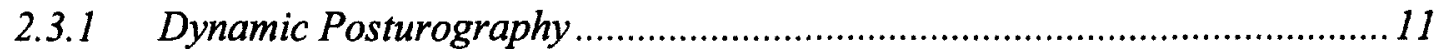

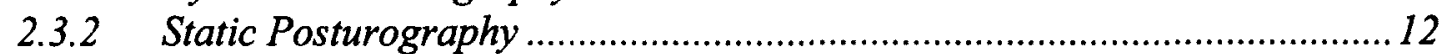

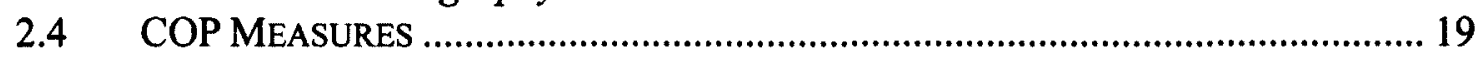

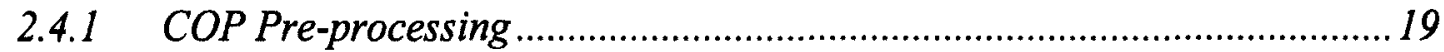

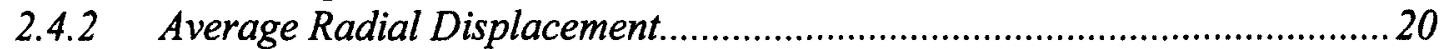

2.4.3 Average Velocity ..............................................................................21

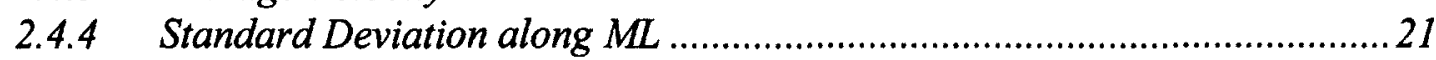

2.4.5 Standard Deviation along AP .............................................................21

2.4.6 Standard Deviation of Radial Displacement ...............................................22

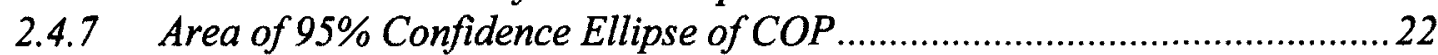

2.5 THEORIES OF POSTURAL STABILITY .................................................................... 23

2.6 INVERTED PENDULUM MODELS OF HUMAN UPRIGHT POSITION ......................... 24

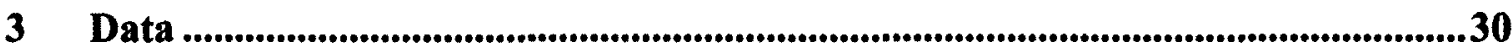

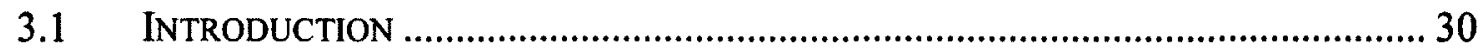

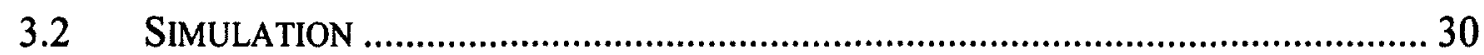

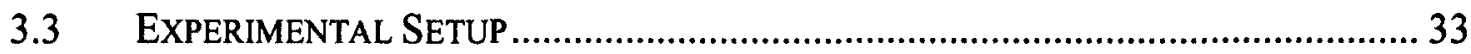

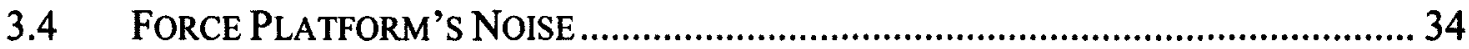

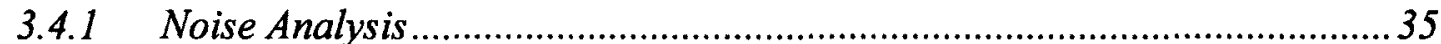

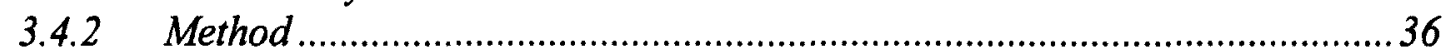

3.4.3 Background Noise Analysis ................................................................ 


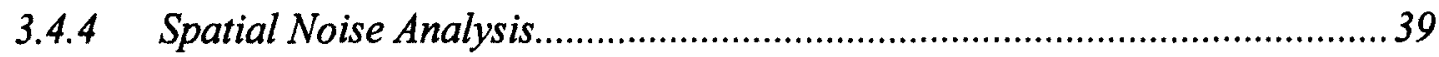

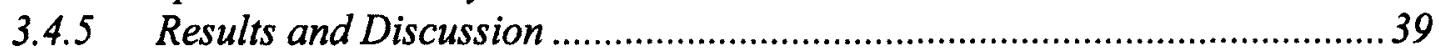

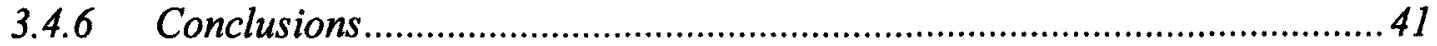

3.5 EXPERIMENTAL DATA FROM HUMAN SUBJECTS ............................................ 42

4 Performance of Center-of-Pressure Measures..................................................................45

4.1 INTRODUCTION

4.2 PERFORMANCE OF COP MEASURES ........................................................... 46

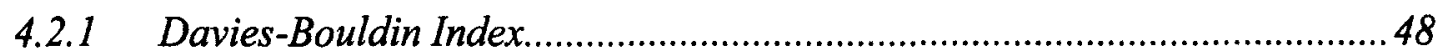

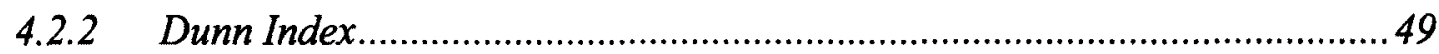

4.2.3 Silhouette Coefficient ........................................................................... 49

4.2.4 Comparison of Validity Indices ...........................................................51

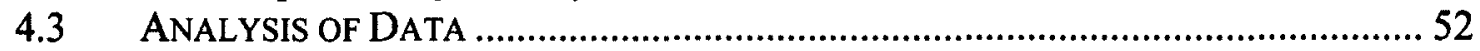

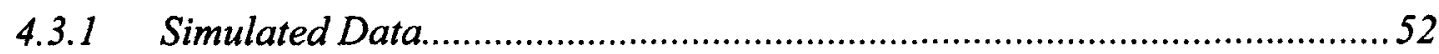

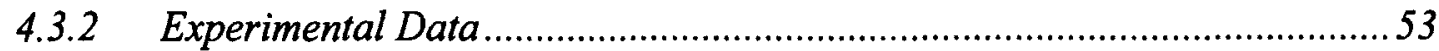

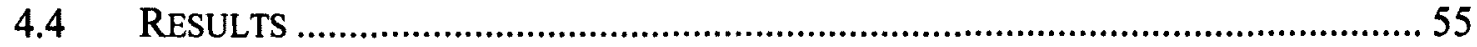

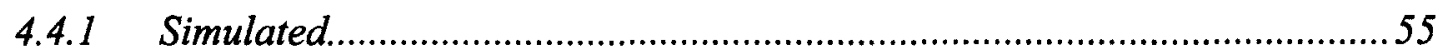

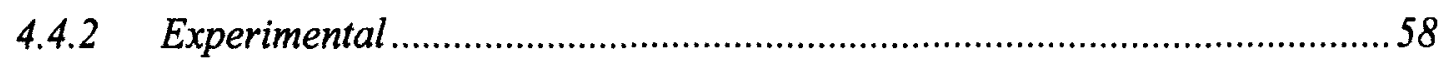

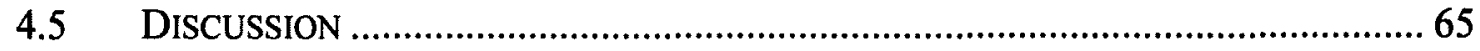

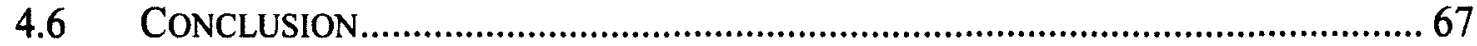

$5 \quad$ Effect of Analysis Window Length .................................................................................68

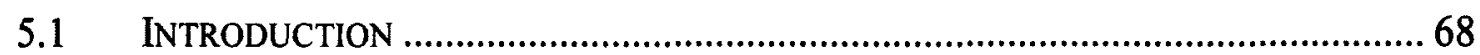

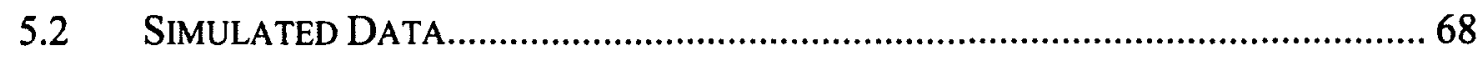

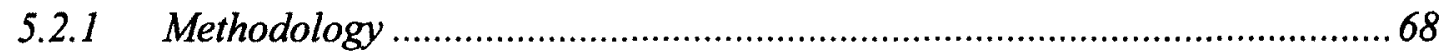

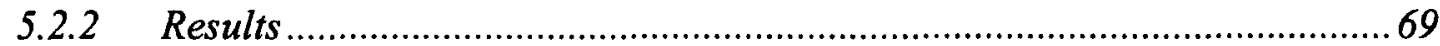

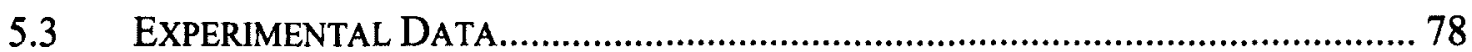

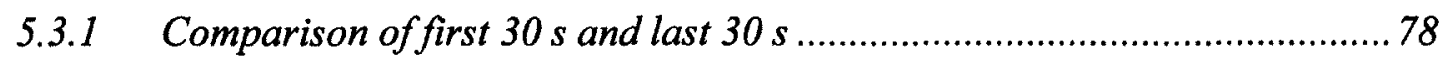

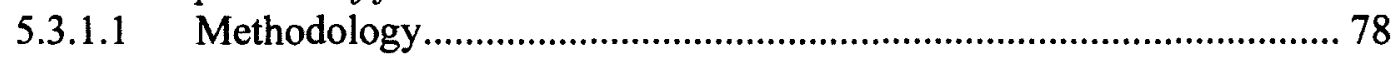

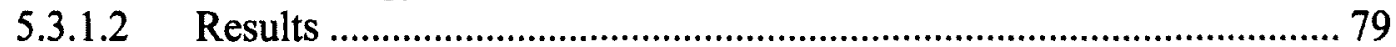

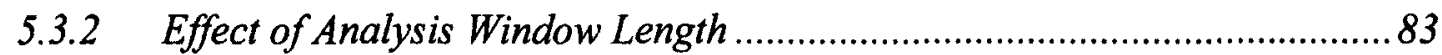

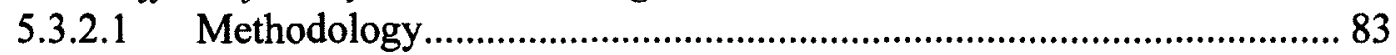

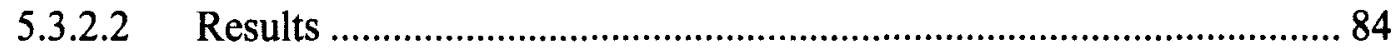

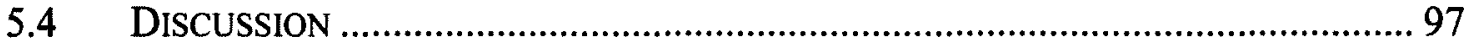

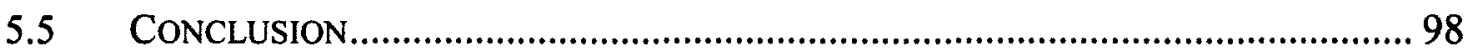

6 Thesis Summary and Future Recommendations .........................................................100

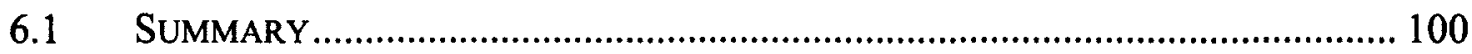

6.2 RECOMMENDATIONS FOR FUTURE WORK ……......................................... 101

7 Appendix A: Box Plots of COP Measures ....................................................................104

8 Appendix B: Plots of Simulated Data ..............................................................................114

9 Appendix C: Statistical Analysis of Effect of Analysis Window Length ...........115

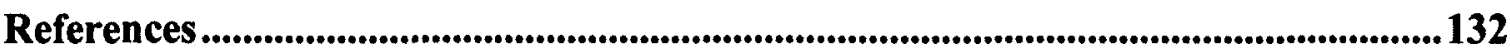




\section{List of Tables}

Table 2.1: Studies characteristics and selected COP parameters measured on a firm surface with EO....................................................................................................... 17

Table 3.1: Inverted pendulum parameters for an average adult male.................................30

Table 3.2: Model gains for four different stability conditions (Boes, 2011) ......................33

Table 3.3: The range of $\mathrm{COP}$ values in noise measurements. ............................................41

Table 3.4: Subject participant information. ........................................................................42

Table 3.5: 11 different sets of the four stability conditions..................................................44

Table 4.1: Mean and standard deviations of simulated COP measures clusters.................57

Table 4.2: Mean and standard deviation of COP measures for the 11 trials of subject $1 . .61$

Table 4.3: Mean and standard deviation of COP measures for the 11 trials of subject 2..61

Table 4.4: Mean and standard deviation of COP measures for the 10 trials of subject 3..61

Table 4.5: Mean and standard deviation of COP measures for the 11 trials of subject $4 . .62$

Table 4.6: Mean and standard deviation of COP measures for the 11 trials of subject 5..62

Table 4.7: Mean and standard deviation of COP measures for the 11 trials of subject $6 . .62$

Table 4.8: Mean and standard deviation of COP measures for the 11 trials of subject 7..63

Table 4.9: Mean and standard deviation of COP measures for the 11 trials of subject $8 . .63$

Table 4.10: Pairwise comparison of experimental COP measure with Bonferroni adjustment. ...............................................................................................................65

Table 5.1: The paired sample t-test on $\mathrm{V}_{\text {avg }}$, for first and last $30 \mathrm{~s}$ windows, for four stability conditions (FT-EO, FT-EC, SL-EO, and SL-EC) and for all eight subjects. 83

Table 5.2: One way repeated measure ANOVA within subject design for different window lengths for subject 1 .........................................................................................8

Table 5.3: One way repeated measure ANOVA within subject design for different window lengths for subject 2 ................................................................................8

Table 5.4: One way repeated measure ANOVA within subject design for different window lengths for subject 3.......................................................................................8 
Table 5.5: One way repeated measure ANOVA within subject design for different window lengths for subject 4 .

Table 5.6: One way repeated measure ANOVA within subject design for different

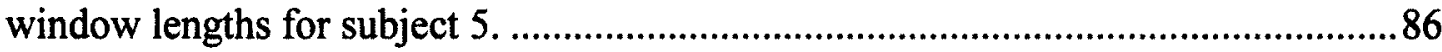

Table 5.7: One way repeated measure ANOVA within subject design for different window lengths for subject 6 .................................................................................. 86

Table 5.8: One way repeated measure ANOVA within subject design for different window lengths for subject 7. ...................................................................................8

Table 5.9: One way repeated measure ANOVA within subject design for different window lengths for subject 8 .................................................................................8

Table A.1: COP measures for pairwise comparison.........................................................112

Table A.2: Pairwise comparison of COP measures.

Table C.1: Pairwise comparison with Sidak correction for FT-EO of 11 trials for subjects 1 .

Table C.2: Pairwise comparison with Sidak correction for FT-EC of 11 trials for subjects 1 116

Table C.3: Pairwise comparison with Sidak correction for SL-EO of 11 trials for subjects 1 . 117

Table C.4: Pairwise comparison with Sidak correction for SL-EC of 11 trials for subjects 1

Table C.5: Pairwise comparison with Sidak correction for FT-EO of 11 trials for subject 2. 118

Table C.6: Pairwise comparison with Sidak correction for FT-EC of 11 trials for subject 2 118

Table C.7: Pairwise comparison with Sidak correction for SL-EO of 11 trials for subject 2 . 119

Table C.8: Pairwise comparison with Sidak correction for SL-EC of 11 trials for subject 2 . 119

Table C.9: Pairwise comparison with Sidak correction for FT-EO of 11 trials for subject 3. 120 
Table C.10: Pairwise comparison with Sidak correction for FT-EC of 11 trials for subject 3. 120

Table C.11: Pairwise comparison with Sidak correction for SL-EO of 11 trials for subject 3. 121

Table C.12: Pairwise comparison with Sidak correction for SL-EC of 11 trials for subject 3. 121

Table C.13: Pairwise comparison with Sidak correction for FT-EO of 11 trials for subject 4. 122

Table C.14: Pairwise comparison with Sidak correction for FT-EC of 11 trials for subject 4. 122

Table C.15: Pairwise comparison with Sidak correction for SL-EO of 11 trials for subject 4. 123

Table C.16: Pairwise comparison with Sidak correction for SL-EC of 11 trials for subject 4. 123

Table C.17: Pairwise comparison with Sidak correction for FT-EO of 11 trials for subject 5. 124

Table C.18: Pairwise comparison with Sidak correction for FT-EC of 11 trials for subject 5 . 124

Table C.19: Pairwise comparison with Sidak correction for SL-EO of 11 trials for subject 5 125

Table C.20: Pairwise comparison with Sidak correction for SL-EC of 11 trials for subject 5 . 125

Table C.21: Pairwise comparison with Sidak correction for FT-EO of 11 trials for subject 6. 126

Table C.22: Pairwise comparison with Sidak correction for FT-EC of 11 trials for subject 6. 126

Table C.23: Pairwise comparison with Sidak correction for SL-EO of 11 trials for subject 6 . 127

Table C.24: Pairwise comparison with Sidak correction for SL-EC of 11 trials for subject 6. 127

Table C.25: Pairwise comparison with Sidak correction for FT-EO of 11 trials for subject 7. 128 
Table C.26: Pairwise comparison with Sidak correction for FT-EC of 11 trials for subject 7.

Table C.27: Pairwise comparison with Sidak correction for SL-EO of 11 trials for subject

7. 129

Table C.28: Pairwise comparison with Sidak correction for SL-EC of 11 trials for subject 7. 129

Table C.29: Pairwise comparison with Sidak correction for FT-EO of 11 trials for subject 8.

Table C.30: Pairwise comparison with Sidak correction for FT-EC of 11 trials for subject 8. 130

Table C.31: Pairwise comparison with Sidak correction for SL-EO of 11 trials for subject 8. 131

Table C.32: Pairwise comparison with Sidak correction for SL-EC of 11 trials for subject 8. 


\section{List of Figures}

Figure 2.1: Computer screen of an individual posturograph and forces from the force platform. The posturograph is in the right corner of the screen and left corner of the screen presents Fx (medio-lateral), Fy (antero-posterior), and Fz (vertically) ground reaction forces, (from top to bottom respectively).

Figure 2.2: (a) A subject standing on the force platform, undergoing static posturography, and (b) Advanced Mechanical Technology Inc. (AMTI) force platform (AccuGait System, Watertown, MA, USA).

Figure 2.3: Forces measured by the force platform in (a) Fz (vertically), (b) Fx (ML), Fy (AP) and (c) moments Mx (ML), My (AP) and Mz (vertically) for subject 1 for Feet Together-Eyes Closed (FT-EC) condition of trial 1

Figure 2.4: 60s data from subject two with FT-EC stability condition of trial 1 (a) COP in ML direction, (b) COP in AP direction, (c) Posturograph two dimensional plot of the AP and ML COP (mean COP values are subtracted), (d) three diamentional posturograph

Figure 2.5: Inverted pendulum models of human upright stance postural control system, consist of pendulum body, open loop (PID) neural control system and a closed loop feedback control system: (a) inverted pendulum model without passive controllers, and (b) inverted pendulum model with passive controller, which produces third torque $\mathrm{T}_{\mathrm{p}}$ after (Maurer \& Peterka, 2005; Peterka, 2000).

Figure 3.1: Inverted pendulum models of human upright stance, two separate models to generate $\mathrm{COP}$ in (a) anteroposterior direction (COPy) and (b) mediolateral direction (COPx). These models contain a PID neural controller, along with a passive controller.

Figure 3.2: Experimental setup showing monitor, force platform and a subject standing on it.

Figure 3.3: Diagram of force platform showing circles around the co-ordinate of interest for placing the load on the surface of the force platform center $=c$, front $=f$, left $=1$, right $=r$ and back $=b$

Figure 3.4: (a) surface of the platform with grid marked to localize the coordinate of interest (b) wooden box, with wooden cube at the base, used to contain the weight and (c) shows the weight on the center of the force platform surface. .38

Figure 3.5: Static load test using a $45.5 \mathrm{~kg}$ weight, placed (c) center of the platform, (f) at the front of the platform, (r) on the right side, (d) on the left side of the platform and (b) on the back of the platform. 38 
Figure 3.6: The posturograph of the force platform (ACG 0536) loaded with static 45.5 $\mathrm{kg}$ at the center (mean value of COP is subtracted from each value of COP to bring the posturograph in the center $(0,0)$ of the graph). Blue lines are the COP of the static load and the red ellipse encloses the area of $95 \%$ confidence ellipse traversed by COP.

Figure 3.7: The force platform (ACG 0536) loaded with $45.5 \mathrm{~kg}$ at center, front, left, right and back successively. COP displacements are $<1.0 \mathrm{~mm}$ in all cases (mean value of $\mathrm{COP}$ is subtracted from each value of COP to bring the posturograph in the center $(0$, $0)$ ). 41

Figure 3.8: A subject is standing on the force platform with feet together, hands on their hips and visually focusing on a fixed target (black dot in red circle) on the wall.......43

Figure 4.1: Illustration of the inter- and intra-cluster distances (or variance) where $C i, C j$, $\mathrm{Ck}$, and $\mathrm{Cl}$ are four different clusters.

Figure 4.2: Illustration of (a) intra- and (b) inter-cluster distances. The red dots indicate clusters centroids for Davies-Bouldin Index 48

Figure 4.3: Illustration of inter-, $b i$, and intra-cluster, $a i$, distances for silhouette coefficient. 50

Figure 4.4: Methodology to investigate the performance of COP measures. 54

Figure 4.5: Box plot of clusters of conventional COP measures for the 100 iterations with different seeds for noise generators of simulation models: (a) average radial displacement $R D a v g($ b) average velocity $(V a v g)$, (c) area of $95 \%$ ellipse traversed by COP $(A R E A)$, (d) standard deviations of COPX $(\sigma \mathrm{x})$, (e) standard deviations of $\operatorname{COPy}(\sigma y)$, and $(\mathrm{f})$ standard deviation of radial displacement $\left(S_{-} D_{-} R D\right)$. 56

Figure 4.6: Silhouette coefficient values for the COP measures of simulated data. .57

Figure 4.7: Box plot of clusters of conventional COP measures for the 11 trials of subject \#2: (a) average radial displacement (RDavg), (b) average velocity (Vavg), (c) area of $95 \%$ ellipse traversed by COP (AREA), (d) standard deviations of COPX $(\sigma x),(\mathrm{e})$ standard deviations of $\operatorname{COPy}(\sigma y)$, and (f) standard deviation of radial displacement $\left(S D_{-} R D\right)$. 59

Figure 4.8: Box plots of clusters of average velocity ( $\mathrm{Vavg}$ ), for different stability conditions for eight subjects for four stability conditions FT-EO, FT-EC, SL-EO, and SL-EC. 60

Figure 4.9: Silhouette coefficient values for six COP measures of four stability conditions of eight subjects (S1 to $\mathrm{S} 8$ ). 
Figure 5.1: Average radial displacement, averaged over 100 trials with error bars for standard deviations and (b) slope of average radial displacement, of simulated COP for four stability conditions (Control, LowSP, MedSP, and HighSP) for different window. .71

Figure 5.2: Average velocity, averaged over 100 trials with error bars for standard deviations and (b) slope of Average velocity, of simulated COP for four stability conditions (Control, LowSP, MedSP, and HighSP) for different window.. 72

Figure 5.3: (a) AREA of 95\% ellipse averaged over 100 trials with error bars for standard deviations and (b) slope of AREA of 95\% ellipse, of simulated COP for four stability conditions (Control, LowSP, MedSP, and HighSP) for different window lengths....73

Figure 5.4: (a) |Standard deviation of $\mathrm{COP}_{\mathrm{x}}$, averaged over 100 trials with error bars for standard deviations and (b) slope of standard deviation of $\mathrm{COP}_{\mathrm{x}}$, of simulated COPx for four stability conditions (Control, LowSP, MedSP, and HighSP) for different window. 74

Figure 5.5: (a) |Standard deviation of $\mathrm{COP}_{\mathrm{y}}$, averaged over 100 trials with error bars for standard deviations and (b) slope of standard deviation of $\mathrm{COP}_{\mathrm{y}}$, of simulated $\mathrm{COP}_{\mathrm{y}}$ for four stability conditions (Control, LowSP, MedSP, and HighSP) for different window. .75

Figure 5.6: (a) Standard deviation of Radial Displacement, averaged over 100 trials with error bars for standard deviations and (b) slope of standard deviation of Radial Displacement, of simulated COP for four stability conditions (Control, LowSP, MedSP, and HighSP) for different window. 76

Figure 5.7: (a) Silhouette coefficient and (b) slope of standard Silhouette coefficient for six COP measures of simulated data of 100 trials for different window lengths.........77

Figure 5.9: Vavg calculated over 1.5s window length with $0.1 \mathrm{~s}$ of overlapping for 11 trials of subject 2 for four stability conditions: (a) FT-EO, (b) FT-EC, (c) SL-EO, and (d) SL-EC. Each line in all graphs represent one trial. 80

Figure 5.10: $V a v g$ calculated over $30 \mathrm{~s}$ window length with $0.1 \mathrm{~s}$ of overlapping for 11 trials of subject 2 for four stability conditions: (a) FT-EO, (b) FT-EC, (c) SL-EO, and (d) SL-EC. Each line in all graphs represent one trial. 81

Figure 5.11: Box plots of $\mathrm{Vavg}$ for 11 trials for four stability conditions for all subjects: (a) FT-EO for S1, S2, S3, S4, S5, S6, S7, and S8, (b) FT-EC for S1, S2, S3, S4, S5, S6, S7, and S8, (c) SL-EO for S1, S2, S3, S4, S5, S6, S7, and S8, and (d) SL-EC for $\mathrm{S} 1, \mathrm{~S} 2, \mathrm{~S} 3, \mathrm{~S} 4, \mathrm{~S} 5, \mathrm{~S} 6, \mathrm{~S} 7$, and S8 82 
Figure 5.12: Average radial displacement and average velocity of experimental data of 11 trials for four stability conditions (FT-EO, FT-EC, SL-EO, and SL-EC) for different window lengths for subject 2 .

Figure 5.13: AREA and standard deviation of $\mathrm{COP}_{\mathrm{x}}$ of experimental data of 11 trials for four stability conditions (FT-EO, FT-EC, SL-EO, and SL-EC) for different window lengths for subject 2 . .91

Figure 5.14: Standard deviation of $\mathrm{COP}_{\mathrm{y}}$ and standard deviation of radial displacement of experimental data of 11 trials for four stability conditions (FT-EO, FT-EC, SL-EO, and SL-EC) for different window lengths of subject 1 for subject 2 . .92

Figure 5.15: Silhouette coefficient for six COP measures of subjects 1 and 2 for 11 trials for different window lengths $(1.5 \mathrm{~s}, 2.0 \mathrm{~s}, 2.5 \mathrm{~s}, 3.0 \mathrm{~s}, 3.5 \mathrm{~s}, 4.0 \mathrm{~s}, 4.5 \mathrm{~s}, 5.0 \mathrm{~s}, 10 \mathrm{~s}, 15$ $\mathrm{s}, 20 \mathrm{~s}, 25 \mathrm{~s})$. .93

Figure 5.16: Silhouette coefficient for six COP measures of subjects 3 and 4 for 11 trials for different window lengths $(1.5 \mathrm{~s}, 2.0 \mathrm{~s}, 2.5 \mathrm{~s}, 3.0 \mathrm{~s}, 3.5 \mathrm{~s}, 4.0 \mathrm{~s}, 4.5 \mathrm{~s}, 5.0 \mathrm{~s}, 10 \mathrm{~s}, 15$ $\mathrm{s}, 20 \mathrm{~s}, 25 \mathrm{~s})$. .94

Figure 5.17: Silhouette coefficient for six COP measures of subjects 5 and 6 for 11 trials for different window lengths $(1.5 \mathrm{~s}, 2.0 \mathrm{~s}, 2.5 \mathrm{~s}, 3.0 \mathrm{~s}, 3.5 \mathrm{~s}, 4.0 \mathrm{~s}, 4.5 \mathrm{~s}, 5.0 \mathrm{~s}, 10 \mathrm{~s}, 15$ $\mathrm{s}, 20 \mathrm{~s}, 25 \mathrm{~s})$. 95

Figure 5.18: Silhouette coefficient for six COP measures of subjects 7 and 8 for 11 trials for different window lengths $(1.5 \mathrm{~s}, 2.0 \mathrm{~s}, 2.5 \mathrm{~s}, 3.0 \mathrm{~s}, 3.5 \mathrm{~s}, 4.0 \mathrm{~s}, 4.5 \mathrm{~s}, 5.0 \mathrm{~s}, 10 \mathrm{~s}, 15$ $\mathrm{s}, 20 \mathrm{~s}, 25 \mathrm{~s})$. .96

Figure A.1: Box plot demonstrates variation of data. A high-variation box plot would be taller. The horizontal line in box is the median, the ends of the box are the upper and lower quartiles, and the vertical lines are the full range of values in the data. 104

Figure A.2: Box plot of clusters of conventional COP measures for the 11 trials of subject 1. 105

Figure A.3: Box plot of clusters of conventional COP measures for the 11 trials of subject 2 106

Figure A.4: Box plot of clusters of conventional COP measures for the 10 trials of subject 3 107

Figure A.5: Box plot of clusters of conventional COP measures for the 11 trials of subject 4. 108

Figure A.6: Box plot of clusters of conventional COP measures for the 11 trials of subject 5 109 
Figure A.7: Box plot of clusters of conventional COP measures for the 11 trials of subject

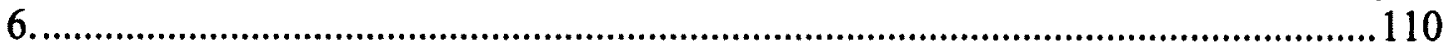

Figure A.8: Box plot of clusters of conventional COP measures for the 11 trials of subject 7.

Figure A.9: Box plot of clusters of conventional COP measures for the 11 trials of subject

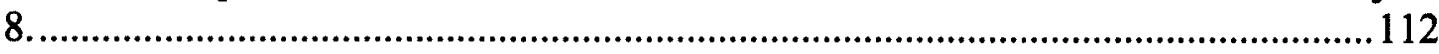

Figure B.1: Posturograph of for 1 of the 100 simulated trials (a) Control, (b) LowSP, (c) MedSP and (d) HighSP stability conditions of simulated COP...............................114 


\section{List of Abbreviations}

\begin{tabular}{|l|l|}
\hline ANOVA & Analysis of Variance \\
\hline AP & Antero-Posterior \\
\hline COG & Center of Gravity \\
\hline COP & Center of Pressure \\
\hline df & degrees of freedom \\
\hline DFA & Detrended Fluctuation Analysis \\
\hline FT-EC & Feet Together Eyes Closed \\
\hline FT-EO & Feet Together Eyes Open \\
\hline HR/s & Hurst Rescaled Range \\
\hline ICC & Intraclass Correlation Coefficients \\
\hline ML & Medio-Lateral \\
\hline MS & Multiple Sclerosis \\
\hline RMS & Root Mean Square \\
\hline SL-EC & Single Leg Eyes Closed \\
\hline SL-EO & Single Leg Eyes Open \\
\hline SP & Spasticity \\
\hline
\end{tabular}




\section{List of Symbols}

\begin{tabular}{|l|l|}
\hline$A R E A$ & Area of $95 \%$ Ellipse of COP \\
\hline $\mathrm{B}_{\mathrm{pas}}$ & Passive damping gain in the model \\
\hline $\mathrm{F}_{\mathrm{x}}$ & Force in medio-lateral direction \\
\hline $\mathrm{F}_{\mathrm{y}}$ & Force in antero-posterior direction \\
\hline $\mathrm{F}_{\mathrm{z}}$ & Force in vertically direction \\
\hline $\mathrm{K}_{\mathrm{d}}$ & Derivative gain of neural controller in model \\
\hline $\mathrm{K}_{\mathrm{I}}$ & Integral gain of neural controller in model \\
\hline $\mathrm{K}_{\mathrm{N}}$ & Disturbance noise gain of Gaussian low pass filter \\
\hline $\mathrm{K}_{\mathrm{P}}$ & Proportional gain of neural controller in model \\
\hline $\mathrm{K}_{\mathrm{pas}}$ & Passive stiffness gain in model \\
\hline $\mathrm{M}_{\mathrm{x}}$ & Moment in medio-lateral direction \\
\hline $\mathrm{M}_{\mathrm{y}}$ & Moment in antero-posterior direction \\
\hline $\mathrm{M}_{\mathrm{z}}$ & Moment in vertically direction \\
\hline$R D_{a v g}$ & Average Radial Displacement \\
\hline$S D_{-} R D$ & Standard Deviation of Radial Displacement \\
\hline$\sigma_{x}$ & Standard Deviation of COP $\mathrm{x}$ (ML) \\
\hline$\sigma_{y}$ & Standard Deviation of COP $\mathrm{y}$ (AP) \\
\hline $\mathrm{T}_{\mathrm{C}}$ & Control torque \\
\hline $\mathrm{T}_{\mathrm{d}}$ & Disturbance torque \\
\hline$\tau_{d}$ & Neurological transmission time delay in inverted pendulum model \\
\hline$\tau_{N}$ & Time constant in low pass filter of input disturbance noise in model \\
\hline$V_{a v g}$ & Average Velocity \\
\hline & \\
\hline
\end{tabular}




\section{Introduction}

\subsection{Motivation}

Measurements of postural stability have been used to identify the risk of falls in frail, elderly populations (Jbabdi, Boissy, \& Hamel, 2008) and neuromuscular diseases (Schmit et al., 2006), such as vertigo (Pivnickova, Dolinay, \& Vasek, 2012) and Parkinson's (Fioretti, Guidi, Ladislao, \& Ghetti, 2004). Falls can occur due to many reasons, such as balance and gait disorders (Lord, Menz, \& Tiedemann, 2003), and cognitive impairment, particularly misperception of orientation (Jensen, Nyberg, Gustafson, \& Lundin-Olsson, 2003).

With the increasing elderly population, the significance of maintaining mobility and ultimately maintaining quality of life becomes more critical (Winter, 1995). Falling is one of the biggest hazards to the health of older adults (CDC, 2012). One out of three people aged 65 or above, fall every year, and suffer moderate to severe injuries (Jensen et al., 2003).

Falls can cause injuries and can create a fear of falling (Pieterse et al., 2006), (Bickerstaffe, Beelen, \& Nollet, 2010). Fear of falling reduces their activities (Curcio, Gomez, \& Reyes-Ortiz, 2009b) and ultimately lowers quality of life and increases health related complications (Fletcher et al., 1996), (Satcher, 1999). Consequence of falls include high mortality, decline in mobility and additional health complications that can eventually change life style and require geriatric care (Jbabdi et al., 2008) (American 
Geriatrics Society, 2001). According to the National Safety Council, USA (CDC, 2012), more than 21,700 Americans died due to falls in $2007,18,000$ of whom were older adults. In 2007 more than 7.9 million were injured by a fall, including 1.8 million older adults.

Fall-related medical costs increased dramatically from $\$ 19$ billion in 2000 to $\$ 28.2$ billion in 2010 and is predicted to be $\$ 54$ billion by 2020 (CDC, 2012). Fall prevention interventions can help to improve postural control, reducing falls in older adults (Salminen et al., 2009), and reducing the health related and social issues (Shimada et al., 2011). This motivates a need to develop better ways to understand and quantify postural stability.

Posturography is a non-invasive method of assessing postural stability in static and dynamic situations (Pivnickova et al., 2012). Static posturography provides a quantitative method to assess postural stability that is easy to conduct (Browne \& O'Hare, 2001). Although unperturbed upright stance position looks static, there exists a process of rocking from the ankle that is often compared with a simple inverted pendulum (Gage, Winter, Frank, \& Adkin, 2004). This low-amplitude swaying can be measured by the center-of-pressure (COP) (Pellecchia \& Shockley, 2005). The posturograph is a two dimensional plot of the antero-posterior (AP) and medio-lateral (ML) displacement of the COP (Baratto, Morasso, Re, \& Spada, 2002). With posturography, an individual's COP trajectory is typically recorded by using a force platform. The COP trajectory reflects the dynamic nature of postural control. COP fluctuations helps us to understand the inherent 
complexity of the postural control system and its constituent processes (Winter, 1995). There are many COP measures; however, it has not well known which COP measure performs better. In this thesis, better performance is attributed to COP measures that are less variable within a stability condition and can discern between different stability conditions. A good COP measure should have high repeatability for a given stability condition (low intra-cluster distances) and be able to discern between different stability conditions (high inter-cluster distances). Typical posturography uses 30-60 s of data (Moghadam et al., 2011; Norris, Marsh, Smith, Kohut, \& Miller, 2005; Salavati et al., 2009). In the clinical environment use of a COP measure having better performance with the least amount of data has a greater importance in the evaluation of postural stability, though the effect of smaller window length on the COP measure is not well known.

\subsection{Thesis Objective}

The following two research questions are addressed in this dissertation:

1. How to quantify the performance of posturographic COP measures, with respect to repeatability (or variability) within a given stability condition and discernability between different stability conditions?

2. How does the analysis window length affect the performance of posturographic COP measures?

These research questions are addressed through the following three main objectives:

1. To develop a methodology to assess the performance of COP measures.

2. To evaluate the relative performance of conventional COP measures using simulated and experimental data from human subjects.

3. To examine the effect of analysis window length on conventional COP measures using simulated and experimental data from human subjects. 


\subsection{Contributions}

This research provides six main contributions in the area of postural stability assessment using static posturography:

1. Development of a method to assess the relative performance of COP measures

A novel method is developed to assess the relative performance of COP measures. This method assesses the performance of COP measures employing cluster analysis; specifically, using the silhouette coefficient.

\section{Analysis of performance of COP measures of simulated data and experimental data}

The analysis was performed to assess the performance of simulated COP measures for four different stability conditions for simulated data and experimental data. The results of simulated data demonstrated that the performance of average velocity of COP was the best for simulated data compared to other five COP measures investigated. Results signify that the average velocity was found to be the most repeatable as its clusters were more compact within a stability condition and the most discernible between the stability conditions.

The results of experimental data also demonstrated that the performance of average COP velocity of is the best for all subjects and all stability conditions compared to other five COP measures investigated.

3. Analysis of the effects of analysis window length on the performance of COP measures for the simulated and experimental data

The effects of analysis window lengths were analysed for simulated and experiment data. Simulated data of $120 \mathrm{~s}$ were used and 31 analysis windows of different lengths were 
selected, from beginning of the data, and then the COP measures were calculated for smaller windows and compared with the measures calculated for larger window, to investigate the effects compare to larger window size. Results demonstrated that window length affects COP measures and the performance improved for larger window sizes. However, there are tradeoffs between larger and smaller window size. A larger window size can obscure transitional effects while a smaller window size demonstrates higher estimation variability.

This analysis of experimental data has two sections. In the first section, average velocity of COP were calculated and compared for two $30 \mathrm{~s}$ windows from $60 \mathrm{~s}$ of data. Results demonstrated that there was statistically significant difference between first and last $30 \mathrm{~s}$ of data. In the second section of the study, smaller analysis windows were analyzed. Results indicated that there were significant effects of the smaller windows on the COP measures other the least effects were found on the average velocity of COP.

\section{Assessment of the noise of the experimental setup to ensure the accuracy of COP measure}

Noise analysis was performed to investigate if there was appreciable noise in the experimental setup (e.g., due to building vibrations). The experiment was performed at Élisabeth Bruyère Research Centre (SCO Health Service) lab ( $2^{\text {nd }}$ floor), the noise analysis data were collected by using the force platform Advanced Mechanical Technology Inc. (AccuGait System, Watertown, MA, USA). The noise analysis results indicated that the background noise for all positions and the spatial noise were less than 1 $\mathrm{mm}$. The noise induced in the force platform due to the experimental set up was low and in the acceptable range. 
Some of these contributions were disseminated in the following publications:

- Baig, S., Chan, A. D. C., Dansereau, R. M., Remaud, A., \& Bilodeau, M. (2012). Performance of center-of-pressure measures. Proceedings of the International Conference on Electrical and Computer Systems (pp. 22-24). Ottawa.

- Baig, S., Dansereau, R. M., Chan, A. D. C., Remaud, A., \& Bilodeau, M. (submitted 2012). Cluster Analysis of Center-of-Pressure Measures. International Journal of Electrical and Computer Systems (IJECS).

\subsection{Overview of the Thesis}

This thesis consists of six chapters.

Chapter 1 provides a brief introduction, motivation, statement of problem, objective, contributions, and overview of the thesis.

Chapter 2 provides comprehensive review on postural stability, discusses various reasons of degradation of postural stability, and how to assess postural stability. Chapter 2 also presents information about posturography and center of pressure measures and the inverted pendulum models for humans in an upright posture, which is used in this thesis.

Chapter 3 provides information about the simulations, experimental setup, equipment used, noise analysis of the experimental setup, and data collection procedures.

Chapter 4 examines the performance of COP measures in terms of repeatability within a given stability condition and differentiability between the different stability conditions for both simulated data and experimental data.

Chapter 5 examines the effects of analysis window length on the COP measures for both simulated data and experimental data.

Chapter 6 presents a summary of contributions and provides recommendations for future work. 


\section{Literature Review}

This chapter presents a literature review on postural stability, assessment of postural stability, and different measures used to assess postural stability. The chapter also provides information on different theories of postural stability. The last section of the chapter presents and discusses the inverted pendulum models of human upright postures.

\subsection{Postural Stability}

Postural control is a complex system for maintaining postural balance in the gravitational field by continuous COP adjustments within the base support (Horak, 1987), (Dietz, 1992). The human body is inherently unstable because most of the body mass lies within the top half of the body. As a result, our control system is continuously performing balance corrective actions (Winter, 1995).

Although the unperturbed upright stance position looks static, there exists a process of rocking from the ankle that is often compared with the simple inverted pendulum (Gage et al., 2004). This low-amplitude swaying can be measured by COP movement (Pellecchia \& Shockley, 2005). The postural control system involves interaction between external forces, such as gravity, the mechanical properties of the body, and neuromuscular forces (Massion, 1994). A fall happens when internal or external perturbations, applied to the body, shifts the COP towards the limits of the base support, and response time and muscular strength are not sufficient to recover or adapt to the 
perturbations. Aging and some diseases affect the forces used to control the postural stability (Mcclenaghan et al., 1996).

Postural stability depends on multisensory systems (vestibular, visual, somatosensory (Massion, 1994) and a cognitive system (Askvik, 2010). When the condition of these systems change due to ageing or disease, body sway often increases, as does the muscle activity used to maintain postural balance (Massion, 1994). Fatigue also increases the burden on the postural control system by increasing the frequency of actions required by the control system to regulate the upright stance, compared to non-fatigued circumstances (Corbeil et al. 2003). Studies have shown that postural sway for patients after stroke can become twice as high as their healthy aged-matched peers (Nichols, 1997). The main symptom of Parkinson's disease is the impaired control of stance and gait coupled with inadequate adjustment of motor performance (Dietz, 1992). Patients of spastic hemiparesis develop a different tension in the triceps surae muscle during stance phase of gait (Berger, Horstmann, \& Dietz, 1984).

Measurements of postural stability are used to identify neuromuscular diseases (Pellecchia \& Shockley, 2005) (Schmit et al., 2006) and to assess the risk of falls in frail elderly populations (Jbabdi et al., 2008). People with neuromuscular disorders demonstrate higher frequency of fall, and these falls cause injuries and create a fear of falling ( Bickerstaffe, Beelen, and Nollet 2010). The fear of falling can result in the restriction of physical activities, which in turn can result in low income, deprivation of healthy activities, and depression (Curcio, Gomez, \& Reyes-Ortiz, 2009b). 
Thirty to sixty percent of the elderly population fall every year (Jbabdi et al., 2008). Consequences of falls for an older adults can include an increase in mortality, decline in mobility, and other health complications that decrease the quality of life and require early geriatric care (American Geriatrics Society, 2001). With increased life expectancy and with an increasing elderly population, the significance of maintaining mobility and ultimately maintaining quality of life becomes more critical (Winter, 1995).

Falls can occur due to many reasons, such as balance or gait disorders (Lord et al., 2003), and cognitive impairments, particularly a misperception of orientation (Jensen et al., 2003). Falls and fall associated fractures are the major reason of disability in the elderly population (Shimada et al., 2011).

Early detection of balance problems to reduce the fall risk in the elderly population and also people with balance disorder due to other pathological reasons, and can enhance the quality of life. Thus early intervention can help to mitigate the risk of falling, and related health and social issues (Shimada et al., 2011). All this motivates researchers and clinicians to develop new ways to understand and quantify postural stability (Curcio, Gomez, \& Reyes-Ortiz, 2009a).

\subsection{Assessment of Postural Stability}

There are a number of technical and non-technical methods for the assessment of postural stability. The technical methods (e.g., ataxia meter and sway magnetometry) are 
cumbersome or require expensive equipment (Browne \& O'Hare, 2001). The nontechnical methods include the Berg balance scale (Berg, Maki, Williams, Holliday, \& Wood-Dauphinee, 1992), the functional reach test (Duncan, Weiner, Chandler, \& Studenski, 1990), and the fall risk index (Tinetti, Williams, \& Mayewski, 1986). These are easy to conduct and do not need expensive equipment (Browne \& O'Hare, 2001). However, these methods may not be sensitive enough to measure minor changes in an individual's postural stability (Browne \& O'Hare, 2001). Posturographic analysis is a technical method and is used to provide a quantitative assessment of postural stability and is relatively easy to conduct (Baratto et al., 2002) (Browne \& O'Hare, 2001). With posturography, an individual's COP trajectory is typically recorded using a force platform. A force platform can detect small changes in an individual's stability condition, making it suitable for assessment of balance and monitoring progress (Browne \& O'Hare, 2001). Figure 2.1 is a computer screen snapshot, showing posturographic data from a force platform; the posturograph is on the right side of the screen and the forces exerted by the subject on the force platform are on the left side of the screen.

\subsection{Posturography}

Posturography is a technique for quantifying postural control in an upright stance. The posturograph is a two dimensional plot of the antero-posterior (AP) and medio-lateral (ML) COP displacements (Baratto et al., 2002); (Baratto et al., 2002). The COP is a point where the resultant reaction ground force vector acts, COP represents the weighted average of all pressures over the surface area of the body, in contact with the ground (Winter, 1995) (Bizzo, Guillet, Patat, \& Gagey, P, 1985). If one foot is on the ground, the 


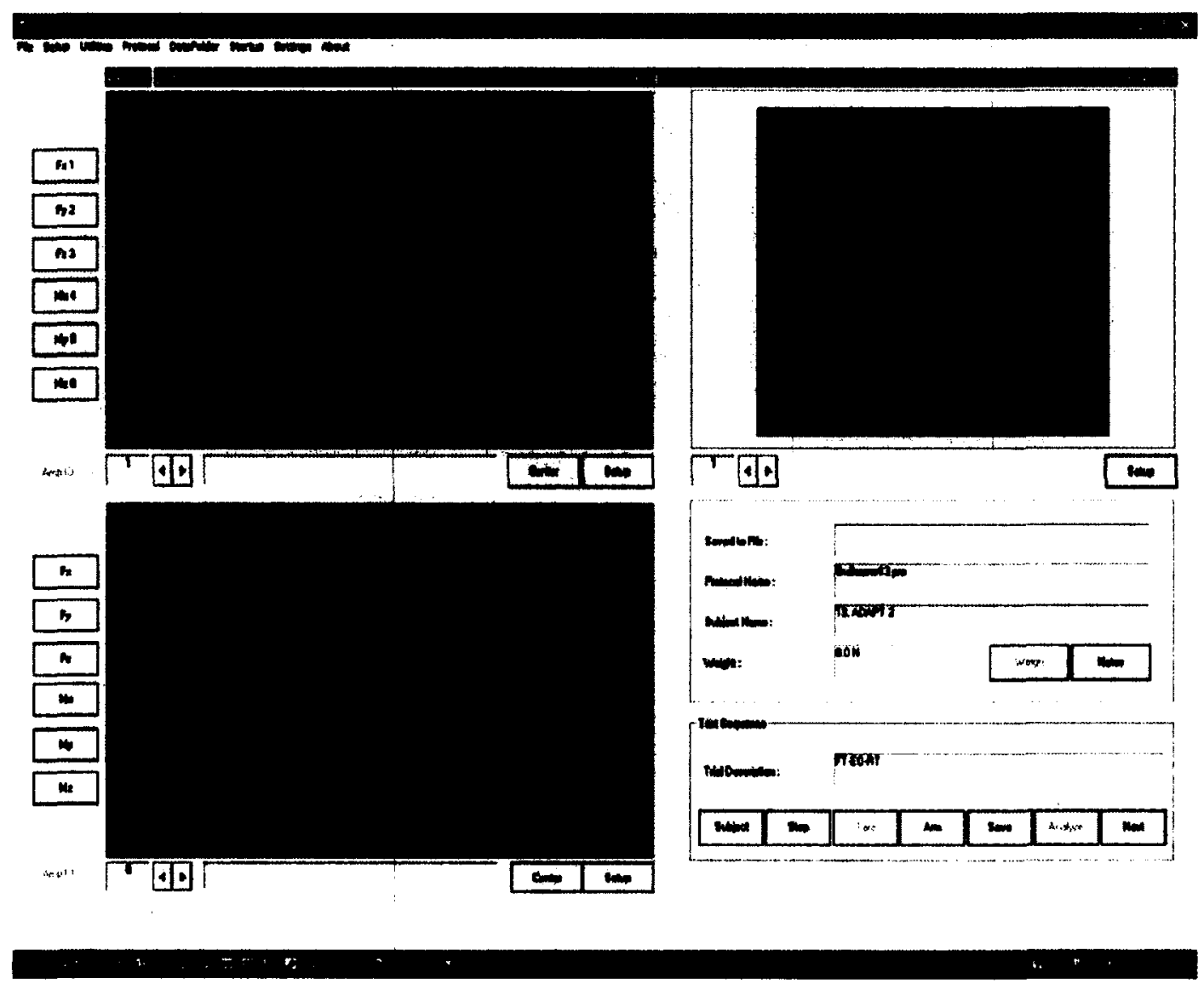

Figure 2.1: Computer screen of an individual posturograph and forces from the force platform. The posturograph is in the right corner of the screen and left corner of the screen presents Fx (medio-lateral), Fy (antero-posterior), and Fz (vertically) ground reaction forces, (from top to bottom respectively).

net COP lies under the foot. If two feet are on the ground, the COP lies somewhere between the feet, depending on the relative weight taken by each foot (Winter, 1995). The posturography analysis method is used in both dynamic and static paradigms.

\subsubsection{Dynamic Posturography}

Dynamic posturography is used to assess a person's stability when the person is perturbed with some random stimuli in order to measure the response to restore equilibrium. Dynamic posturography is used to assess the central nervous system's 
adaptive mechanism for postural control and in rehabilitation and management of postural balance (Jacobson, Newman, \& Kartush, 1997).

\subsubsection{Static Posturography}

In an unperturbed, upright, static stance position, the body undergoes continuous lowamplitude oscillations; these oscillations can be measured by the COP (Pellecchia \&

Shockley, 2005). In static posturography, the COP displacements occurring during unperturbed upright stance are analyzed. The initial few seconds of COP data are suggested to be removed before analysis in order to avoid initial transient effects. In the literature 5-10 s of COP data are usually discarded in order to avoid any initial condition effects (Braga B. et al., 2012; Lin, Seol, Nussbaum, \& Madigan, 2008; Norris et al., 2005). Figure 2.2 (a) depicts an example of a static posturography session where a subject is maintaining a standing posture with their feet together.

In static posturography, a force platform (Figure 2.2 (b)) is used to measure the COP during a static stance. Figure 2.3 shows the forces and the moments recorded for subject 2 , standing on two feet with their eyes closed.

These forces are used to calculate COP by the following equations

$$
\begin{aligned}
& \operatorname{COP}_{x}=100 \frac{\left(-F_{x} D_{z}-M_{y}\right)}{F_{z}}(\mathrm{~cm}), \\
& \operatorname{COP}_{y}=100 \frac{\left(-F_{y} D_{z}+M_{x}\right)}{F_{z}}(\mathrm{~cm}) .
\end{aligned}
$$


$F_{x}, F_{y}, F_{z}(N)$ are the transducer force outputs in the $x(\mathrm{ML}), y(\mathrm{AP})$, and $z$ vertical direction, respectively.

$M_{x}, M_{y}, M_{z}(N \cdot m)$ are the transducer moment outputs the $x(\mathrm{ML}), y(\mathrm{AP})$, and $z$ vertical direction, respectively.

$D_{z}(m)$ is the distance from the top surface of the transducer to transducer calibrated origin.

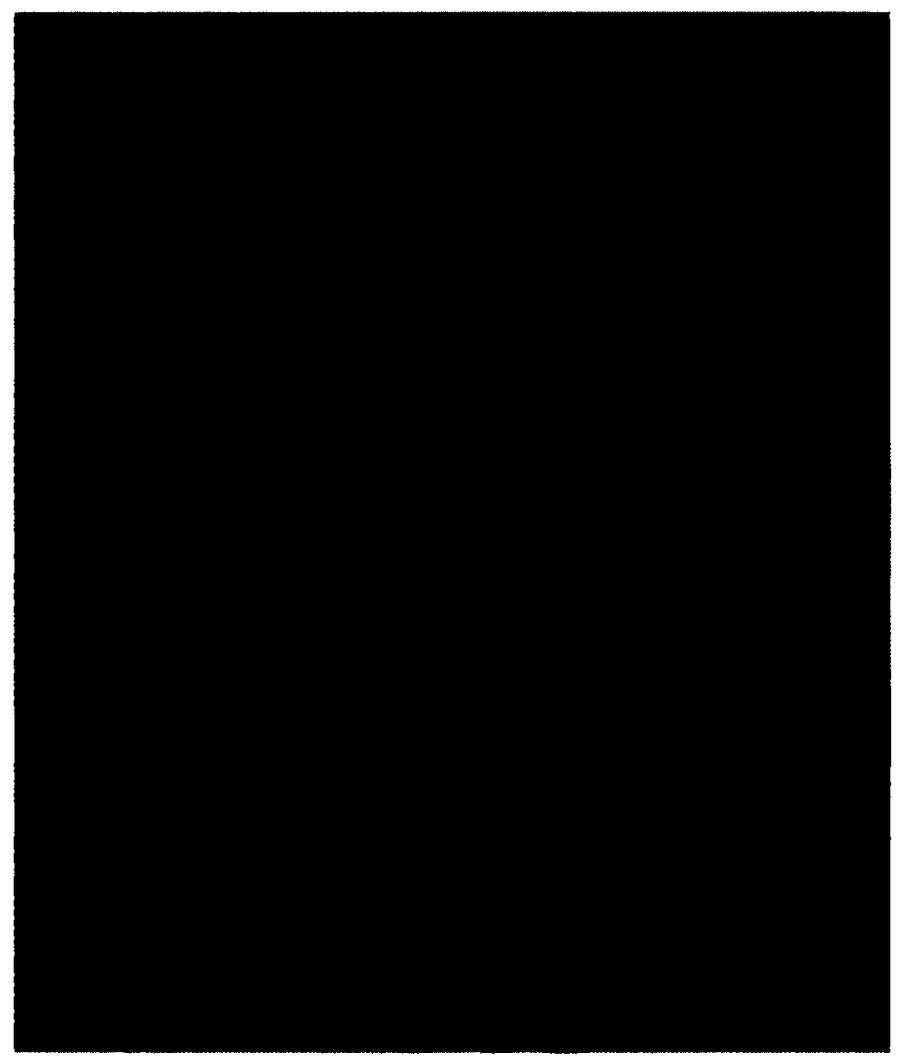

(a)

(b)

Figure 2.2: (a) A subject standing on the force platform, undergoing static posturography, and (b) Advanced Mechanical Technology Inc. (AMTI) force platform (AccuGait System, Watertown, MA, USA) 


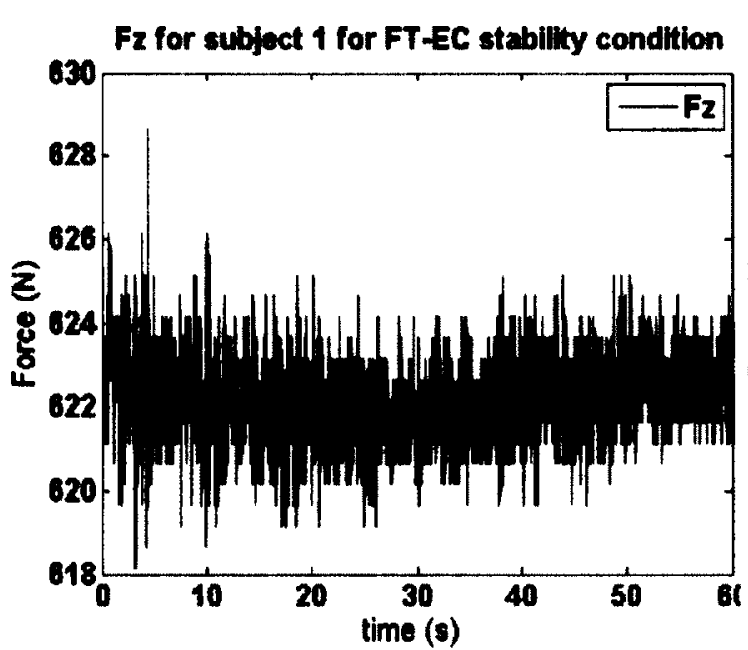

(a)

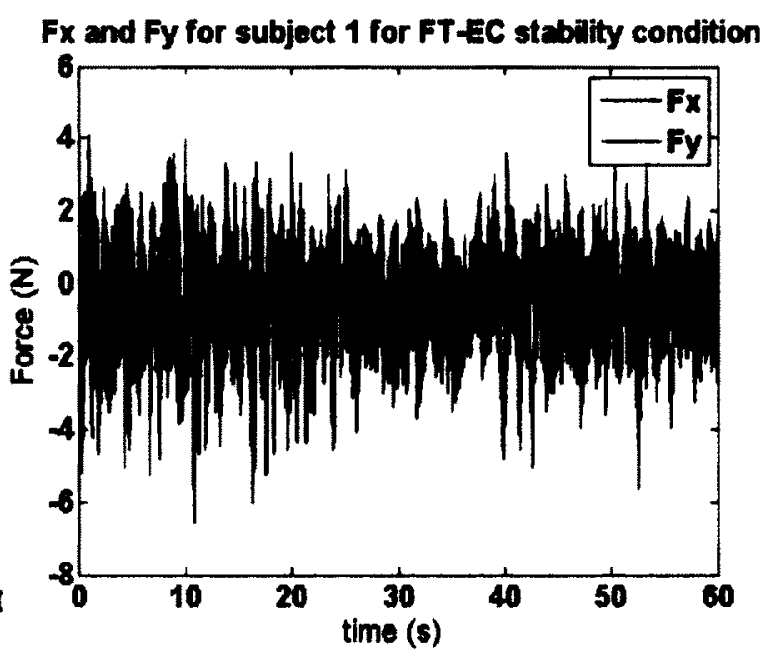

(b)

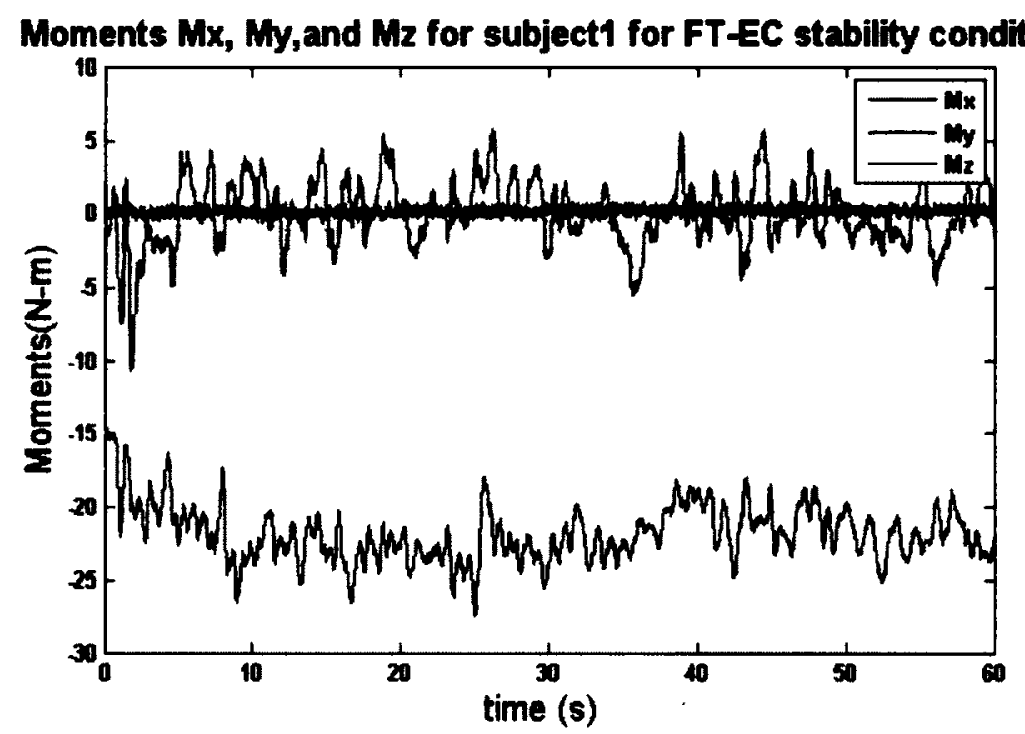

(c)

Figure 2.3: Forces measured by the force platform in (a) Fz (vertically), (b) Fx (ML), Fy (AP) and (c) moments Mx (ML), My (AP) and Mz (vertically) for subject 1 for Feet Together-Eyes Closed (FT-EC) condition of trial 1

Figure 2.4 (a), and (b) present COP time series in $x$ and $y$ directions and (c) presents the two dimensional posturograph of COP while (d) presents the three dimensional for subject 2, trial 1 with feet together-eyes closed (FT-EC). 
The COP trajectory reflects the dynamic nature of the subject's postural control. This dynamic nature of the COP displacements help us to understand the inherent complexity of the postural control system and its constituent processes (Winter, 1995). Quantitative measures of postural stability can be derived from the COP movements. These COP measures have been shown to be sensitive to various health conditions. For example, low back pain patients have been reported to exhibit greater COP excursions and a higher average velocity as compared to healthy individuals (Ruhe, Fejer, \& Walker, 2011; Salavati et al., 2009). The patient with anterior cruciate ligament injury demonstrated an increase in the area and average velocity of $\mathrm{COP}$ and patient with ankle instability higher average velocity in both AP and ML directions. (Salavati et al., 2009).The study also demonstrated that test-retest reliability of average velocity of COP demonstrate high to very high reliability compare to standard deviation of amplitude, standard deviation of velocity, phase plane portrait, and area of $95 \%$ confidence ellipse (Salavati et al., 2009).

The other study had shown average velocity was the most reliable measure among median power frequency, root mean square (RMS) distance, sway area, and two fractal measures derived from Hurst rescaled range analysis $\left(\mathrm{H}_{\mathrm{R} / \mathrm{S}}\right)$ and detrended fluctuation analysis (DFA) within-day and between-day (Lin et al., 2008).

Lafond et al. reported that within-day intraclass correlation coefficients (ICC) values in $\mathrm{AP}$ and ML directions of 0.77 and 0.90 for mean velocity, 0.02 and 0.24 for median 
power frequency, 0.52 and 0.61 for RMS distance, and 0.47 for sway area (Lafond, Corriveau, Hébert, \& Prince, 2004).

The older participants (61-67 years) demonstrated better relative reliability than younger (19-23 years) participants for COP measure, average velocity, median power frequency, RMS distance, sway area, $\mathrm{H}_{\mathrm{R} / \mathrm{S}}$ and DFA(Lin et al., 2008). The ICC were 0.77 for older and 0.92 for younger in AP direction and 0.79 for older and 0.91 for younger in ML direction for mean velocity (Lin et al., 2008).

Doyle et al. suggest that COP measures, anterior-posterior standard deviation, mediallateral standard deviation, average velocity and $95 \%$ confidence ellipse reached acceptable levels of reliability with at least five trials, $60 \mathrm{~s}$ each (Doyle, Hsiao-Wecksler, Ragan, \& Rosengren, 2007). The investigation were performed on COP measures calculated for window lengths $30 \mathrm{~s}, 60 \mathrm{~s}$, and $90 \mathrm{~s}$ of 10 trials each from fifteen subjects.

Reliability of COP measures, root mean square, mean power frequency and mean position of COP was found to increase with increased sample duration (Carpenter, Frank, Winter, \& Peysar, 2001). These measures were investigated for $15 \mathrm{~s}, 30 \mathrm{~s}, 60$ and $120 \mathrm{~s}$ data of 49 participants, for 3 trials.

The COP measures are used to estimate the postural stability in standing by using static posturograph, however there are no standard procedures have been reported for study design (Ruhe, Fejer, \& Walker, 2010). Some of studies reviewed are tabulated in the table 2.1. 
Table 2.1: Studies characteristics and selected COP parameters measured on a firm surface with EO.

\begin{tabular}{|c|c|c|c|c|c|c|}
\hline \multirow{2}{*}{ Study } & $\begin{array}{c}\text { RDavg } \\
\text { (cm) }\end{array}$ & $\begin{array}{c}\text { Velocity } \\
(\mathrm{cm} / \mathrm{s})\end{array}$ & $\begin{array}{l}\text { Area } \\
\left(\mathrm{cm}^{2}\right)\end{array}$ & $\begin{array}{c}\text { SD-COPX } \\
\text { (cm) }\end{array}$ & $\begin{array}{c}\text { SD-COPX } \\
(\mathrm{cm})\end{array}$ & $\begin{array}{c}\text { SD_RD } \\
\text { (cm) }\end{array}$ \\
\hline & $\begin{array}{l}\text { Mean } \\
\text { (SD) }\end{array}$ & $\begin{array}{c}\text { Mean } \\
\text { (SD) }\end{array}$ & $\begin{array}{l}\text { Mean } \\
\text { (SD) }\end{array}$ & $\begin{array}{c}\text { Mean } \\
\text { (SD) }\end{array}$ & $\begin{array}{c}\text { Mean } \\
\text { (SD) }\end{array}$ & $\begin{array}{l}\text { Mean } \\
\text { (SD) }\end{array}$ \\
\hline $\begin{array}{l}\text { (Moghadam et al., 2011), } \\
\mathrm{n}=3 \text {, Age } 60-83 \text { years, } 10 \\
\text { male and } 6 \text { female } \\
\text { healthy. } \\
\mathrm{fs}=100 \mathrm{~Hz}, 30 \text { s data }\end{array}$ & ----. & $\begin{array}{c}1.37 \\
(0.16)\end{array}$ & $\begin{array}{c}1.17 \\
(0.68)\end{array}$ & $\begin{array}{c}0.19 \\
(0.06)\end{array}$ & $\begin{array}{c}0.33 \\
(0.07)\end{array}$ & -...-. \\
\hline $\begin{array}{l}\text { (Salavati et al., 2009) } \\
n=3 \text {, Age } 18-36 \text { years } \\
30 \text { male and } 3 \text { female with } \\
\text { musculoskeletal disorders, } \\
\mathrm{fs}=200 \mathrm{~Hz} 30 \text { s data }\end{array}$ & --.-- & $\begin{array}{c}1.37 \\
(0.26)\end{array}$ & $\begin{array}{c}6.48 \\
(4.67)\end{array}$ & $\begin{array}{c}0.59 \\
(0.16)\end{array}$ & $\begin{array}{c}0.50 \\
(0.22)\end{array}$ & ------ \\
\hline $\begin{array}{l}\text { (Norris et al., 2005) } \\
\mathrm{n}=10, \text { Age } 21-29 \text { years, } \\
\text { healthy, fs }=100 \mathrm{~Hz} \\
30 \text { s data }\end{array}$ & ---- & $\begin{array}{c}1.839 \\
(0.275)\end{array}$ & $\begin{array}{c}0.404 \\
(0.184)\end{array}$ & $-\cdots$ & $\cdots$ & ----- \\
\hline $\begin{array}{l}\text { (Norris et al., 2005) } \\
n=10, \text { Age } 68-79 \text { years, } \\
\text { Low-risk of fall, } \\
\text { fs }=100 \mathrm{~Hz} 30 \mathrm{~s} \text { data }\end{array}$ & --.- & $\begin{array}{c}2.163 \\
(0.433)\end{array}$ & $\begin{array}{c}0.524 \\
(0.195)\end{array}$ & --- & ------ & \\
\hline $\begin{array}{l}\text { Norris et al., 2005) } \\
\mathrm{n}=10, \text { Age } 57-80 \text { years, } \\
\text { High-risk of fall, } \mathrm{fs}=100 \\
\text { Hz } 30 \mathrm{~s} \text { data }\end{array}$ & $-\cdots$ & $\begin{array}{c}4.779 \\
(2.670)\end{array}$ & $\begin{array}{c}3.001 \\
(4.692)\end{array}$ & & & \\
\hline $\begin{array}{l}\text { (Wolff et al., 1998) } \\
\mathrm{n}=10, \text { Age } 15-18 \text { years, } \\
48 \text { female and } 44 \text { male } \\
\text { healthy, fs }=50 \mathrm{~Hz} 30 \mathrm{~s} \text { data }\end{array}$ & $\begin{array}{l}0.43 \\
(0.1)\end{array}$ & $\begin{array}{c}0.81 \\
(0.25)\end{array}$ & ----- & 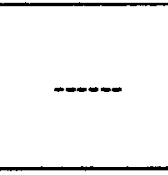 & --.- & \\
\hline $\begin{array}{l}\text { (Tanaka, Nakashizuka, } \\
\text { Uetake, \& Itoh, 2000) } \\
\text { n=11, Age } 20-23 \text { years, } \\
\text { healthy, fs }=50 \mathrm{~Hz}\end{array}$ & $\ldots$ & $\begin{array}{l}3.242 \\
(0.16)\end{array}$ & ----- & -..-_-. & ------ & ------ \\
\hline $\begin{array}{l}\text { Present Study } \\
\mathrm{n}=11 \text { Age } 21--48 \text { years, } \\
5 \text { male and } 3 \text { female } \\
\text { healthy, } \mathrm{fs}=100 \mathrm{~Hz}\end{array}$ & $\begin{array}{c}0.565 \\
(0.130)\end{array}$ & $\begin{array}{c}2.206 \\
(0.279)\end{array}$ & $\begin{array}{c}3.709 \\
(1.869)\end{array}$ & $\begin{array}{c}0.445 \\
(0.127)\end{array}$ & $\begin{array}{c}0.420 \\
(0.122)\end{array}$ & $\begin{array}{c}0.315 \\
(0.073)\end{array}$ \\
\hline $\begin{array}{l}\text { Present Study } \\
\mathrm{n}=10 \text { average adult male, } \\
\text { simulated, } 30 \mathrm{~s} \text { data, } \\
\text { healthy } \mathrm{fs}=100 \mathrm{~Hz}\end{array}$ & $\begin{array}{c}0.169 \\
(0.025)\end{array}$ & $\begin{array}{c}1.895 \\
(0.065)\end{array}$ & $\begin{array}{c}0.146 \\
(0.033)\end{array}$ & $\begin{array}{c}0.040 \\
(0.007)\end{array}$ & $\begin{array}{c}0.198 \\
(0.030)\end{array}$ & $\begin{array}{c}0.111 \\
(0.017)\end{array}$ \\
\hline
\end{tabular}


Due to heterogeneity in the experimental mental design it is difficult to have a direct comparison to reach some conclusion (Ruhe et al., 2010, 2011).

There are numerous COP measures; however it is not evident which measure is optimal (Shepard \& Janky, 2010).The aim of our research is to develop a method which to quantify the performance of posturographic center-of-pressure (COP) measures, with respect to repeatability within a given stability condition and ability to discern between different stability conditions.

The second aim of the study is to investigate effect of analysis window length on performance the performance of $\mathrm{COP}$ measure.

For the research the following six conventional COP measures were selected:

1) Average radial displacement $\left(R D_{\text {avg }}\right)$, (Gosselin, Rassoulian, \& Brown, 2004),

2) Average velocity $\left(V_{\text {avg }}\right)$ (Gosselin et al., 2004),

3) Area of the $95 \%$ confidence ellipse (AREA) (Cavalheiro, Almeida, Pereira, \& Andrade, 2009),

4) Standard deviation of $\operatorname{COP}_{x}\left(\sigma_{x}\right)$ (Doyle et al., 2007) (Clair \& Riach, 1996),

5) Standard deviation of $\operatorname{COP}_{y}\left(\sigma_{y}\right)$ (Doyle et al., 2007) (Clair \& Riach, 1996),

6) Standard deviation of radial displacement (SD_RD), (Prieto, Myklebust, Hoffmann, Lovett, \& Myklebust, 1996). 

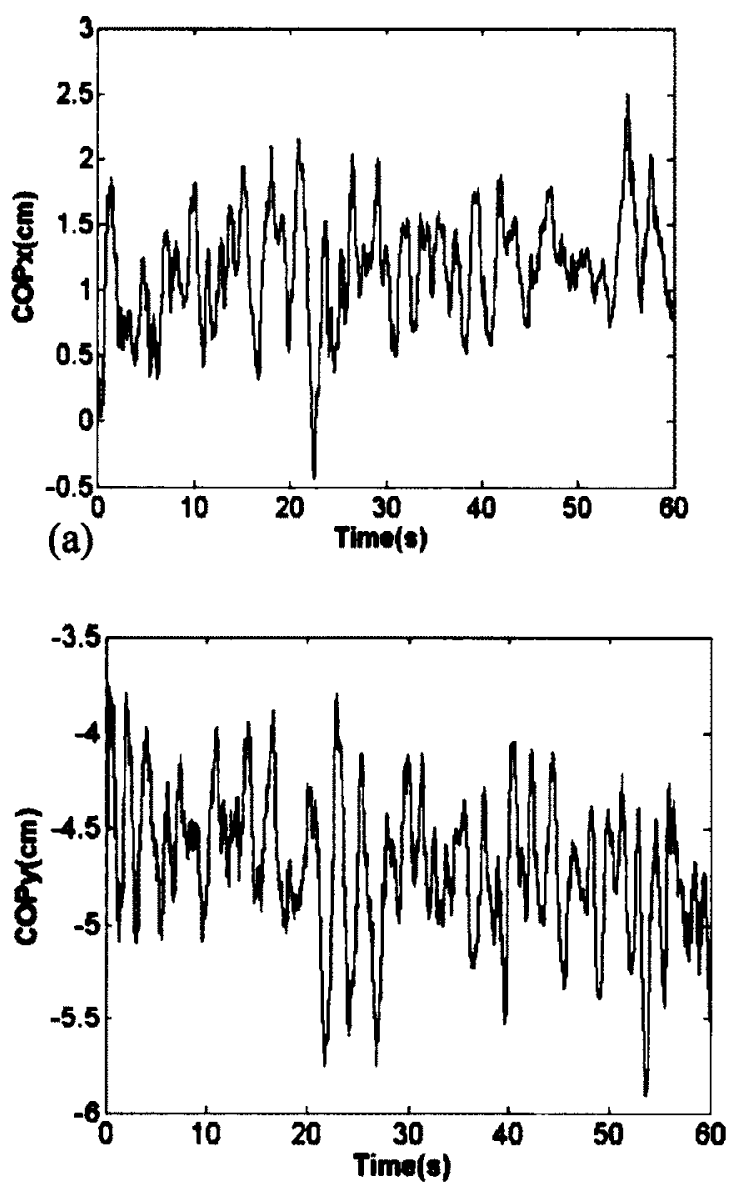

(b)

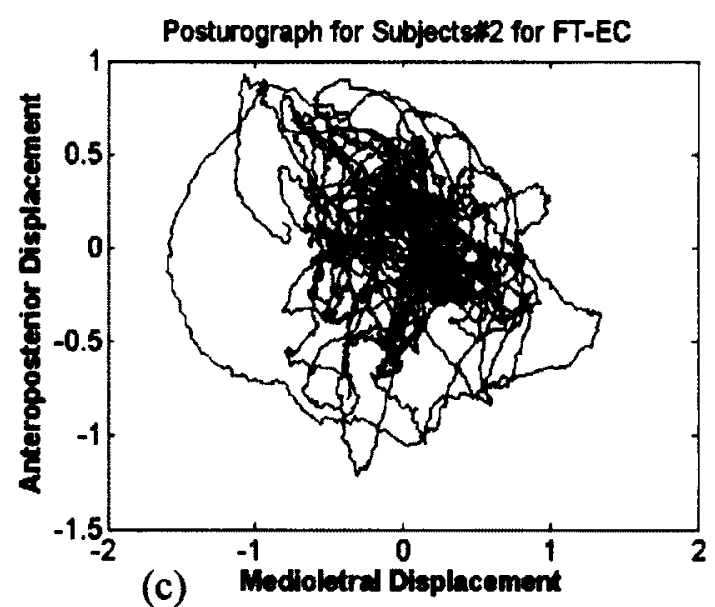

3D Posturograph of 608 for Subject 2

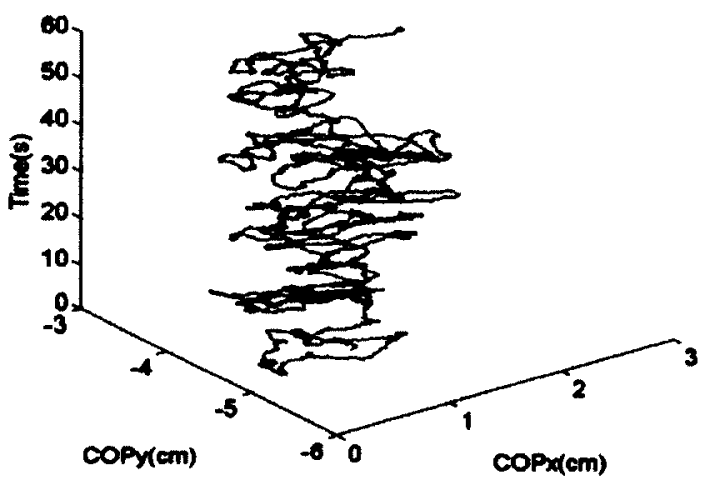

(d)

Figure 2.4: 60s data from subject two with FT-EC stability condition of trial 1 (a) COP in ML direction, (b) COP in AP direction, (c) Posturograph two dimensional plot of the AP and ML COP (mean COP values are subtracted), (d) three diamentional posturograph.

\subsection{COP Measures}

\subsubsection{COP Pre-processing}

The average COP value is subtracted from all data points as a preprocessing step. This process is as follows: 


$$
x_{i}=\left(X_{i}-A V G X\right)
$$

$$
y_{i}=\left(Y_{i}-A V G Y\right)
$$

where

$$
\begin{aligned}
& x_{i}=\begin{array}{l}
\text { displacement of COP along } \mathrm{x} \text {-axis of ith sample with mean } \\
\text { displacement removed }
\end{array} \\
& \mathrm{y}_{i}=\begin{array}{l}
\text { displacement of COP along } \mathrm{x} \text {-axis of ith sample with mean } \\
\text { displacement removed }
\end{array} \\
& X_{i}=\text { displacements of COP along the } \mathrm{x} \text {-axis of } i \text { th sample } \\
& Y_{i}=\text { displacements of COP along the } \mathrm{y} \text {-axis of } i \text { th sample } \\
& A V G X=\text { average position of all COP } \mathrm{x} \text { coordinates } \\
& A V G Y=\text { average position of all COP } \mathrm{y} \text { coordinates }
\end{aligned}
$$

\subsubsection{Average Radial Displacement}

The average radial displacement of COP, $R D_{\text {avg }}$ is computed as follows

$$
R D_{\text {avg }}=\frac{\sum_{i=1}^{N} r_{i}}{N}
$$

$$
N=\text { Total number of samples }
$$

where

$$
r_{i}=\sqrt{x_{i}^{2}+y_{i}^{2}}
$$




$$
r_{i}=\text { Radial displacement of COP of the } i \text { th sample. }
$$

\subsubsection{Average Velocity}

The average velocity of the COP, $V_{\text {avg }}$, is computed as

$$
V_{\text {avg }}=\frac{L}{N \cdot T_{S}}
$$

where $T_{s}=1 / f_{s} \quad f_{s}:$ sampling frequency

Total length of the COP's trajectory $(L)$ is defined by the following equation.

$$
L=\sum_{i=2}^{N} \sqrt{\left(x_{i}-x_{i-1}\right)^{2}+\left(y_{i}-y_{i-1}\right)^{2}} .
$$

\subsubsection{Standard Deviation along ML}

The standard deviation of the postural sway $\mathrm{COP}_{\mathrm{x}}$ time series data along the ML ( $x$-axis), $\sigma_{\mathbf{x}}$, is calculated as follows.

$$
\sigma_{x}=\sqrt{\frac{1}{(N-1)} \sum_{i=1}^{N}\left(x_{i}\right)^{2}}
$$

\subsubsection{Standard Deviation along AP}

The standard deviation of the postural sway of $\mathrm{COP}_{\mathrm{y}}$ time series data along the AP (y axis), $\sigma_{y}$, is calculated as follows.

$$
\sigma_{y}=\sqrt{\frac{1}{(N-1)} \sum_{i=1}^{N}\left(y_{i}\right)^{2}}
$$




\subsubsection{Standard Deviation of Radial Displacement}

The standard deviation of the radial displacement, $S D_{-} R D$, is calculated as follows.

$$
S D_{-} R D=\sqrt{\frac{1}{(N-1)} \sum_{i=1}^{N}\left(r_{i}-R D_{a v g}\right)^{2}} .
$$

\subsubsection{Area of $95 \%$ Confidence Ellipse of COP}

The area of the $95 \%$ confidence ellipse contains $95 \%$ of the data points of COP trajectory, assuming a Gaussian COP distribution. Lengths of the major and minor axes of the $95 \%$ ellipse are calculated, respectively, by the following equations (Cavalheiro et al., 2009) (BioAnalysis, V2.2, 2004).

$$
\begin{gathered}
S_{\text {major }}=\sqrt{F\left(\sigma_{x}^{2}+\sigma_{y}^{2}+D\right)} \\
S_{\text {minor }}=\sqrt{F\left(\sigma_{x}^{2}+\sigma_{y}^{2}-D\right)}
\end{gathered}
$$

The intermediate value $F, F=3.00$, from Table of $F$ statistic at a confidence level of $1-\alpha$. Where $\alpha=0.05$ when the sample size $>120$.

where

$$
\begin{aligned}
& D=\sqrt{\left(\sigma_{x}^{2}+\sigma_{y}^{2}\right)^{2}-4\left(\sigma_{x}^{2} \sigma_{y}^{2}-\sigma_{x y}^{2}\right)} \\
& \sigma_{x y}=\frac{1}{(N-1)} \sum_{i=1}^{N}\left(x_{i}\right) \cdot\left(y_{i}\right) /\left(\sigma_{x} \cdot \sigma_{y}\right) .
\end{aligned}
$$

$\sigma_{x y}$ is a correlation coefficient of $X$ and $Y$.

Area of the $95 \%$ ellipse is calculated by the following equation (BioAnalysis, V2.2, 2004). 


$$
A R E A=(2 \pi F) \sqrt{\sigma_{x}^{2} \sigma_{y}^{2}-\sigma_{x y}^{2}}
$$

The slope of the $95 \%$ ellipse is an angle, between the major axis of the ellipse and $\mathrm{x}$-axis (BioAnalysis, V2.2, 2004) is

$$
A N G L E=\operatorname{atan}(m)
$$

where

$$
m=\sigma_{x y} /\left(a-\sigma_{y}^{2}\right)
$$

and $a$ is an intermediate value defined by the following equation

$$
a=\left(\sigma_{x}^{2}+\sigma_{y}^{2}+D\right) / 2 \text {. }
$$

\subsection{Theories of Postural Stability}

Postural control refers to the maintenance of balance and orientation in the gravitational field, which is essential for everyday activities, such as walking and reaching for objects. The postural control system receives information from various afferent systems and integrates this information within the central nervous system to adjust the posture. Damage to any of these systems cause context-specific instability (Horak, 1987), (Dietz, 1992).

Postural stability depends on multisensory systems (e.g., vestibular, visual, somatosensory), the neuromuscular system (Massion, 1994), and the cognitive system (Askvik, 2010). The visual system is engaged in planning our movements and is used to 
help avoid collisions with obstacles (Winter, 1995). The vestibular system functions in a manner similar to a gyroscope, sensing linear and angular accelerations (Winter, 1995). The somatosensory system is a group of sensors which assist in sensing velocity and position of all body segments, and their orientation (Winter, 1995). The sensory information from these systems are integrated in the central nervous system; the relative involvement of each of these inputs depends on the task and the surrounding environment (Horak, 1987).

Collins and De Luca (Collins \& De Luca, 1993) believe that, in addition to the above closed loop mechanism, the postural control system also employs open-loop control schemes for maintaining erect posture; the open loop activation signal results in small mechanical fluctuations at various joints of the body (Collins \& De Luca, 1993).

According to Gurfinkel (1994) there exists an internal postural body scheme, that does not mainly depend on sensory information but deals with body kinematics and kinetics and body orientation. This body scheme is also used for motor control to maintain body stability (Massion, 1994), (Gurfinkel, 1994).

\subsection{Inverted Pendulum Models of Human Upright Position}

Studies have shown that upright stance of a human can be modeled with a simple inverted pendulum model (Johansson, Magnusson, \& Akesson, 1988) (Peterka, 2000). In the thesis inverted pendulum model for human upright stance posture is used to simulate the COP data. The center-of-pressure (COP) time series and stabilogram diffusion 
function (SDF) produced by a simple inverted pendulum model, with the appropriate selection of model parameters, closely resemble with physiologically measured COP time series and SDF of the human postural control system (Peterka, 2000) (Valles et al., 2006), (Maurer \& Peterka, 2005). SDF that summarizes the mean square COP displacement as a function of the time interval between COP comparisons (Peterka, 2000). An inverted pendulum model for a human body from Peterka (2000) is presented in Figure 2.5 (a). The model consists of an open loop neural control system, a closed-loop feedback control system, and an inverted pendulum body with two torques applied at the ankle joint. It is assumed that a neural control system senses body away deviation(error signal) from an upright reference position, $\theta_{\text {ref }}=0$, then sends commands to various muscles, which generate a corrective torque proportional to the error signal, derivative of the error signal and integral of the error signal (i.e., PID neural controller). The input to the model is the torque exerted about the ankle joint. This torque consists of two components, one due to a random disturbance torque, $T_{d}$, intended to generate body sway patterns similar to those observed experimentally and the other due to a controller torque $T_{C}$ generated in proportion to body motion following a feedback delay of $\tau_{d}$, which accounts for neurological transmission time delay. One output is body sway angle, in the AP direction or ML direction, depending on the parameter selected.

This output is fed back, compared to the reference position, and input to a PID controller that generates $\mathrm{T}_{\mathrm{C}}$. The other output is COP displacement (AP or ML). The value of $y_{p}$ $\left(C O P_{y}\right.$ or $\left.C O P_{x}\right)$ is computed by the following equation (Brenière, 1996), (Peterka, 2000). 


$$
J \ddot{y}_{g}=m g h\left(y_{g}-y_{p}\right)
$$

where

$$
\begin{aligned}
& y_{p}=C O P_{y} \text { and } y_{g} \text { is the displacement of center-of-gravity (COG) } \\
& \ddot{y}_{g}=\text { acceleration of COG }
\end{aligned}
$$

$J\left(\mathrm{~kg} \cdot \mathrm{m}^{2}\right)$ moment of inertia of the body

$m(\mathrm{~kg})$ mass of the body (excluding the feet)

$g\left(m / s^{2}\right)$ acceleration due to gravity

$h(m)$ height of the body (height of the body from COG to the ankle joint)

Assuming a relative away deviation $\theta$ is small for stable posture. Small angle approximation can be employed $(\sin \theta \approx \theta$ ), without significant loss of accuracy (Peterka, 2000). Control torque is a function of the deviation (error signal) from the desired position and the actual body position. Control torque is generated in proportion to the error signal, derivative of the error signal, and integral of the error signal, which is used to model a proportional, integral and derivative (PID) neural controller of a human body (Maurer \& Peterka, 2005). The feedback control torque is applied with a time 
delay $\tau_{\mathrm{d}}$ representing conduction, processing, and muscle activation delays. The PID controller properties are specified by $K_{P}$ as a spring constant that relates to stiffness control, $\mathrm{K}_{\mathrm{D}}$ is the factor controlling the damping of the system, and $\mathrm{K}_{\mathrm{I}}$ is a factor that controls the steady-state error in the system. Variation in open loop PID parameters and the closed loop time delay generate variations in COP that mimic real human COP signals.

The inverted pendulum model analysis allows to interpret experimentally observed changes in COP in terms of variations in neural controller and time delay parameters (Peterka, 2000). A more complex model(Maurer \& Peterka, 2005) uses a passive controller that includes two gains, $\mathrm{K}_{\text {pas }}$ (passive stiffness) and $\mathrm{B}_{\text {pas }}$ (passive damping), which produce a passive torque $T_{p}$ of the body in Figure $2.5(b)$. There is a difference of opinion about the significance of active versus passive torque contribution to generate corrective torque, because Peterka and Loughlin believe that active torque plays a dominant role (Peterka \& Loughlin, 2004) while Loram and Lakie believe that passive torque plays the dominant role (Loram \& Lakie, 2002). Study have shown that an optimized model of the inverted pendulum with passive components, to match conventional posturographic measures to healthy adult, exhibit the best fit when passive components converge to zero (Maurer \& Peterka, 2005). 


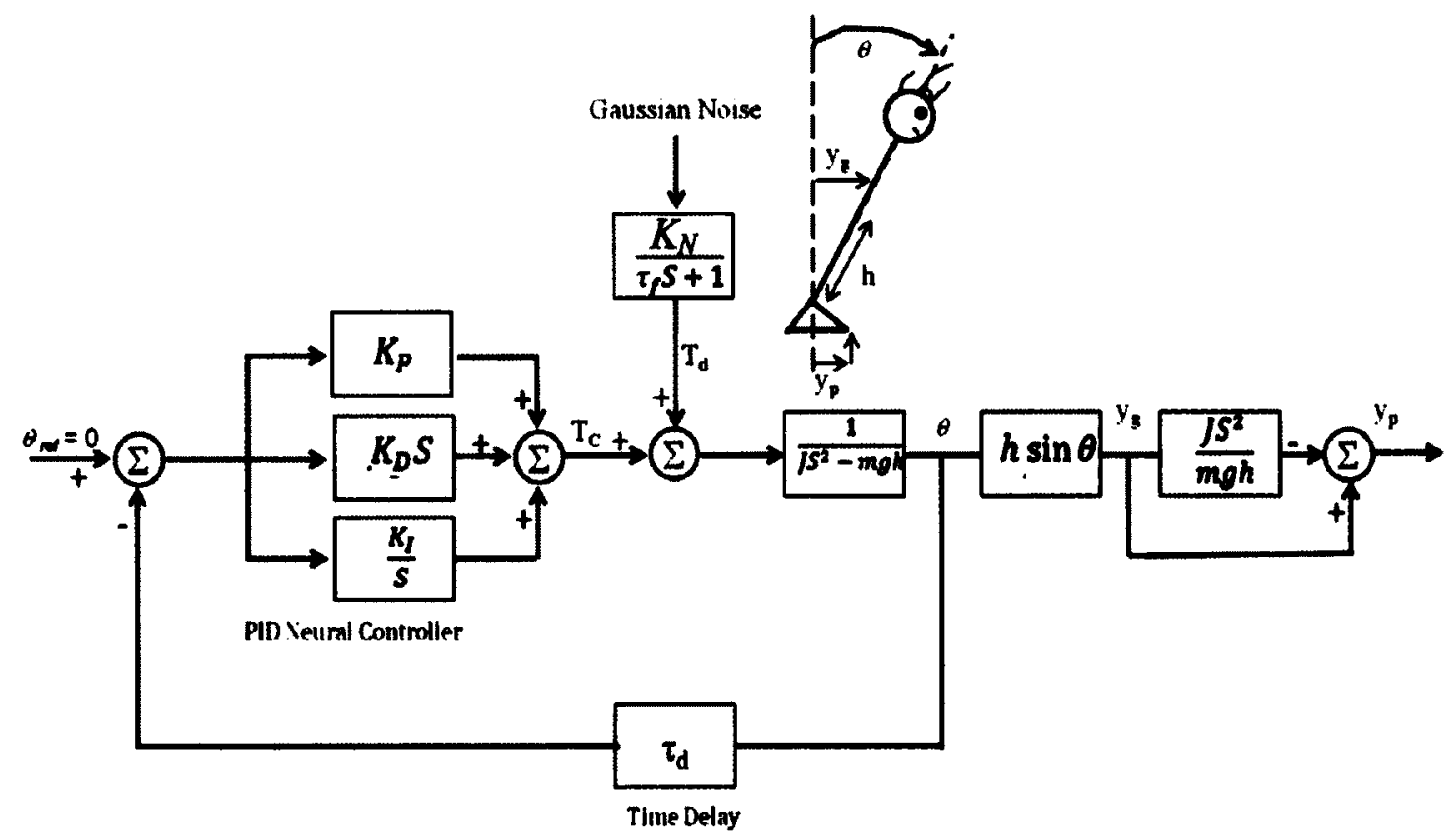

(a)

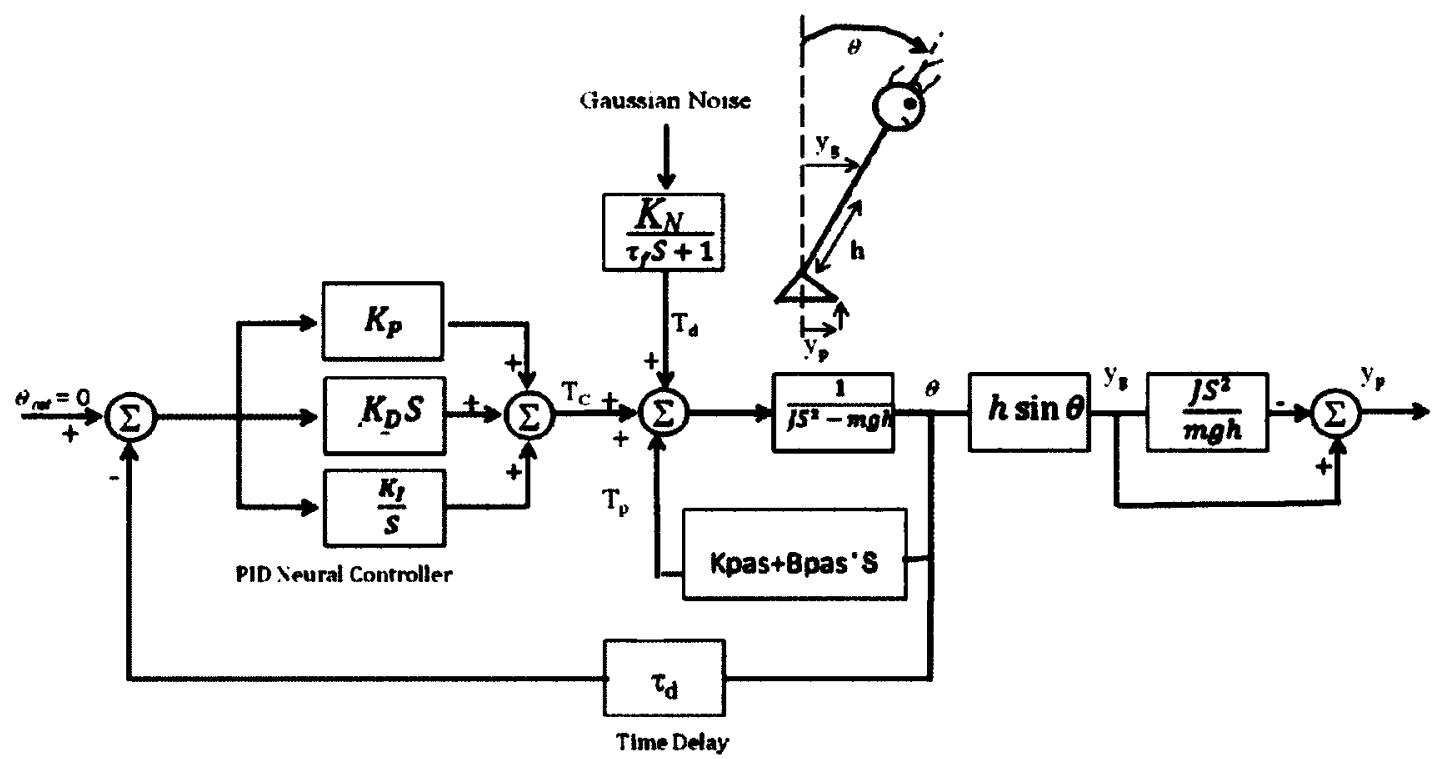

(b)

Figure 2.5: Inverted pendulum models of human upright stance postural control system, consist of pendulum body, open loop (PID) neural control system and a closed loop feedback control system: (a) inverted pendulum model without passive controllers, and (b) inverted pendulum model with passive controller, which produces third torque $T_{p}$ after (Maurer \& Peterka, 2005; Peterka. 2000). 
Human posture continuously undergoes small deviation of sway around an equilibrium point in a static upright stance position. The disturbance torque $T_{d}$ is used to simulate these deviations and an appropriate corrective torque $T_{c}$ produced by the PID neural controller is used to control these deviations.

The models of healthy individuals compared to the models of individuals having a stability impairment have different parameters for the PID controller and noise gain (Boes, 2011) (Bustamante Valles et al., 2008). The model for individuals with Multiple Sclerosis (MS), the PID gains indicate an increased proportional gain in neurological controller in the ML direction, and increased input noise gain in the ML with high spasticity MS (Boes, 2011). The significant differences in the model gains suggests that different postural control strategies are used by individuals with MS compare to healthy individuals (Boes, 2011). Comparing different model gains depicting physiological components can assist to enhance the understanding of changes in the postural control systems strategies due to diseases (Boes, 2011) (Bustamante Valles et al., 2008). 


\section{Data}

\subsection{Introduction}

This chapter provides information on the posturography data used in this thesis. The data includes simulated data and data collected from human subjects. Section 3.2 describes the simulation and the simulated data. Section 3.3 describes the experimental setup and equipment used to acquire posturography data from human subjects. Section 3.4 presents an analysis of the noise in the force platform to ensure the accuracy and precision of the data collected. The accuracy of measured data is the degree of closeness of the measured value to the true value of data, while the precision is the repeatability or reproducibility of the data (Nist-traceability, 2010). Section 3.5 outlines the protocols used to collect the data and details of the subjects who participated in this research.

\subsection{Simulation}

An inverted pendulum was used to model the upright stance of a human. The parameters for the inverted pendulum are set to an average adult male individual (Peterka, 2000), which are presented in Table 3.1.

Table 3.1: Inverted pendulum parameters for an average adult male.

\begin{tabular}{|l|c|l|}
\hline \multicolumn{1}{|c|}{ Body parameters } & Symbols & \multicolumn{1}{c|}{ Values } \\
\hline $\begin{array}{l}\text { Moment of inertia } \\
\text { about ankle joint axis }\end{array}$ & $J$ & $66 \mathrm{~kg} \cdot \mathrm{m}^{2}$ \\
\hline Mass & $m$ & $76 \mathrm{~kg}$ (excluding feet) \\
\hline Height & $h$ & $0.87 \mathrm{~m}$ (COG to ankle joint) \\
\hline $\begin{array}{l}\text { Acceleration } \\
\text { due to gravity }\end{array}$ & $g$ & $9.8 \mathrm{~m} / \mathrm{s}^{2}$ \\
\hline
\end{tabular}


Two separate models are used to generate COP in AP and ML direction (Valles et al., 2006). These models use a PID neural controller, along with a passive controller (Boes, 2011) as discussed in Section 2.6. Figure 3.1 illustrates the models used to simulate the COP data in this thesis.

Four sets of model parameters were used to mimic four stability conditions for humans with different health conditions. The model parameters were selected from (Boes, 2011). The four sets of model parameters correspond to a normal control population (Control) and three levels of spasticity of Multiple Sclerosis (MS): low (LowSP), medium (MedSP), and high (HighSP). This provides four stability conditions, with stability decreasing from Control to LowSP to MedSP to HighSP. Parameters of models for simulation are given in the Table 3.2. It is assumed that the PID neural control system can sense the deviation of the body from its reference position and generate a corrective torque $T_{\mathfrak{c}}$ relative to the deviation in the opposite direction to bring the body back to an equilibrium position. A Gaussian noise with zero mean and unity variance was generated to create the disturbance torque $T_{d}$. Different seeds from the random number generator were used for both $\mathrm{AP}$ and $\mathrm{ML}$ noise generators and different seeds were used for every run. The values of $\mathrm{K}_{1}, \tau_{d}$, and $\tau_{N}$ were held constant for both AP and ML models (Boes, 2011). The feedback time $\tau_{d}$ delay was set between the range of $0.1 \mathrm{~s}$ to $0.171 \mathrm{~s}, \tau_{N}$ for the low pass noise filter was set to $0.32 \mathrm{~s}$ and the value of $\mathrm{K}_{\mathrm{L}}$ to $0.6 \mathrm{~N} \cdot \mathrm{m} \cdot \mathrm{s}^{-1} \cdot \mathrm{rad}^{-1}(\mathrm{Boes}$, 2011). All simulations were performed with Simulink version 7.12.0 (MathWorks Inc., 
Natick, MA, USA). The simulation used Dormand-Prince algorithm (ode5) with fixed step size of $0.01 \mathrm{~s}$.

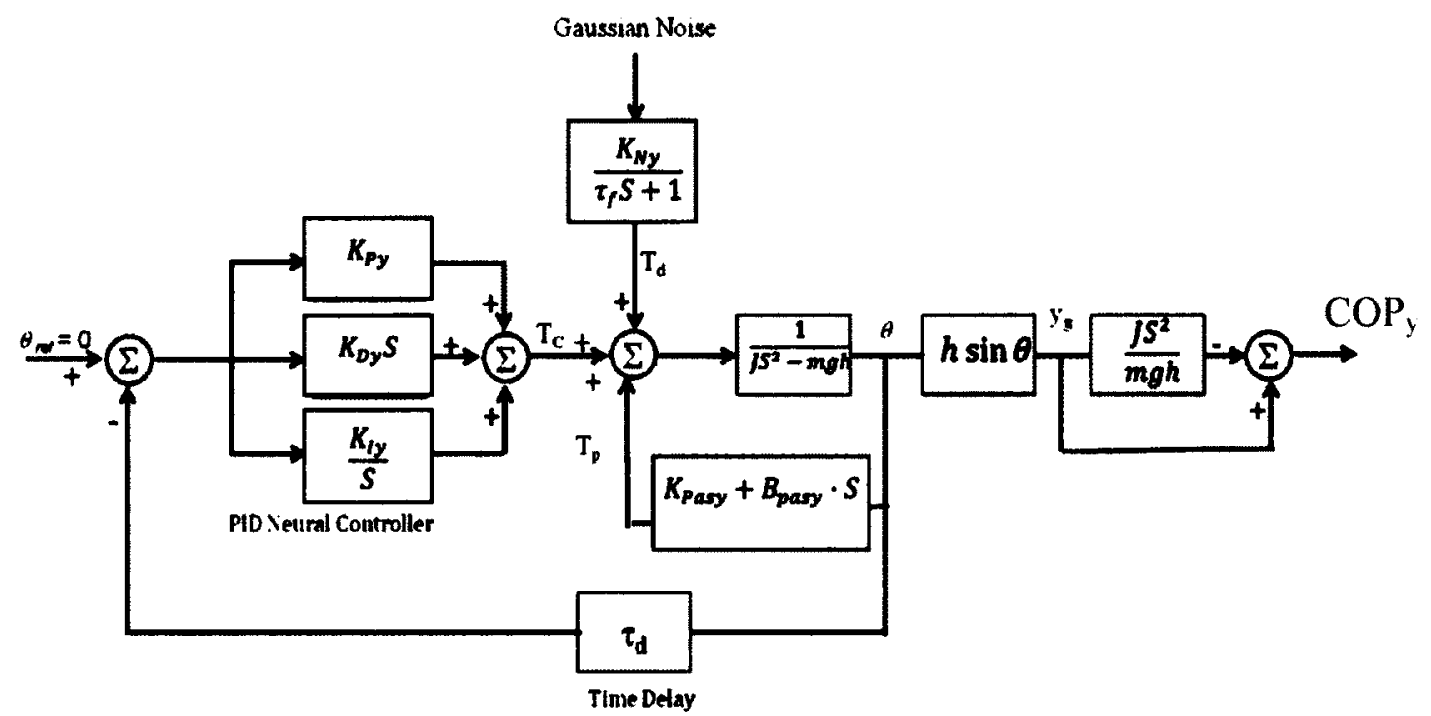

(a)

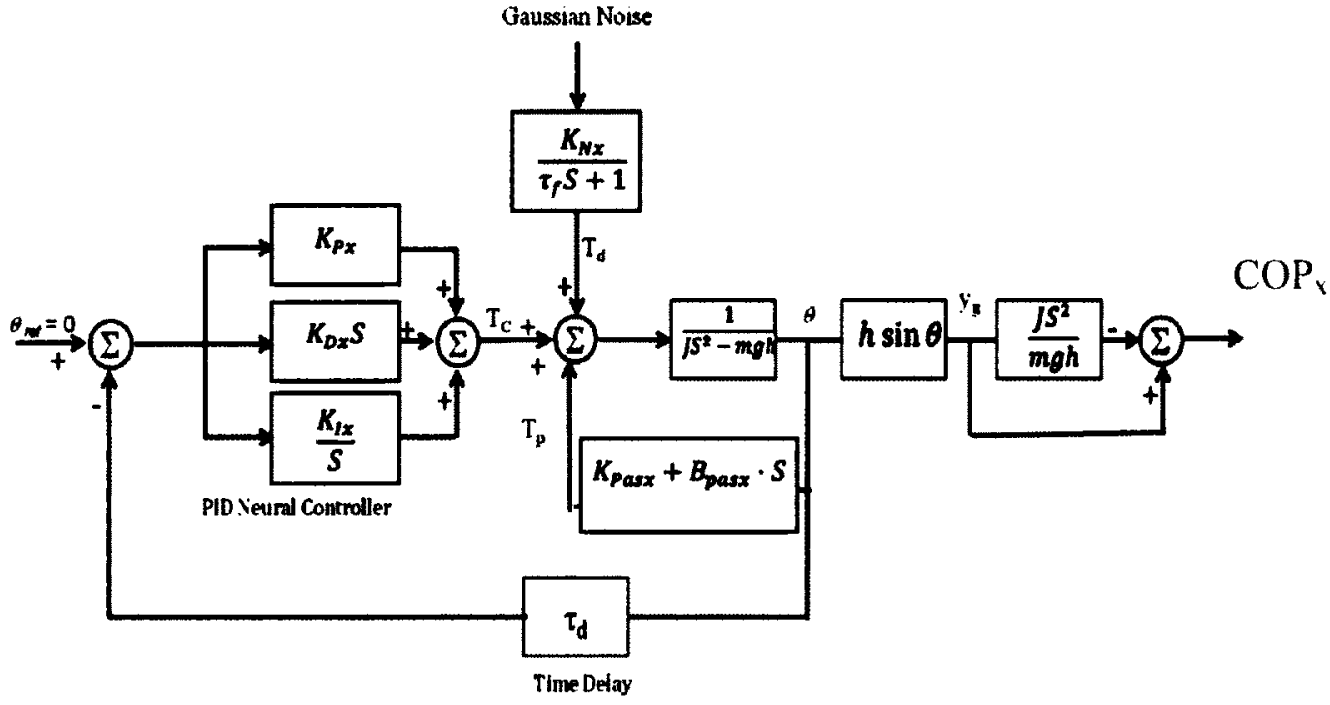

(b)

Figure 3.1: Inverted pendulum models of human upright stance, two separate models to generate COP in (a) anteroposterior direction (COPy) and (b) mediolateral direction (COPx). These models contain a PID neural controller, along with a passive controller. 
Table 3.2: Model gains for four different stability conditions (Boes, 2011)

\begin{tabular}{|c|c|c|c|c|c|c|c|c|}
\hline \multirow{2}{*}{$\begin{array}{c}\text { Model } \\
\text { Parameters }\end{array}$} & \multicolumn{2}{|c|}{ Control } & \multicolumn{2}{|c|}{$\begin{array}{c}\text { MS } \\
\text { LowSP }\end{array}$} & \multicolumn{2}{|c|}{$\begin{array}{c}\text { MS } \\
\text { MedSP }\end{array}$} & \multicolumn{2}{|c|}{$\begin{array}{c}\text { MS } \\
\text { HighSP }\end{array}$} \\
\hline & Mean & $\begin{array}{l}\text { Std. } \\
\text { Dev. }\end{array}$ & Mean & $\begin{array}{l}\text { Std. } \\
\text { Dev. }\end{array}$ & Mean & $\begin{array}{l}\text { Std. } \\
\text { Dev. }\end{array}$ & Mean & $\begin{array}{l}\text { Std. } \\
\text { Dev. }\end{array}$ \\
\hline$K_{D y}\left(\mathrm{~N} \cdot \mathrm{m} \cdot \mathrm{s} \cdot \mathrm{rad}^{-1}\right)$ & 0.30 & 0.35 & 0.84 & 0.96 & 0.88 & 1.04 & 0.89 & 1.04 \\
\hline$K_{P y}\left(\mathrm{~N} \cdot \mathrm{m} \cdot \mathrm{rad}^{-1}\right)$ & 9.44 & 1.36 & 10.54 & 5.33 & 10.87 & 1.11 & 10.9 & 1.11 \\
\hline$K_{l y}\left(\mathrm{~N} \cdot \mathrm{m} \cdot \mathrm{s}^{-1} \cdot \mathrm{rad}^{-1}\right)^{*}$ & 0.60 & 0.00 & 0.60 & 0.00 & 0.60 & 0.00 & 0.60 & 0.00 \\
\hline$K_{N y}(\mathrm{~N} \cdot \mathrm{m})$ & 3.42 & 1.30 & 4.33 & 17.00 & 5.25 & 3.06 & 6.33 & 3.06 \\
\hline$K_{\text {pasy }}\left(\mathrm{N} \cdot \mathrm{m} \cdot \mathrm{rad}^{-1}\right)$ & 10.08 & 0.66 & 10.00 & 8.87 & 10.27 & 0.54 & 10.15 & 0.54 \\
\hline$B_{\text {pasy }}\left(\mathrm{N} \cdot \mathrm{m} \cdot \mathrm{s} \cdot \mathrm{rad}^{-1}\right)$ & 2.12 & 0.81 & 1.39 & 0.76 & 1.75 & 1.15 & 1.76 & 1.15 \\
\hline$K_{D x}\left(\mathrm{~N} \cdot \mathrm{m} \cdot \mathrm{s} \cdot \mathrm{rad}^{-1}\right)$ & 0.69 & 0.81 & 0.66 & 1.82 & 0.73 & 0.67 & 0.94 & 0.67 \\
\hline$K_{P x}\left(\mathrm{~N} \cdot \mathrm{m} \cdot \mathrm{rad}^{-1}\right)$ & 9.63 & 0.67 & 9.96 & 1.76 & 10.87 & 1.36 & 11.00 & 1.36 \\
\hline$K_{I x}\left(\mathrm{~N} \cdot \mathrm{m} \cdot \mathrm{s}^{-1} \cdot \mathrm{rad}^{-1}\right)^{*}$ & 0.60 & 0.00 & 0.60 & 0.00 & 0.60 & 0.00 & 0.60 & 0.00 \\
\hline$K_{N x}(\mathrm{~N} \cdot \mathrm{m})$ & 0.68 & 0.35 & 3.16 & 5.02 & 4.06 & 4.29 & 4.63 & 4.29 \\
\hline$K_{\text {pasx }}\left(\mathrm{N} \cdot \mathrm{m} \cdot \mathrm{rad}^{-1}\right)$ & 9.45 & 1.09 & 10.00 & 0.99 & 10.03 & 1.12 & 9.95 & 1.12 \\
\hline$B_{\text {pasx }}\left(\mathrm{N} \cdot \mathrm{m} \cdot \mathrm{s} \cdot \mathrm{rad}^{-1}\right)$ & 1.50 & 1.04 & 1.00 & 0.92 & 1.67 & 1.11 & 1.33 & 1.11 \\
\hline
\end{tabular}

\subsection{Experimental Setup}

An Advanced Mechanical Technology Inc. (AMTI) force platform (AccuGait System, Watertown, MA, USA) was connected to a computer for COP data recording as shown in

Figure 3.2. Data were sampled at $100 \mathrm{~Hz}$ using a 16-bit analog-to-digital converter that is built into the force platform and no filtering was performed other than force platform built in filtering. The data were processed offline in Matlab (MathWorks Inc., Natick, MA, USA). The statistical analysis was performed using SPSS (SPSS, Inc., Chicago, IL, USA). 


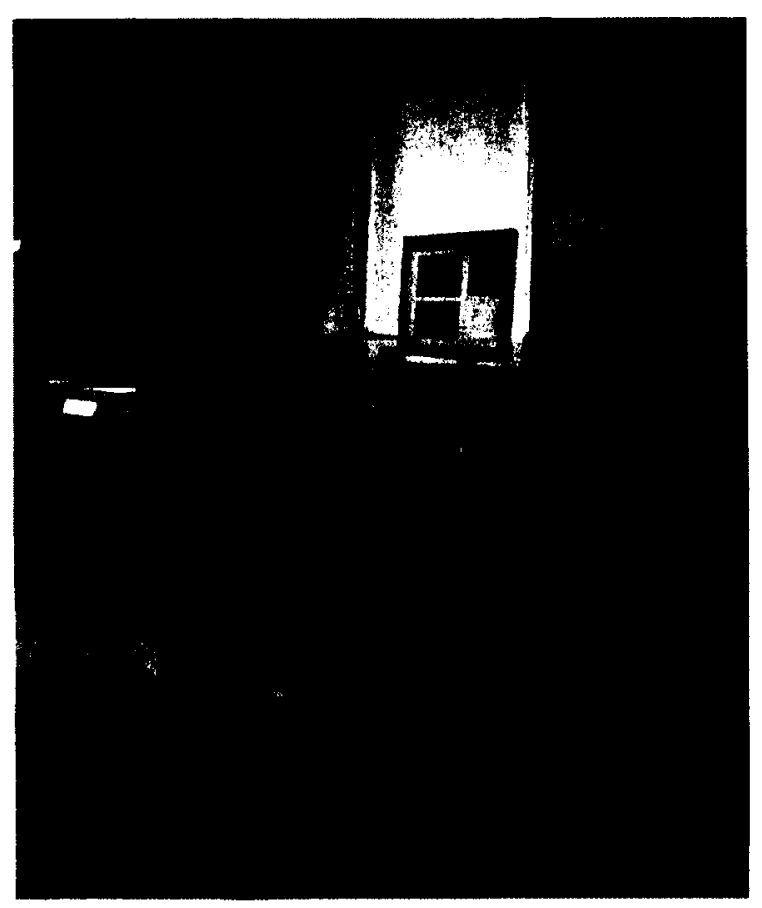

Figure 3.2: Experimental setup showing monitor, force platform and a subject standing on it.

\subsection{Force Platform's Noise}

The force platform is an instrument that measures the reaction force exerted by the body standing or moving on platforms surface. The force platform measures these forces by the electrical signal produced by transducers, proportional to the force applied by the person's weight (Browne \& O’Hare, 2000a).

The force platform is highly susceptible to different kinds of noises, such as building and ground vibrations. Noise can be due to improper force platform installation (Hall, Fleming, Donal, Millbank, \& Paul, 1996), where the platform was not installed to minimize vibration (“Advanced Mechanical Technology, Inc. (AMTI)," 2012). Other sources of noise include electronic noise, non-linearity of the transducers response, and 
deformation of the force platform's top plate over time (Browne \& O'Hare, 2000a). Spatial noise can be caused by electronic noise and hysteresis of the system and different transducer offset voltages.

The changes in postural stability due to a balance disorder can be small. For example, a 5 $\mathrm{mm}$ sway of COP was reported for a healthy volunteer and $7.1 \mathrm{~mm}$ for a patient with moderate Parkinson's disease (Browne \& O'Hare, 2000b); a difference of only $2.1 \mathrm{~mm}$. Therefore, the accuracy of COP measures is important for balance assessment of the patient so that the changes in the postural balance of a patient over time can be detected accurately. The experimental setup, used in this research, was assessed for its accuracy using the static load test (Bizzo et al., 1985; Browne \& O'Hare, 2000b; Gill \& O'Connor, 1997).

\subsubsection{Noise Analysis}

To ensure the accurate estimation of the various COP measures, it is necessary to investigate the baseline noise and precision of the force platform. In the static load test, used to investigate force platform's performance, known loads are applied on different coordinates and the COP displacement was measured. This COP displacement is representative of the amount of noise present in the system.

COP displacement due to static load on the platform at any given point represents the background noise while the spatial noise is due to variations in measurements when measurements are taken at different locations on the force platform. According to the 
Association Française de Posturologie, COP displacement should be within $1 \mathrm{~mm}$ (Bizzo et al., 1985)

The spatial accuracy can be measured by placing calibrated loads precisely on the different coordinates of interest on the force platform (Browne \& O'Hare, 2000a, 2000b), (Bizzo et al., 1985). Ideally the value of COP displacement should be the same regardless of the position where the subject is standing or the load is placed on the surface of the platform.

According to Bizzo (1985) when a static load between $10 \mathrm{~kg}$ and $40 \mathrm{~kg}$ is applied to the force platform, the COP must be $<1 \mathrm{~mm}$ (Bizzo et al., 1985). The maximum load was suggested to be comparable to the average adult weight (Hall et al., 1996). The number of coordinates where the load is applied, needs to be appropriate in order to achieve reasonable coverage of the platform surface (Hall et al., 1996). The spatial accuracy was measured by Mita (Mita et al., 1993), Barrett (Barrett, Hyde, \& Hark, 1987) and Bobbert (Bobbert \& Schamhardt, 1990), by stacking the load on the different coordinates of interest on the force platform successively. Gill and O'Connor have designed a rig system (Gill \& O'Connor, 1997) to apply the calibrated load on required coordinate to measure the accuracy of the force platform..

\subsubsection{Method}

The methodology was designed by the author with her supervisors. The experiment was conducted at Élisabeth Bruyère hospital research lab affiliated with Ottawa University by Research Associate Anthony Remaud in the supervision of Professor Martin Bilodeau 
University of Ottawa. The force platform noise data were collected by applying a static load of $45.5 \mathrm{~kg}$ which is less than average adult weight (Hall et al., 1996) on the force platform. The force platform was divided into a grid of $4 \times 4$ squares. The load was applied on five different positions: first at the center (c) of the force platform and then the load is shifted from center to the adjacent coordinates at front (f), left (1), right (r) and back (b) positions, respectively (Figure 3.3).

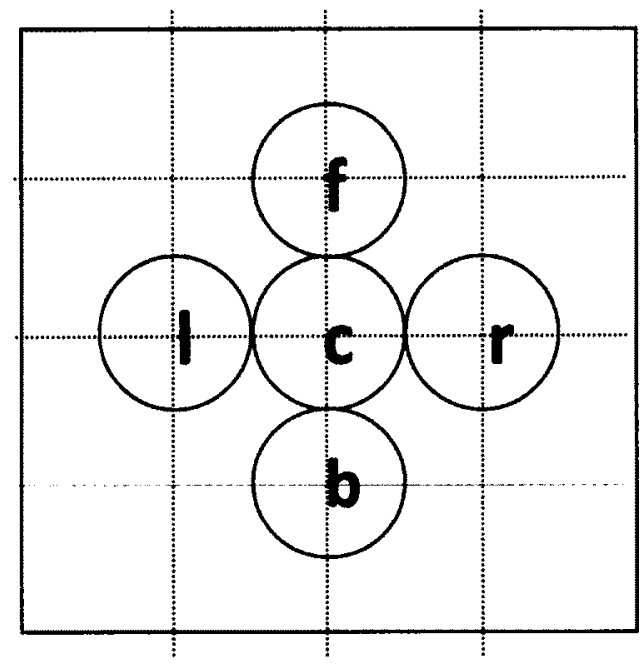

Figure 3.3: Diagram of force platform showing circles around the co-ordinate of interest for placing the load on the surface of the force platform center $=c$, front $=f$, left $=l$, right $=r$ and back $=\mathbf{b}$

A wooden box (Figure 3.4b) was used to contain the required load. The box was positioned lying on a wooden cube [8 $\times 8 \times 4 \mathrm{~cm}$ ] (Figure 3.4c), to place the load precisely on the coordinate of interest. Figure 3.4 (a) presents the force platform with grid marked to investigate the presence of noise on the co-ordinates of interests. Figure 3.5 presents the load on different positions on the force plate. Data were recorded for $120 \mathrm{~s}$ and values of maximum COP displacement for the static load were calculated. 


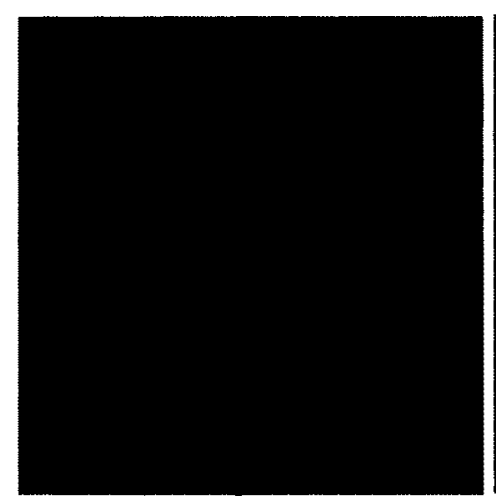

(a)

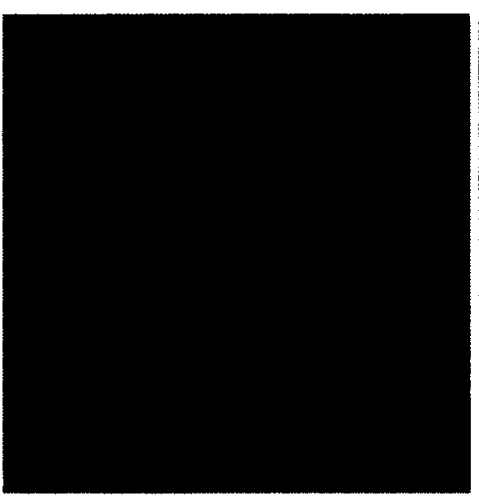

(b)

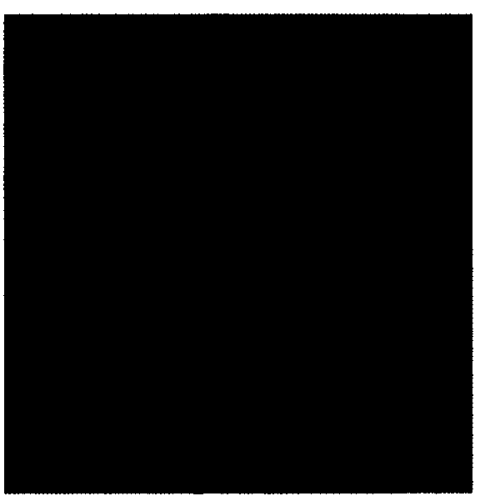

(c)

Figure 3.4: (a) surface of the platform with grid marked to localize the coordinate of interest (b) wooden box, with wooden cube at the base, used to contain the weight and (c) shows the weight on the center of the force platform surface.

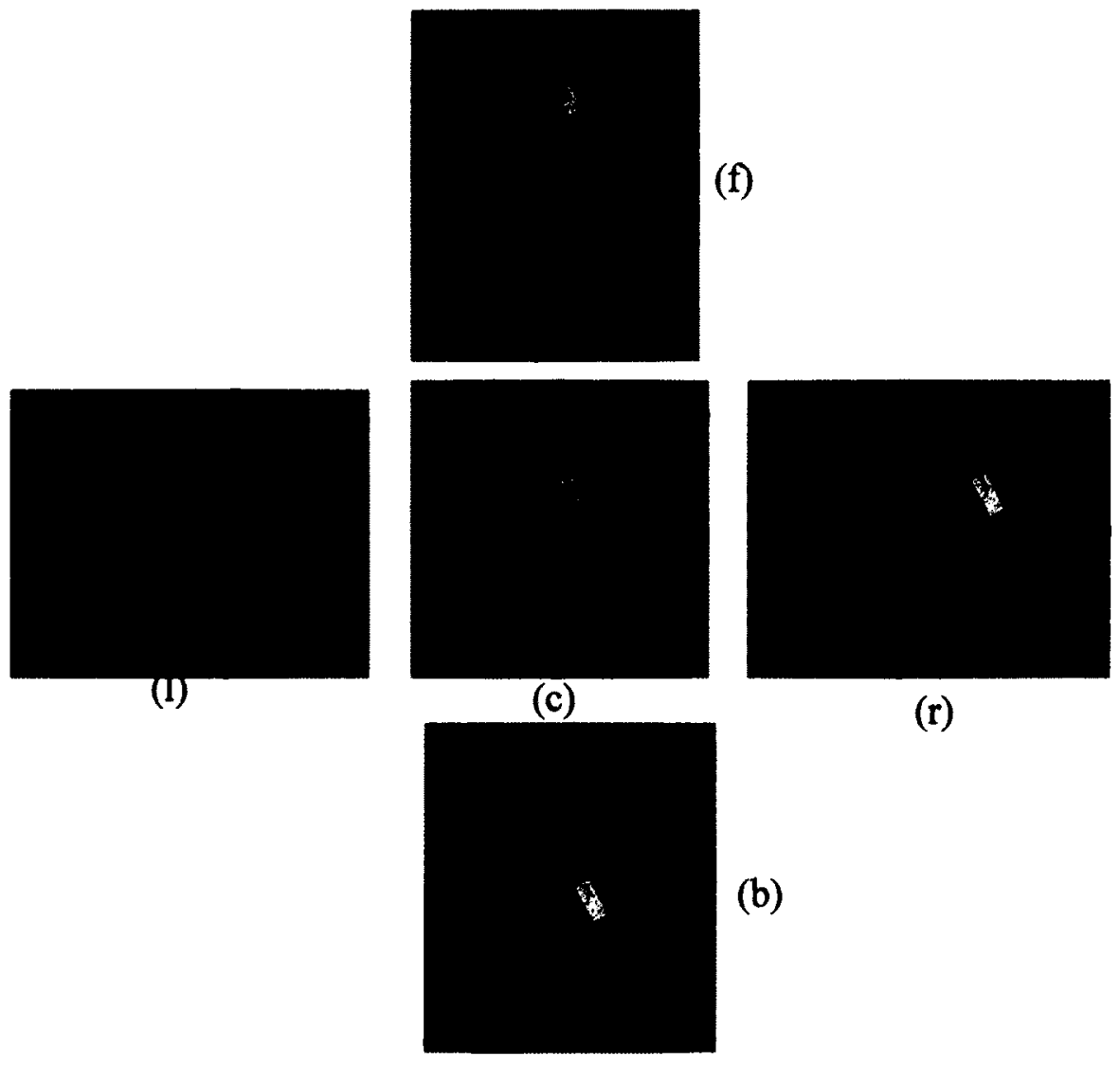

Figure 3.5: Static load test using a $45.5 \mathrm{~kg}$ weight, placed (c) center of the platform, (f) at the front of the platform, (r) on the right side, (d) on the left side of the platform and (b) on the back of the platform. 


\subsubsection{Background Noise Analysis}

The background noise in the force platform was estimated by examining the data when the load was applied at five coordinate positions on the force platform. The presence of COP displacement at any given point on the platform represents background noise depicted in Figure 3.6. The measured values of COP displacement are the amount of background noise present in the system.

\subsubsection{Spatial Noise Analysis}

The spatial noise was estimated by examining the variation in data when the load was applied on five different coordinates successively on the force platform (Browne \& O'Hare, 2000a, 2000b), (Bizzo et al., 1985); i.e., Center, Front, Left, Right and Back positions. The COP displacement values were calculated for each load position. The variation in the COP displacement values was an estimate of the spatial noise. The COP displacements for different positions are shown in Figure 3.7.

\subsubsection{Results and Discussion}

Figure 3.6 presents the posturograph when the load was placed on the center of the force platform. Figure 3.7 shows the posturograph on all five coordinates (center, front, left, right and back). The mean value of $\mathrm{COP}$ is subtracted from each recording to center the posturograph to the $(0,0)$ position. The area of $95 \%$ confidence ellipse traversed by the COP is included in both Figure 3.6 and Figure 3.7. This ellipse is a representation of the $95 \%$ of background noise. The presence of COP displacement at any given point on the platform represents background noise, while the variation in the values of COP for different positions are the presentation of spatial noise. 


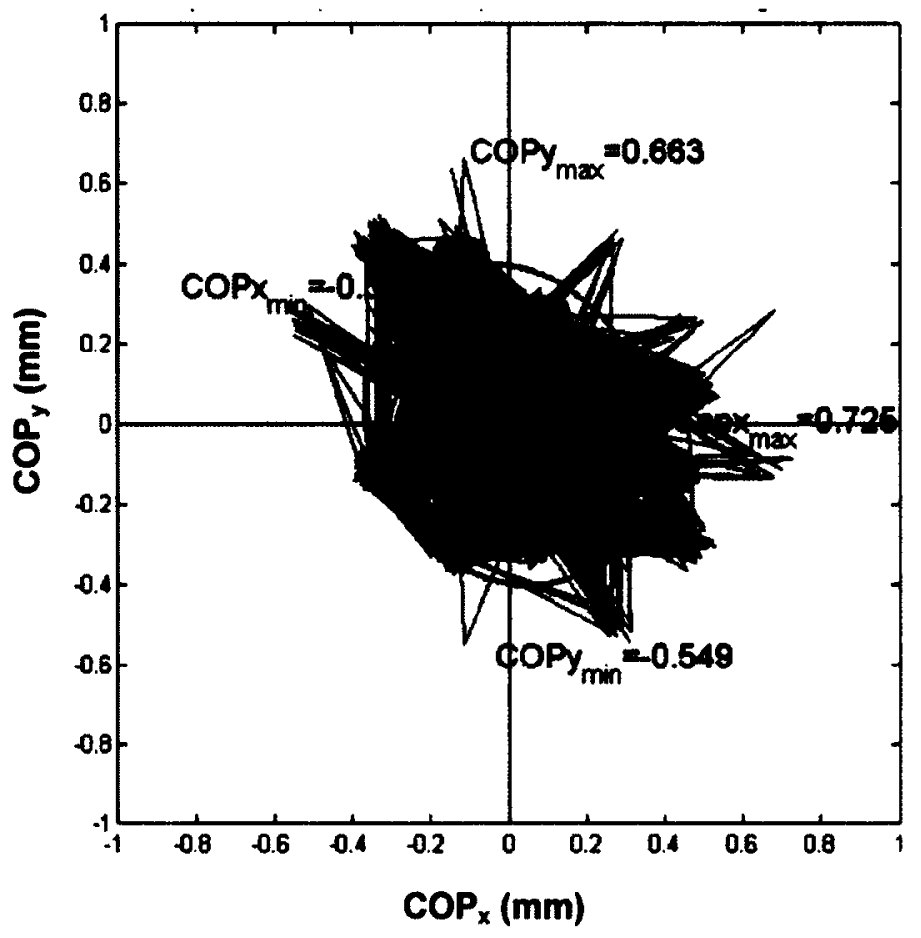

Figure 3.6: The posturograph of the force platform (ACG 0536) loaded with static $45.5 \mathrm{~kg}$ at the center (mean value of COP is subtracted from each value of COP to bring the posturograph in the center $(0,0)$ of the graph). Blue lines are the COP of the static load and the red ellipse encloses the area of $95 \%$ confidence ellipse traversed by $\mathrm{COP}$.

Table 3.3 presents the maximum COP displacements, the maximum background noise. The maximum COP displacement was $0.737 \mathrm{~mm}$, found for the center position of the load. The background noise was similar for all other positions, which was less than $1 \mathrm{~mm}$ as suggested by the Association Française de Posturologie (Browne \& O'Hare, 2000a). The maximum difference in maximum $\mathrm{COP}$ displacements $\left(\mathrm{COP}_{\max }\right)$ was $0.031 \mathrm{~mm}$, which was less than $1 \mathrm{~mm}$. Results suggesting that both background noise and spatial noise were within an acceptable range. 

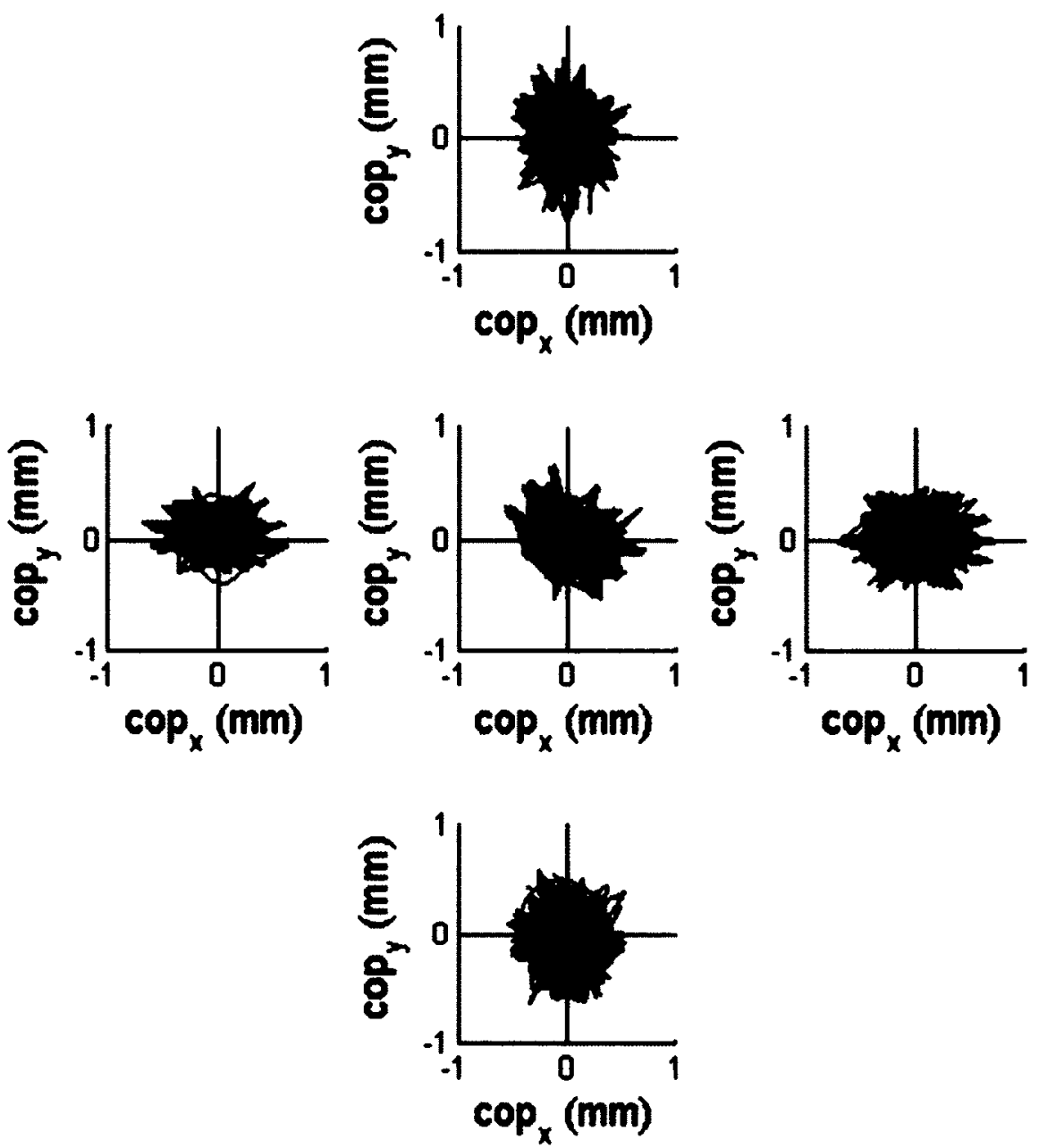

Figure 3.7: The force platform (ACG 0536) loaded with $45.5 \mathrm{~kg}$ at center, front, left, right and back successively. COP displacements are $<1.0 \mathrm{~mm}$ in all cases (mean value of COP is subtracted from each value of COP to bring the posturograph in the center $(0,0)$ ).

Table 3.3: The range of COP values in noise measurements.

\begin{tabular}{|c|c|c|c|c|c|}
\hline \multirow{2}{*}{$\begin{array}{c}\text { Background } \\
\text { Noise }\end{array}$} & \multicolumn{5}{|c|}{ Load Position (mm) } \\
\cline { 2 - 6 } & Center & Left & Right & Front & Back \\
\hline COP $_{\max }$ & 0.737 & 0.706 & 0.736 & 0.732 & 0.726 \\
\hline
\end{tabular}

\subsubsection{Conclusions}

The background noise for all positions and the spatial noise are less than $1 \mathrm{~mm}$. Therefore, the experimental setup is verified to be suitable for COP measures 
performance analysis, according to the Association Française de Posturologie (Browne \& O'Hare, 2000a), which require background and spatial noise to be less than $1 \mathrm{~mm}$.

\subsection{Experimental Data from Human Subjects}

The experiment was conducted at Élisabeth Bruyère hospital research lab affiliated with Ottawa University by Research Associate Anthony Remaud in the supervision of Professor Martin Bilodeau University of Ottawa. Experimental data were collected from eight subjects with no known postural balance disorder for four different stability conditions. This research was reviewed and approved by the Research Ethics Boards (REB) of the Bruyère Continuing Care, University of Ottawa. The details of subjects are given in the Table 3.4. The primary goal is to develop a methodology to investigate the performance of different COP measures. The second aim is to investigate the effect of analysis window length on the performance of COP measures.

Table 3.4: Subject participant information.

\begin{tabular}{|c|c|c|c|c|c|c|}
\hline $\begin{array}{c}\text { Subject } \\
\#\end{array}$ & Gender & Age & $\begin{array}{c}\text { Height } \\
(\mathrm{cm})\end{array}$ & $\begin{array}{c}\text { Weight } \\
(\mathbf{k g})\end{array}$ & $\begin{array}{c}\text { Preferred supporting leg } \\
\text { for single leg (SL) stance }\end{array}$ & $\begin{array}{c}\text { Medication or } \\
\text { balance problem }\end{array}$ \\
\hline 1 & M & 31 & 168 & 64.3 & right leg & none \\
\hline 2 & M & 31 & 192 & 81.8 & left leg & none \\
\hline 3 & M & 25 & 185 & 83.9 & right leg & none \\
\hline 4 & F & 48 & 155 & 53.6 & right leg & none \\
\hline 5 & F & 25 & 160 & 51.3 & right leg & none \\
\hline 6 & M & 45 & 170 & 68.9 & left leg & none \\
\hline 7 & M & 33 & 173 & 79.4 & right leg & none \\
\hline 8 & F & 21 & 168 & 65.8 & right leg & none \\
\hline
\end{tabular}


Each participant performed 11 trials. Each trial consisted of four measurements, one for each of the four postural stability conditions: 1) feet together, eyes open (FT-EO), 2) feet together, eyes closed (FT-EC), 3) single leg, eyes open (SL-EO), and 4) single leg, eyes closed (SL-EC). During each measurement, the participant was visually focusing on a fixed target, with their hands on their hips (Figure 3.8). The order of stability conditions was randomized to create 11 sets of the four stability conditions (Table 3.5). The order of these sets was randomized between subjects. Measurements of sixty seconds were performed for each stability condition, with 60 seconds of rest between two stability conditions within a trial. A rest of $120 \mathrm{~s}$ was also introduced between each set of four stability conditions to avoid muscle fatigue.

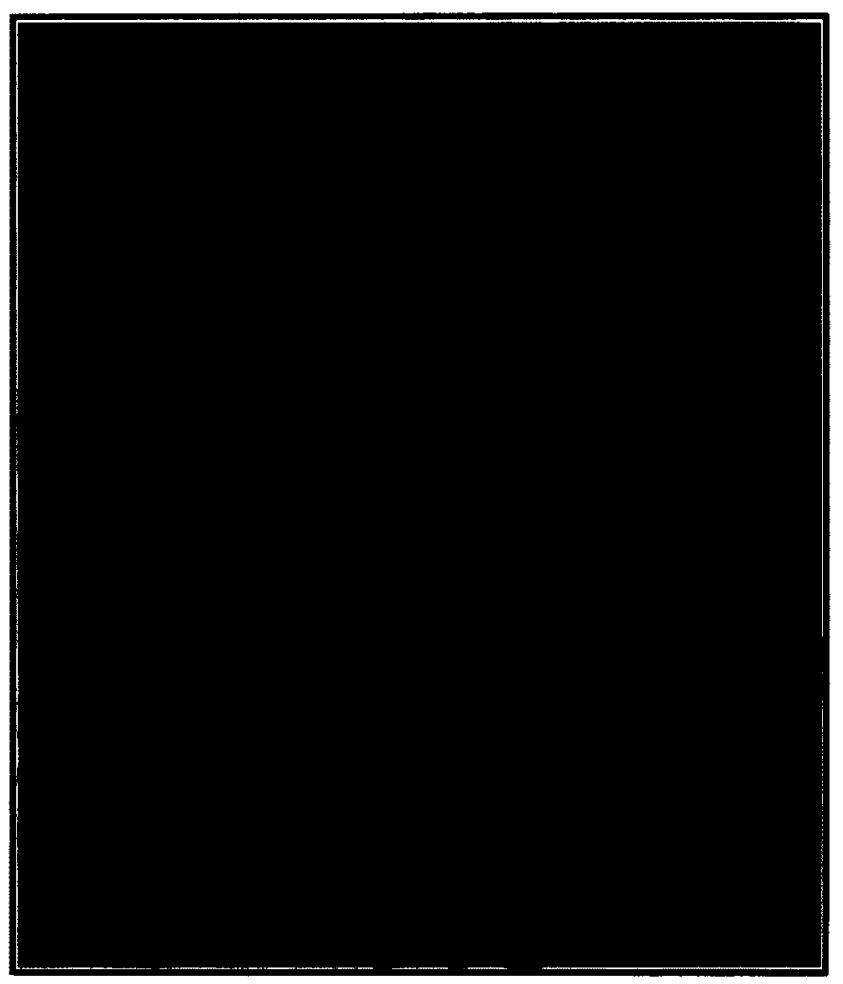

Figure 3.8: A subject is standing on the force platform with feet together, hands on their hips and visually focusing on a fixed target (black dot in red circle) on the wall. 
Table 3.5: 11 different sets of the four stability conditions.

\begin{tabular}{|c|l|}
\hline Order of sets & Set of stability conditions \\
\hline 1 & FT-EO, FT-EC, SL-EO, SL-EC \\
\hline 2 & FT-EC, SL-EO, SL-EC, FT-EO \\
\hline 3 & SL-EO, SL-EC, FT-EO, FT-EC \\
\hline $\mathbf{4}$ & SL-EC, FT-EO, FT-EC, SL-EO \\
\hline $\mathbf{5}$ & FT-EO, SL-EO, FT-EC, SL-EC \\
\hline $\mathbf{6}$ & SL-EO, FT-EC, SL-EC, FT-EO \\
\hline 7 & FT-EC, SL-EC, FT-EO, SL-EO \\
\hline $\mathbf{8}$ & SL-EC, FT-EO, SL-EO, FT-EC \\
\hline 9 & FT-EC, FT-EO, SL-EC, SL-EO \\
\hline 10 & FT-EO, SL-EC, SL-EO, FT-EC \\
\hline 11 & SL-EC, SL-EO, FT-EC, FT-EO \\
\hline
\end{tabular}




\section{Performance of Center-of-Pressure Measures}

\subsection{Introduction}

A methodology was developed to investigate the performance of COP measures. This methodology was applied to six conventional COP measures from simulated data (Section 3.2) and experimental data (Section 3.5). Cluster analysis was used to assess the performance of COP measures. The COP measure is considered more repeatable if there is less intra-trial variability and discernible if there is high inter-trial variability.

A good COP measure should have low variability for a given stability condition (low intra-cluster distances or high compactness) and as well be able to discern between different stability conditions (high inter-clusters distances). To validate the intra-cluster homogeneity and inter-cluster separation of the clustering, the inherent quantities, cluster compactness or variance and cluster separation or distance of the distribution of the data are used. There is variety of validity indices used to validate the goodness of the clusters, which is used here to evaluate the performance of the COP measures.

In this study, the clusters of COP measures already exist. The performance (goodness) of COP measures are quantified using a cluster validity index, which provides a measure of how well (performance) COP measures (of 11 trials) are clustered for the given stability conditions. 


\subsection{Performance of COP Measures}

Cluster analysis was used to quantify the performance of COP measures in the sense of repeatability within a stability condition and differentiability between different stability conditions.

Good clusters have high intra-cluster similarities or low variance between the objects of the same cluster as well as have low inter-cluster similarities or high variance between the objects of different clusters (Figure 4.1). Cluster validity indices are used to quantify the compactness within the cluster and separation between the clusters (Žalik \& Žalik, 2011). For a given subject, the repeated trials were used to form clusters of COP measures, based on stability conditions. A good stability measure will minimize the intracluster distances (increased repeatability for a given level of stability) and maximize the inter-cluster distances (increased ability to differentiate between different levels of stability). 


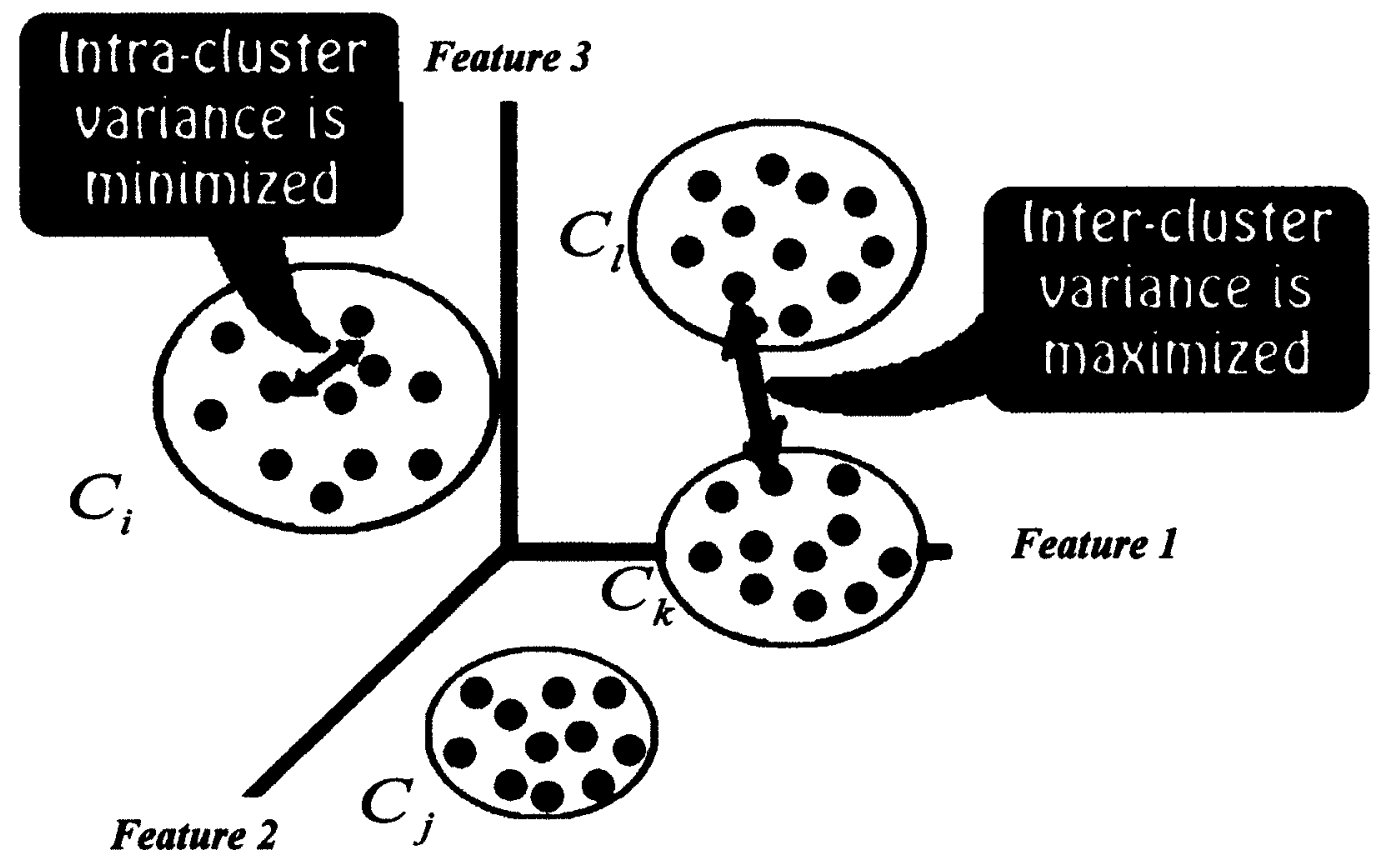

Figure 4.1: Illustration of the inter- and intra-cluster distances (or variance) where $C_{l}, C_{j}$, $C_{k}$, and $C_{l}$ are four different clusters.

There are various cluster validity indices. The aim is to find a suitable index to evaluate the performance of $\mathrm{COP}$ measures by quantifying the inter- and intra-cluster distances; all the distances used in the study are Euclidean distances. The distance between points $x=\left\{x_{1}, \ldots x_{n}\right\}$ and $y=\left\{y_{1}, \ldots y_{n}\right\}$ in Euclidean space $\mathbb{R}^{n}$ is given by

$$
d(x, y)=\sqrt{\sum_{i=1}^{n}\left|x_{i}-y_{i}\right|^{2}}
$$

The following three validity indices were investigated

1. Davies-Bouldin Index

2. Dunn Index

3. Silhouette Coefficient 


\subsubsection{Davies-Bouldin Index}

The Davies-Bouldin (DB) Index (Davies \& Bouldin, 1979) is a function of the ratio of the sum of within-cluster (i.e., intra-cluster) scatter to between cluster (i.e., inter-cluster) separation. Figure 4.2 presents inter- and intra-cluster distances. If $C=\left\{C_{1}, \ldots, C_{K}\right\}$ is a set of $K$ clusters for $N$ objects then the Davies-Bouldin Index is defined as:

where

$$
D B=\frac{1}{K} \sum_{i=1}^{K} R_{i}
$$

$$
\begin{aligned}
& R_{i}=\max _{j=1, \ldots, i \neq j} R_{i j} \\
& R_{i \neq j}=\frac{\operatorname{var}\left(C_{i}\right)+\operatorname{var}\left(C_{j}\right)}{d\left(v_{i}, v_{j}\right)} . \\
& \operatorname{var}\left(C_{i}\right)=\text { variance of } C_{i} \\
& d\left(v_{i}, v_{j}\right)=\text { Euclidean distance between centroids } v_{i}, v_{j}
\end{aligned}
$$

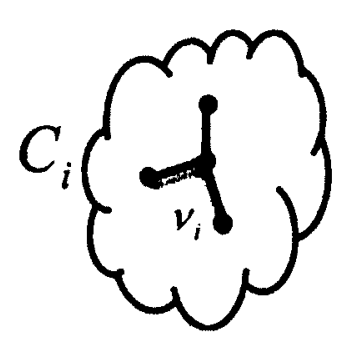

(a)

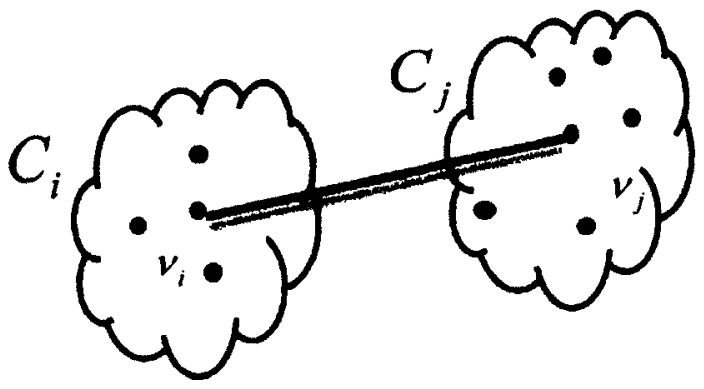

(b)

Figure 4.2: Illustration of (a) intra- and (b) inter-cluster distances. The red dots indicate clusters centroids for Davies-Bouldin Index. 
It is noted that $R_{i j}=R_{j i}, C_{i}$ is the $i^{\text {th }}$ cluster, $v_{i}$ is the centroid for cluster $i, R_{i j}$ is a ratio for which the numerator is a measure of intra-cluster similarity and the denominator is a measure of inter-cluster separation. A low scatter and a high distance between clusters is required which leads to the low values of $R_{i j}$, to minimize the $\mathrm{DB}$ index; thus a low value of $\mathrm{DB}$ index is desirable.

\subsubsection{Dunn Index}

The Dunn Index (DI) (Dunn, 1974) was defined for the crisp clustering; crisp clustering means having non overlapping clustering. The Dunn Index is define as follow

$$
D I(C)=\min _{i \in C}\left\{\min _{j \in C, i \neq j}\left\{\frac{\min _{x \in C_{i}, y \in C_{j}} d(x, y)}{\max _{k \in C}\left\{\max _{x, y \in C} d(x, y)\right\}}\right\}\right\}
$$

where

$\min _{x \in C_{i}, y \in C_{j}} d(x, y):$ Minimum distance between clusters $C_{i}$ and $C_{j}$ (inter-cluster distance), from different clusters

$\max _{x, y \in c_{i}} d(x, y)$ : Maximum distance of two objects from the same cluster, i.e., intracluster distance of cluster $C_{i}$.

A higher value of the Dunn Index is desirable.

\subsubsection{Silhouette Coefficient}

The silhouette coefficient (Rousseeuw, 1987) calculates the silhouette width for each object, the average silhouette width for each cluster, and the overall average silhouette width for a total data set. Figure 4.3 presents inter- and intra-cluster distances. 


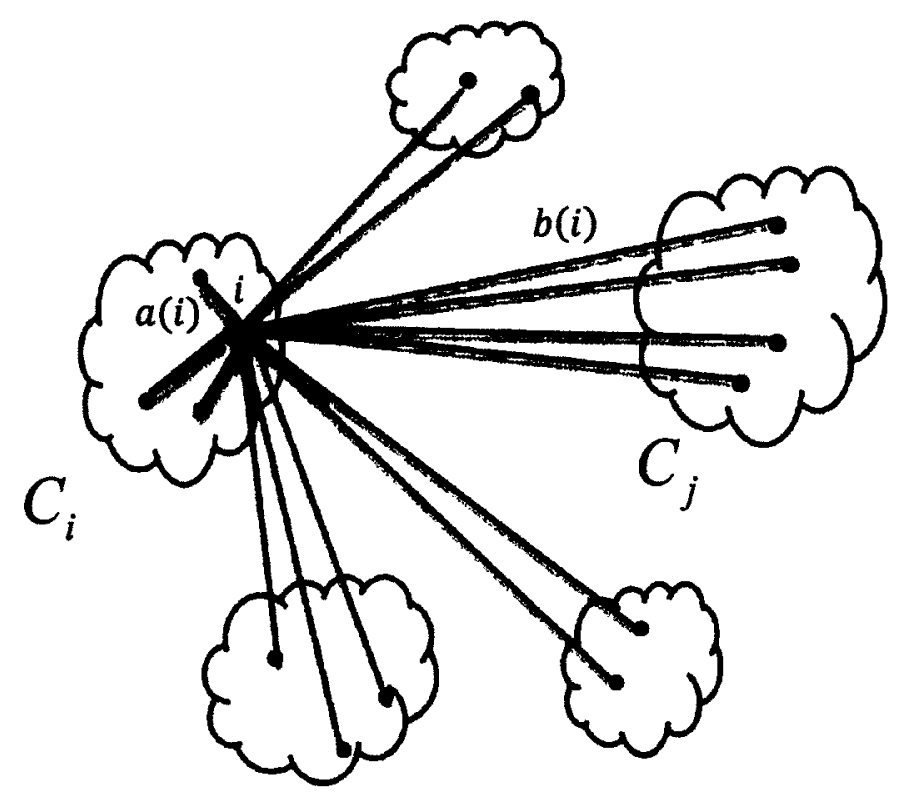

Figure 4.3: Illustration of inter-, $b(t)$, and intra-cluster, $a(i)$, distances for silhouette coefficient.

The silhouette coefficient (SC) is defined by following equation

$$
S C=\frac{1}{N} \sum_{i=1}^{N} S(i)
$$

where

$$
\begin{aligned}
& N=\text { number of all objects in whole data set. } \\
& S(i)=\frac{b(i)-a(i)}{\max \{a(i), b(i)\}} \\
& -1 \leq S(i) \leq 1
\end{aligned}
$$

$a(i)$ : average distance of $i^{\text {th }}$ object to all other objects in the same cluster (Figue 4.3).

$$
b(i)=\min _{C_{i} \neq C_{j}} d\left(i, C_{j}\right)
$$


$d\left(i, C_{j}\right)=$ average distance of $i^{\text {th }}$ object of $C_{i}$ to all objects of $C_{j}$ and $C_{i} \neq C_{j}$ then computing $d\left(i, C_{j}\right)$ for all other clusters and select the smallest of those and denoted by

- Silhouette coefficient $S(i)$ value lies between $-1 \leq S(i) \leq 1$

- Close to 1 means objects are well clustered

- Close to -1 means object is misclassified

- Zero means choice is arbitrary

- Largest overall average silhouette coefficient desirable

- The largest overall average silhouette coefficient $S C$ also lies between $-1 \leq S C \leq 1$

\subsubsection{Comparison of Validity Indices}

The difference between Dunn Index and the Davies-Bouldin index is that the DaviesBouldin index is a function of the ratio of the sum of within-cluster scatter to betweencluster separation, it uses both the clusters and their sample means (Davies and Bouldin, 1970), while Dunn Index use the average error of each cluster. The Dunn Index and the Davies-Bouldin index were design for crisp clustering while the silhouette coefficient can assess the overlap of clusters.

The Dunn Index, the Davies-Bouldin index and the silhouette coefficient were investigated for cluster analysis of the COP measures. The COP measures were clustered on the basis of four stability conditions (FT-EO, FT-EC, SL-EO, SL-EC). Thus each measure has four clusters and each cluster consist of 11 data points (trials). The COP measures' clusters for different stability conditions are not always crisp for different stability conditions. Some of the clusters of measures overlap between the conditions. The silhouette coefficient can give information about the overlap of the clusters, thus it 
appears to be the most suitable index among the investigated indices for the assessment of the performance of COP measures.

\subsection{Analysis of Data}

\subsubsection{Simulated Data}

The cluster analysis was performed on the simulated COP data of four different stability conditions: control (Control), MS with low spasticity (LowSP), MS with medium spasticity (MedSP), and MS with high spasticity (HighSP) (see Section 3.2). All simulations were simulated for $150 \mathrm{~s}$ and 100 times per stability condition. The data produced by the simulation were processed offline in Matlab (MathWorks Inc., Natick, MA, USA) for evaluation of performance of COP measures. The first $120 \mathrm{~s}$ of data were discarded, to avoid the effects of initial conditions and only the last $30 \mathrm{~s}$ of data were used to make it comparable with the experimental data window length used for performance analysis (see Section 4.3.2). The six COP measures evaluated were 1) average radial displacement $\left.\left(R D_{\text {avg }}\right), 2\right)$ average velocity $\left.\left(V_{\text {avg }}\right), 3\right)$ area of the $95 \%$ confidence ellipse $(A R E A), 4)$ standard deviation of $\left.\operatorname{COP}_{x}\left(\sigma_{x}\right), 5\right)$ standard deviation of $\operatorname{COP}_{y}\left(\sigma_{y}\right)$ and 6) standard deviation of radial displacement $\left(S D_{-} R D\right)$. These measures were described in Section 2.4. These measures were evaluated for 100 iterations and then were clustered based on the four stability conditions. There were four clusters and each cluster consists of 100 elements. To quantify the inter- and intra-cluster distances, the silhouette coefficients were calculated. A larger silhouette coefficient will suggest better performance of a COP measure. The better measure will be repeatable within the given stability cluster and discernible between the different stability clusters. 
Figure B.1, Appendix B presents posturograph of four stability conditions (Control, LowSP, MedSP and HighSP) of simulated COP. Figure B.2, Appendix B present plots of COP time series of simulated data for control stability condition in ML and AP directions.

\subsubsection{Experimental Data}

The cluster analysis was performed on experimental data with four stability conditions: FT-EO, FT-EC, SL-EO, and SL-EC. The same six COP measures $\left(R D_{\text {avg }}, V_{\text {avg }}, A R E A\right.$, $\sigma_{x}, \sigma_{y}$ and $\left.S D_{R D}\right)$ were evaluated for experimental data, which were evaluated for the simulated data. While $60 \mathrm{~s}$ of data were collected for each trial, the COP measures were calculated only for the last 30 seconds of data to avoid any initial conditions. An analysis of the first $30 \mathrm{~s}$ and last $30 \mathrm{~s}$ of data suggested that subjects might be still establishing their static posture during the initial 30 seconds (this will be discussed in further detail in Chapter 5). These measures were clustered by using the 11 trials based on stability conditions. Thus each measure has four clusters and each cluster consist of 11 data points (trials). These measures were clustered and analyzed separately for each subject and each measure by calculating the overall average silhouette coefficient width over 11 trial and all (four) stability conditions to find the best measure. We define the best measure as exhibiting a higher average silhouette coefficient, resulting in a measure is more repeatable within the given stability cluster and discernible between the different stability clusters. To quantify the inter- and intra-cluster distances, the silhouette coefficient 
(Rousseeuw, 1987) was calculated. A larger silhouette coefficient will suggest better performance of a COP measure.

To investigate whether the best $\mathrm{COP}$ measure, according to the silhouette coefficient, was statistically best among investigated COP measures, statistical analysis was performed. For statistical analysis a repeated measure analysis of variance (ANOVA) within subject and post-hoc tests with Bonferroni adjustment were performed. The significance level was set at 0.05 . Figure 4.4 represents the overall methodology followed.

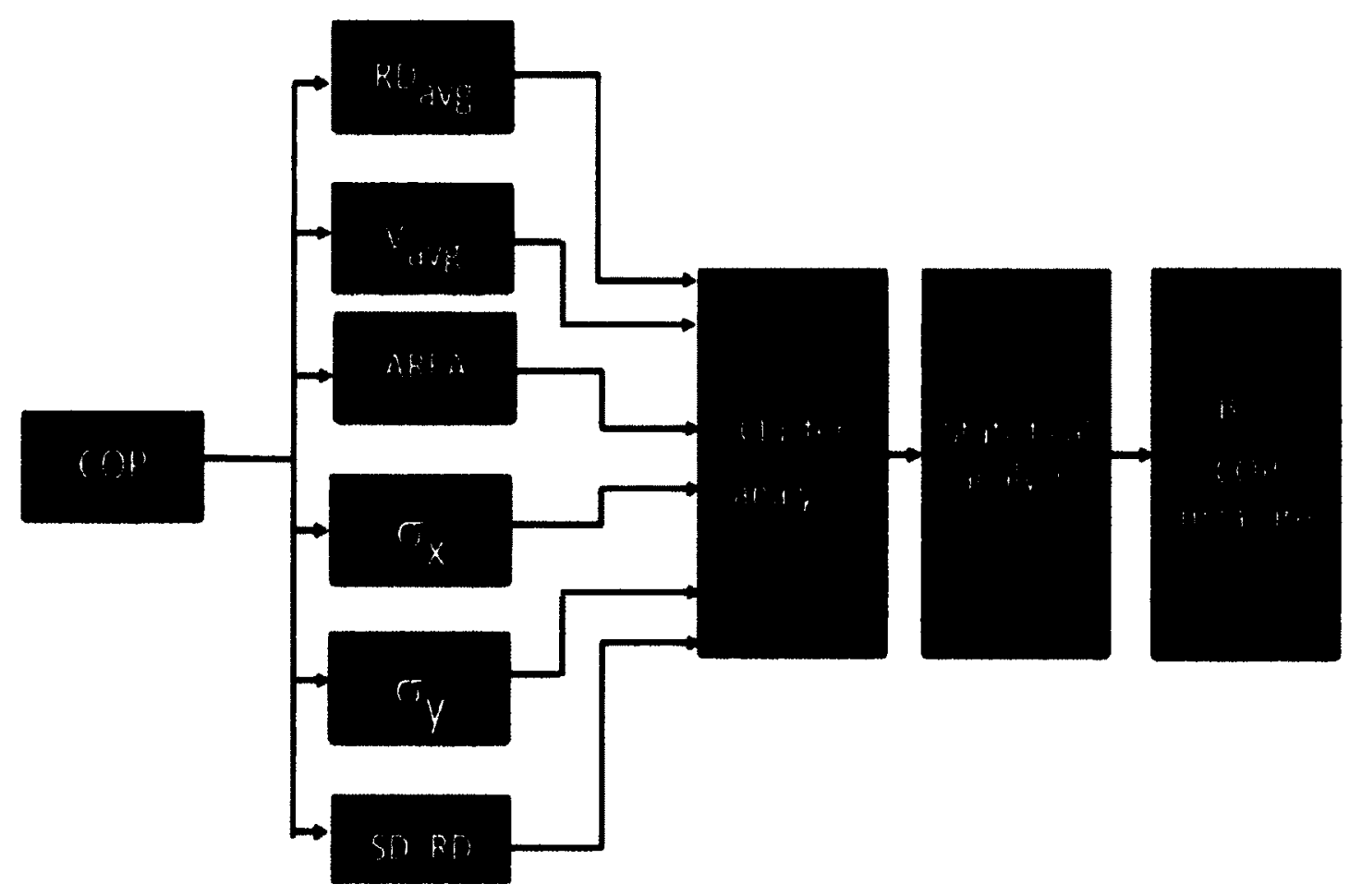

Figure 4.4: Methodology to investigate the performance of COP measures. 


\subsection{Results}

\subsubsection{Simulated}

Figure 4.5 presents the box plots of six COP measures for the four stability conditions, and each measure shows stability from highest stability to lowest stability condition, Control to LowSP to MedSP to HighSP, for the simulated data. The boxes for average velocity are compact and well separated compared to the other five COP measures. This suggests that average velocity of COP was more repeatable within each stability condition and can better differentiate between the different stability conditions for the simulated data. Table 4.1 presents the values of mean and standard deviation of COP clusters.

The silhouette coefficient of average velocity $\left(V_{a v g}\right)$ is largest among the values investigated. Indeed, the silhouette coefficient $(0.803)$ for $V_{\text {avg }}$ is much larger than the other silhouette coefficients; $43 \%$ larger than the next largest silhouette coefficient (0.461) for $A R E A$ (Figure 4.6). This implies that the clusters for average velocity are more compact and well separated. The average velocity of simulated COP is the best measure in terms of repeatability and differentiability. 

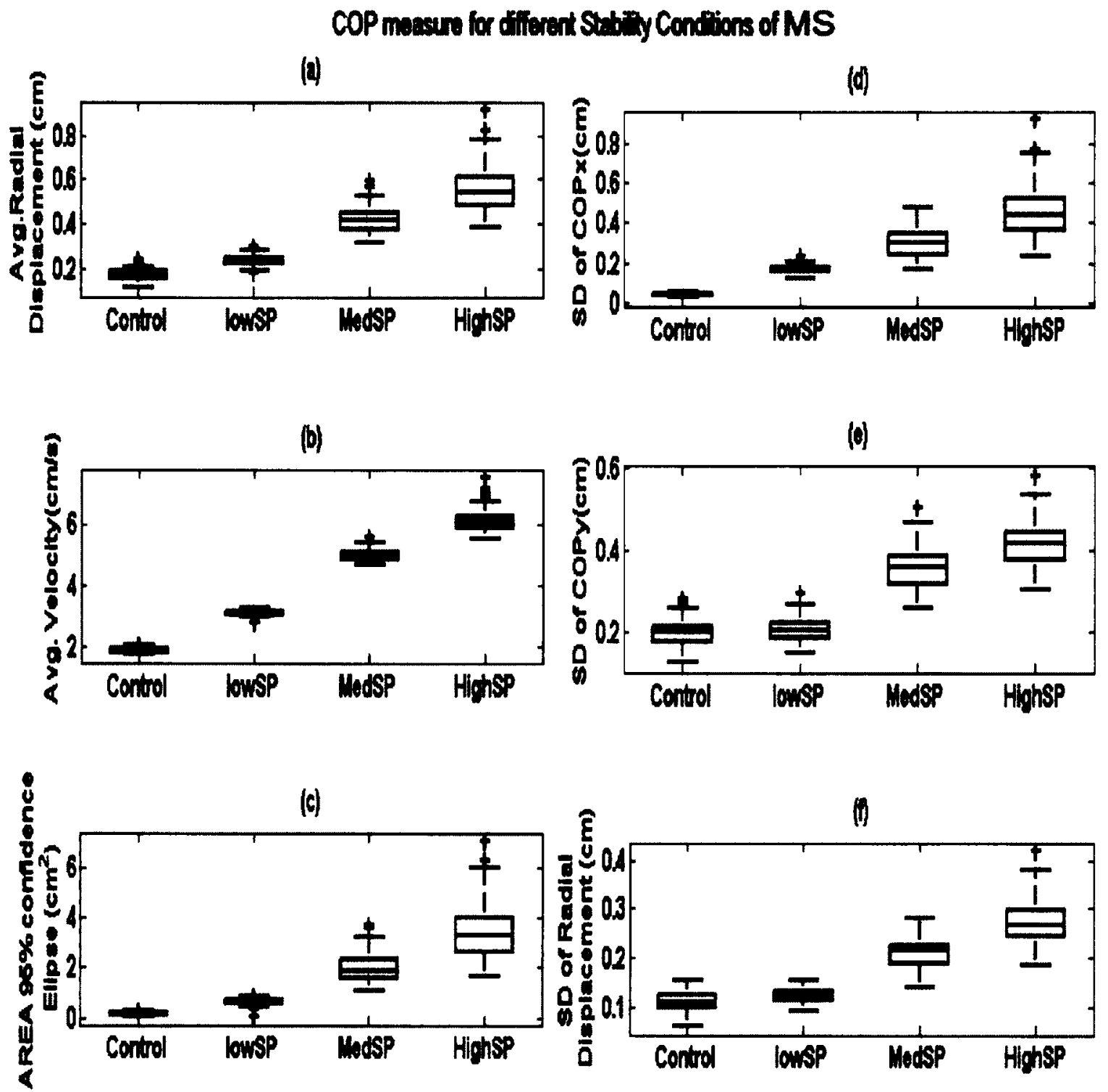

Figure 4.5: Box plot of clusters of conventional COP measures for the 100 iterations with different seeds for noise generators of simulation models: (a) average radial displacement $R D_{a v g}$ (b) average velocity $\left(V_{\text {avg }}\right)$, (c) area of $95 \%$ ellipse traversed by COP $(A R E A)$, (d) standard deviations of $\operatorname{COP}_{x}\left(\sigma_{x}\right)$, (e) standard deviations of $\operatorname{COP}_{y}\left(\sigma_{y}\right)$, and (f) standard deviation of radial displacement (SD_RD). 
Table 4.1: Mean and standard deviations of simulated COP measures clusters.

\begin{tabular}{|l|c|c|c|c|c|c|c|c|}
\hline \multirow{2}{*}{ COP Measures } & \multicolumn{2}{|c|}{ Control } & \multicolumn{2}{c|}{ LowSP } & \multicolumn{2}{c|}{ MedSP } & \multicolumn{2}{c|}{ HighSP } \\
\cline { 2 - 9 } & Mean & Std. Dev. & Mean & Std. Dev. & Mean & Std. Dev. & Mean & Std. Dev. \\
\hline$R_{\text {avg }}(\mathrm{cm})$ & 0.169 & 0.025 & 0.235 & 0.022 & 0.418 & 0.052 & 0.560 & 0.102 \\
\hline $\boldsymbol{V}_{\text {avg }}(\mathrm{cm} / \mathrm{s})$ & 1.895 & 0.065 & 3.092 & 0.071 & 4.994 & 0.160 & 6.144 & 0.357 \\
\hline $\boldsymbol{A R E A}\left(\mathrm{cm}^{2}\right)$ & 0.146 & 0.033 & 0.623 & 0.115 & 1.968 & 0.519 & 3.492 & 1.149 \\
\hline$\sigma_{\boldsymbol{x}}(\mathrm{cm})$ & 0.040 & 0.007 & 0.166 & 0.020 & 0.299 & 0.064 & 0.458 & 0.129 \\
\hline$\sigma_{y}(\mathrm{~cm})$ & 0.198 & 0.030 & 0.206 & 0.029 & 0.356 & 0.049 & 0.415 & 0.054 \\
\hline$S_{\text {SD }}(\mathrm{cm})$ & 0.111 & 0.017 & 0.122 & 0.013 & 0.210 & 0.025 & 0.274 & 0.044 \\
\hline
\end{tabular}

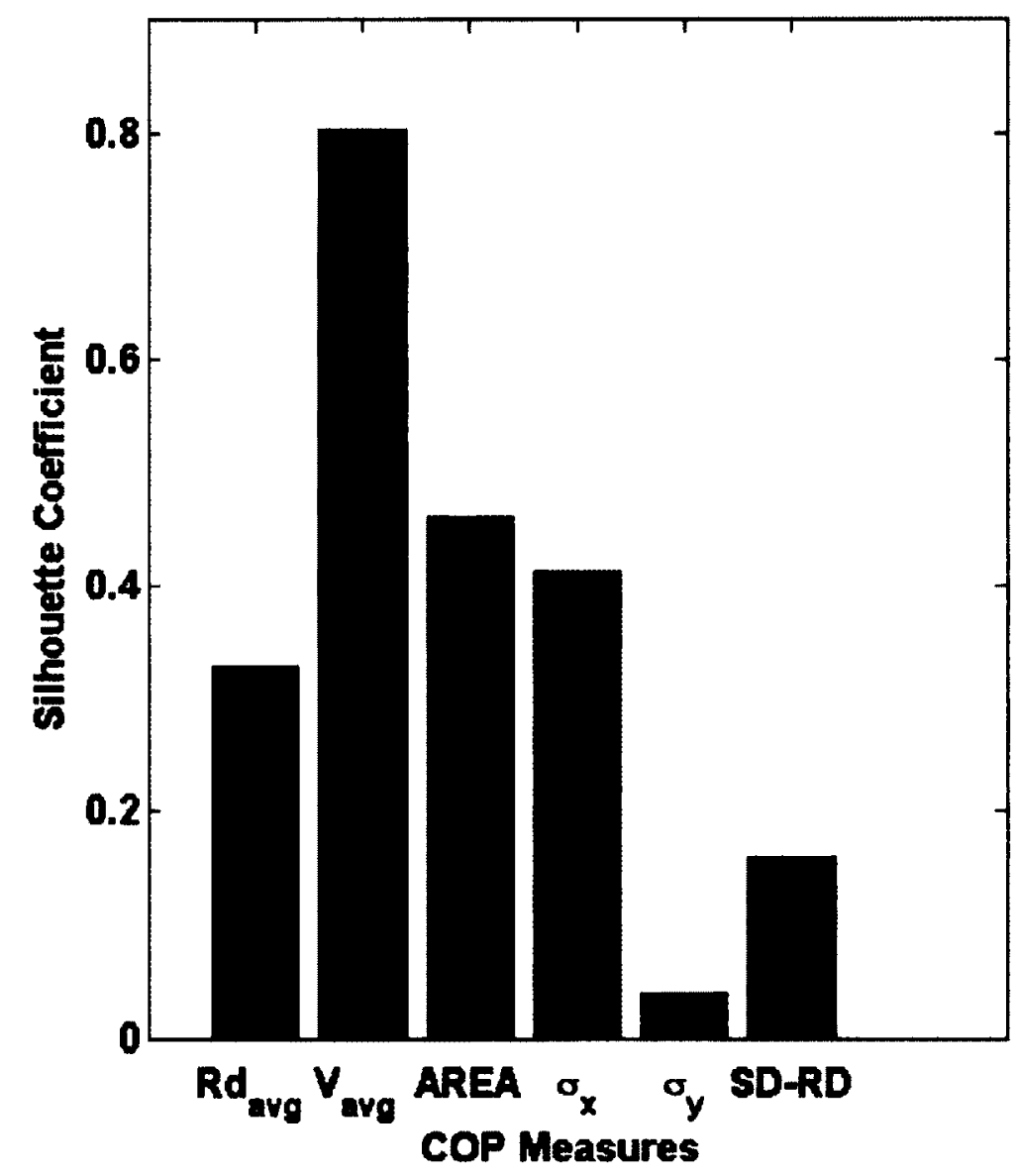

Figure 4.6: Silhouette coefficient values for the COP measures of simulated data. 


\subsubsection{Experimental}

Figure 4.7 presents box plots of the clusters of COP measures for subject 2; other subjects exhibited similar behaviours and Tables $4.2-4.9$ present the mean and standard deviation of COP measures clusters for subjects 1 to 8 . Figure A.1 presents the explanation of the box plot in Appendix A. The box plots for all eight subjects are presented in Figures A.2A.9 in Appendix A. The values of each measure increased from FT-EO, to FT-EC, to SLEO, to SL-EC, suggesting a decrease in postural stability through these postures. The smaller sizes of the boxes for average velocity $\left(V_{\text {avg }}\right)$ suggest they are repeatable. These box plots also show that the $V_{\text {avg }}$ clusters are well-separated (non-overlapped) compared to other COP measures, which suggest different stability conditions are more easily discerned. Figure 4.8 shows the box plots for average velocity for all eight subjects.

Figure 4.9 presents a plot of the silhouette coefficients for the six COP measures. The values of silhouette coefficient for $V_{\text {avg }}$ were the highest for each subject, indicating that clusters for $V_{a v g}$ were well separated and compact compared to other measures. The silhouette coefficient values for $V_{\text {avg }}$ (mean 0.5154 , standard deviation 0.1522 ), for all subjects, are much higher than other COP measure (next highest silhouette coefficient values is for $R D_{\text {avg }}$; mean 0.1741 , standard deviation 0.1189 ). A negative silhouette coefficient indicates that clusters are overlapped. A negative silhouette coefficient was observed for AREA, standard deviation of $\operatorname{COP}_{x}\left(\sigma_{x}\right)$, standard deviation of $\operatorname{COP}_{y}\left(\sigma_{y}\right)$, and standard deviation of radial displacement $\left(S D_{-} R D\right)$. This implies that these measures would have difficulties to differentiate between different stability conditions. The 
smallest silhouette coefficient for $V_{\text {avg }}$ is 0.262 for subject 3; however, this is still the largest silhouette coefficient for subject 3 and much higher than the next largest silhouette coefficient for $R D_{\text {avg }}$ for subject $3(0.0736)$.

\section{COP measures for different Satability Conditions}
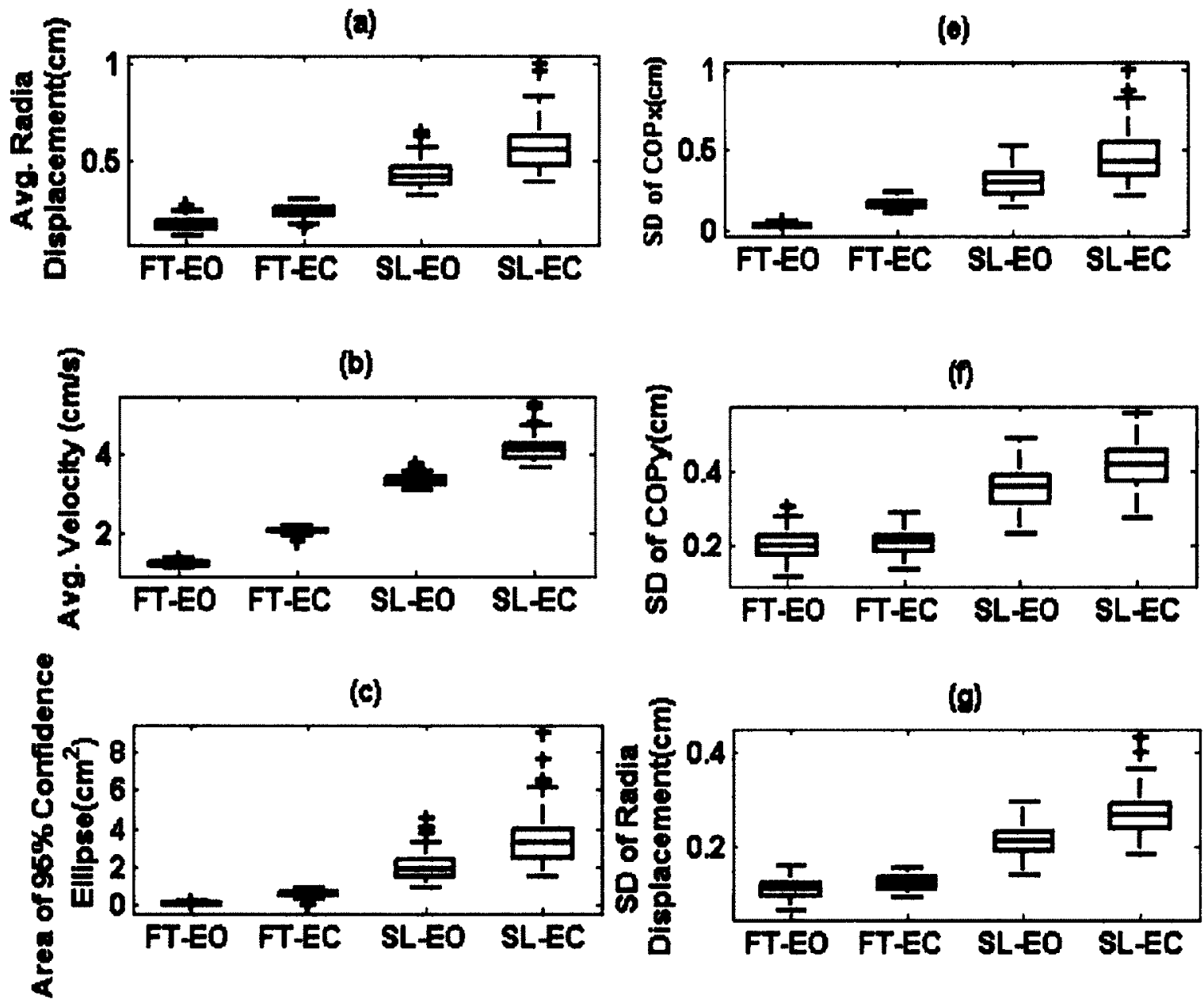

Figure 4.7: Box plot of clusters of conventional COP measures for the 11 trials of subject \#2: (a) average radial displacement $\left(R D_{\text {avg }}\right)$, (b) average velocity $\left(V_{\text {avg }}\right)$, (c) area of $95 \%$ ellipse traversed by COP $(A R E A)$, (d) standard deviations of $C O P_{x}\left(\sigma_{x}\right)$, (e) standard deviations of $\operatorname{COP}_{y}\left(\sigma_{y}\right)$, and (f) standard deviation of radial displacement $\left(S S_{-} R D\right)$. 
(a) Subject 1

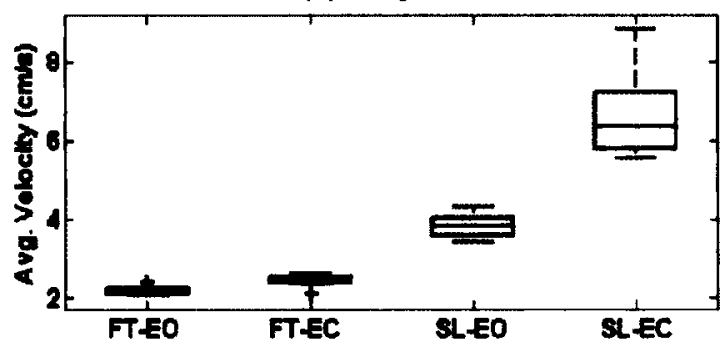

(b) Subject 2

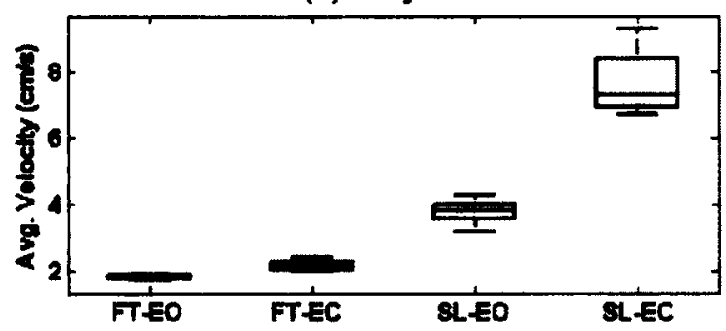

(c) subject 3

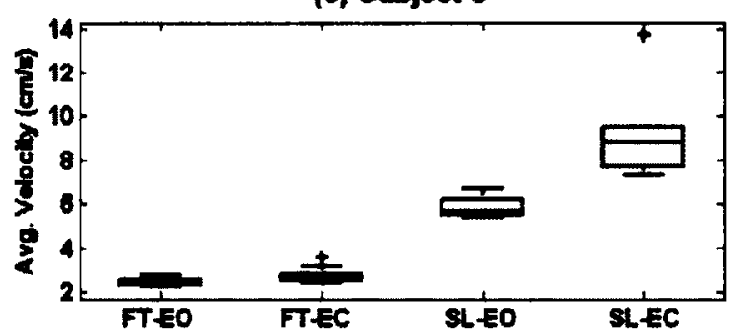

(d) Subject 4

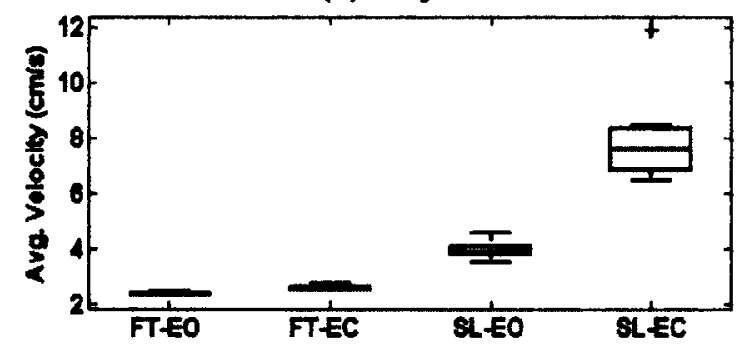

(e) Subject 5

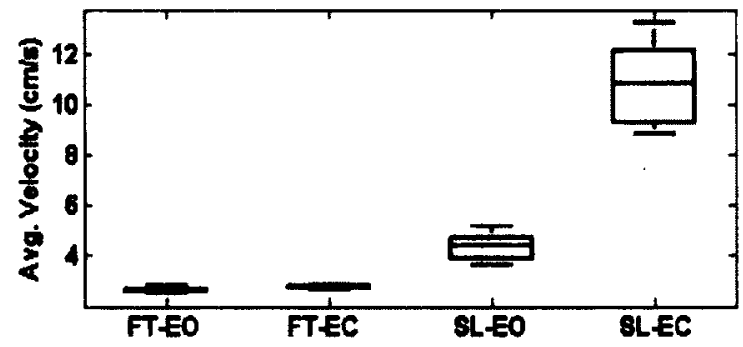

(f) Subject 6

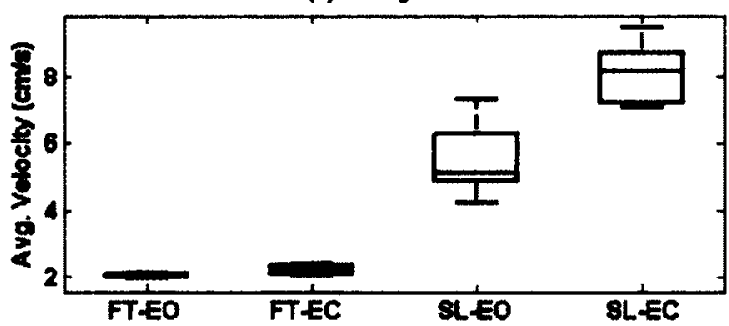

(g) Subject 7

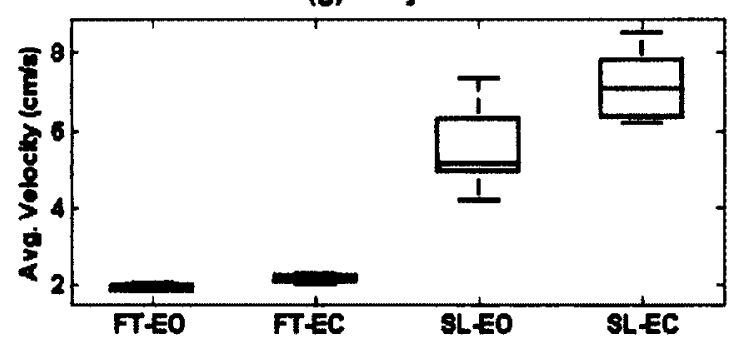

(h) Subject 8

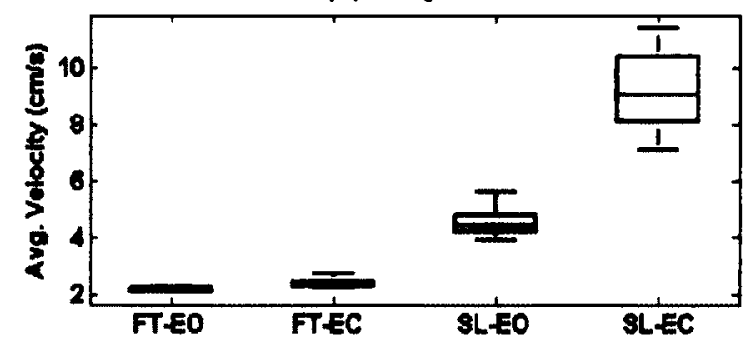

Figure 4.8: Box plots of clusters of average velocity $\left(V_{a v g}\right)$, for different stability conditions for eight subjects for four stability conditions FT-EO, FT-EC, SL-EO, and SL-EC. 
Table 4.2: Mean and standard deviation of COP measures for the 11 trials of subject 1.

\begin{tabular}{|c|c|c|c|c|c|c|c|c|}
\hline \multirow{2}{*}{ copHinenes } & \multicolumn{2}{|c|}{ Ho } & \multicolumn{2}{|c|}{45} & \multicolumn{2}{|c|}{840} & \multicolumn{2}{|c|}{ ows } \\
\hline & 401 & $(1+1)$ & $y$ & cos & 1, & 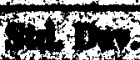 & 14 & SD \\
\hline & 0.481 & 0.126 & 0.436 & 0.082 & 0.830 & 0.102 & 0.991 & 0.115 \\
\hline & 2.196 & 0.099 & 2.474 & 0.133 & 3.867 & 0.288 & 6.685 & 1.144 \\
\hline & 2.523 & 0.968 & 2.159 & 0.768 & 7.341 & 1.765 & 11.354 & 2.536 \\
\hline & 0.388 & 0.086 & 0.392 & 0.046 & 0.511 & 0.064 & 0.769 & 0.119 \\
\hline 2 & 0.366 & 0.110 & 0.292 & 0.079 & 0.780 & 0.114 & 0.787 & 0.089 \\
\hline$(1, a(6)$ & 0.235 & 0.039 & 0.224 & 0.016 & 0.425 & 0.071 & 0.483 & 0.053 \\
\hline
\end{tabular}

Table 4.3: Mean and standard deviation of COP measures for the 11 trials of subject 2.

\begin{tabular}{|c|c|c|c|c|c|c|c|c|}
\hline & 4 & & & & & 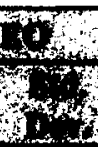 & & 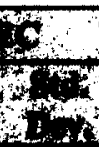 \\
\hline & 0.480 & 0.109 & 0.548 & 0.104 & 0.867 & 0.094 & 1.230 & 0.144 \\
\hline 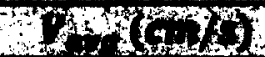 & 1.797 & 0.058 & 2.156 & 0.129 & 3.772 & 0.340 & 7.669 & 0.868 \\
\hline $19 \gamma \times(c)$ & 2.628 & 1.165 & 3.543 & 1.293 & 8.338 & 1.423 & 17.542 & 4.332 \\
\hline & 0.393 & 0.090 & 0.465 & 0.096 & 0.568 & 0.047 & 1.036 & 0.139 \\
\hline & 0.354 & 0.099 & 0.405 & 0.094 & 0.802 & 0.126 & 0.902 & 0.106 \\
\hline 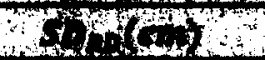 & 0.229 & 0.051 & 0.288 & 0.058 & 0.469 & 0.064 & 0.612 & 0.089 \\
\hline
\end{tabular}

Table 4.4: Mean and standard deviation of COP measures for the 10 trials of subject 3.

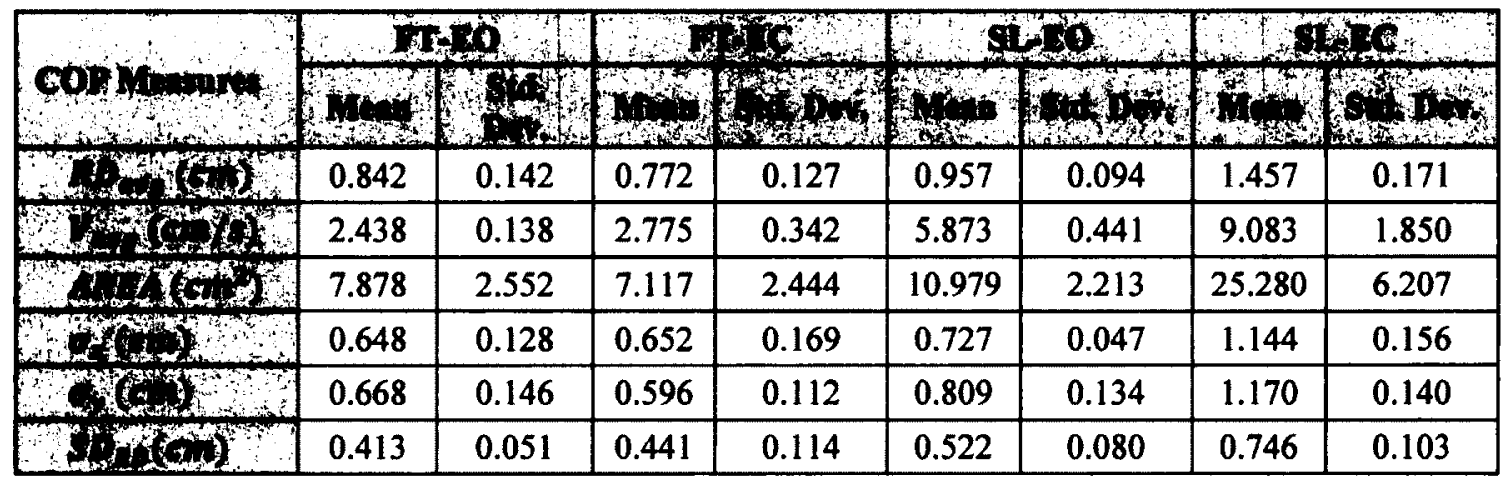


Table 4.5: Mean and standard deviation of COP measures for the 11 trials of subject 4.

\begin{tabular}{|c|c|c|c|c|c|c|c|c|}
\hline \multirow[b]{2}{*}{ 90414ambit } & \multicolumn{2}{|c|}{$M D D$} & \multicolumn{2}{|c|}{ IT-EC } & \multicolumn{2}{|c|}{$S=3$} & \multicolumn{2}{|c|}{ 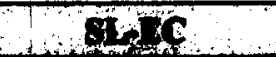 } \\
\hline & & 07 & Mons & 940 & & & & \\
\hline & 0.476 & 0.051 & 0.669 & 0.283 & 0.804 & 0.100 & 1.430 & 0.236 \\
\hline & 2.387 & 0.043 & 2.569 & 0.079 & 3.959 & 0.314 & 7.877 & 1.488 \\
\hline & 2.482 & 0.473 & 4.692 & 2.818 & 7.009 & 1.593 & 26.777 & 12.081 \\
\hline & 0.406 & 0.097 & 0.452 & 0.074 & 0.542 & 0.065 & 1.268 & 0.316 \\
\hline & 0.338 & 0.066 & 0.580 & 0.362 & 0.725 & 0.140 & 1.105 & 0.229 \\
\hline & 0.248 & 0.049 & 0.350 & 0.155 & 0.424 & 0.084 & 0.886 & 0.309 \\
\hline
\end{tabular}

Table 4.6: Mean and standard deviation of COP measures for the 11 trials of subject 5.

\begin{tabular}{|c|c|c|c|c|c|c|c|c|}
\hline & & & & 4 & & $y^{2}$ & I & $\frac{2}{4+4}$ \\
\hline $2 x_{+\infty}$ & 0.445 & 0.126 & 0.463 & 0.073 & 0.754 & 0.115 & 1.467 & 0.214 \\
\hline 13 & 2.644 & 0.075 & 2.785 & 0.054 & 4.363 & 0.513 & 10.737 & 1.538 \\
\hline 28 & 2.139 & 0.992 & 2.546 & 0.711 & 6.030 & 1.344 & 27.182 & 8.697 \\
\hline & 0.218 & 0.051 & 0.249 & 0.028 & 0.390 & 0.071 & 0.856 & 0.179 \\
\hline 4 & 0.283 & 0.038 & 0.346 & 0.041 & 0.476 & 0.050 & 1.218 & 0.289 \\
\hline$y_{3}$ & 0.403 & 0.143 & 0.395 & 0.078 & 0.698 & 0.156 & 1.177 & 0.113 \\
\hline
\end{tabular}

Table 4.7: Mean and standard deviation of COP measures for the 11 trials of subject 6.

\begin{tabular}{|c|c|c|c|c|c|c|c|c|}
\hline \multirow{2}{*}{ opernowos } & \multicolumn{2}{|c|}{ Mud } & \multicolumn{2}{|c|}{$\Delta y^{2}$} & \multicolumn{2}{|c|}{ odo } & \multicolumn{2}{|c|}{$8 x$} \\
\hline & & Dी & & & & & & $6+10$ \\
\hline & 0.581 & 0.063 & 0.573 & 0.068 & 0.966 & 0.111 & 1.190 & 0.096 \\
\hline & 2.067 & 0.063 & 2.241 & 0.128 & 5.540 & 0.999 & 8.078 & 0.805 \\
\hline & 3.872 & 0.770 & 3.646 & 0.737 & 10.880 & 2.591 & 17.410 & 4.697 \\
\hline & 0.553 & 0.092 & 0.525 & 0.104 & 0.690 & 0.101 & 0.985 & 0.237 \\
\hline & 0.385 & 0.052 & 0.383 & 0.075 & 0.854 & 0.135 & 0.946 & 0.100 \\
\hline $94{ }^{\prime}(\alpha)$ & 0.346 & 0.058 & 0.317 & 0.058 & 0.527 & 0.106 & 0.667 & 0.245 \\
\hline
\end{tabular}


Table 4.8: Mean and standard deviation of COP measures for the 11 trials of subject 7.

\begin{tabular}{|c|c|c|c|c|c|c|c|c|}
\hline & & & & $\mathrm{CC}$ & & & & $\frac{1}{4}$ \\
\hline & 0.623 & 0.161 & 0.642 & 0.126 & 0.966 & 0.111 & 1.115 & 0.120 \\
\hline & 1.927 & 0.071 & 2.147 & 0.094 & 5.540 & 0.999 & 7.138 & 0.817 \\
\hline & 4.412 & 2.033 & 4.842 & 1.778 & 10.880 & 2.591 & 14.652 & 3.582 \\
\hline & 0.479 & 0.140 & 0.521 & 0.069 & 0.690 & 0.101 & 0.857 & 0.085 \\
\hline & 0.511 & 0.186 & 0.500 & 0.143 & 0.854 & 0.135 & 0.904 & 0.156 \\
\hline & 0.344 & 0.104 & 0.339 & 0.053 & 0.527 & 0.106 & 0.556 & 0.119 \\
\hline
\end{tabular}

Table 4.9: Mean and standard deviation of COP measures for the 11 trials of subject 8.

\begin{tabular}{|c|c|c|c|c|c|c|c|c|}
\hline & & & 8 & $\begin{array}{l}30 \\
6 x \\
6\end{array}$ & & $\frac{4}{4}$ & 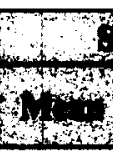 & $8 \mathrm{c}$ \\
\hline & 0.588 & 0.131 & 0.541 & 0.053 & 0.864 & 0.141 & 1.371 & 0.276 \\
\hline & 2.194 & 0.057 & 2.398 & 0.138 & 4.543 & 0.513 & 9.153 & 1.344 \\
\hline & 3.741 & 1.629 & 3.472 & 0.717 & 7.991 & 2.357 & 23.289 & 9.384 \\
\hline & 0.472 & 0.110 & 0.467 & 0.060 & 0.569 & 0.125 & 1.096 & 0.254 \\
\hline & 0.454 & 0.124 & 0.402 & 0.041 & 0.777 & 0.167 & 1.110 & 0.271 \\
\hline$S,(00)$ & 0.302 & 0.047 & 0.297 & 0.036 & 0.442 & 0.082 & 0.753 & 0.219 \\
\hline
\end{tabular}




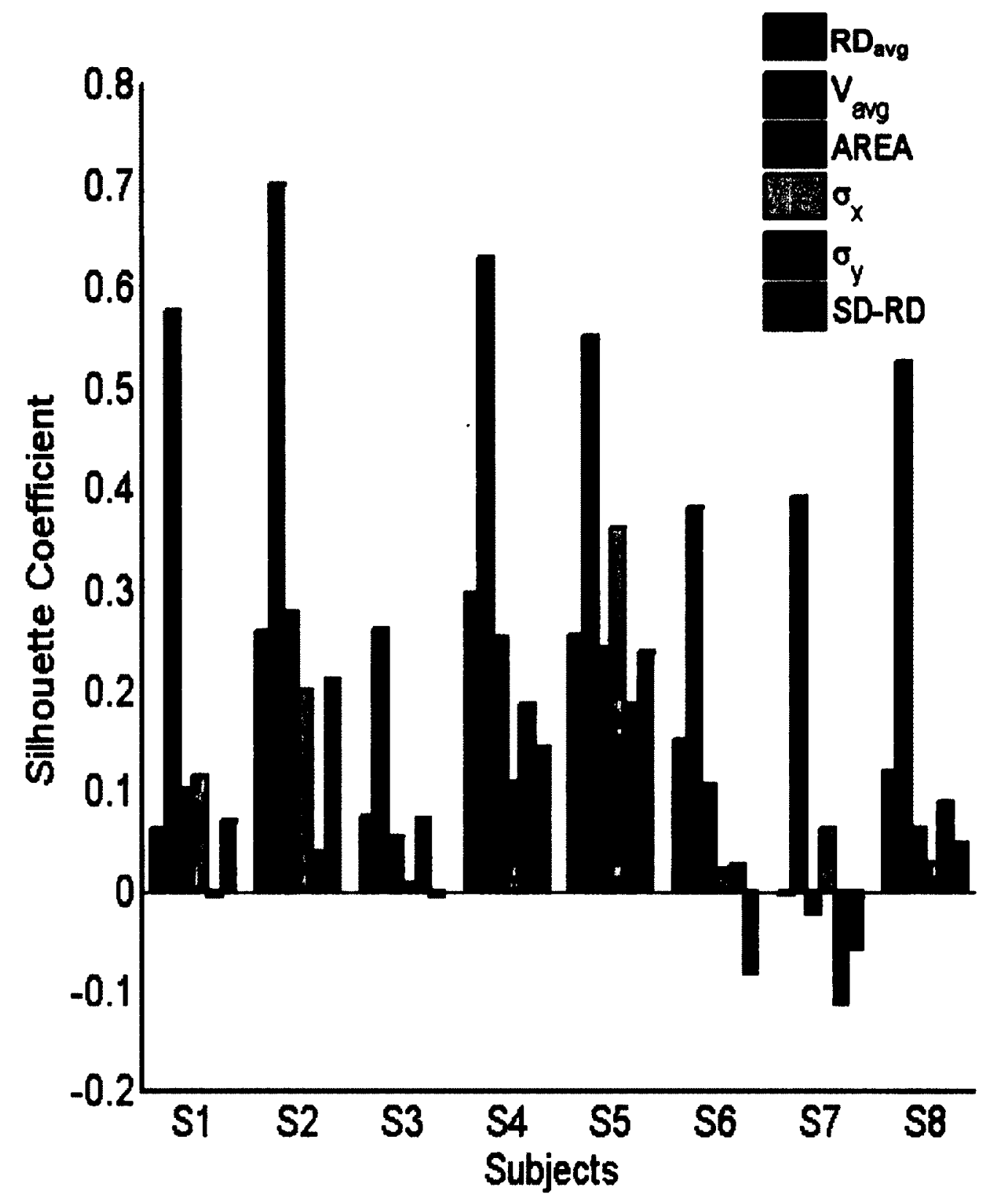

Figure 4.9: Silhouette coefficient values for six COP measures of four stability conditions of eight subjects (S1 to S8). 
A repeated measure ANOVA design with, single factor, within subject was performed. Results of the ANOVA indicate that the silhouette coefficients for six COP measures within a given subject are significantly different $(F(5,35)=57.93 p<0.001)$. This suggests that silhouette coefficients of at least two of the six measures are different (Figure 4.9). To find out if the silhouette coefficient for $V_{\text {avg }}$ is significantly larger, a post-hoc tests with the Bonferroni correction was conducted; results are presented in the Table 4.10 Pairwise comparison revealed that silhouette coefficients for $V_{\text {avg }}$ were significantly larger than all the compared COP measures $(\mathrm{p}<0.001)$. Pairwise comparison for all measures are presented in table A.2 in Appendix A.

Table 4.10: Pairwise comparison of experimental COP measure with Bonferroni adjustment.

\begin{tabular}{|c|c|c|c|c|c|}
\hline \multirow{2}{*}{$\begin{array}{l}\text { COP Measures } \\
\text { Pair }\end{array}$} & \multirow{2}{*}{$\begin{array}{c}\text { Mean Difference } \\
\text { of COP Measure } \\
\text { Pair }\end{array}$} & \multirow{2}{*}{ Std. Error } & \multirow[t]{2}{*}{ Sig." } & \multicolumn{2}{|c|}{$\begin{array}{l}\text { 95\% Confidence Interval for } \\
\text { Difference }\end{array}$} \\
\hline & & & & Lower Bound & Upper Bound \\
\hline$V_{a v g}-R D_{a v g}$ & $0.351^{*}$ & 0.039 & 0.001 & 0.182 & 0.520 \\
\hline$V_{\alpha v g}-A R E A$ & $0.369^{\circ}$ & 0.033 & $<0.001$ & 0.223 & 0.514 \\
\hline$V_{a v g}-\sigma_{x}$ & $0.390^{*}$ & 0.044 & 0.001 & 0.198 & 0.582 \\
\hline$V_{a v g}-\sigma_{y}$ & $0.443^{*}$ & 0.052 & 0.001 & 0.218 & 0.667 \\
\hline$V_{\text {avg }}-S D \_R D$ & $0.432^{\circ}$ & 0.032 & $<0.001$ & 0.293 & 0.571 \\
\hline
\end{tabular}

\subsection{Discussion}

Good clustering is expected to have low degree of overlap, a larger separation distance between clusters, and compactness within each cluster. Silhouette coefficient is used to quantify the compactness within the cluster and separation between the clusters; higher value implies better clustering. 
The results of both simulated data and experimental data show that the silhouette coefficient for $V_{a v g}$ is the largest amongst the COP measures examined. This implies that clusters of $V_{\text {avg }}$ are well clustered compared to the cluster of other COP measures examined.

For experimental data the differences between silhouette coefficient values were shown to be significantly different $(\alpha=0.05)$. The silhouette coefficient value for average velocity is statistically larger compared to the other five COP measures. The $V_{\text {avg }}$ of COP exhibited the best performance amongst the six COP measures $\left(R D_{\text {avg }}, V_{\text {avg }}, A R E A\right.$, $\sigma_{x}, \sigma_{y}$ and $\left.S D_{-} R D\right)$ being able to better discern between the different stability conditions.

These results are consistent with other works that found that the average velocity of COP tends to be a more sensitive measure (Raymakers, Samson, \& Verhaar, 2005) and reliable among many COP measures (Salavati et al., 2009) (Lin et al., 2008). Lutoto et al. reported that among three COP measures, (1) COP velocity, (2) average position shift in AP and (3) maximal position shift in ML direction, the COP velocity was found to be most reliable and sensitive measure (Luoto S, Aalto H, Taimela S, Hurri H, Pyykkö I, 1998). Lafond et al. estimated test-retest reliability of six COP measures, (1) root mean square (RMS), (2) COP range, (3) COP mean velocity, (4) mean power frequency (MPF), (5) median power frequency (MedPF), and (6) sway area., their result suggest that average velocity of COP measure was most reliable among investigated measures (Lafond et al., 2004). 
In this study the performance of the conventional measures were compared. There are several other COP measures (e.g., approximate entropy (Pincus, 1991), sample entropy (Richman \& Moorman, 2000), Lyapunov exponent (Abarbanel, Gills, Liu, \& Roy, 1996); their performance can be assessed using the method developed in the thesis.

\subsection{Conclusion}

Cluster analysis provides a quantitative approach to compare the performance of different measures in different stability conditions. A COP measure's performances better if it is less variability (variance) between the trials within a stability condition and high variability (variance) between different stability conditions. The outcome of cluster analysis for both experimental data and simulated data, using the silhouette coefficient, suggests that $V_{a v g}$ is a better measure compared to the other five investigated measures: 1) average radial displacement $\left.\left(R D_{\text {avg }}\right), 2\right)$ area of the $95 \%$ confidence ellipse $(A R E A)$, 3) standard deviation of $\left.\operatorname{COP}_{x}\left(\sigma_{x}\right), 4\right)$ standard deviation of $\operatorname{COP}_{y}\left(\sigma_{y}\right)$, and 5) standard deviation of radial displacement $\left(S D_{-} R D\right)$. For a given stability condition, $V_{\text {avg }}$ values can be more repeatable between trials and can be able to better differentiate between different stability conditions $V_{\text {avg }}$ thus demonstrated best performance . 


\section{Effect of Analysis Window Length}

\subsection{Introduction}

In this chapter, the effects of analysis window length on COP measures were investigated. The effects were analyzed first on simulated data and then on experimental data. The analysis of experimental data is twofold. First is to investigate if there is any difference between first and last $30 \mathrm{~s}$ of $60 \mathrm{~s}$ data, due to transitional effects in the first 30 s. The second is to investigate the effects of the analysis windows of different lengths on the performance of COP measures.

\subsection{Simulated Data}

\subsubsection{Methodology}

To investigate the effect of analysis window length on the simulated COP measures, models (see Section 3.2) were simulated for $150 \mathrm{~s}$ and 100 times. The last $120 \mathrm{~s}$ data of the $150 \mathrm{~s}$ simulated data were analyzed. The first $30 \mathrm{~s}$ of data were discarded to avoid any effects due to initial conditions. Each simulation was run 100 times for four different stability conditions (Control, LowSP, MedSP, and HighSP). The 31 windows of different lengths $1.5 \mathrm{~s}, 2.0 \mathrm{~s}, 2.5 \mathrm{~s}, 3.0 \mathrm{~s}, 3.5 \mathrm{~s}, 4.0 \mathrm{~s}, 4.5 \mathrm{~s}, 5.0 \mathrm{~s}, 10 \mathrm{~s}, 15 \mathrm{~s}, 20 \mathrm{~s}, 25 \mathrm{~s}, 30 \mathrm{~s}, 35 \mathrm{~s}$, $40 \mathrm{~s}, 45 \mathrm{~s}, 50 \mathrm{~s}, 55 \mathrm{~s}, 60 \mathrm{~s}, 65 \mathrm{~s}, 70 \mathrm{~s}, 75 \mathrm{~s}, 80 \mathrm{~s}, 85 \mathrm{~s}, 90 \mathrm{~s}, 95 \mathrm{~s}, 100 \mathrm{~s}, 105 \mathrm{~s}, 110 \mathrm{~s}, 115$ $\mathrm{s}$, and $120 \mathrm{~s}$ were used for the analysis. These windows were selected from beginning of the $120 \mathrm{~s}$ data. Six COP measures: 1) average radial displacement $\left.\left(R D_{\text {avg }}\right), 2\right)$ average velocity $\left.\left(V_{\text {avg }}\right), 3\right)$ area of the $95 \%$ confidence ellipse $\left.(A R E A) 4\right)$ standard deviation of 
$\left.\operatorname{COP}_{x}\left(\sigma_{x}\right), 5\right)$ standard deviation of $\operatorname{COP}_{y}\left(\sigma_{y}\right)$ and 6) standard deviation of radial displacement $\left(S D_{-} R D\right)$ were calculated for all 31 window lengths.

Performance of COP measures for smaller windows was assessed by cluster analysis. COP measures were clustered into 31 sets of clusters for each analysis window length. Each set of cluster consists of four clusters based on the four stability conditions. The silhouette coefficients were calculated for all sets of clusters and for six COP measures $\left(R D_{\text {avg }}, V_{\text {avg }}, A R E A, \sigma_{x}, \sigma_{y}\right.$, and $\left.S D_{-} R D\right)$ independently.

\subsubsection{Results}

Figure 5.1-5.6 are plots of average values and standard deviations of six COP measures: $R D_{\text {avg }}, V_{\text {avg }}, A R E A, \sigma_{x}, \sigma_{y}$, and $S D_{-} R D$ over 100 runs and their slopes. The slope of the COP measures was calculated by using forward difference first degree approximation Appendix C.1. The COP measures graphs demonstrate an increasing trend in the values while their slope demonstrates a decreasing trend, with increasing window lengths, for all four stability conditions. The graphs of COP measures gradually level off with increasing window length. For window length $20 \mathrm{~s}$ the slope of COP measures graphs dropped to more than $90 \%$ from their maximum slope for all COP measures and for all stability conditions, except for $A R E A$ for stability condition HighSP, the slope dropped to $89.5 \%$ in Figure 5.3 (b). For $30 \mathrm{~s}$ window length COP measures graphs almost plateau and the slope dropped to $95 \%$ or more of their maximum values. Figures $5.1(\mathrm{~b})-5.6(\mathrm{~b})$, except for $A R E A$ which dropped to $94.9 \%$. Thus for experimental data analysis the $30 \mathrm{~s}$ window length was chosen as the COP measures slopes decreased almost to $95 \%$ of their 
maximum values. The $30 \mathrm{~s}$ window length could be a good choice to analyse the stability of an individual.

Performance of COP measures as a function of window length was also evaluated by using cluster analysis. Figure 5.7(a) presents the results and demonstrates better performance for larger window size. The silhouette coefficient values for window lengths also level off for higher value of window lengths. The slope analysis for silhouette coefficient performance graphs were also performed Figure 5.7 (b). Slope for $20 \mathrm{~s}$ window length dropped to $80 \%$ or more of their maximum slope for all COP measures other than $\mathrm{COP}_{y}$ for that slope dropped to $75.6 \%$ of its maximum slope. For $30 \mathrm{~s}$ window length the slope of $\left(V_{a v g}\right)$ dropped $97.3 \%$ of its maximum value while other five COP measures show dropped $90 \%$ or more for 60 s window length. However the performance $V_{\text {avg }}$ was always higher Figure 5.7 (a) and the performance of other measure never reach to $V_{\text {avg }}$ performance.

If the clinician's objective is to use a COP measure with better performance and least amount of data then $V_{\text {avg }}$ can be a good choice among the six COP measures investigated. 
(a)

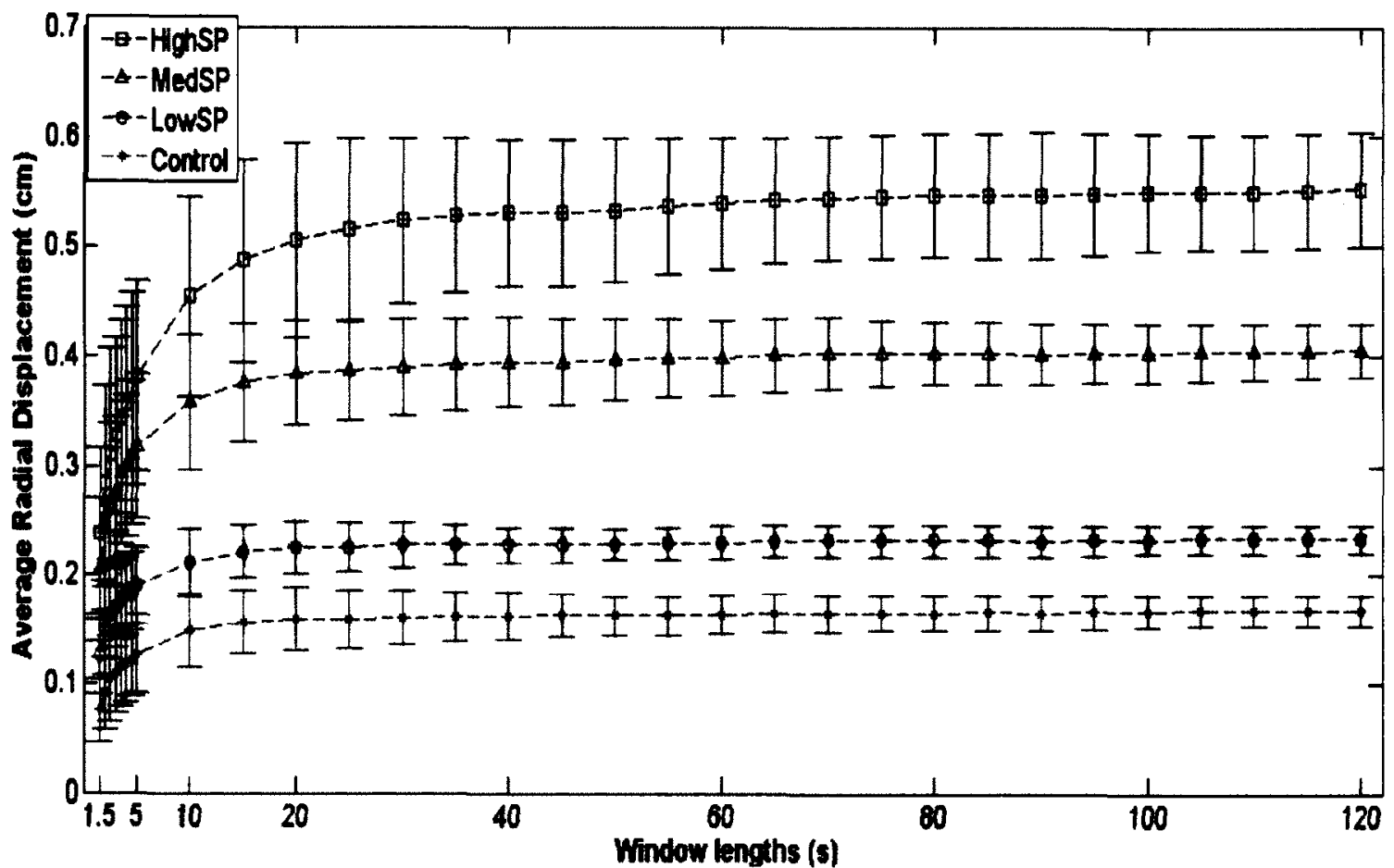

(b)

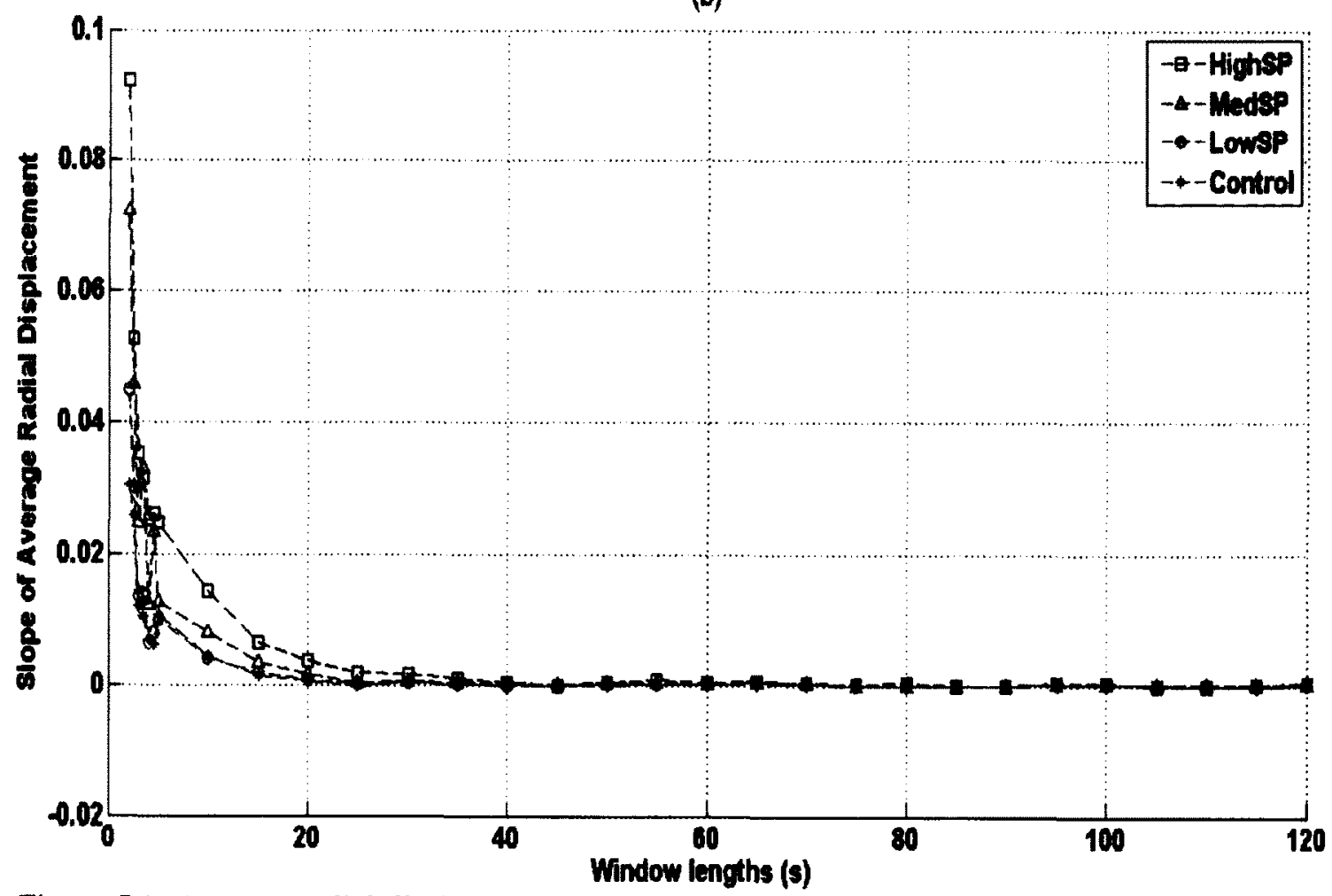

Figure 5.1: Average radial displacement, averaged over 100 trials with error bars for standard deviations and (b) slope of average radial displacement, of simulated COP for four stability conditions (Control, LowSP, MedSP, and HighSP) for different window. 
(a)

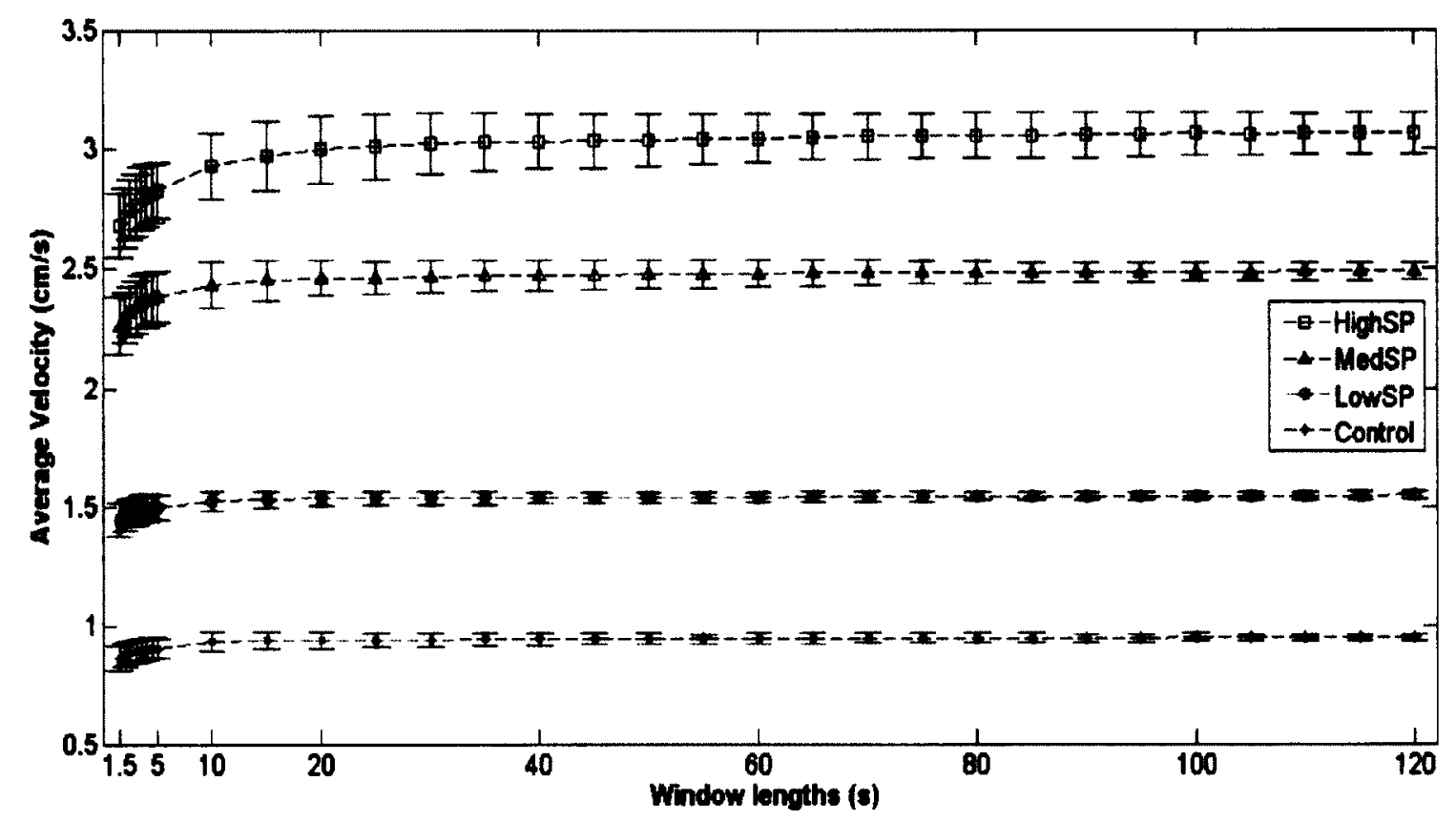

(b)

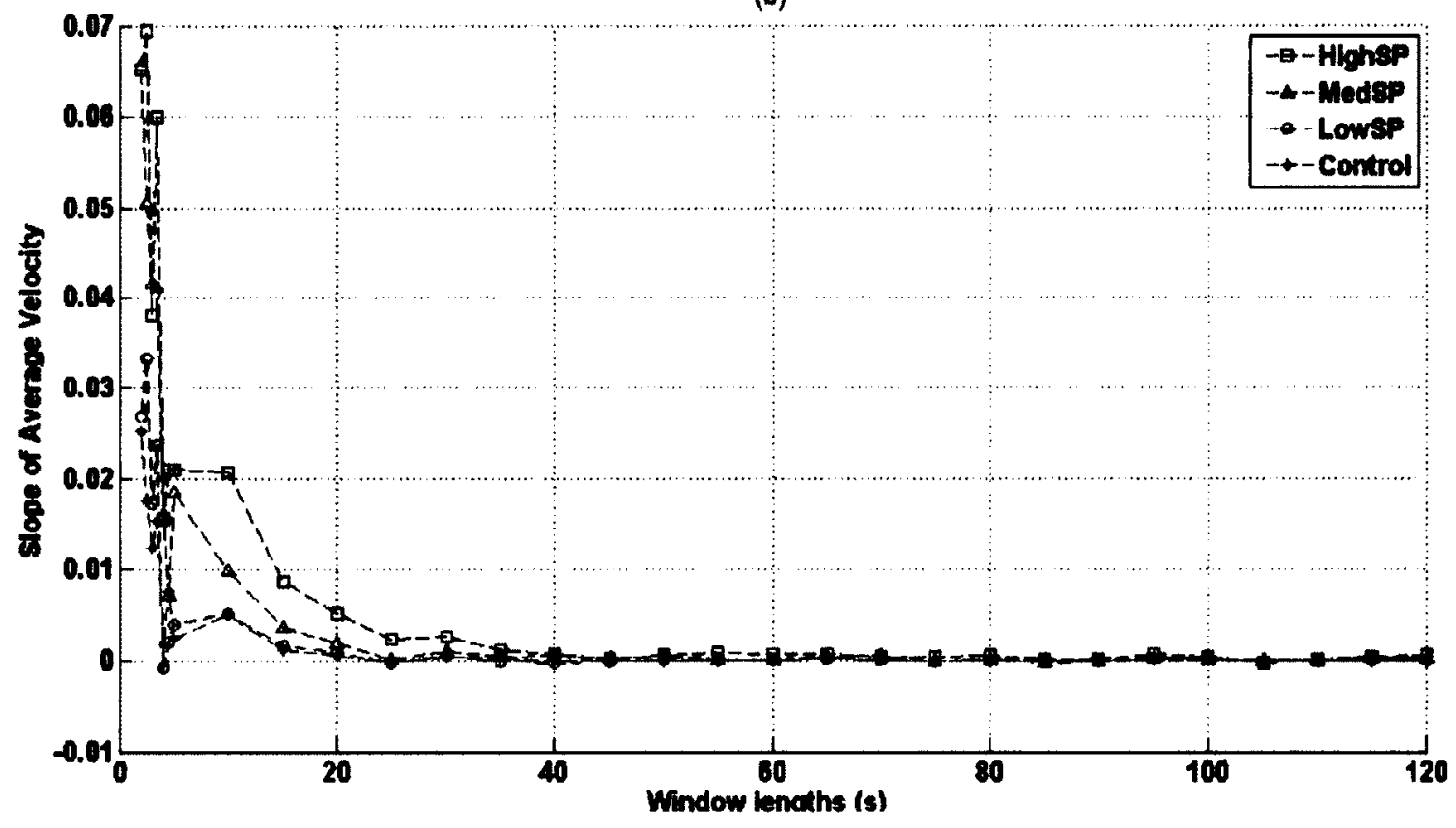

Figure 5.2: Average velocity, averaged over 100 trials with error bars for standard deviations and (b) slope of Average velocity, of simulated COP for four stability conditions (Control, LowSP, MedSP, and HighSP) for different window.. 
(a)

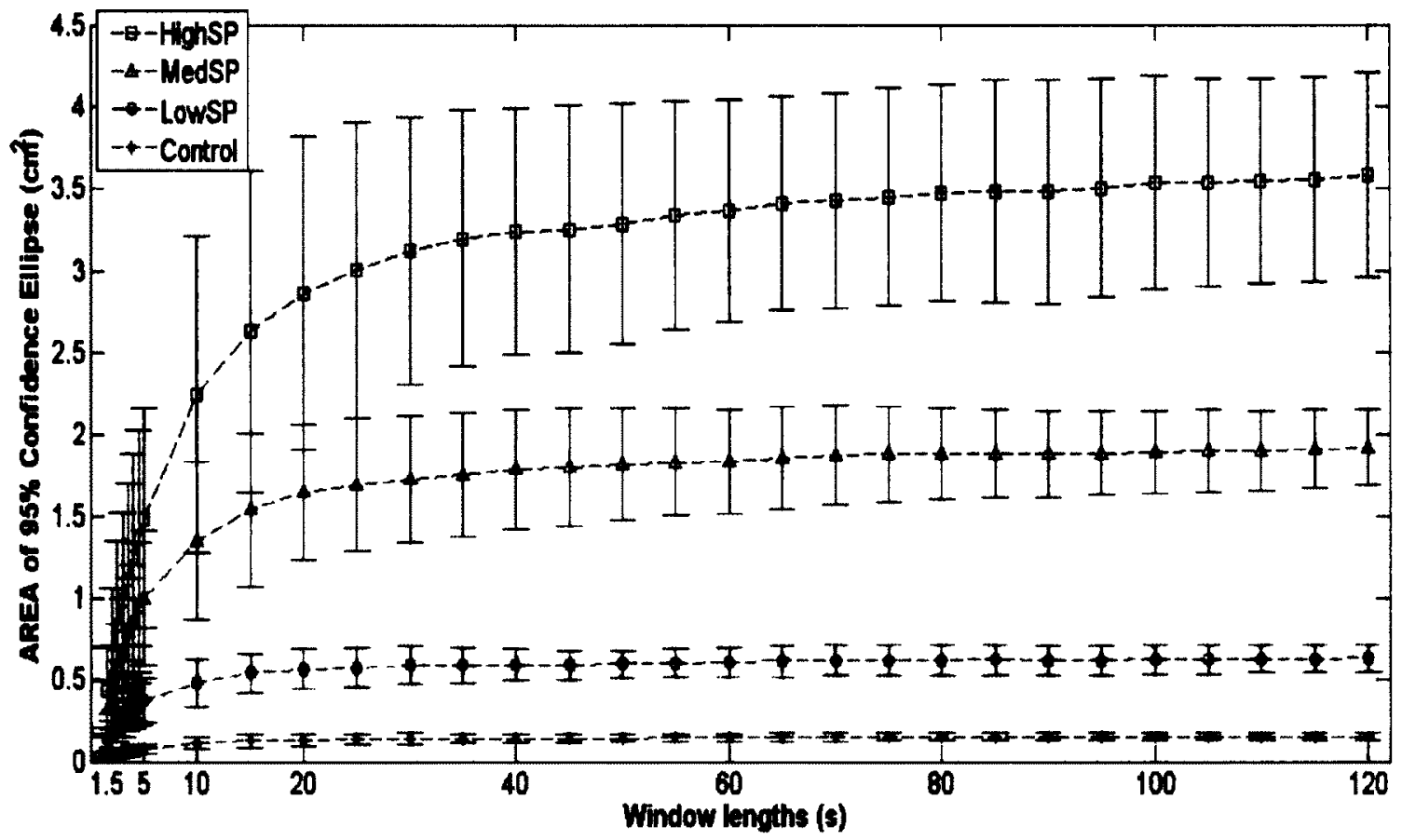

(b)

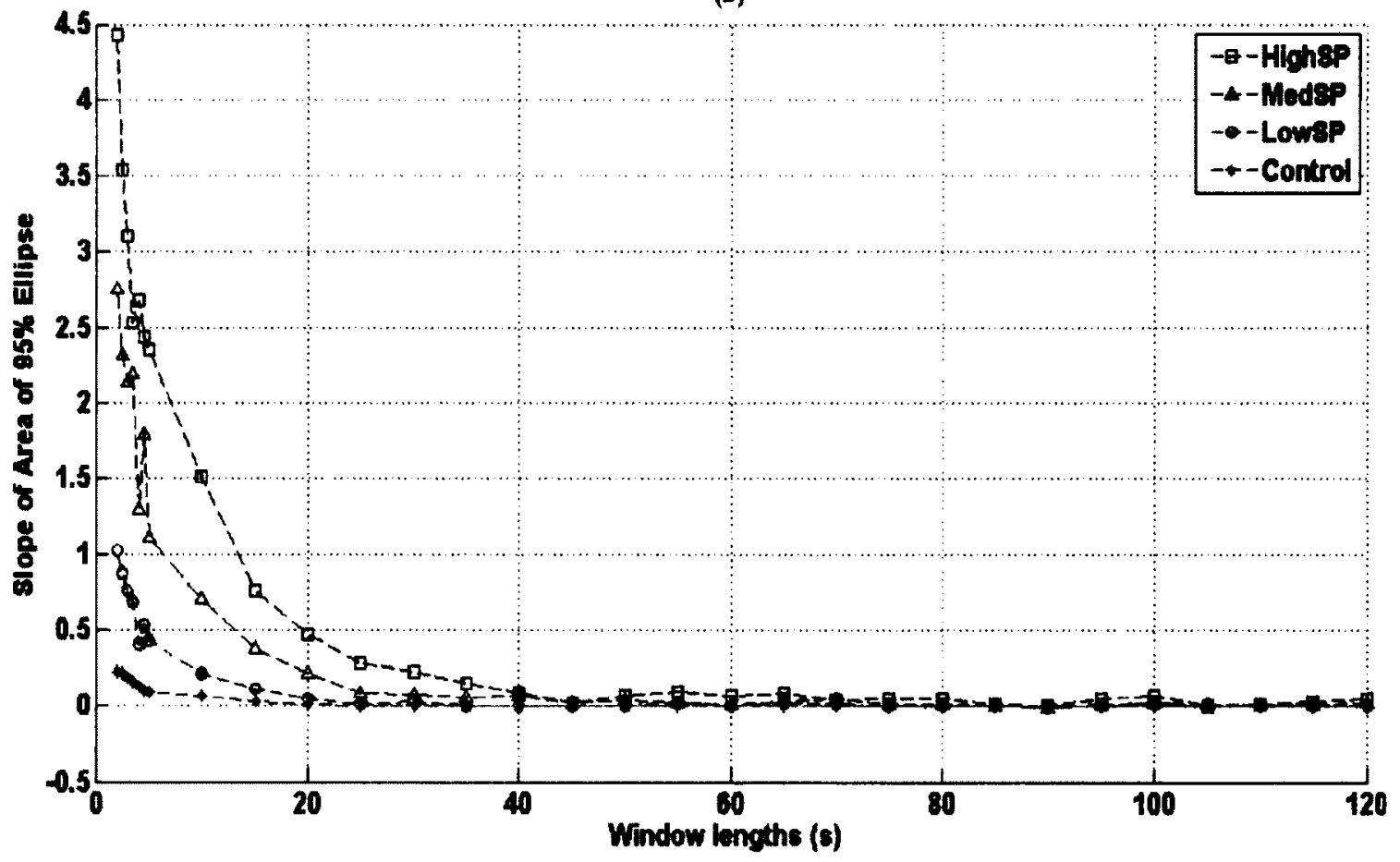

Figure 5.3: (a) AREA of 95\% ellipse averaged over 100 trials with error bars for standard deviations and (b) slope of AREA of $95 \%$ ellipse, of simulated COP for four stability conditions (Control, LowSP, MedSP, and HighSP) for different window lengths. 
(a)

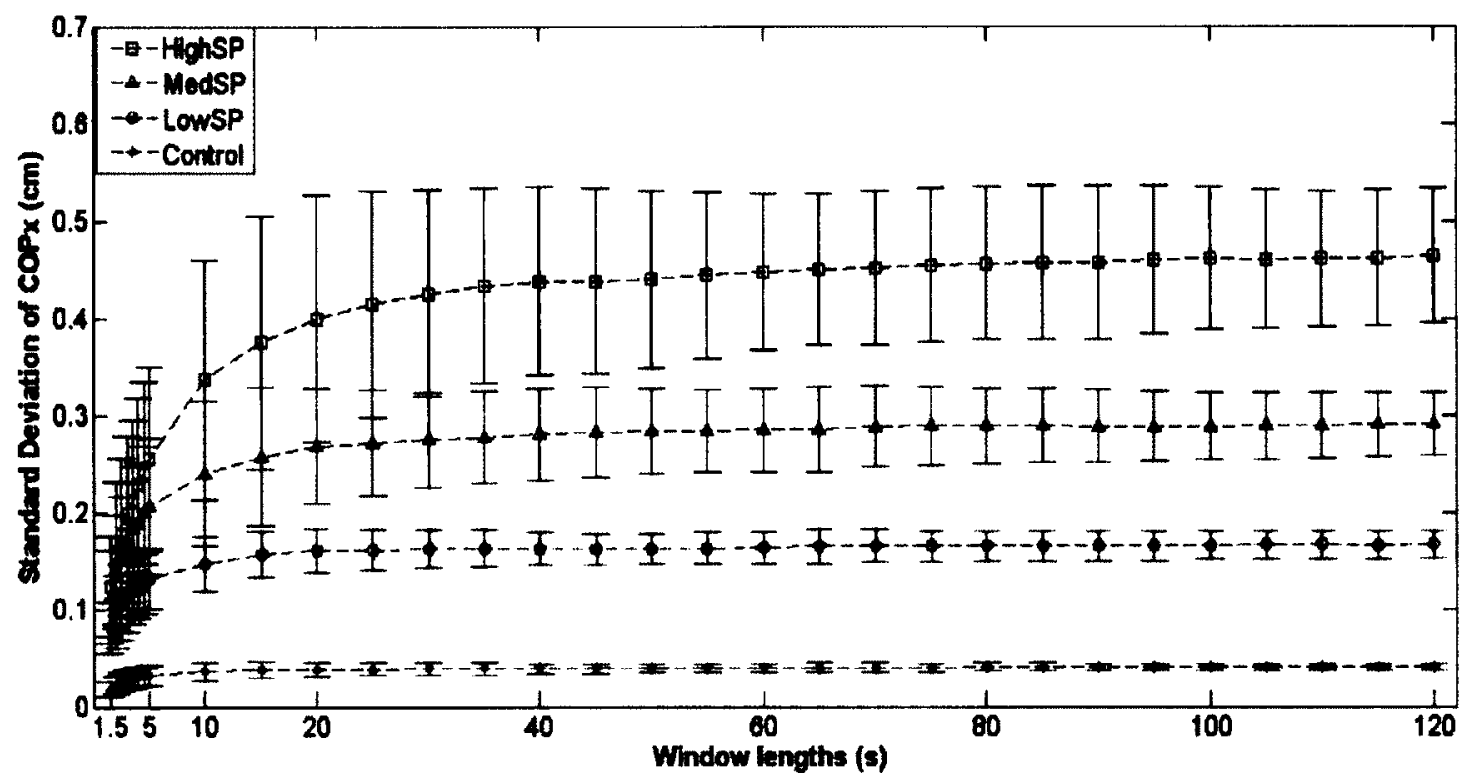

(b)

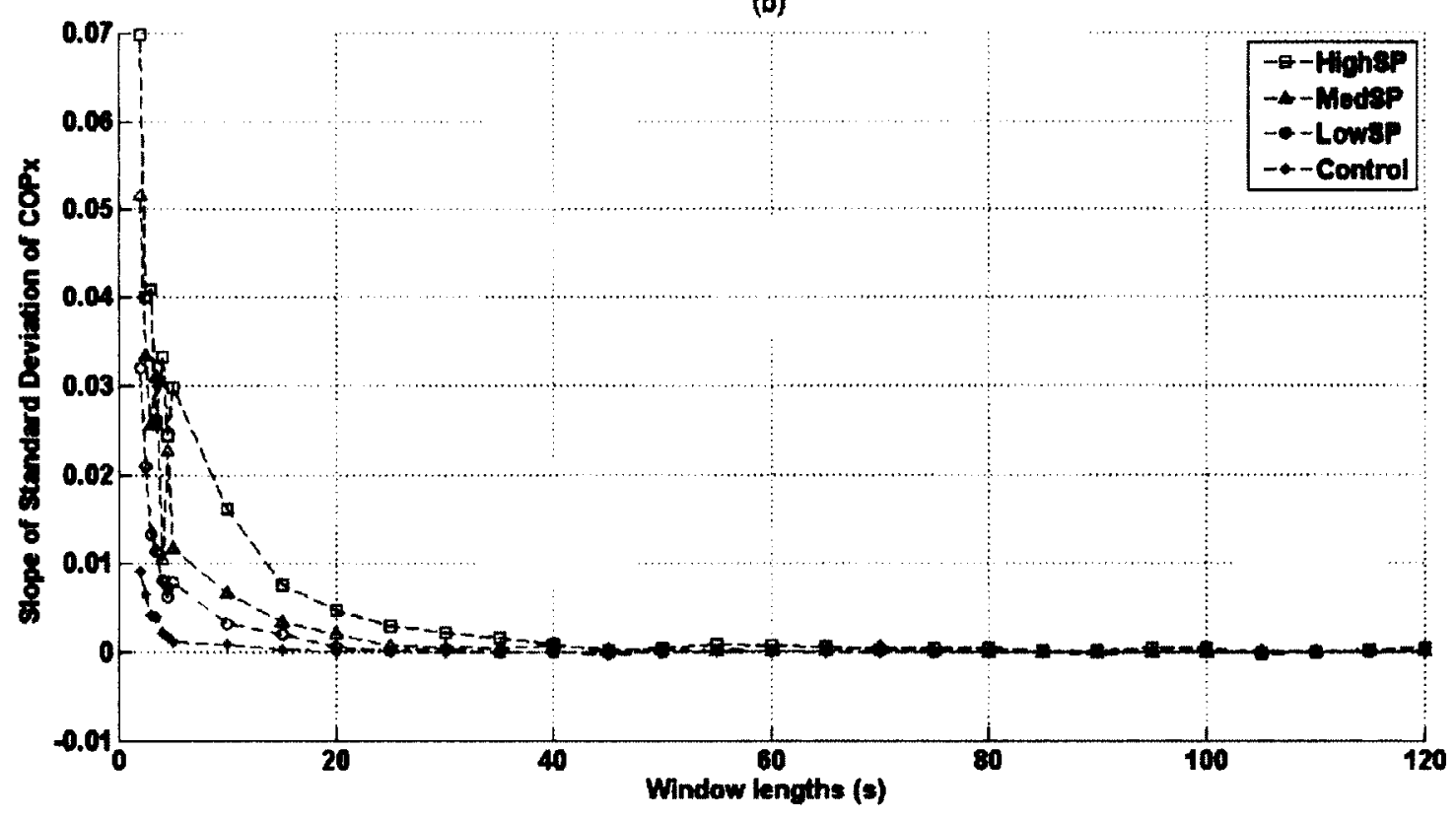

Figure 5.4: (a) |Standard deviation of $\mathrm{COP}_{\mathrm{x}}$, averaged over 100 trials with error bars for standard deviations and (b) slope of standard deviation of COP, of simulated COPx for four stability conditions (Control, LowSP, MedSP, and HighSP) for different window. 
(a)

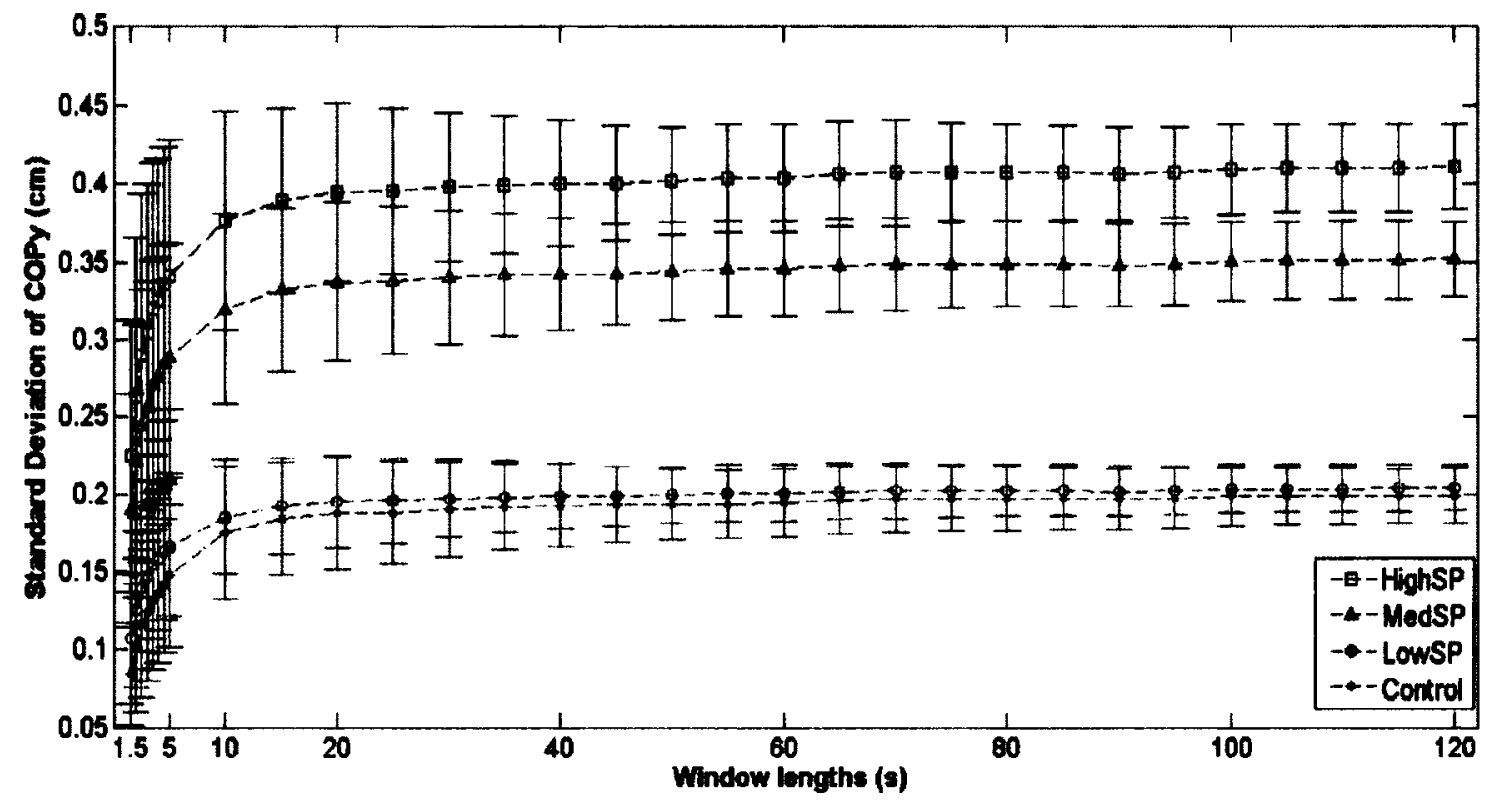

(b)

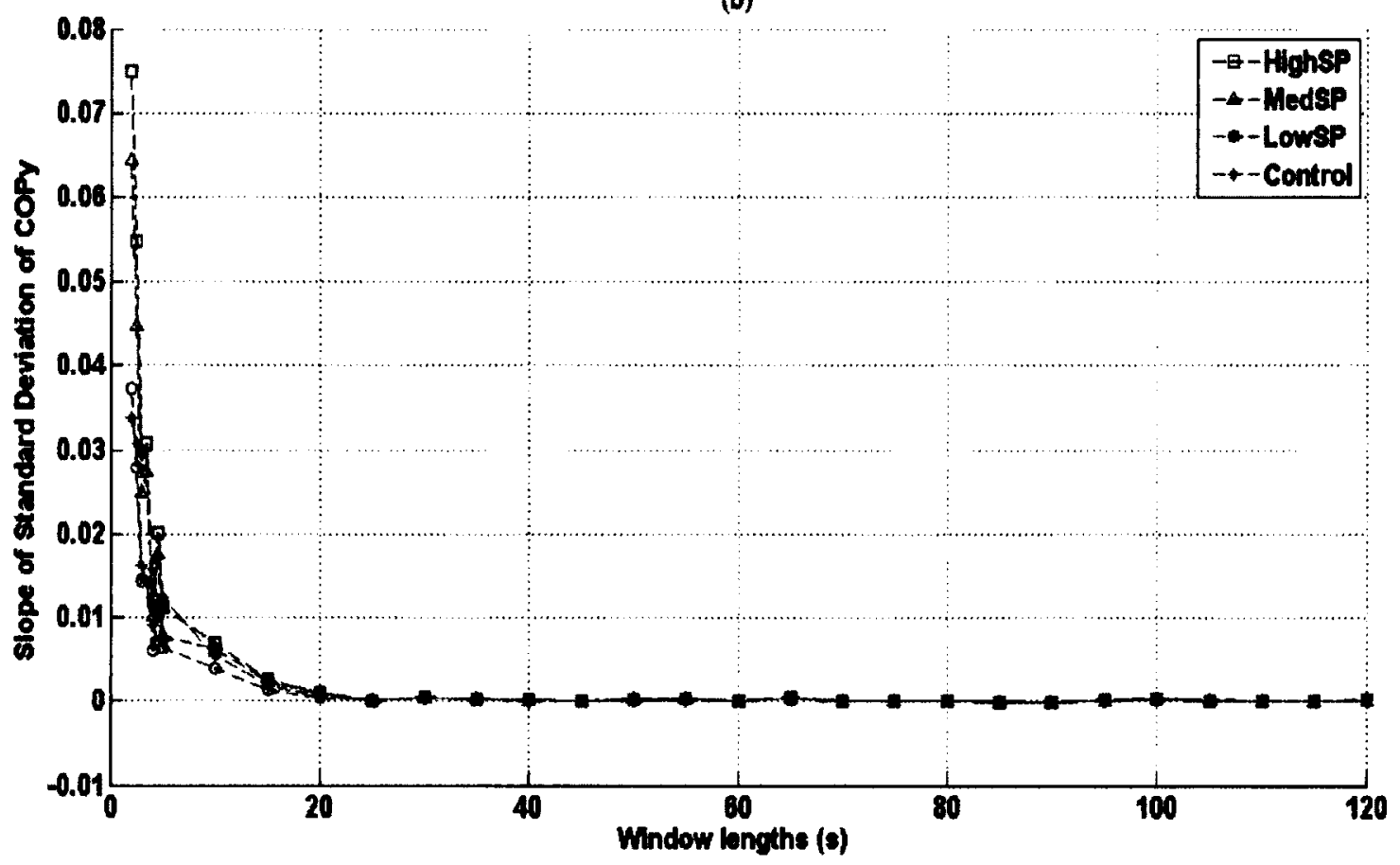

Figure 5.5: (a) |Standard deviation of $\mathrm{COP}_{\mathrm{y}}$, averaged over 100 trials with error bars for standard deviations and (b) slope of standard deviation of $\mathrm{COP}_{\mathrm{y}}$, of simulated $\mathrm{COP}_{\mathrm{y}}$ for four stability conditions (Control, LowSP, MedSP, and HighSP) for different window. 
(a)

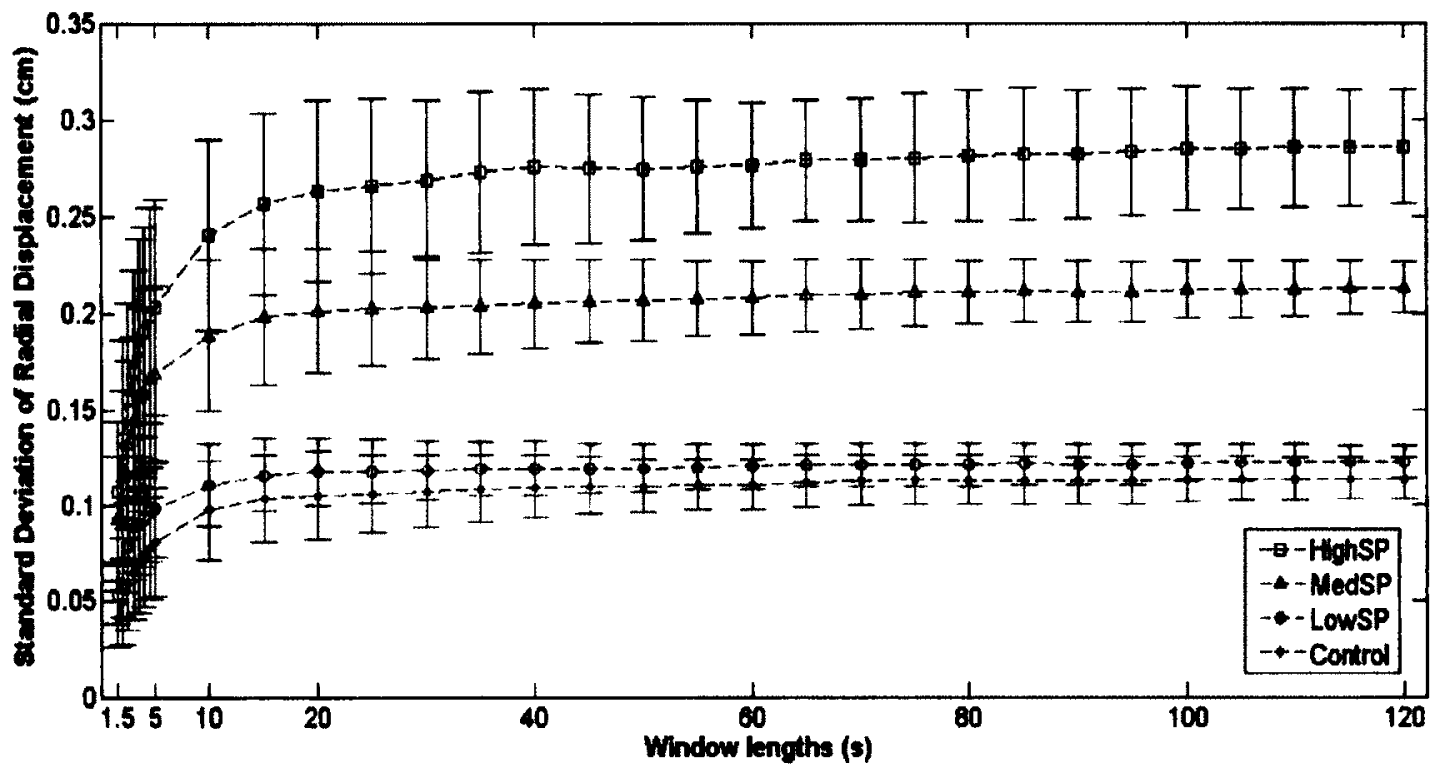

(b)

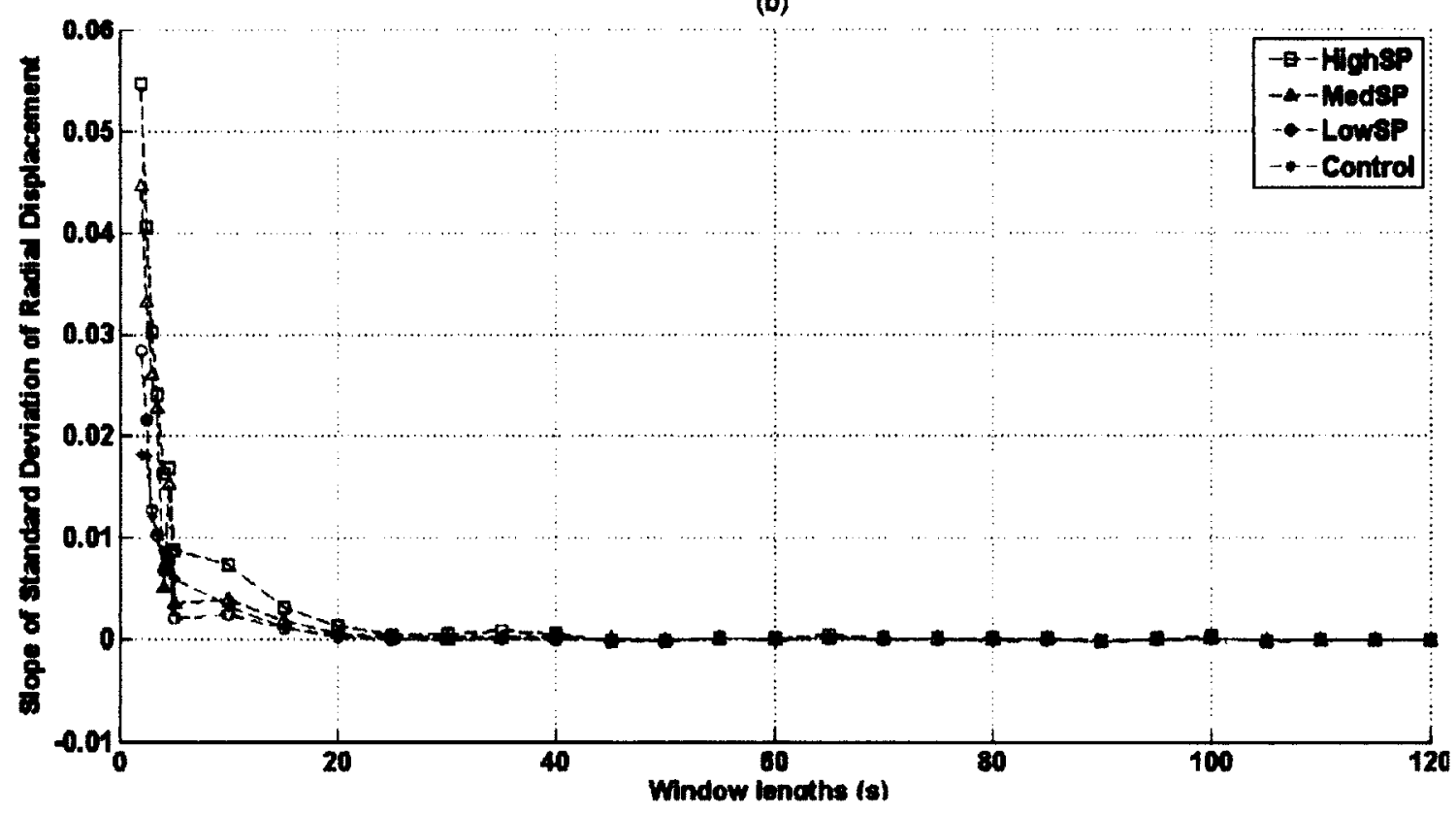

Figure 5.6: (a) Standard deviation of Radial Displacement, averaged over 100 trials with error bars for standard deviations and (b) slope of standard deviation of Radial Displacement, of simulated COP for four stability conditions (Control, LowSP, MedSP, and HighSP) for different window. 


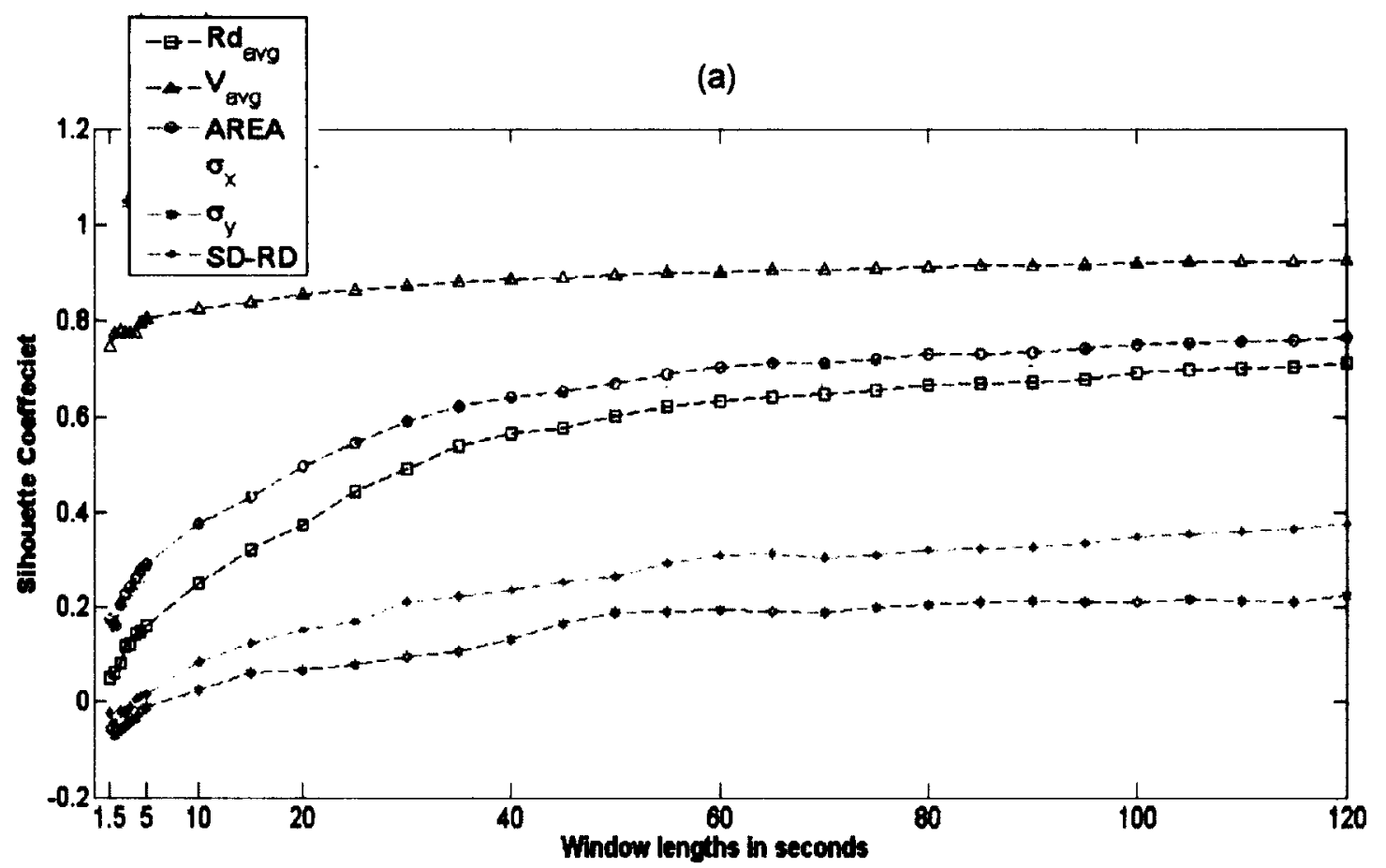

(b)

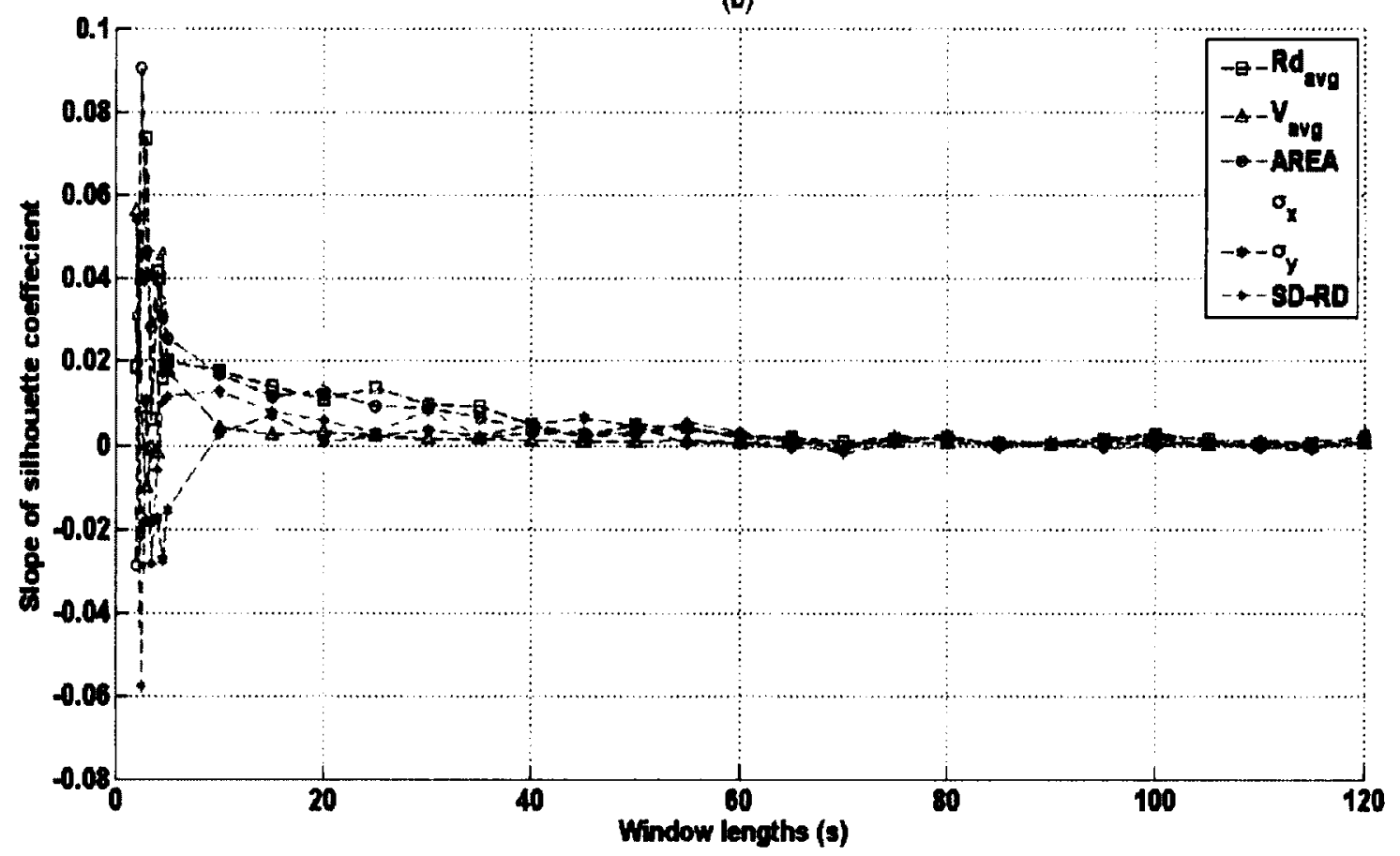

Figure 5.7: (a) Silhouette coefficient and (b) slope of standard Silhouette coefficient for six COP measures of simulated data of $\mathbf{1 0 0}$ trials for different window lengths. 


\subsection{Experimental Data}

\subsubsection{Comparison of first $30 \mathrm{~s}$ and last $30 \mathrm{~s}$}

\subsubsection{Methodology}

The COP measures were calculated over $1.5 \mathrm{~s}$ moving window length with a step of $0.5 \mathrm{~s}$ for $60 \mathrm{~s}$ of 11 trials and four stability conditions (FT-EO, FT-EC, SL-EO, SL-EC) the typical results of subject 2 are presented in Figure 5.5. These graphs shows COP average velocity become velocity become steadier. Then $\left(V_{\text {avg }}\right)$ were calculated over $30 \mathrm{~s}$ moving window length with a step of $0.1 \mathrm{~s}$ for $60 \mathrm{~s}$ of 11 trials and four stability conditions (FT-EO, FT-EC, SL-EO, SL-EC) the typical results of subject 2 are presented in Figure 5.6.

The preliminary visual analysis of these graphs suggested that the stability was not constant through the entire $60 \mathrm{~s}$ recording. It was thought that during the first few seconds, subjects might be still establishing their stability.

To investigated if there is any difference between first and last $30 \mathrm{~s}$ of $60 \mathrm{~s}$ data the COP data of 8 subjects for 11 trials, each trial consisting of 4 stability conditions, were analyzed, $60 \mathrm{~s}$. The investigation was performed only on the average velocity of COP due to its better performance compared to other five COP measures $\left(R D_{\text {avg }}, A R E A, \sigma_{x}, \sigma_{y}\right.$, and $S D_{-} R D$ ) for simulated data (see Section 4.3.1). Then COP average velocity $\left(V_{\text {avg }}\right)$ was calculated for first and last $30 \mathrm{~s}$ windows of $60 \mathrm{~s}$ data, for 11 trials and for 4 stability conditions presented in Figure 5.6 as box plots. 
These average velocity values for the first $30 \mathrm{~s}$ and the last $30 \mathrm{~s}$ window were compared by testing the hypothesis that there is no difference between theses values. The paired sample t-test was performed to investigate the difference between them.

\subsubsection{Results}

Figure 5.5-5.6 demonstrates constant decrease in $V_{\text {avg }}$ with increasing analysis window length and more variations between the trials for the smaller windows however, as window moves towards the last 30 s average velocity become steadier.

Figure 5.7 presents the box plot of average velocity of $\operatorname{COP}\left(V_{\text {avg }}\right)$ for all 8 subjects and for the four stability conditions. Box plots demonstrate the difference between the values of $V_{\text {avg }}$ for the first and last $30 \mathrm{~s}$ of $60 \mathrm{~s}$ data. The differences between the first $30 \mathrm{~s}$ and last $30 \mathrm{~s}$ windows are evident for most of the subjects and for most the stability conditions.

To assess the statically significant difference between first and last $30 \mathrm{~s}$ in the COP data quantitatively, during quiet standing for a $60 \mathrm{~s}$ data collection window for different stability conditions, the paired sample t-test was performed. Paired sample t-test $(\alpha=0.05)$ were performed to compare first and last $30 \mathrm{~s}$ windows of the $60 \mathrm{~s}$ data, for four stability conditions (FT-EO, FT-EC, SL-EO, and SL-EC) and for all eight subjects. The results for $V_{\text {avg }}$, the paired sample $t$-test are presented in Table 5.1. The results of Paired sample t-test $(p<0.05)$ revealed that, that there are statistically significant differences between the first and last $30 \mathrm{~s}$ values of $V_{\text {avg }}$, with few exceptions. Therefore, 
last $30 \mathrm{~s}$ of $60 \mathrm{~s}$ data were used for performance analysis and for analysis of effect of analysis window lengths on the performance of $\mathrm{COP}$ measure to avoid any variations that could be the effects of initial transition.
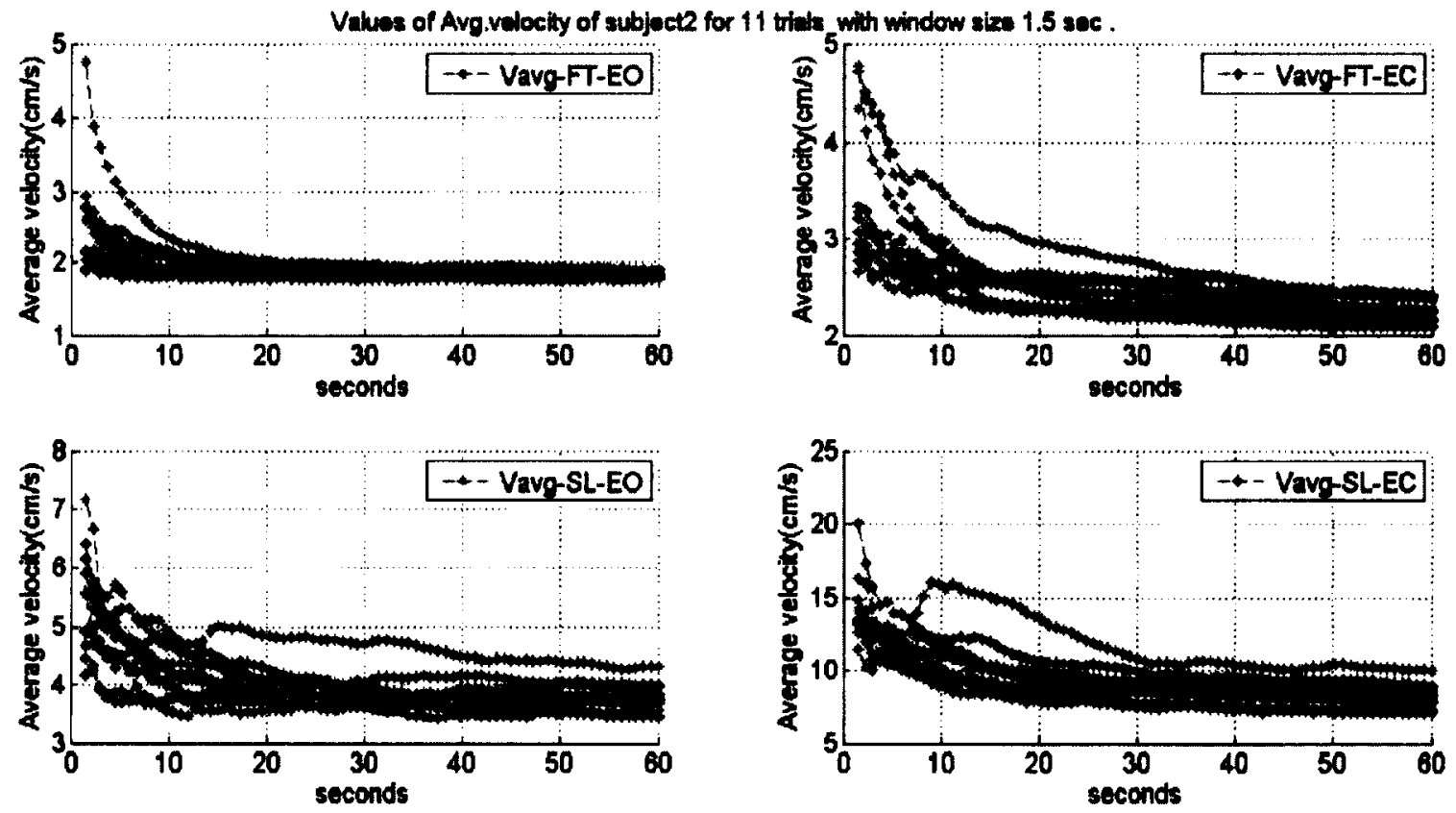

Figure 5.8: $V_{\text {avg }}$ calculated over $1.5 \mathrm{~s}$ window length with $0.1 \mathrm{~s}$ of overlapping for 11 trials of subject 2 for four stability conditions: (a) FT-EO, (b) FT-EC, (c) SL-EO, and (d) SL-EC. Each line in all graphs represent one trial. 
(a) FT-EO

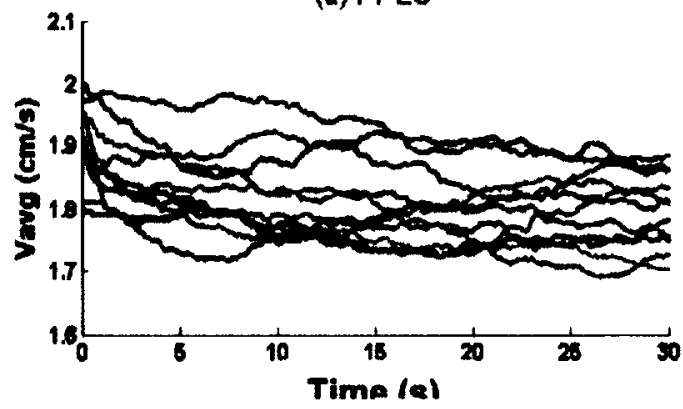

(c) SL-EO

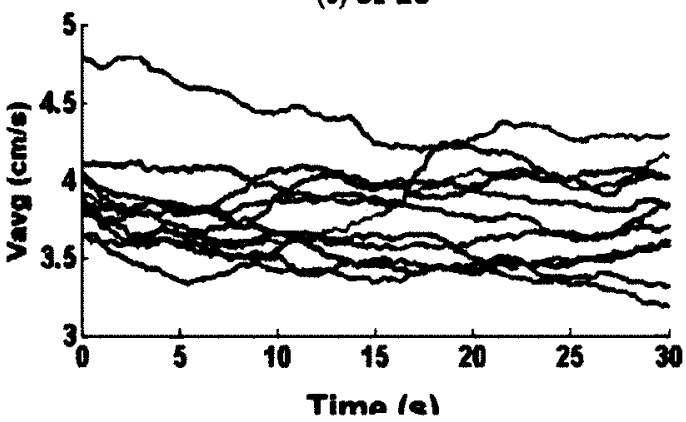

(c) FT-EC

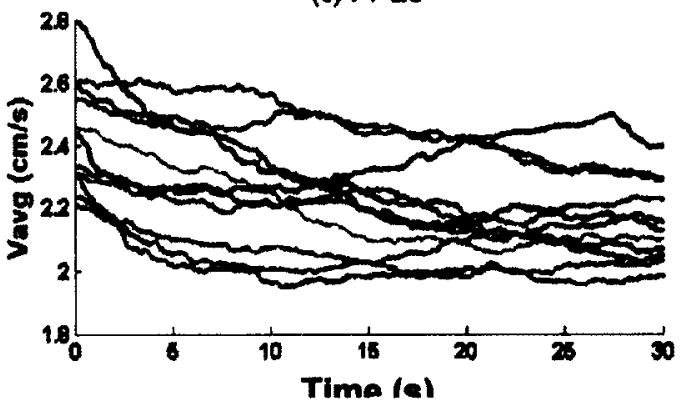

(d) SL-EC

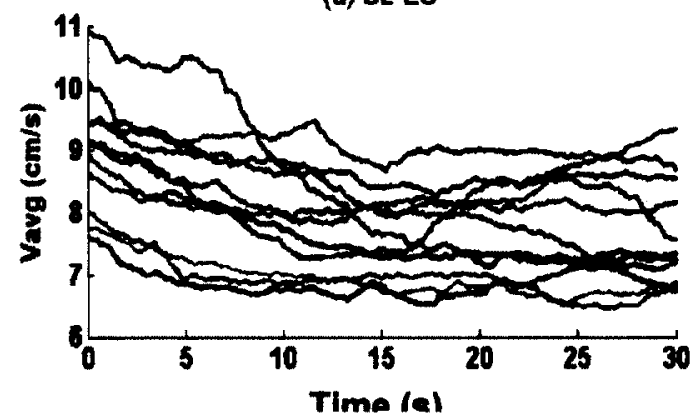

Figure 5.9: $V_{a v g}$ calculated over $30 \mathrm{~s}$ window length with $0.1 \mathrm{~s}$ of overlapping for 11 trials of subject 2 for four stability conditions: (a) FT-EO, (b) FT-EC, (c) SL-EO, and (d) SL-EC. Each line in all graphs represent one trial. 
(a) FT-EO

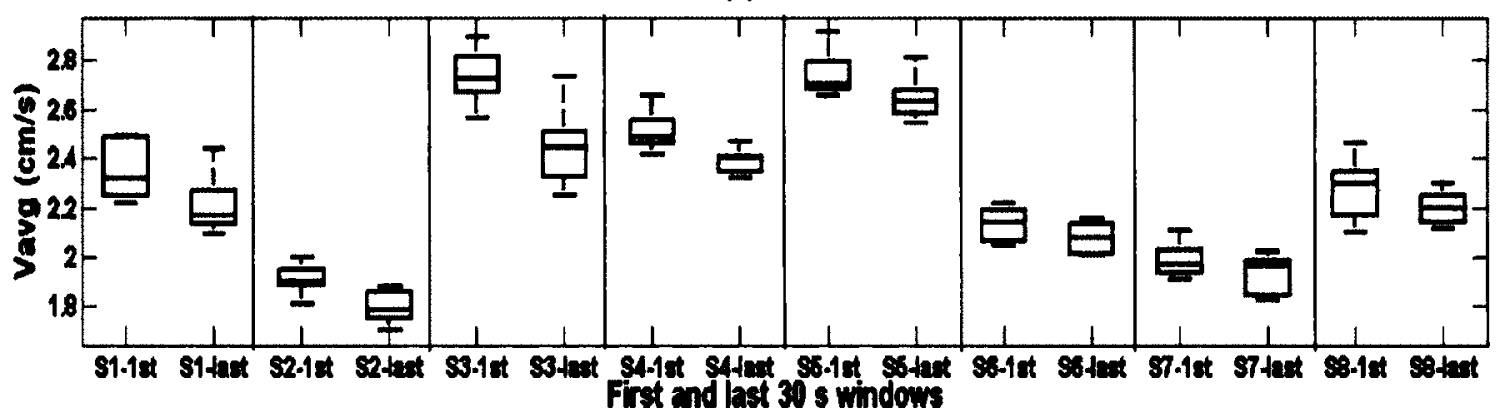

(b) FTEC

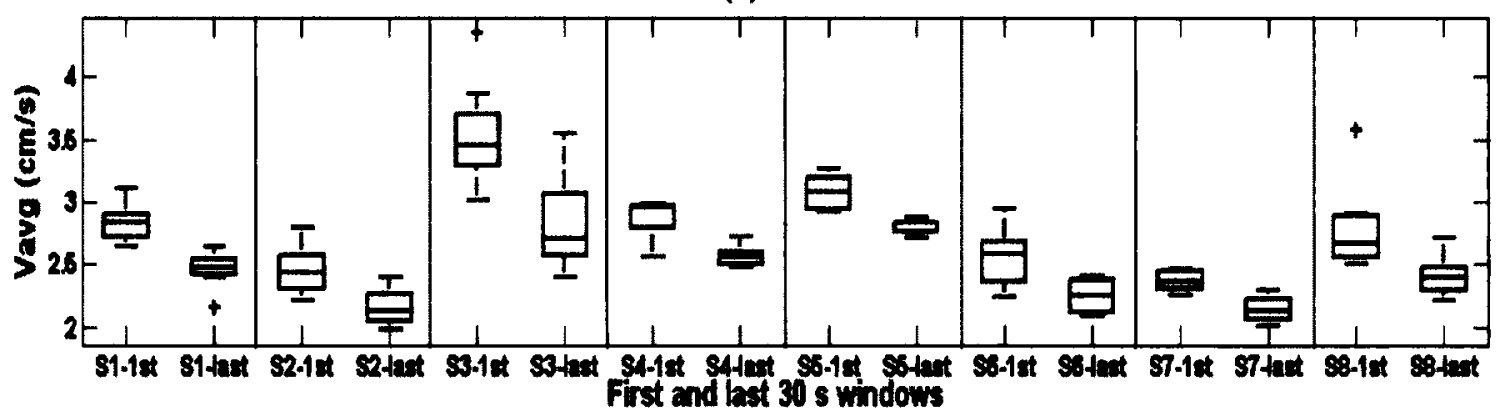

(c) StEO

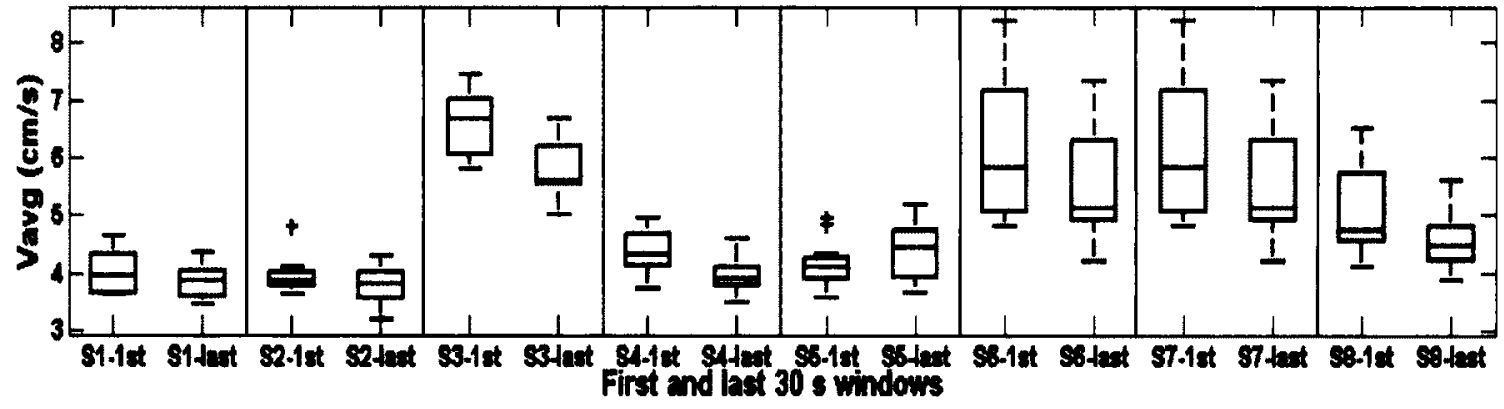

(d) SLEC

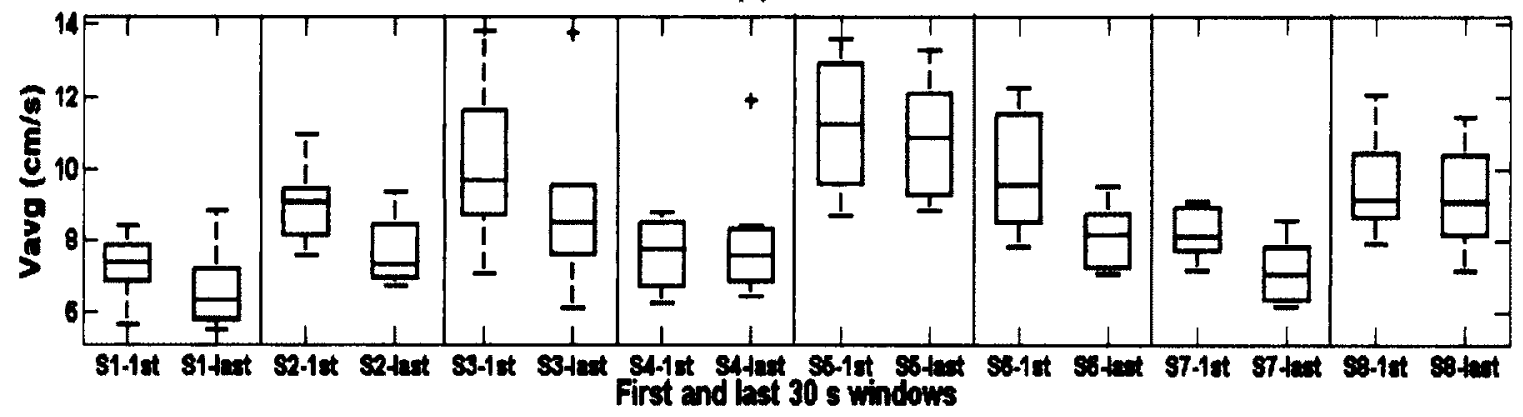

Figure 5.10: Box plots of $\boldsymbol{V}_{\text {avg }}$ for 11 trials for four stability conditions for all subjects: (a) FTEO for S1, S2, S3, S4, S5, S6, S7, and S8, (b) FT-EC for S1, S2, S3, S4, S5, S6, S7, and S8, (c) SL-EO for S1, S2, S3, S4, S5, S6, S7, and S8, and (d) SL-EC for S1, S2, S3, S4, S5, S6, S7, and S8 
Table 5.1: The paired sample t-test on $V_{\text {avg }}$, for first and last $30 \mathrm{~s}$ windows, for four stability conditions (FT-EO, FT-EC, SL-EO, and SL-EC) and for all eight subjects.

\begin{tabular}{|c|c|c|c|c|c|c|c|c|}
\hline \multicolumn{9}{|c|}{ Paired sample t-test $(\alpha=0.05)$} \\
\hline \multirow{2}{*}{$\left(1^{\text {st }} 30 \mathrm{~s}-\right.$ last $\left.30 \mathrm{~s}\right)$} & \multicolumn{8}{|c|}{ p, Sig. (2-tailed) [df $=10]$} \\
\hline & $\begin{array}{c}\text { Subject } \\
1\end{array}$ & $\begin{array}{c}\text { Subject } \\
2\end{array}$ & $\begin{array}{c}\text { Subject } \\
\mathbf{3}\end{array}$ & $\begin{array}{c}\text { Subject } \\
4\end{array}$ & $\begin{array}{c}\text { Subject } \\
5\end{array}$ & $\begin{array}{c}\text { Subject } \\
6\end{array}$ & $\begin{array}{c}\text { Subject } \\
7\end{array}$ & $\begin{array}{c}\text { Subject } \\
8\end{array}$ \\
\hline FT-EO & 0.673 & goot & $\operatorname{sed}$ & 8001 & 400 & 050 & Syin & $8 x^{2}$ \\
\hline FT-EC & 6001 & nimat. & 004 & 8021 & 0,034 & 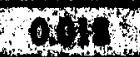 & 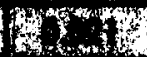 & Btis \\
\hline SL-EO & 0.013 & d601 & $\$ 011$ & 000 & 002 & $009 \%$ & 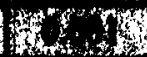 & 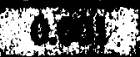 \\
\hline SL-EC & 0.673 & 0.179 & 0.335 & 0.560 & 0.096 & 086 & ond & 0.322 \\
\hline
\end{tabular}

\subsubsection{Effect of Analysis Window Length}

\subsubsection{Methodology}

To investigate the effect of analysis window length, the last $30 \mathrm{~s}$ of data of the $60 \mathrm{~s}$ data were analyzed to avoid initial variation while subjects established their static posture. The 13 windows of different lengths, $1.5 \mathrm{~s}, 2.0 \mathrm{~s}, 2.5 \mathrm{~s}, 3.0 \mathrm{~s}, 3.5 \mathrm{~s}, 4.0 \mathrm{~s}, 4.5 \mathrm{~s}, 5.0 \mathrm{~s}, 10 \mathrm{~s}, 15$ s, $20 \mathrm{~s}, 25 \mathrm{~s}$ and $30 \mathrm{~s}$, of last $30 \mathrm{~s}$ of $60 \mathrm{~s}$ data were used for the analysis. These windows were started from the beginning of the $30 \mathrm{~s}$ data. Six COP measures $\left(R D_{\text {avg }}, V_{\text {avg }}, A R E A\right.$, $\sigma_{x}, \sigma_{y}$, and $\left.S D_{-} R D\right)$ were calculated for each window for 11 trials and four stability conditions. The COP measures were compared using one way ANOVA within subject was performed and presented in Tables 5.2 to 5.9 The post-hoc tests with the Sidak correction were performed to investigate in particular which analysis window significantly different compared to the $30 \mathrm{~s}$ window. 


\subsubsection{Results}

Figure 5.7-5.9 are the plots of the six COP measures $\left(R D_{\text {avg }}, V_{\text {avg }}, S D_{-} R D, A R E A, \sigma_{x}\right.$ and $\sigma_{y}$ ) for four stability conditions (FT-EO, FT-EC, SL-EO, and SL-EC) and 11 trials, calculated for different window lengths for subject 2. A repeated measure ANOVA design within subject one factor with 13 levels ( 13 window lengths) for 11 trials were performed for each measure and for each stability condition separately. Results are presented in Tables 5.2 to 5.9. The results of ANOVA $(p<0.05)$ signified that at least two of window lengths were significantly different for all subjects, for all stability conditions (FT-EO, FT-EC, SL-EO, and SL-EC) and for all COP measures, except $V_{\text {avg }}$ and few other exceptions. Other exceptions include $R D_{a v g}$ and $\sigma_{y}$ for subject 3 for SLEC $(p>0.05)$, Tables 5.2 to 5.9 .

The ANOVA results $(p>0.05)$ for $V_{\text {avg }}$ signifies that there is no statistically significant difference between the different analysis window lengths, $1.5 \mathrm{~s}, 2.0 \mathrm{~s}, 2.5 \mathrm{~s}, 3.0 \mathrm{~s}, 3.5 \mathrm{~s}$, $4.0 \mathrm{~s}, 4.5 \mathrm{~s}, 5.0 \mathrm{~s}, 10 \mathrm{~s}, 15 \mathrm{~s}, 20 \mathrm{~s}, 25 \mathrm{~s}$, for all subjects, all stability conditions (FT-EO, FT-EC, SL-EO, and SL-EC) with exception of subjects S5 for SL-EC and S8 for FT-EO. 
Table 5.2: One way repeated measure ANOVA within subject design for different window lengths for subject 1 .

\begin{tabular}{|c|c|c|c|c|c|c|c|c|}
\hline \multicolumn{9}{|c|}{$\begin{array}{l}\text { 1 WAY ANOVA - Subject1 } \\
\text { (for } 1.5 \mathrm{~s}, 2.0 \mathrm{~s}, 2.5 \mathrm{~s}, 3.0 \mathrm{~s}, 3.5 \mathrm{~s}, 4.0 \mathrm{~s}, 4.5 \mathrm{~s}, 5.0 \mathrm{~s}, 10 \mathrm{~s}, 15 \mathrm{~s}, 20 \mathrm{~s}, 25 \mathrm{~s}, 30 \mathrm{~s} \text { windows) }\end{array}$} \\
\hline \multirow{2}{*}{$\begin{array}{c}\text { COP } \\
\text { Mensures }\end{array}$} & \multicolumn{2}{|c|}{ FT-EO } & \multicolumn{2}{|c|}{ FT-EC } & \multicolumn{2}{|c|}{ SLEO } & \multicolumn{2}{|c|}{ SL-EC } \\
\hline & $\mathbf{p}$ & $F(12,120)$ & p & $F(12,120)$ & p & $F(12,120)$ & p & $F(12,120)$ \\
\hline RDavg & $<0001$ & 17.898 & 80.001 & 17.124 & 6001 & 5.927 & $3 \times 21$ & 5.246 \\
\hline$\overline{V_{a v g}}$ & 0.350 & 1.120 & 0.637 & 0.812 & 0.982 & 0.331 & 0.999 & 0.187 \\
\hline AREA & 50.091 & 27.193 & $<0.001$ & 21.045 & regal & 9.759 & Solot & 9.437 \\
\hline$\sigma_{x}$ & $<0091$ & 8.819 & 5000 & 19.140 & 6000 & 7.835 & $400 \mathrm{~s}$ & 6.677 \\
\hline$\overline{\sigma_{y}}$ & (xapd & 19.673 & 1009 & 12.483 & $<001$ & 4.656 & 2010 & 4.231 \\
\hline SD_RD & $<6001$ & 25.129 & $<0.00$ & 22.606 & 5000 & 7.610 & $30 \%$ & 6.504 \\
\hline
\end{tabular}

Table 5.3: One way repeated measure ANOVA within subject design for different window lengths for subject 2.

\begin{tabular}{|c|c|c|c|c|c|c|c|c|}
\hline \multicolumn{9}{|c|}{$\begin{array}{c}\text { 1 WAY ANOVA - Subject } 2 \\
\text { (for } 1.5 \mathrm{~s}, 2.0 \mathrm{~s}, 2.5 \mathrm{~s}, 3.0 \mathrm{~s}, 3.5 \mathrm{~s}, 4.0 \mathrm{~s}, 4.5 \mathrm{~s}, 5.0 \mathrm{~s}, 10 \mathrm{~s}, 15 \mathrm{~s}, 20 \mathrm{~s}, 25 \mathrm{~s}, 30 \mathrm{~s} \text { windows) } \\
\end{array}$} \\
\hline \multirow{2}{*}{$\begin{array}{c}\text { COP } \\
\text { Measures }\end{array}$} & \multicolumn{2}{|c|}{ FT-EO } & \multicolumn{2}{|c|}{ FT-EC } & \multicolumn{2}{|c|}{ SL-EO } & \multicolumn{2}{|c|}{ SLEC } \\
\hline & $\mathbf{P}$ & $F(12,120)$ & p & $F(12,120)$ & p & $F(12,120)$ & $\mathbf{p}$ & $F(12,120)$ \\
\hline RDavg & enool & 24.047 & $<0.001$ & 5.932 & 50001 & 24.180 & 304 & 7.229 \\
\hline$V_{\text {avg }}$ & 0.159 & 435 & 0.808 & 0.636 & 0.999 & 0.188 & 0.951 & 0.424 \\
\hline AREA & $<0.001$ & 26.287 & capol & 10.934 & $<0001$ & 26.287 & $<001$ & 13.490 \\
\hline$\sigma_{x}$ & $<001$ & 19.257 & $<001$ & 7.222 & eopol & 9.138 & 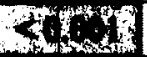 & 8.831 \\
\hline$\sigma_{y}$ & 5001 & 26.082 & $\times 063$ & 5.452 & sols & 24.740 & SAm & 5.377 \\
\hline SD_RD & $<0,001$ & 20.447 & $<0.001$ & 20.447 & $<0001$ & 17.092 & $\operatorname{sen}$ & 13.263 \\
\hline
\end{tabular}

Table 5.4: One way repeated measure ANOVA within subject design for different window lengths for subject 3.

\begin{tabular}{|c|c|c|c|c|c|c|c|c|}
\hline \multicolumn{9}{|c|}{$\begin{array}{l}\text { 1 WAY ANOVA - Subject } 3 \\
\text { (for } 1.5 \mathrm{~s}, 2.0 \mathrm{~s}, 2.5 \mathrm{~s}, 3.0 \mathrm{~s}, 3.5 \mathrm{~s}, 4.0 \mathrm{~s}, 4.5 \mathrm{~s}, 5.0 \mathrm{~s}, 10 \mathrm{~s}, 15 \mathrm{~s}, 20 \mathrm{~s}, 25 \mathrm{~s}, 30 \mathrm{~s} \text { windows) }\end{array}$} \\
\hline \multirow{2}{*}{$\begin{array}{c}\text { COP } \\
\text { Measures }\end{array}$} & \multicolumn{2}{|c|}{ FT-EO } & \multicolumn{2}{|c|}{ FT-EC } & \multicolumn{2}{|c|}{ SL-EO } & \multicolumn{2}{|c|}{ SL-EC } \\
\hline & $\mathbf{P}$ & $F(12,120)$ & $\mathrm{p}$ & $F(12,120)$ & $\mathbf{p}$ & $F(12,120)$ & $\mathbf{p}$ & $F(12,120)$ \\
\hline RDavg & $<0.001$ & 20.165 & $<0.001$ & 8.520 & $<0,001$ & 12.100 & 0.065 & 1.750 \\
\hline$V_{\text {avg }}$ & 0.235 & 1.289 & 0.015 & 2.204 & 0.068 & 1.726 & 0.410 & 1.049 \\
\hline AREA & $<0.001$ & 27.970 & $<0,001$ & 28.512 & $<0.001$ & 16.507 & 0.006 & 2.477 \\
\hline$\sigma_{x}$ & $<0.001$ & 8.568 & $<0.001$ & 3.945 & sod & 4.040 & $\log 2$ & 2.809 \\
\hline$\sigma_{y}$ & $<0.001$ & 22.738 & $<0.001$ & 18.847 & 50.001 & 14.826 & 0.459 & 0.993 \\
\hline SD_RD & $<0.001$ & 23.305 & $<0.001$ & 14.090 & $<0001$ & 16.100 & 0.001 & 3.125 \\
\hline
\end{tabular}


Table 5.5: One way repeated measure ANOVA within subject design for different window lengths for subject 4.

\begin{tabular}{|c|c|c|c|c|c|c|c|c|}
\hline \multicolumn{9}{|c|}{$\begin{array}{c}\text { 1 WAY ANOVA - Subject } 4 \\
\text { (for } 1.5 \mathrm{~s}, 2.0 \mathrm{~s}, 2.5 \mathrm{~s}, 3.0 \mathrm{~s}, 3.5 \mathrm{~s}, 4.0 \mathrm{~s}, 4.5 \mathrm{~s}, 5.0 \mathrm{~s}, 10 \mathrm{~s}, 15 \mathrm{~s}, 20 \mathrm{~s}, 25 \mathrm{~s}, 30 \mathrm{~s} \text { windows) }\end{array}$} \\
\hline \multirow{2}{*}{$\begin{array}{c}\text { COP } \\
\text { Measures }\end{array}$} & \multicolumn{2}{|c|}{ FT-EO } & \multicolumn{2}{|c|}{ FT-EC } & \multicolumn{2}{|c|}{ SL-EO } & \multicolumn{2}{|c|}{ SL-EC } \\
\hline & $\mathbf{P}$ & $F(12,120)$ & $\mathbf{P}$ & $F(12,120)$ & $\mathbf{p}$ & $F(12,120)$ & $\mathbf{p}$ & $F(12,120)$ \\
\hline RDavg & $<0,001$ & 14.998 & $<0.001$ & 11.306 & $<0.001$ & 31.166 & 5601 & 3.297 \\
\hline$V_{\text {avg }}$ & 0.263 & 1.241 & 0.254 & 1.255 & 0.894 & 0.526 & 0.385 & 1.078 \\
\hline AREA & $<0.001$ & 30.619 & $<0.001$ & 16.019 & $<0.001$ & 30.802 & $<001$ & 3.473 \\
\hline$\sigma_{x}$ & $<0.001$ & 12.051 & $<0001$ & 24.515 & $<0.001$ & 14.623 & 0,4 & 2.901 \\
\hline$\sigma_{y}$ & $<0.001$ & 16.687 & $<0001$ & 7.315 & $<0.001$ & 26.507 & 56 & 7.534 \\
\hline SD_RD & $<0.001$ & 17.570 & $<0091$ & 19.168 & $<0.001$ & 38.908 & $\cos 4$ & 6.524 \\
\hline
\end{tabular}

Table 5.6: One way repeated measure ANOVA within subject design for different window lengths for subject 5.

\begin{tabular}{|c|c|c|c|c|c|c|c|c|}
\hline \multicolumn{9}{|c|}{$\begin{array}{c}\text { 1 WAY ANOVA - Subject } 5 \\
\text { (for } 1.5 \mathrm{~s}, 2.0 \mathrm{~s}, 2.5 \mathrm{~s}, 3.0 \mathrm{~s}, 3.5 \mathrm{~s}, 4.0 \mathrm{~s}, 4.5 \mathrm{~s}, 5.0 \mathrm{~s}, 10 \mathrm{~s}, 15 \mathrm{~s}, 20 \mathrm{~s}, 25 \mathrm{~s}, 30 \mathrm{~s} \text { windows) }\end{array}$} \\
\hline \multirow{2}{*}{$\begin{array}{c}\text { COP } \\
\text { Measures }\end{array}$} & \multicolumn{2}{|c|}{ FT-EO } & \multicolumn{2}{|c|}{ FT-EC } & \multicolumn{2}{|c|}{ SL-EO } & \multicolumn{2}{|c|}{ SL-EC } \\
\hline & $\mathbf{P}$ & $F(12,120)$ & $\mathbf{p}$ & $F(12,120)$ & $\mathbf{p}$ & $F(12,120)$ & $\mathbf{p}$ & $F(12,120)$ \\
\hline RDavg & $<0.001$ & 28.308 & 0.000 & 14.427 & 0.045 & 1.867 & 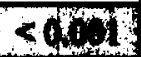 & 40.161 \\
\hline$V_{\text {avg }}$ & 0.364 & 1.102 & 0.959 & 0.405 & 0.767 & 0.680 & $20 \mathrm{pg}$ & 3.250 \\
\hline AREA & $<0.001$ & 59.295 & 0.000 & 16.727 & 0.000 & 5.170 & $<0,01$ & 48.135 \\
\hline$\overline{\sigma_{x}}$ & $<0.001$ & 17.207 & $<0,001$ & 6.449 & 0.001 & 3.159 & $<001$ & 16.549 \\
\hline$\sigma_{y}$ & $<0.001$ & 23.373 & $<0.001$ & 16.575 & 0.091 & 1.633 & 8001 & 27.943 \\
\hline SD_RD & $<0.001$ & 24.982 & $<0.001$ & 22.122 & $<0.001$ & 9.425 & 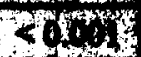 & 26.756 \\
\hline
\end{tabular}

Table 5.7: One way repeated measure ANOVA within subject design for different window lengths for subject 6.

\begin{tabular}{|c|c|c|c|c|c|c|c|c|}
\hline \multicolumn{9}{|c|}{$\begin{array}{c}\text { 1 WAY ANOVA - Subject } 6 \\
\text { (for } 1.5 \mathrm{~s}, 2.0 \mathrm{~s}, 2.5 \mathrm{~s}, 3.0 \mathrm{~s}, 3.5 \mathrm{~s}, 4.0 \mathrm{~s}, 4.5 \mathrm{~s}, 5.0 \mathrm{~s}, 10 \mathrm{~s}, 15 \mathrm{~s}, 20 \mathrm{~s}, 25 \mathrm{~s}, 30 \mathrm{~s} \text { windows) }\end{array}$} \\
\hline \multirow{2}{*}{$\begin{array}{c}\text { COP } \\
\text { Measures }\end{array}$} & \multicolumn{2}{|c|}{ FT-EO } & \multicolumn{2}{|c|}{ FT-EC } & \multicolumn{2}{|c|}{ SL-EO } & \multicolumn{2}{|c|}{ SL-EC } \\
\hline & $\mathbf{P}$ & $F(12,120)$ & $\mathbf{p}$ & $F(12,120)$ & $p$ & $F(12,120)$ & p & $F(12,120)$ \\
\hline RDavg & $<0.001$ & 14.258 & $<0.001$ & 14.427 & $<0.001$ & 8.567 & 0600 & 10.386 \\
\hline$V_{\text {avg }}$ & 0.069 & 1.729 & 0.959 & 0.405 & 0.366 & 1.100 & 0.430 & 1.026 \\
\hline AREA & $<0.001$ & 37.007 & $<0.001$ & 16.727 & $<0.001$ & 12.168 & $<6001$ & 15.367 \\
\hline$\overline{\sigma_{x}}$ & $<0.001$ & 8.868 & $<0.001$ & 6.449 & 0.014 & 2.226 & 90a4 & 2.592 \\
\hline$\sigma_{y}$ & $<0.001$ & 14.920 & $<0.001$ & 16.575 & $<0.001$ & 9.799 & $<0901$ & 22.733 \\
\hline SD_RD & $<0.001$ & 14.411 & $<0.001$ & 22.122 & $<0.001$ & 5.528 & $<0.01$ & 9.343 \\
\hline
\end{tabular}


Table 5.8: One way repeated measure ANOVA within subject design for different window lengths for subject 7.

\begin{tabular}{|c|c|c|c|c|c|c|c|c|}
\hline \multicolumn{9}{|c|}{$\begin{array}{c}\text { WAY ANOVA - Subject7 } \\
\text { (for } 1.5 \mathrm{~s}, 2.0 \mathrm{~s}, 2.5 \mathrm{~s}, 3.0 \mathrm{~s}, 3.5 \mathrm{~s}, 4.0 \mathrm{~s}, 4.5 \mathrm{~s}, 5.0 \mathrm{~s}, 10 \mathrm{~s}, 15 \mathrm{~s}, 20 \mathrm{~s}, 25 \mathrm{~s}, 30 \mathrm{~s} \text { windows) }\end{array}$} \\
\hline \multirow{2}{*}{$\begin{array}{c}\text { COP } \\
\text { Measures }\end{array}$} & \multicolumn{2}{|c|}{ FT-EO } & \multicolumn{2}{|c|}{ FT-EC } & \multicolumn{2}{|c|}{ SL-EO } & \multicolumn{2}{|c|}{ SL-EC } \\
\hline & p & $F(12,120)$ & p & $F(12,120)$ & $\mathbf{p}$ & $F(12,120)$ & p & $F(12,120)$ \\
\hline RDavg & $<0,001$ & 9.883 & $<0.001$ & 14.427 & $<0,001$ & 3.407 & 5001 & 16.457 \\
\hline$V_{\text {avg }}$ & 0.981 & 0.338 & 0.959 & 0.405 & 0.370 & 1.095 & 0.820 & 0.622 \\
\hline AREA & $<0.001$ & 10.869 & $<0.001$ & 16.727 & $<0,001$ & 6.911 & 8001 & 21.031 \\
\hline$\sigma_{x}$ & $<0.001$ & 12.037 & $<0.001$ & 6.449 & 0001 & 3.120 & $20 \times 1$ & 7.774 \\
\hline$\sigma_{y}$ & $<0.001$ & 8.345 & $<0.001$ & 16.575 & 0.001 & 3.194 & 3014 & 17.939 \\
\hline SD_RD & $<0.001$ & 24.947 & $<0,001$ & 22.122 & cocol & 8.202 & $\cos 1$ & 20.913 \\
\hline
\end{tabular}

Table 5.9: One way repeated measure ANOVA within subject design for different window lengths for subject 8.

\begin{tabular}{|c|c|c|c|c|c|c|c|c|}
\hline \multicolumn{9}{|c|}{$\begin{array}{c}\text { 1 WAY ANOVA - Subject } 8 \\
\text { (for } 1.5 \mathrm{~s}, 2.0 \mathrm{~s}, 2.5 \mathrm{~s}, 3.0 \mathrm{~s}, 3.5 \mathrm{~s}, 4.0 \mathrm{~s}, 4.5 \mathrm{~s}, 5.0 \mathrm{~s}, 10 \mathrm{~s}, 15 \mathrm{~s}, 20 \mathrm{~s}, 25 \mathrm{~s}, 30 \mathrm{~s} \text { windows) }\end{array}$} \\
\hline \multirow{2}{*}{$\begin{array}{c}\text { COP } \\
\text { Measures }\end{array}$} & \multicolumn{2}{|c|}{ FT-EO } & \multicolumn{2}{|c|}{ FT-EC } & \multicolumn{2}{|c|}{ SL-EO } & \multicolumn{2}{|c|}{ SLEC } \\
\hline & p & $F(12,120)$ & p & $F(12,120)$ & $\mathbf{p}$ & $F(12,120)$ & p & $F(12,120)$ \\
\hline RDavg & $<0.001$ & 14.591 & $<0.001$ & 14.427 & $<0.001$ & 13.609 & 80.001 & 11.968 \\
\hline$V_{\text {avg }}$ & 0.0393 & 1.912 & 0.959 & 0.405 & 0.995 & 0.254 & 0.502 & 0.948 \\
\hline AREA & $<0.001$ & 20.835 & $<0.001$ & 16.727 & $<0.004$ & 17.412 & $\$ 0001$ & 13.730 \\
\hline$\sigma_{x}$ & $<0,001$ & 7.551 & $<0.001$ & 6.449 & $<0.601$ & 5.522 & $<0,001$ & 4.756 \\
\hline$\overline{\sigma_{y}}$ & $<0.001$ & 25.481 & $<0.001$ & 16.575 & $<0,001$ & 18.935 & $<0001$ & 14.211 \\
\hline$\overline{\text { SD_RD }}$ & $<0.001$ & 25.043 & $<0.001$ & 22.122 & $<0.001$ & 26.714 & senot & 13.589 \\
\hline
\end{tabular}

The post-hoc tests with the Sidak correction were performed to investigate in particular which analysis window lengths were different compare to the $30 \mathrm{~s}$ window length, for all six COP measures $\left(R D_{\text {avg }}, V_{\text {avg }}, S D_{-} R D, A R E A, \sigma_{x}\right.$ and $\left.\sigma_{y}\right)$, for all subjects and for all stability conditions (FT-EO, FT-EC, SL-EO, and SL-EC). The results of paired sample post-hoc tests are presented in Appendix C, Tables C.1 to C.32. The post-hoc tests results $(p<0.05)$ signifies that there were significant differences in the COP measures other than 
$V_{\text {avg }}$, calculated for different window lengths, $1.5 \mathrm{~s}, 2.0 \mathrm{~s}, 2.5 \mathrm{~s}, 3.0 \mathrm{~s}, 3.5 \mathrm{~s}, 4.0 \mathrm{~s}, 4.5 \mathrm{~s}$, $5.0 \mathrm{~s}, 10 \mathrm{~s}, 15 \mathrm{~s}, 20 \mathrm{~s}$, and $25 \mathrm{~s}$, compared to a $30 \mathrm{~s}$ window with some exceptions. The exceptions may be the individual behavior of subjects see Table C.1 to C32. The post-hoc tests results $(p>0.05)$ for $V_{\text {avg }}$ revealed that there is no statistically significant differences in the $V_{\text {avg }}$ values calculated for different window lengths $(1.5 \mathrm{~s}, 2.0 \mathrm{~s}, 2.5 \mathrm{~s}$, $3.0 \mathrm{~s}, 3.5 \mathrm{~s}, 4.0 \mathrm{~s}, 4.5 \mathrm{~s}, 5.0 \mathrm{~s}, 10 \mathrm{~s}, 15 \mathrm{~s}, 20 \mathrm{~s}, 25 \mathrm{~s}$ ) compared to $30 \mathrm{~s}$ window length for all stability conditions (FT-EO, FT-EC, SL-EO, and SL-EC) and for all subjects without any exceptions see Appendix C Table C.1 to C.32.

The results also demonstrate that there are no significant $(p>0.05)$ differences between $30 \mathrm{~s}$ window compared to $15 \mathrm{~s}, 20 \mathrm{~s}$, and $25 \mathrm{~s}$ windows for all subjects and stability conditions.

However Figure 5.8 for $V_{\text {avg }}$ also shows higher variations for smaller windows compared to $30 \mathrm{~s}$ window between the trials; the single trial for smaller window of less than $15 \mathrm{~s}$ does not appear to be a good representation of a given stability condition.

Performance of window lengths was also evaluated by using cluster analysis. Figure 5.15-18 presents the results of 8 subjects. Figure 5.15-18 demonstrates that better performance (i.e., higher silhouette coefficient) of $V_{\text {avg }}$ for larger window sizes, while the other five COP measures $\left(R D_{\text {avg }}, S D_{-} R D, A R E A, \sigma_{x}\right.$ and $\left.\sigma_{y}\right)$ show increases in performances with larger window sizes for some cases. The $V_{\text {avg }}$ always has the highest silhouette coefficient and demonstrates good performance even for smaller windows. The 
same results were obtained from the statistical analysis, presented in Appendix C Table C.1 to C.32. Silhouette coefficient for standard deviation of $C O P_{y}$ show drop in value for 30 s window length only for subject 2 this could be due to an increase in variation between the trials, i.e. the subject might have changed his position a little in the AP direction during one of the trial as window length the increased. 

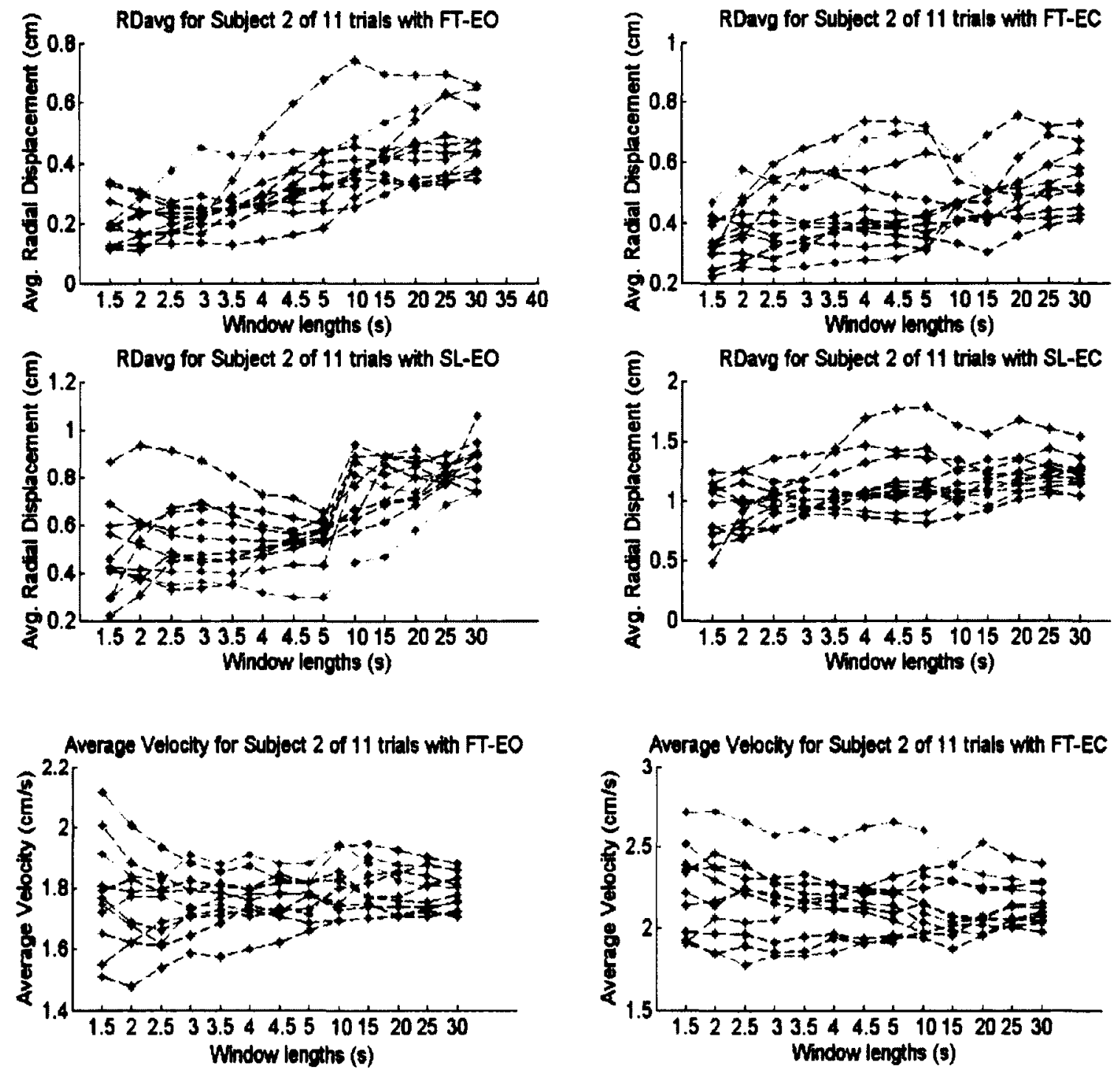

Average Velocity for Subject 2 of 11 trials with SL-EO

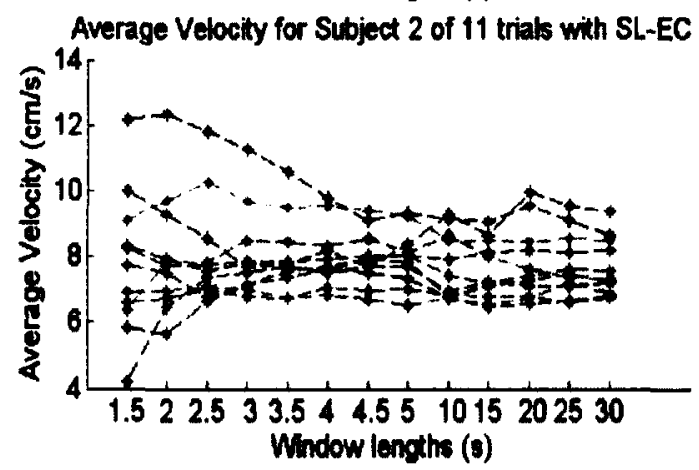

Figure 5.11: Average radial displacement and average velocity of experimental data of 11 trials for four stability conditions (FT-EO, FT-EC, SL-EO, and SL-EC) for different window lengths for subiect 2. 

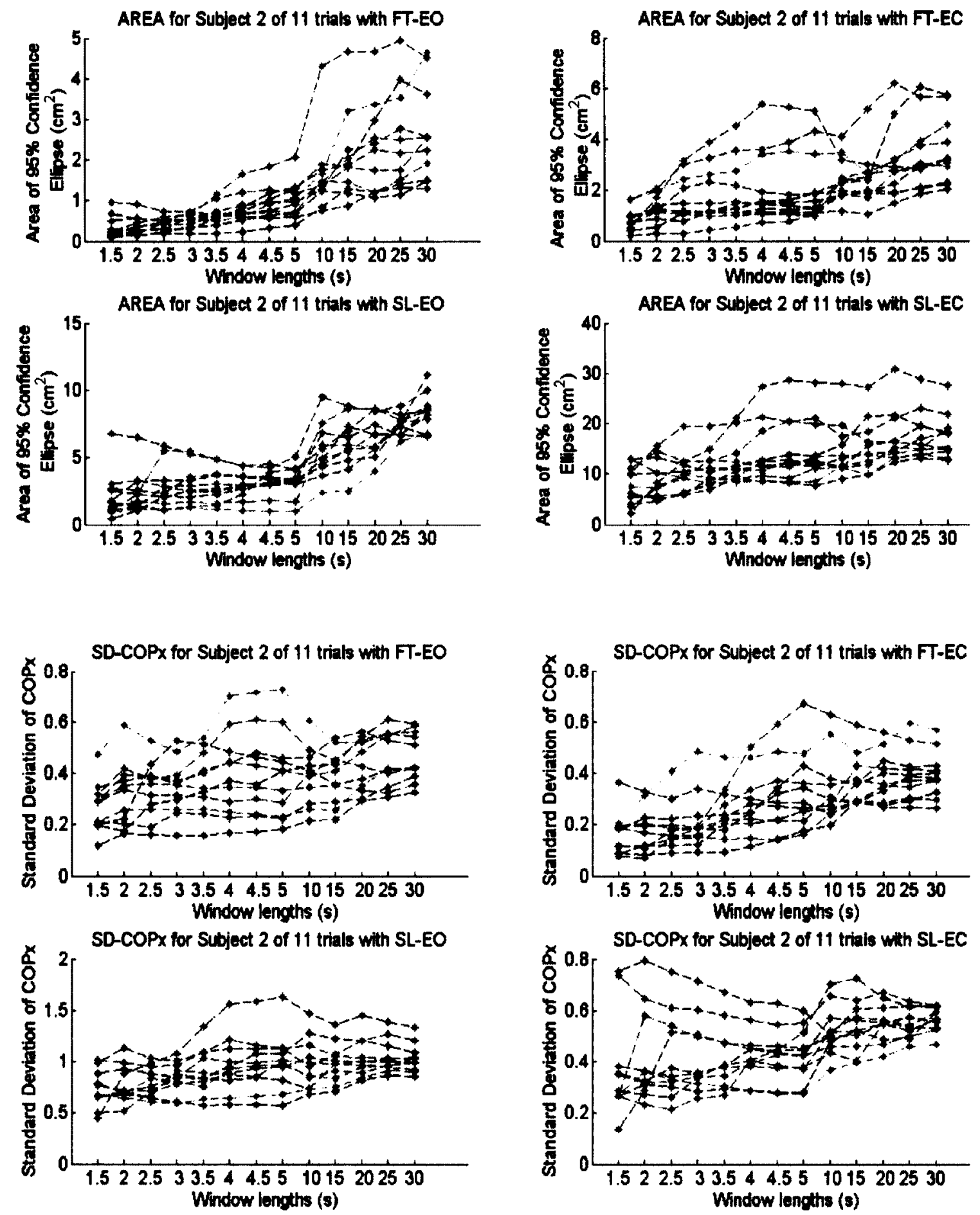

Figure 5.12: AREA and standard deviation of $C O P_{x}$ of experimental data of 11 trials for four stability conditions (FT-EO, FT-EC, SL-EO, and SL-EC) for different window lengths for subject 2. 

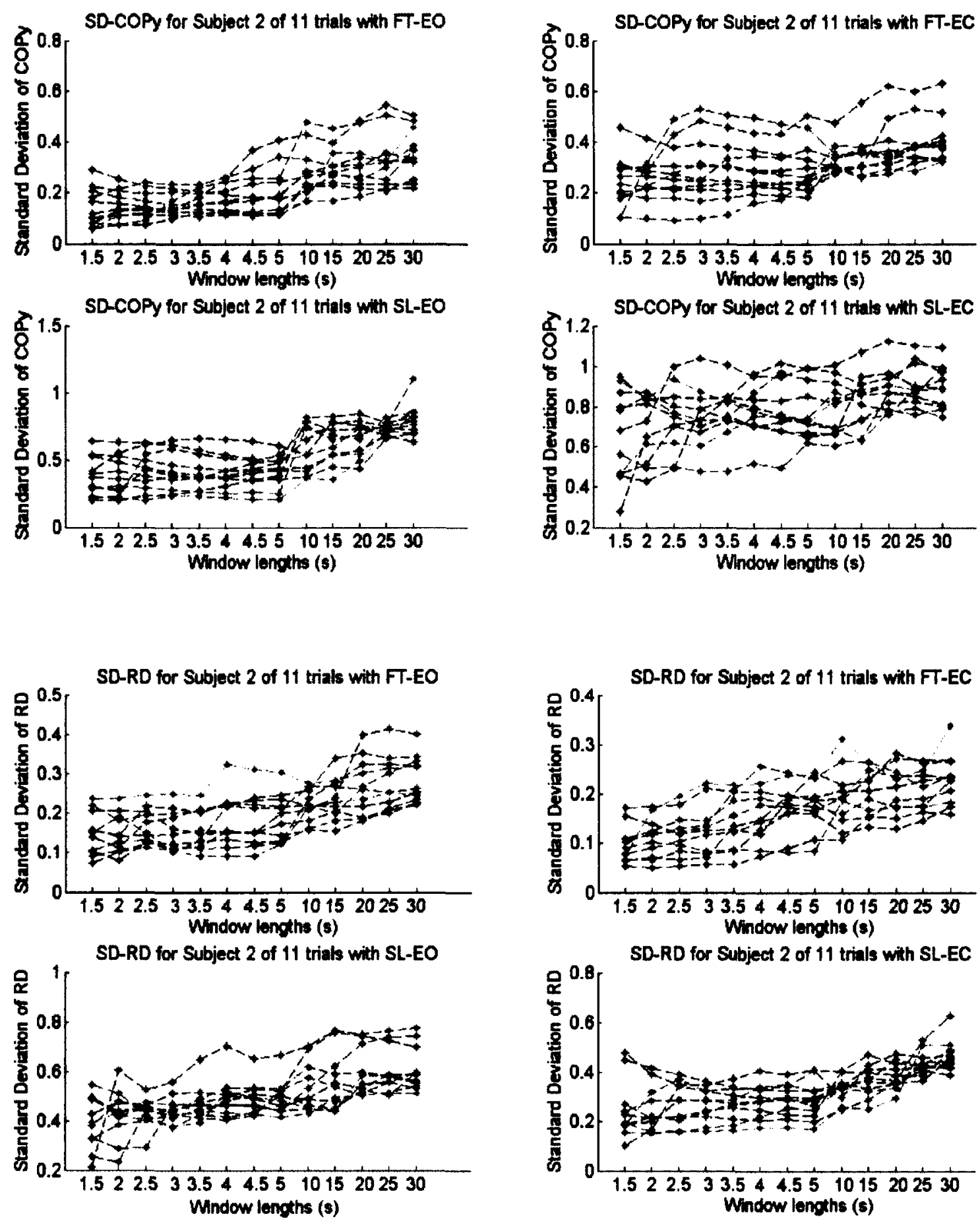

Figure 5.13: Standard deviation of $\mathrm{COP}_{\mathrm{y}}$ and standard deviation of radial displacement of experimental data of 11 trials for four stability conditions (FT-EO, FT-EC, SL-EO, and SL-EC) for different window lengths of subject 1 for subject 2. 

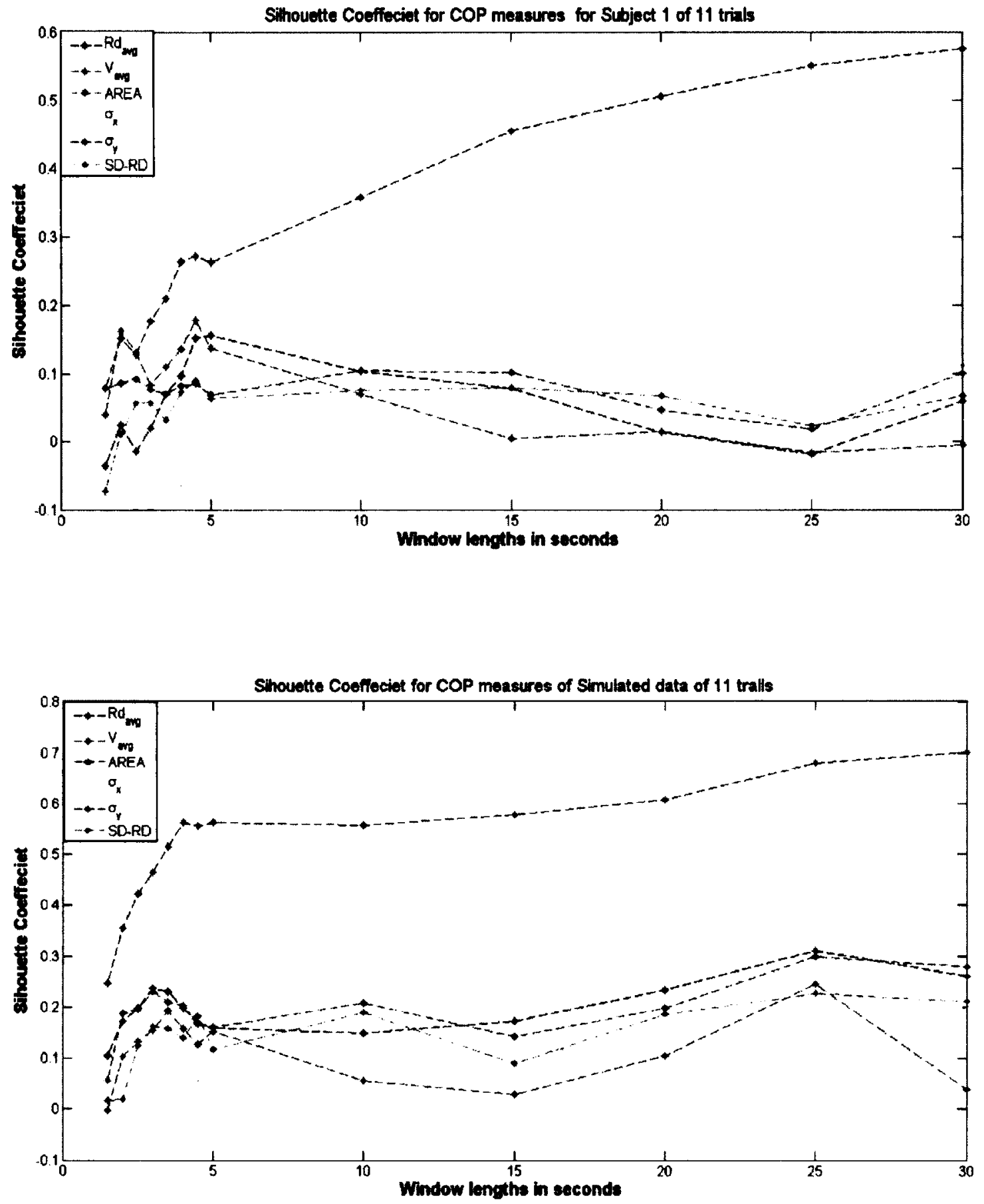

Figure 5.14: Silhouette coefficient for six COP measures of subjects 1 and 2 for 11 trials for different window lengths ( $1.5 \mathrm{~s}, 2.0 \mathrm{~s}, 2.5 \mathrm{~s}, 3.0 \mathrm{~s}, 3.5 \mathrm{~s}, 4.0 \mathrm{~s}, 4.5 \mathrm{~s}, 5.0 \mathrm{~s}, 10 \mathrm{~s}, 15 \mathrm{~s}, 20 \mathrm{~s}, 25 \mathrm{~s})$. 

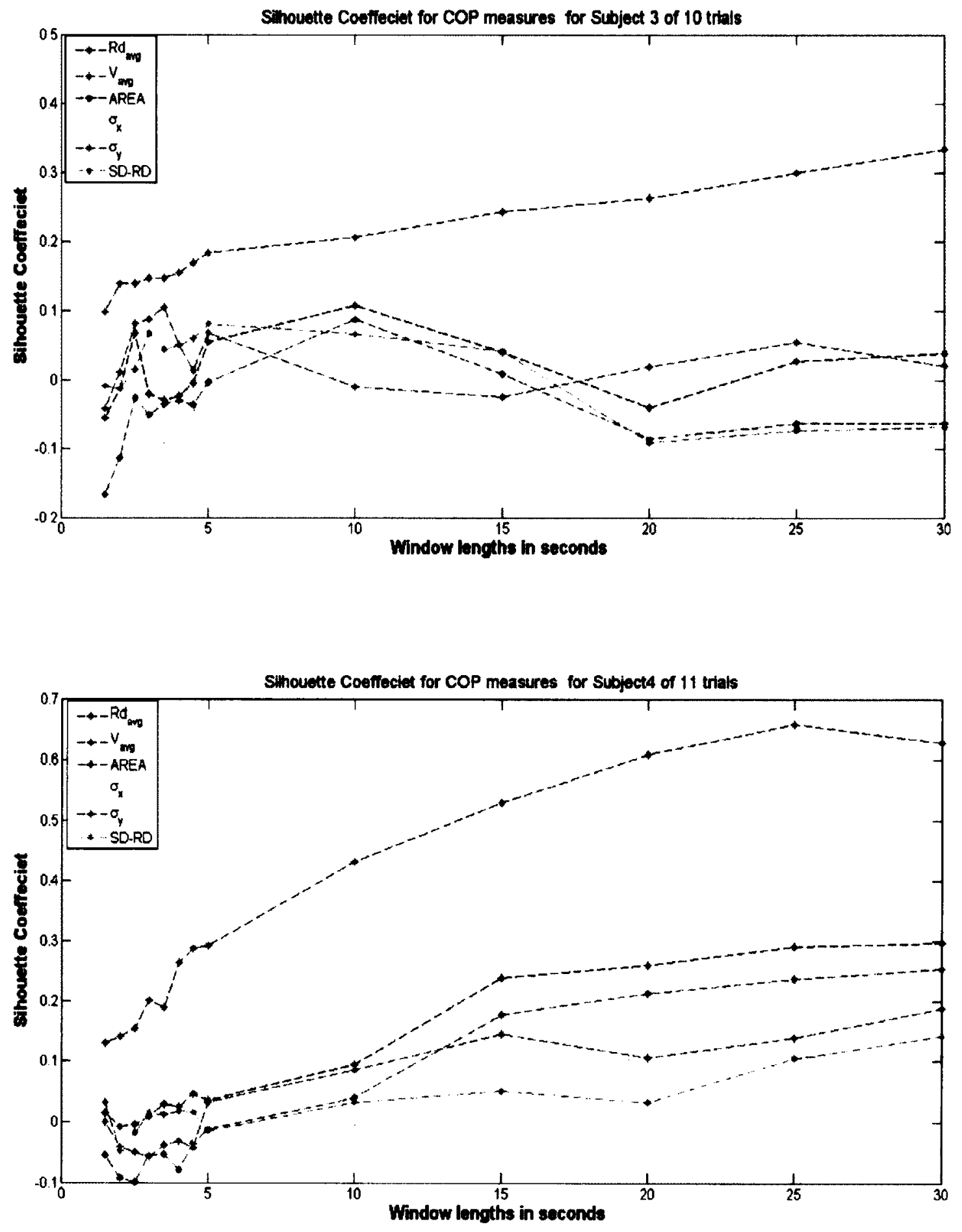

Figure 5.15: Silhouette coefficient for six COP measures of subjects 3 and 4 for 11 trials for different window lengths ( 1.5 s, 2.0 s, 2.5 s, 3.0 s, 3.5 s, 4.0 s, 4.5 s, 5.0 s, 10 s, 15 s, 20 s, 25 s). 

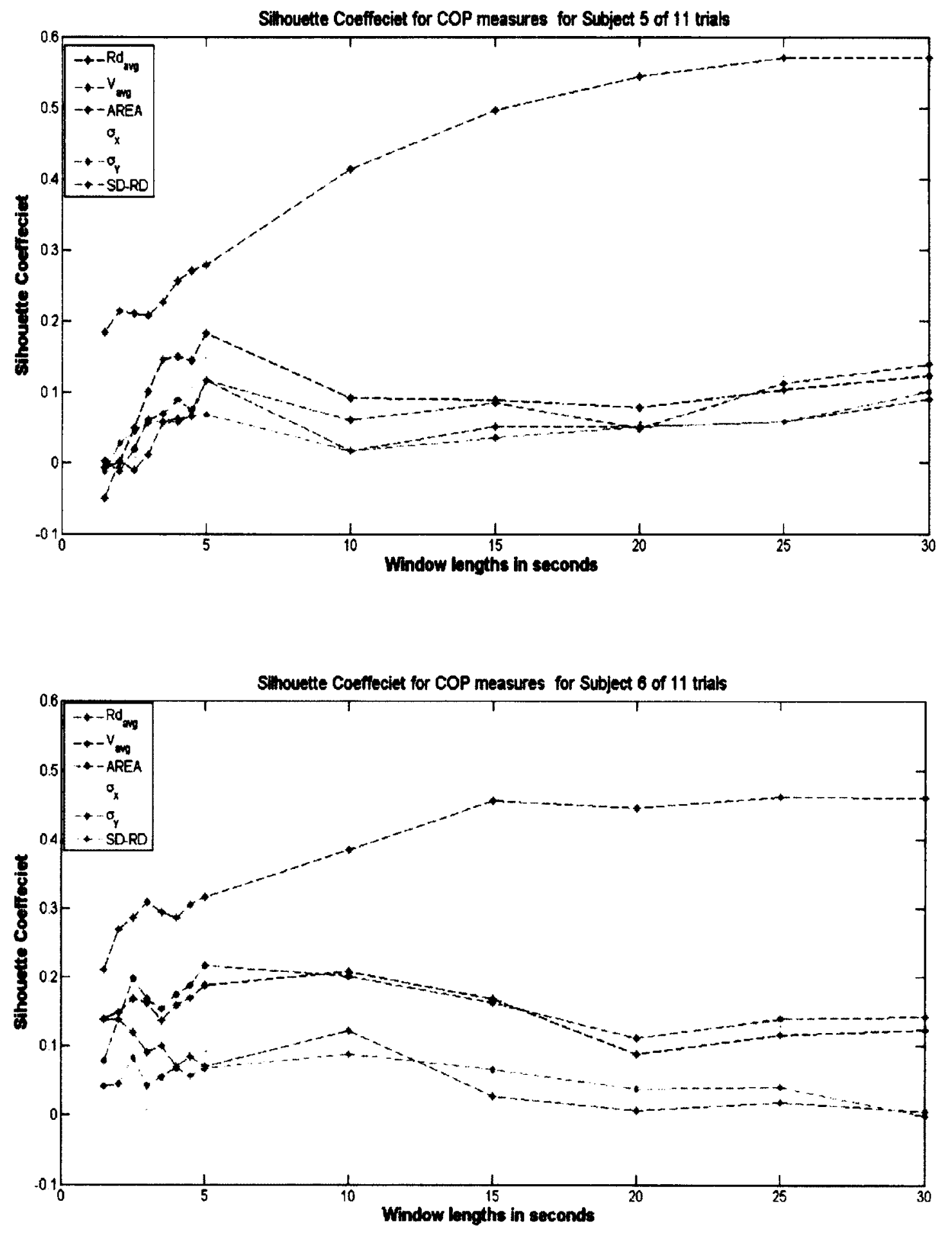

Figure 5.16: Silhouette coefficient for six COP measures of subjects 5 and 6 for 11 trials for different window lengths ( $1.5 \mathrm{~s}, 2.0 \mathrm{~s}, 2.5 \mathrm{~s}, 3.0 \mathrm{~s}, 3.5 \mathrm{~s}, 4.0 \mathrm{~s}, 4.5 \mathrm{~s}, 5.0 \mathrm{~s}, 10 \mathrm{~s}, 15 \mathrm{~s}, 20 \mathrm{~s}, 25 \mathrm{~s})$. 

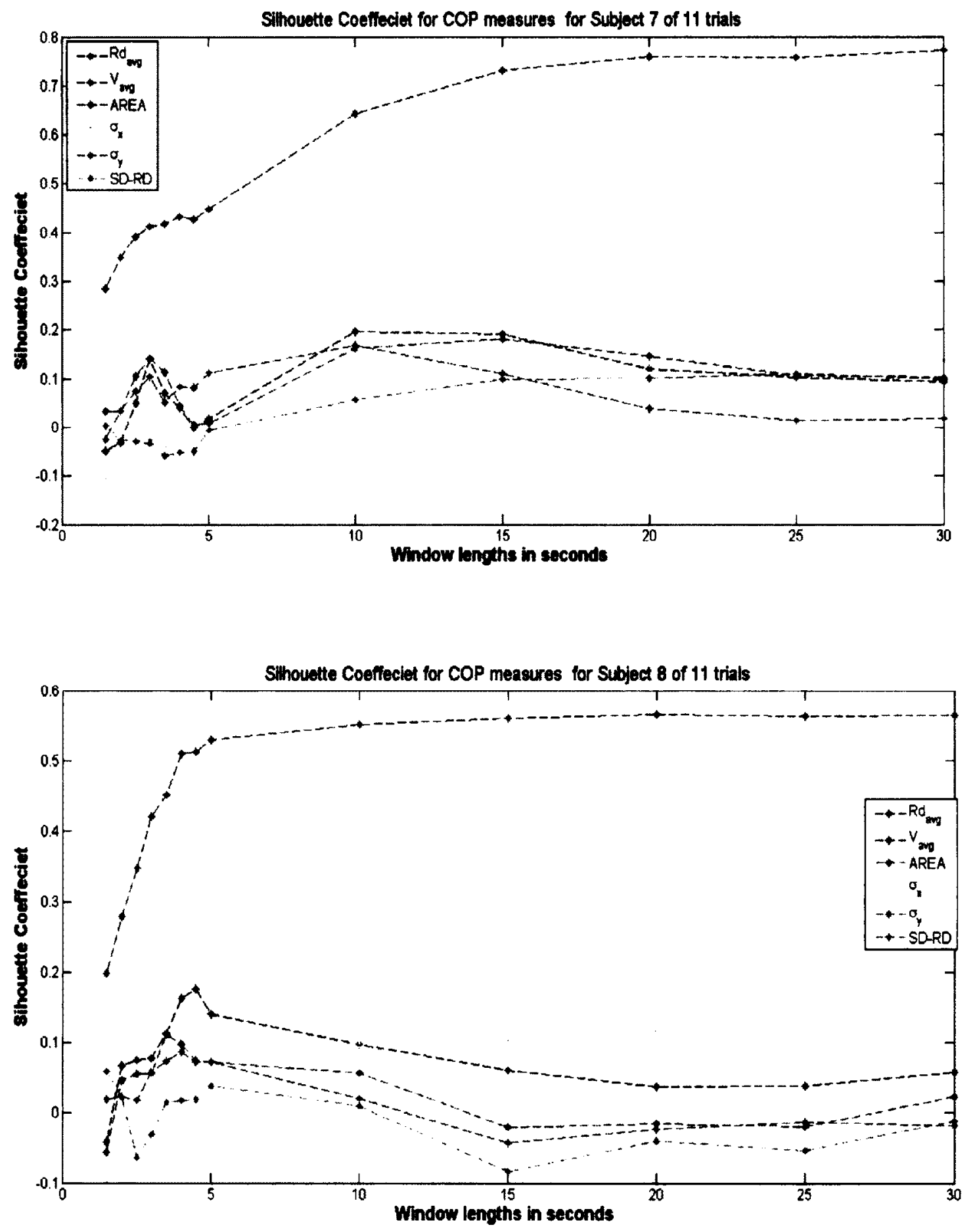

Figure 5.17: Silhouette coefficient for six COP measures of subjects 7 and 8 for 11 trials for different window lengths (1.5 s, 2.0 s, 2.5 s, 3.0 s, 3.5 s, 4.0 s, 4.5 s, 5.0 s, 10 s, 15 s, 20 s, 25 s). 


\subsection{Discussion}

The present study investigated effects of analysis window lengths on six COP measures. Results for the simulated data suggest that the performance of COP measures increased with increasing analysis window length. This implies that window length affects the performance of the COP measures.

Experimental results also revealed that the length of the analysis window does affect the COP measures; it was evident from Figure 5.8 to 5.10 and from the performance analysis of COP measures as a function of window length for both simulated Figure 5.4 and experimental data Figure 15 to 18 . The Figure 5.8 to 5.10 show values of $\mathrm{COP}$ measures increased with increased in duration except average velocity which decreased slightly. The increase in the variability of COP measure can be the result of strategies adopted by the subjects for balancing with the increasing window length. It can be the possibility that the subjects may move slightly and begin to sway around anther home base. or has chosen more than one home bases to sway around as the time increases (Clair \& Riach, 1996).

LeClair and Riach (Clair \& Riach, 1996)compared COP measures, standard deviation $\mathrm{COP}_{\mathrm{x}}$, standard deviation $\mathrm{COP}_{\mathrm{y}}$, average velocity of COP, standard deviation $\mathrm{F}_{\mathrm{x}}$, standard deviation $F_{y}$ and standard deviation $F_{z}$, collected at differing time durations $(10,20,30$, 45 and $60 \mathrm{~s}$ ) during four different visual and stance conditions. The study found that COP measures increased (standard deviation $\mathrm{COP}_{\mathrm{x}}$, standard deviation $\mathrm{COP}_{\mathrm{y}}$ ), while $\mathrm{COP}$ average velocity decreased with increased test duration. 
LeClair and Riach demonstrated also window length is important in the test-retest reliability of COP measure, optimum test-retest reliability was obtained at that $20 \mathrm{~s}$ and $30 \mathrm{~s}$ window length and $\mathrm{COP}$ velocity was reliable in retest situation, (Clair \& Riach, 1996).

In the present study the performance of COP measures $\left(R D_{\text {avg }}, V_{\text {avg }}, A R E A, \sigma_{x}, \sigma_{y}\right.$ and $S D_{-} R D$ ) increased with the increase in the window length in most of the cases.. However the slope analyses of performance of simulated COP measures suggest that $30 \mathrm{~s}$ or larger window length required for reliable COP measures. For diagnostic purposes in the clinical environment 30 s or larger windows could be used to have reliable COP measures.

The better performance of COP average velocity were consistent for smaller windows, which suggest that average velocity's performance better than other COP measures, as it exhibits a higher silhouette coefficient suggesting less variability (higher repeatability) between the trials, making the different stability conditions more discernible

\subsection{Conclusion}

The study demonstrated that the analysis window size is important in the consistency and validity of COP measures. Conventionally, COP measures analyzed for 30-60s seconds or longer. There are trade-offs associated with the length of the analysis window; a longer 
analysis window size can obscure transitional effects (e.g., muscle fatigue/recovery), while a small window size contains less data and therefore suffers from higher estimation variability. Recording COP data for a longer period of time can also fatigue the person. Fatigue increases the burden on the postural control system by increasing the frequency of actions required by the control system to regulate the upright stance compared to nonfatigued circumstances (Corbeil et al. 2003).

Results demonstrated that the selection of analysis window length does affect the COP measure. The results suggest that average velocity of COP is most repeatable between the trials amongst the measures investigated. 


\section{Thesis Summary and Future Recommendations}

\subsection{Summary}

Static posturography provides a quantitative method to assess postural stability and is easy to conduct (Browne \& O'Hare, 2001). Postural stability analysis is useful in a variety of applications, such as assessing the risk of falls for the elderly population and investigating neuromuscular disorders. In static posturography, a force platform is used to measure the center-of-pressure (COP) during a static stance; variations in the COP are used to quantify postural stability (lower variation in COP, implies higher postural stability). In the thesis, methods to assess the performance of COP measures, as well as the effects of analysis window length on COP measures presented and evaluated. First, these methods are applied on simulated COP measures and then on experimentally acquired COP measures. The simple inverted pendulum model for human upright stance posture was used to simulate COPs while eight human subjects were used to acquire the experimental data.

The six conventional COP measure were average COP velocity, average radial displacement, area of the $95 \%$ confidence ellipse, standard deviation of radial displacement, standard deviation of COPx (medio-lateral) and standard deviation of COPy (antero-posterior). These measures were computed for four different stability conditions: 1) feet together, eyes open, 2) feet together, eyes closed, 3) single leg, eyes open, and 4) single leg, eyes closed. 
A good stability measure should have low variance within a given stability condition and as well high variance (discernability) between different stability conditions. Results of the performance analysis demonstrated that $V_{\text {avg }}$ is the best measure compared to the other COP measures examined. This implies that the values of $V_{\text {avg }}$ are less variable for a given stability condition and discernible for different stability conditions.

The second contribution of the thesis is to examine the effect of analysis window length on the COP measures. COP measures are computed by using smaller analysis windows, and the effects are evaluated using statistical analysis. This investigation was performed on data for both simulated and experimentally acquired COP measures. From the results, it was evident that the selection of analysis window does affect all COP measures except largely average velocity.

The findings from the research can assist in guiding future research to develop more strategies, so that postural stability measurement could be included in the routine physical check, for early detection of instability, to reduce the risk of fall in the elderly population as well as individuals with balance disorders due to other pathologies and enhance the quality of life. Thus early intervention can help us not only to reduce the risk of falling and also the health related, and social issues.

\subsection{Recommendations for Future Work}

The future work can address the following problems.

\section{Non-conventional COP measure of static posturography}


More recent COP measures include approximate entropy (Cavanaugh et al., 2005), sample entropy (Donker, Roerdink, Greven, \& Beek, 2007), and Lyapunov exponent (Donker et al., 2007). The approximate (Cavanaugh et al., 2005) and sample entropy (Donker et al., 2007), are used to measure the regularities of the COP time series. The largest Lyapunov exponent (Donker et al., 2007) is a measure of local stability of a dynamical system. There is room for research to find out which of these measures may have better performance in term of low intra-stability condition variance and high interstability conditions variance (discernability). The method developed in this thesis for performance analysis could be applied to assess the performance of non-conventional COP measures. Additional research is required to explore other good measures, reliable and easier to conduct in the clinical environment for diagnostic purposes.

\section{Performance of dynamic posturographic measures}

Several studies have demonstrated that posturography is a useful tool to assess balance problems for patients with neurologic disorders. Dynamic posturography is used to increase the test sensitivity for balance assessment (Baloh, Jacobson, Beykirch, \& Honrubia, 1998). The performance of dynamic posturographic measures can be evaluated to find a better measure.

\section{Testing the developed methodology on clinical data}

The work presented in the thesis provides methods to compare the performance of different COP measures. Research could be expanded to test the methodology developed, on clinical data of the patients using repeated trials over an extended period of time during the treatment. 


\section{Establishing a standard metrics}

More research and data are required to extend the work for the establishment of standard metrics to assess the postural stability (Buckley, 1989). This is so that the postural stability measurement can be included in the routine physical check up for early detection of risk of fall in the elderly population or any balance disorder. 


\section{Appendix A: Box Plots of COP Measures}

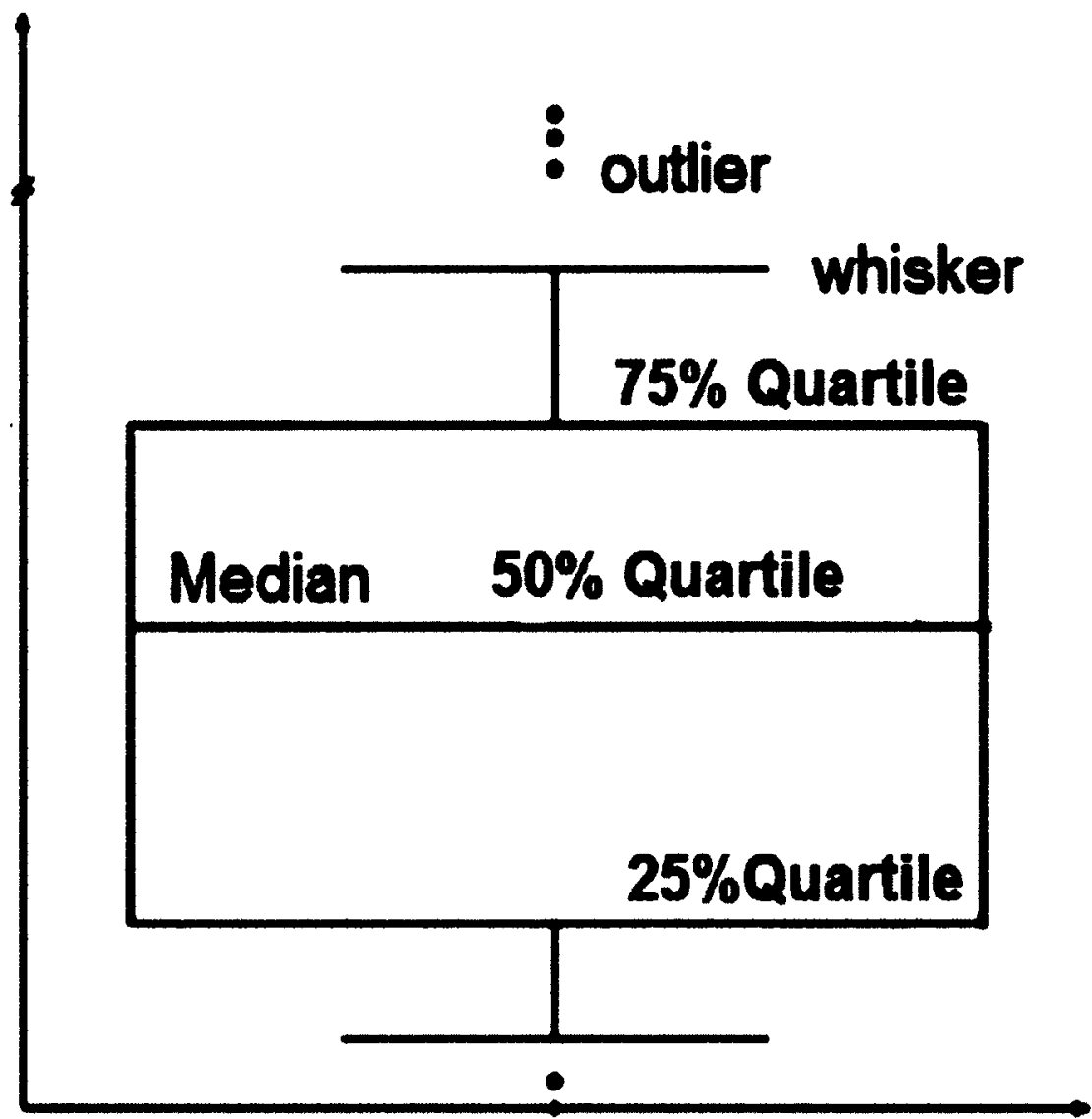

Figure A.1: Box plot demonstrates variation of data. A high-variation box plot would be taller. The horizontal line in box is the median, the ends of the box are the upper and lower quartiles, and the vertical lines are the full range of values in the data. 

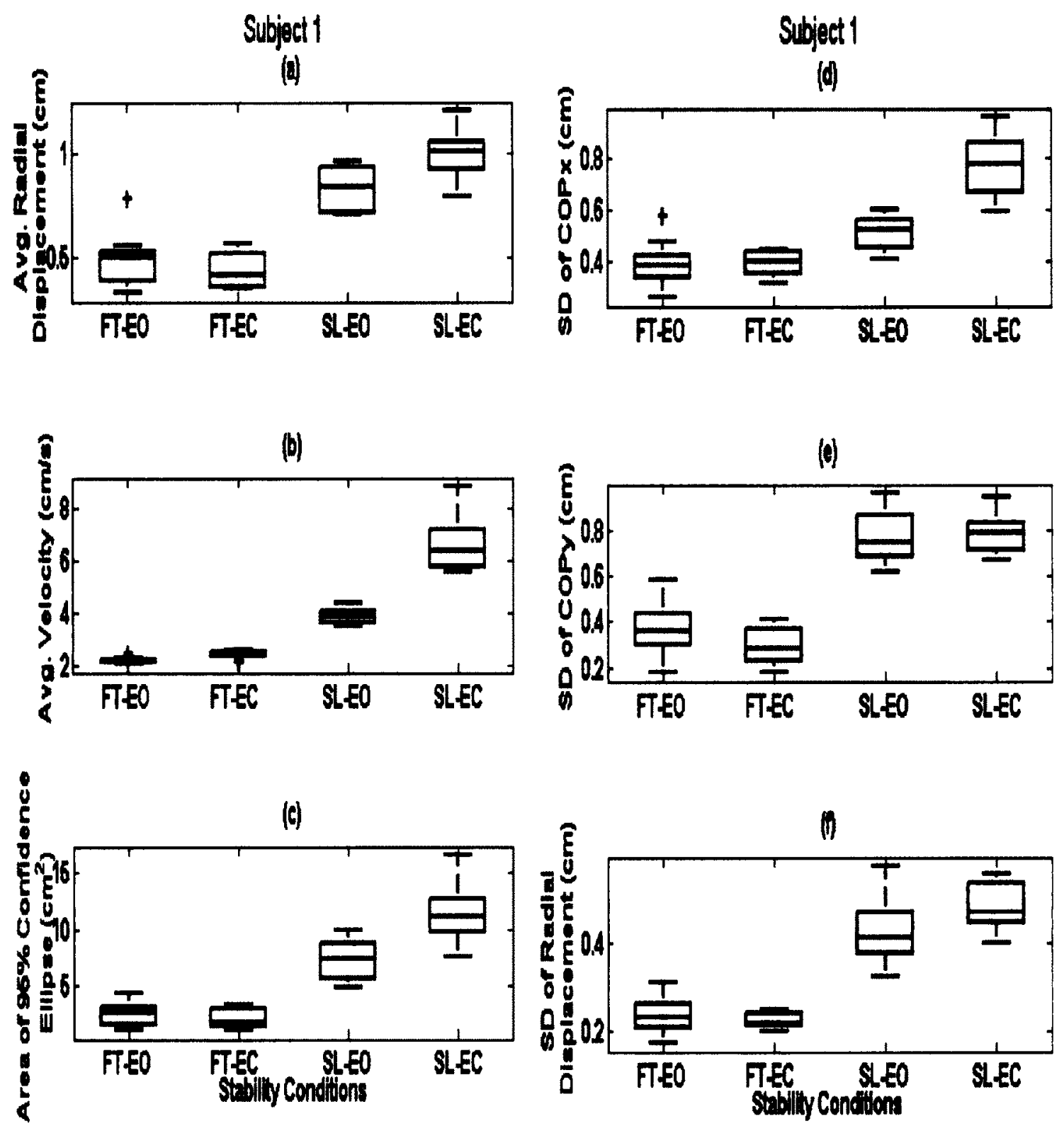

Figure A.2: Box plot of clusters of conventional COP measures for the 11 trials of subject 1. 

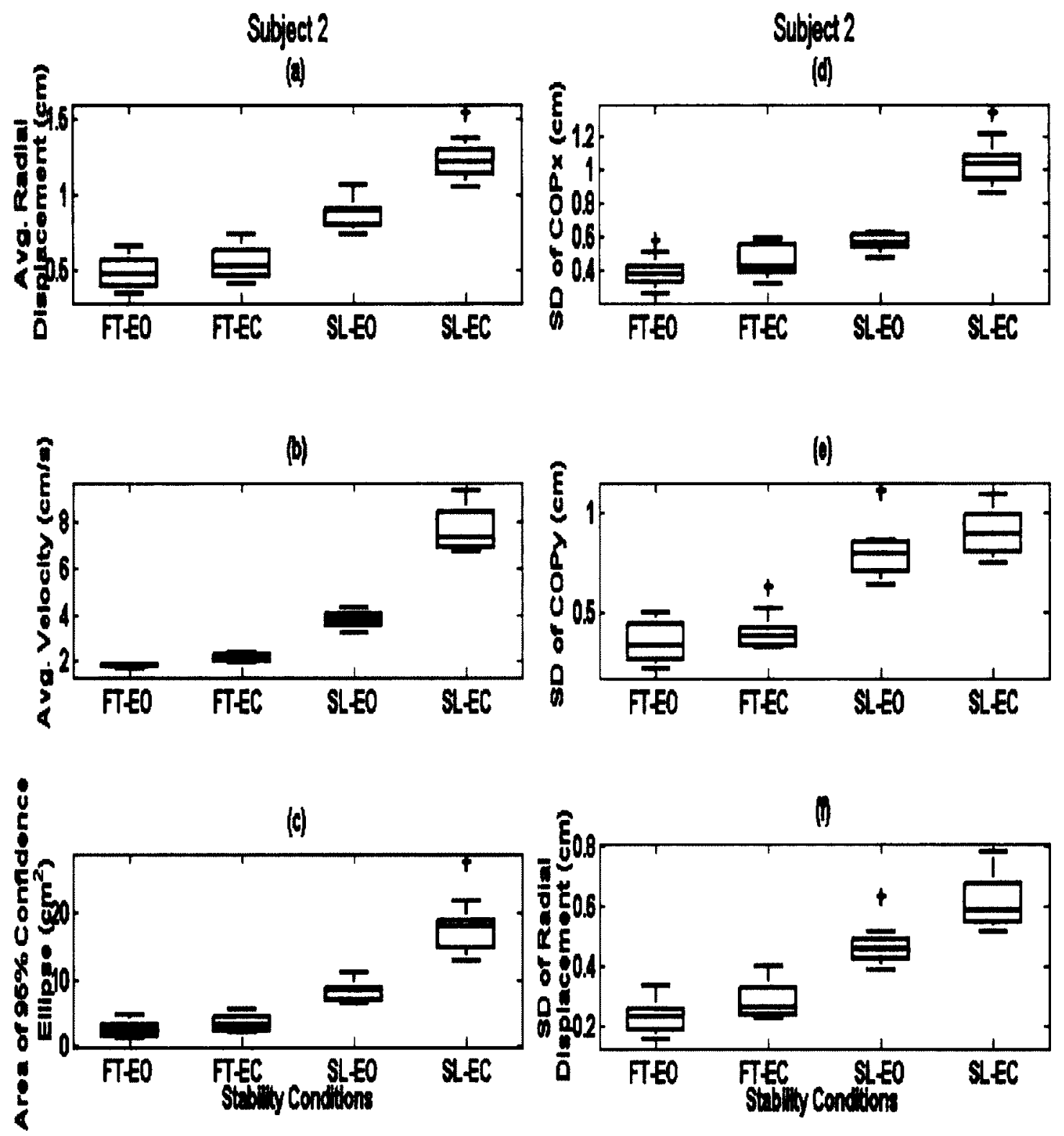

Figure A.3: Box plot of clusters of conventional COP measures for the 11 trials of subject 2. 

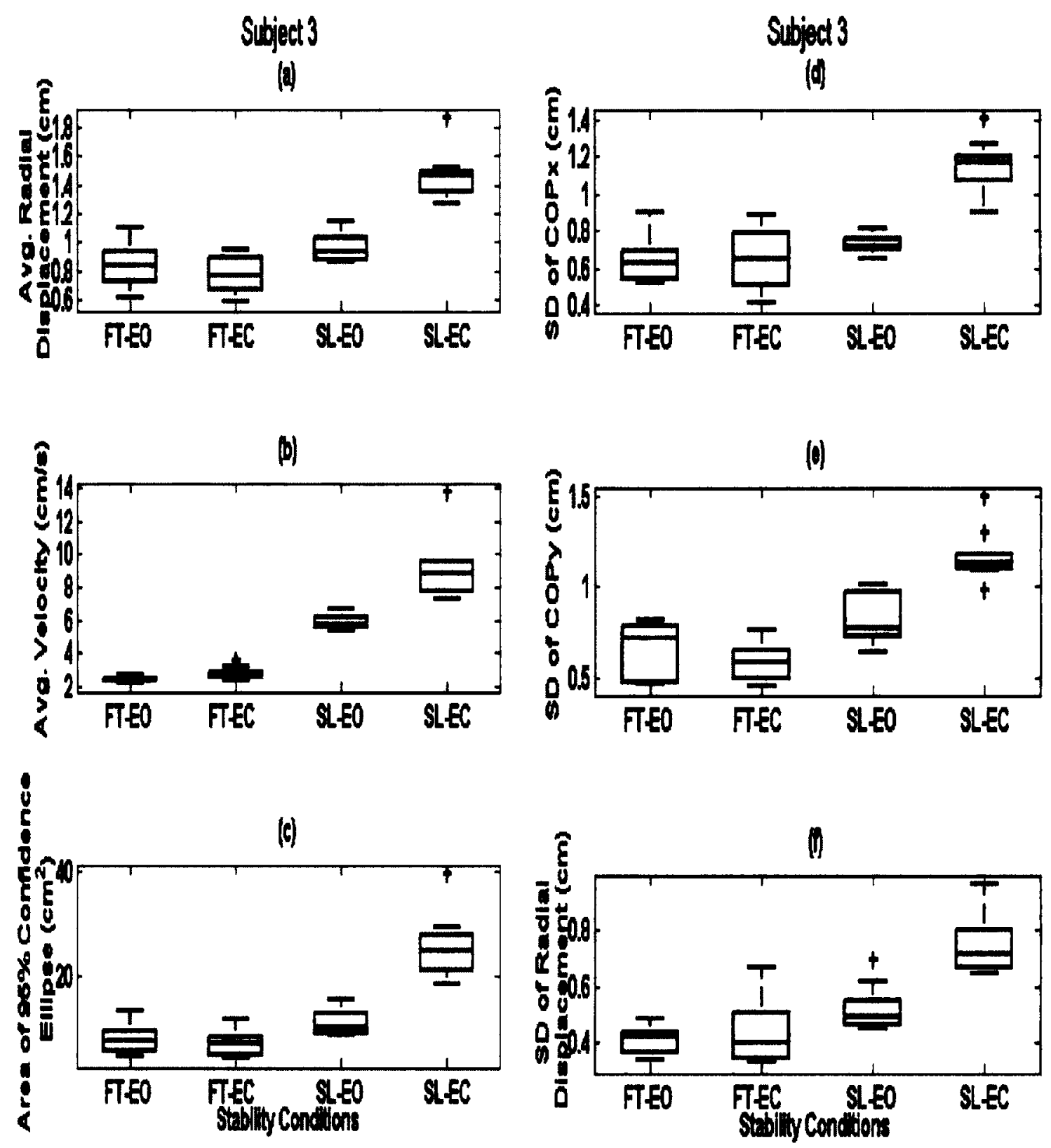

Figure A.4: Box plot of clusters of conventional COP measures for the 10 trials of subject 3. 

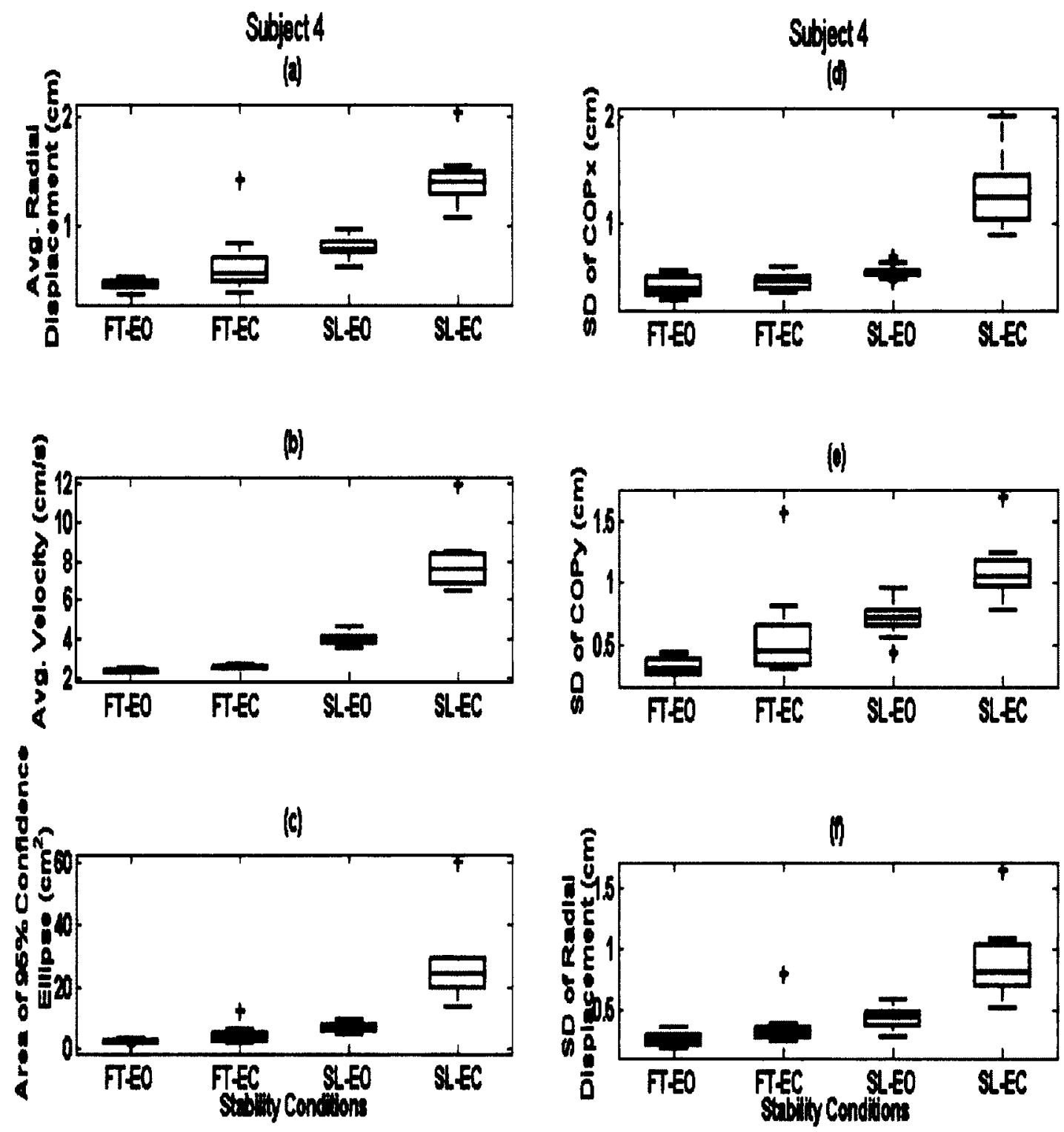

Figure A.5: Box plot of clusters of conventional COP measures for the 11 trials of subject 4. 

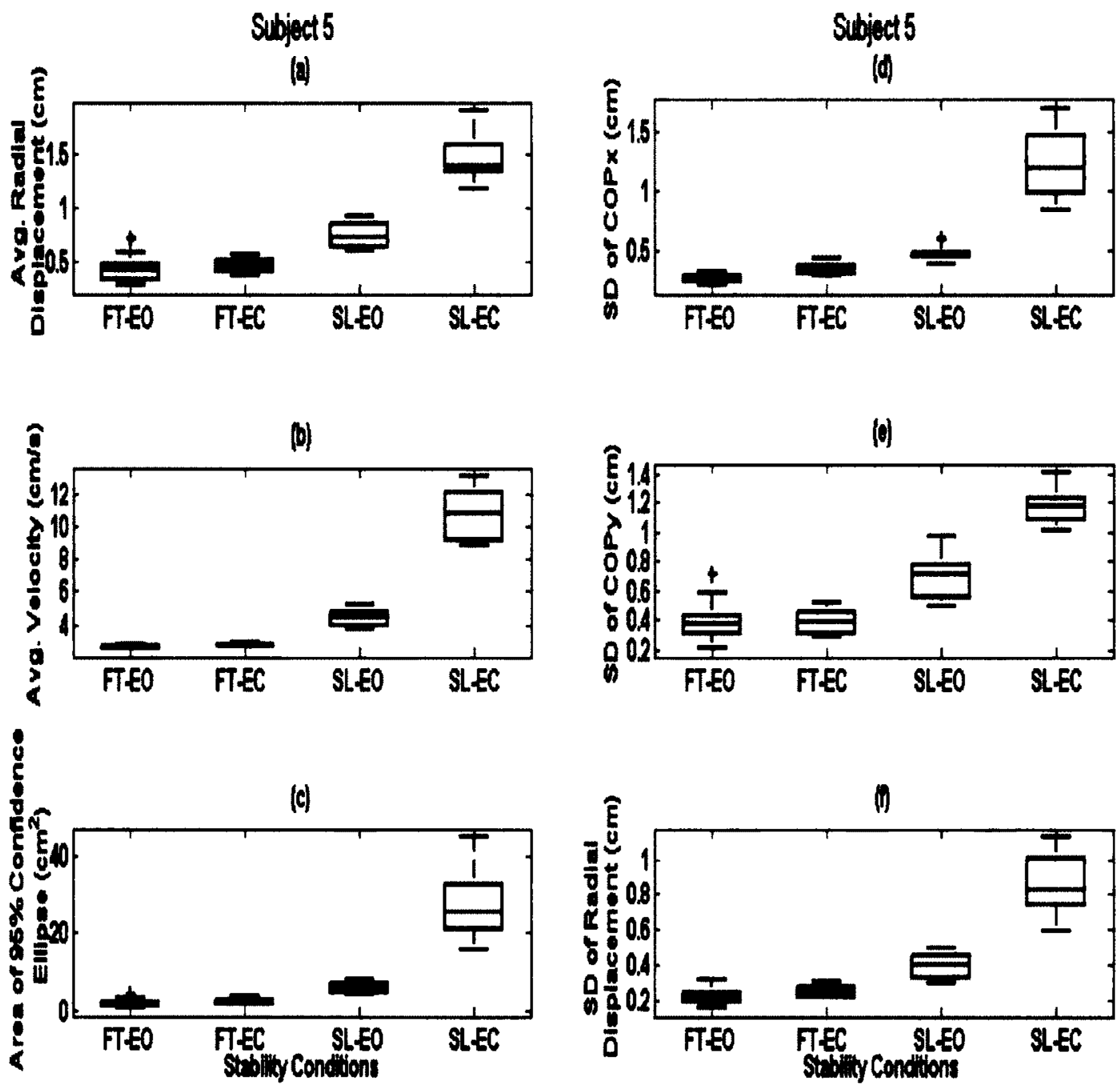

Figure A.6: Box plot of clusters of conventional COP measures for the 11 trials of subject 5. 

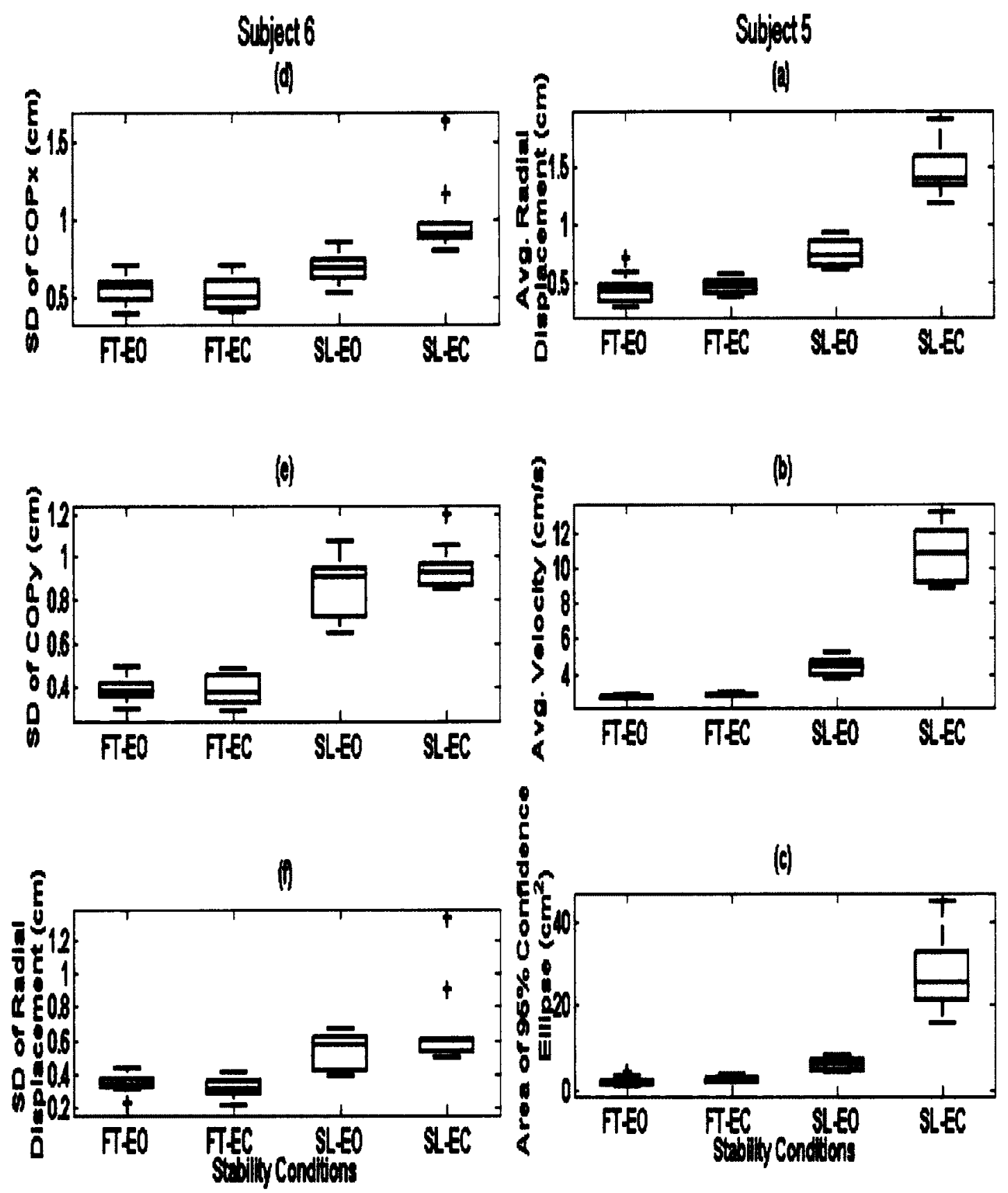

Figure A.7: Box plot of clusters of conventional COP measures for the 11 trials of subject 6. 

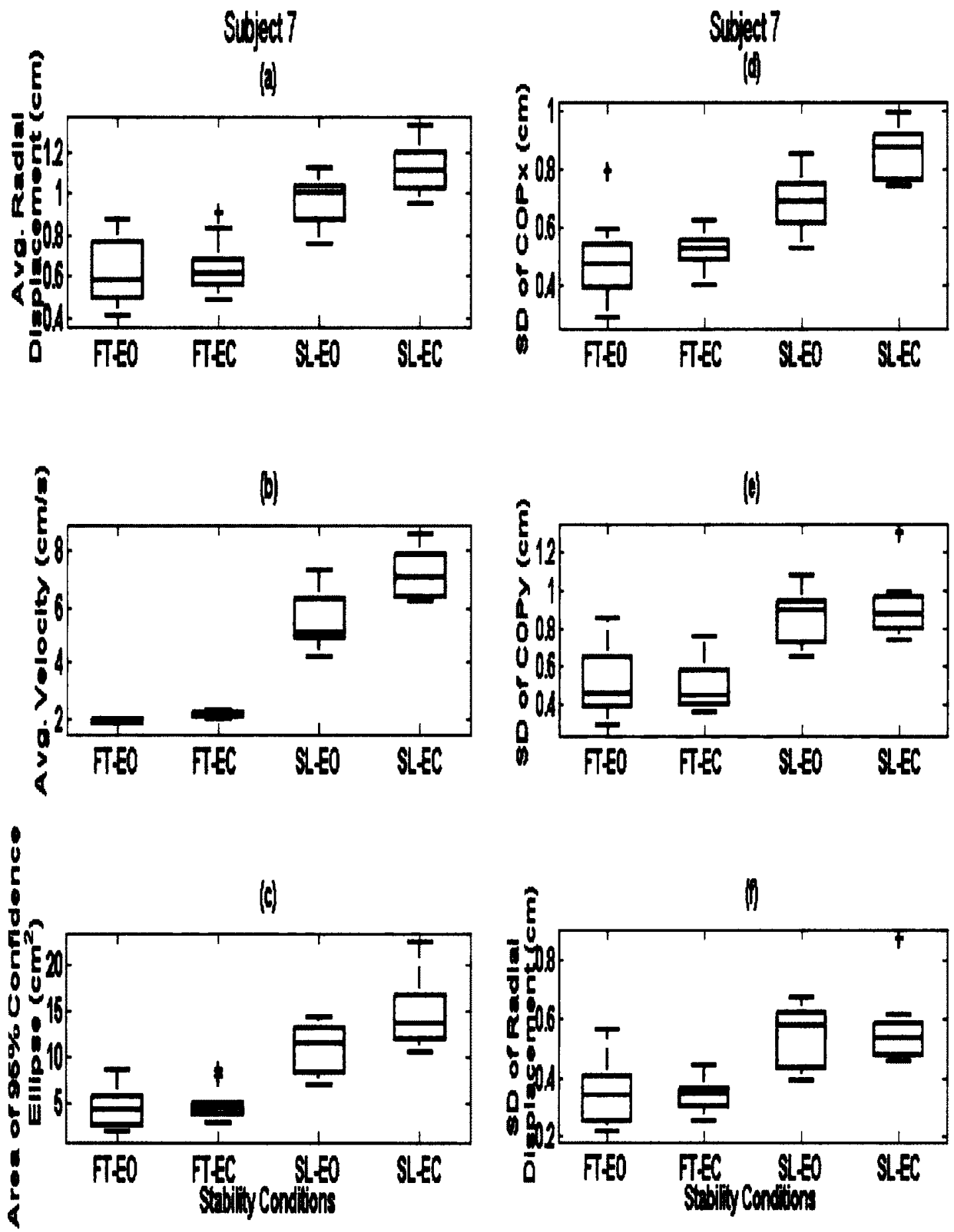

Figure A.8: Box plot of clusters of conventional COP measures for the 11 trials of subject 7. 

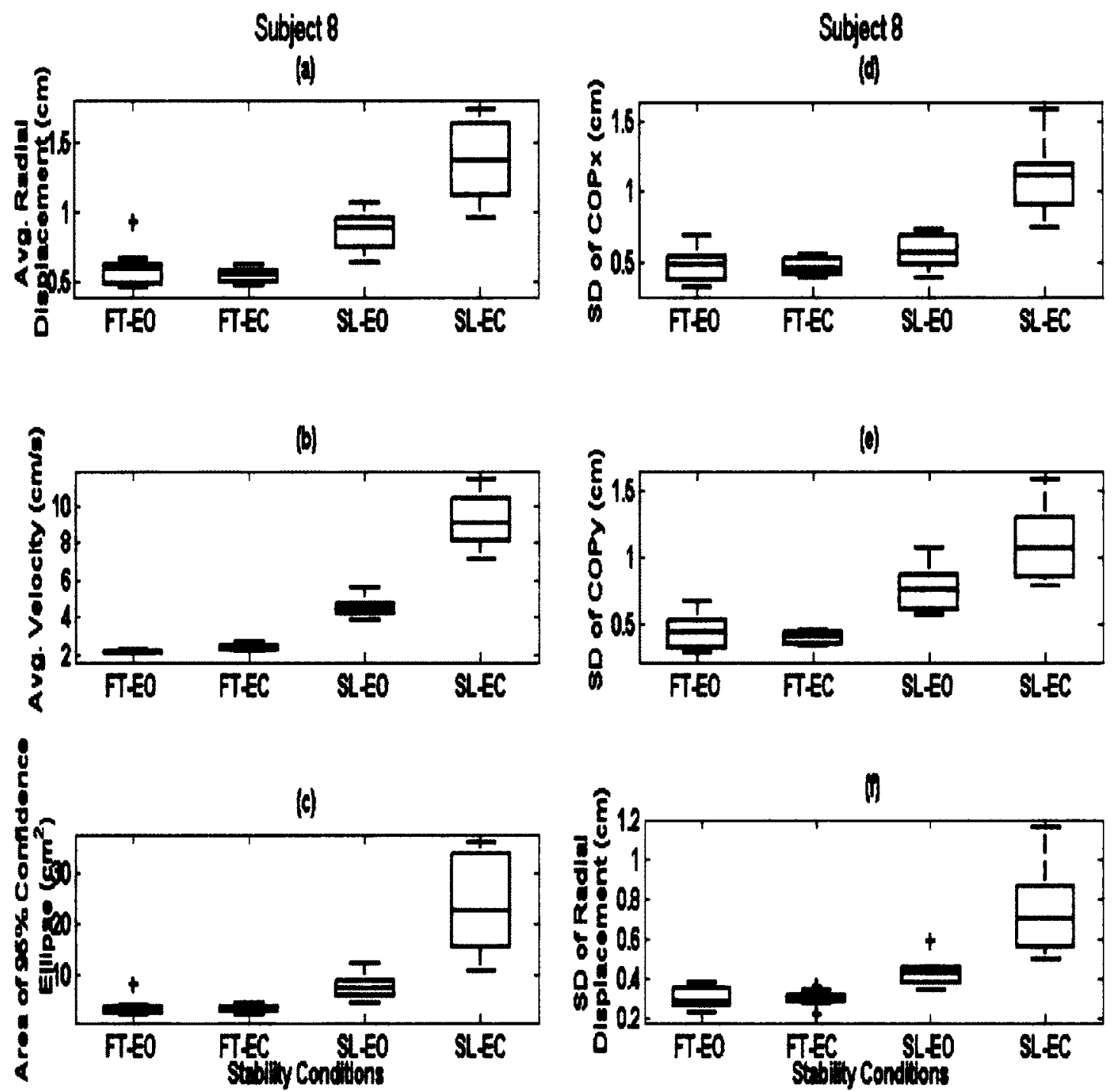

Figure A.9: Box plot of clusters of conventional COP measures for the 11 trials of subject 8.

Table A.1: COP measures for pairwise comparison.

\begin{tabular}{|c|c|}
\hline $\begin{array}{cc}c 0 \\
\text { meanure }\end{array}$ & 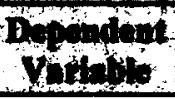 \\
\hline 1 & $V_{\text {avg }}$ \\
\hline 2 & $R D_{a v g}$ \\
\hline 3 & AREA \\
\hline 4 & $\sigma_{x}$ \\
\hline 5 & $\sigma_{y}$ \\
\hline 6 & SD_RD \\
\hline
\end{tabular}


Table A.2: Pairwise comparison of COP measures.

\begin{tabular}{|c|c|c|c|c|c|c|}
\hline \multirow{2}{*}{$\begin{array}{l}\text { (I) COP } \\
\text { mengure }\end{array}$} & \multirow{2}{*}{ (J) COP } & \multirow{2}{*}{ 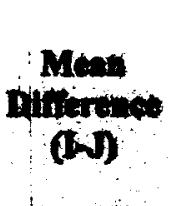 } & \multirow{2}{*}{$\begin{array}{l}\text { Std. } \\
\text { Errot }\end{array}$} & \multirow[t]{2}{*}{ ste" } & \multicolumn{2}{|c|}{$\begin{array}{l}93 \% \text { Confidence } \\
\text { Intervel tor } \\
\text { Dingerede }\end{array}$} \\
\hline & & & & & $\begin{array}{l}\text { Lower } \\
\text { Eonud }\end{array}$ & Deper \\
\hline \multirow{5}{*}{1} & 2 & $-0.351^{*}$ & 0.039 & 0.001 & -0.520 & -0.182 \\
\hline & 3 & 0.017 & 0.012 & 1.000 & -0.034 & 0.069 \\
\hline & 4 & 0.039 & 0.037 & 1.000 & -0.120 & 0.198 \\
\hline & 5 & 0.092 & 0.024 & 0.096 & -0.012 & 0.196 \\
\hline & 6 & 0.081 & 0.027 & 0.322 & -0.039 & 0.201 \\
\hline \multirow{5}{*}{2} & 1 & $0.351^{*}$ & 0.039 & 0.001 & 0.182 & 0.520 \\
\hline & 3 & $0.369^{*}$ & 0.033 & 0.000 & 0.223 & 0.514 \\
\hline & 4 & $0.390^{*}$ & 0.044 & 0.001 & 0.198 & 0.582 \\
\hline & 5 & $0.443^{*}$ & 0.052 & 0.001 & 0.218 & 0.667 \\
\hline & 6 & $0.432^{*}$ & 0.032 & 0.000 & 0.293 & 0.571 \\
\hline \multirow{5}{*}{3} & 1 & -0.017 & 0.012 & 1.000 & -0.069 & 0.034 \\
\hline & 2 & $-0.369^{\circ}$ & 0.033 & 0.000 & -0.514 & -0.223 \\
\hline & 4 & 0.022 & 0.031 & 1.000 & -0.114 & 0.158 \\
\hline & 5 & 0.074 & 0.029 & 0.593 & -0.054 & 0.202 \\
\hline & 6 & 0.064 & 0.021 & 0.293 & -0.028 & 0.155 \\
\hline \multirow{5}{*}{4} & 1 & -0.039 & 0.037 & 1.000 & -0.198 & 0.120 \\
\hline & 2 & $-0.390^{\circ}$ & 0.044 & 0.001 & -0.582 & -0.198 \\
\hline & 3 & -0.022 & 0.031 & 1.000 & -0.158 & 0.114 \\
\hline & 5 & 0.053 & 0.041 & 1.000 & -0.126 & 0.231 \\
\hline & 6 & 0.042 & 0.023 & 1.000 & -0.057 & 0.141 \\
\hline \multirow{5}{*}{5} & 1 & -0.092 & 0.024 & 0.096 & -0.196 & 0.012 \\
\hline & 2 & $-0.443^{*}$ & 0.052 & 0.001 & -0.667 & -0.218 \\
\hline & 3 & -0.074 & 0.029 & 0.593 & -0.202 & 0.054 \\
\hline & 4 & -0.053 & 0.041 & 1.000 & -0.231 & 0.126 \\
\hline & 6 & -0.011 & 0.033 & 1.000 & -0.155 & 0.133 \\
\hline \multirow{5}{*}{6} & 1 & -0.081 & 0.027 & 0.322 & -0.201 & 0.039 \\
\hline & 2 & $-0.432^{\circ}$ & 0.032 & 0.000 & -0.571 & -0.293 \\
\hline & 3 & -0.064 & 0.021 & 0.293 & -0.155 & 0.028 \\
\hline & 4 & -0.042 & 0.023 & 1.000 & -0.141 & 0.057 \\
\hline & 5 & 0.011 & 0.033 & 1.000 & -0.133 & 0.155 \\
\hline
\end{tabular}




\section{Appendix B: Plots of Simulated Data}

(a)

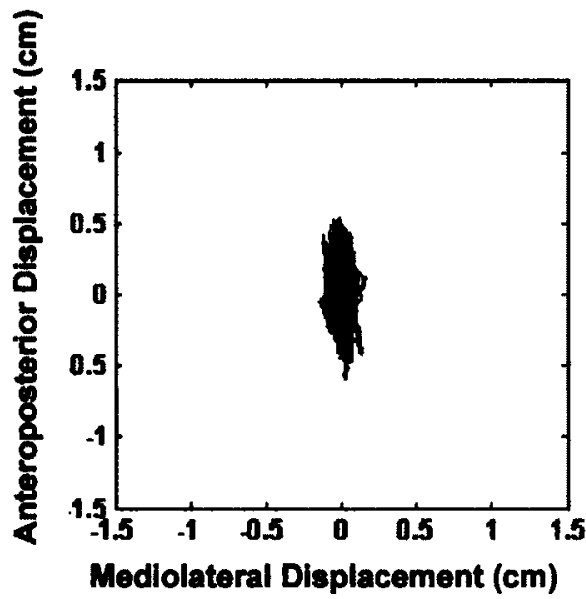

(b)

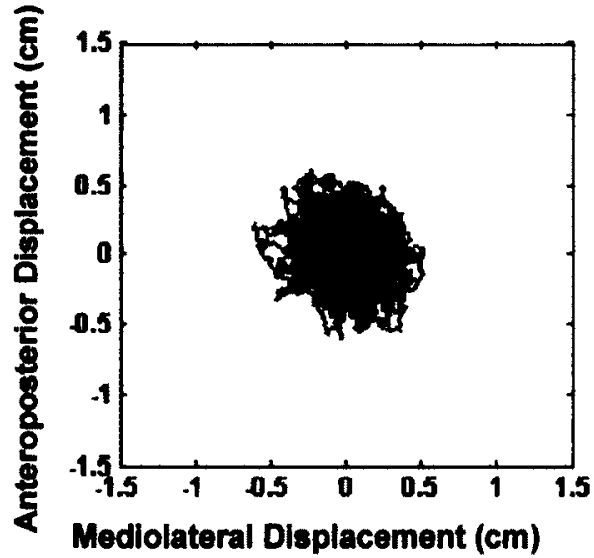

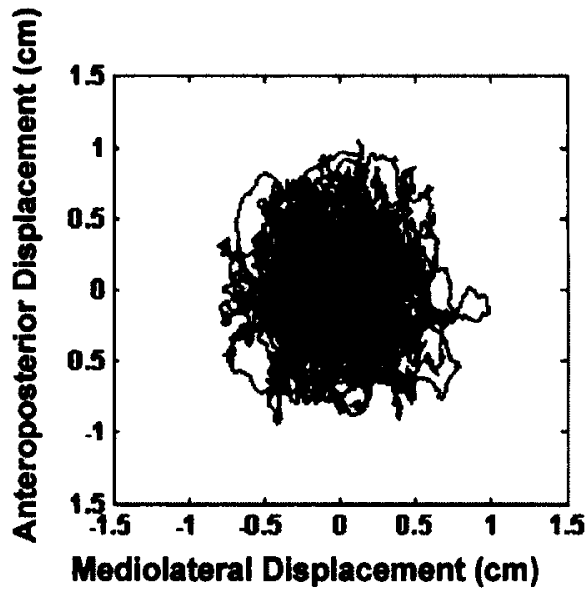

(c)

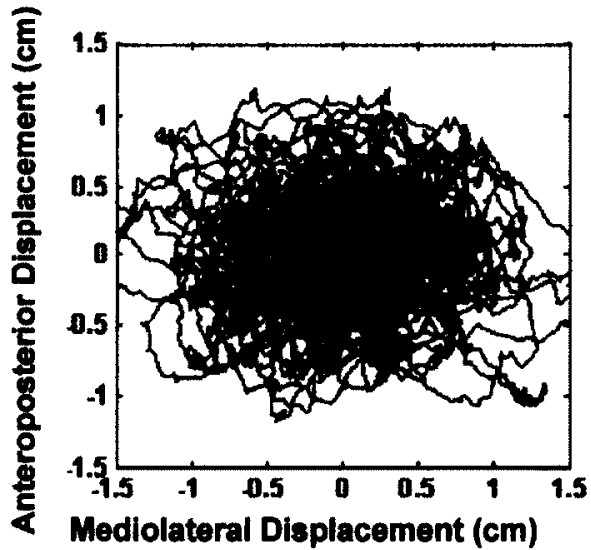

(d)

Figure B.1: Posturograph of for 1 of the 100 simulated trials (a) Control, (b) LowSP, (c) MedSP and (d) HighSP stability conditions of simulated COP.
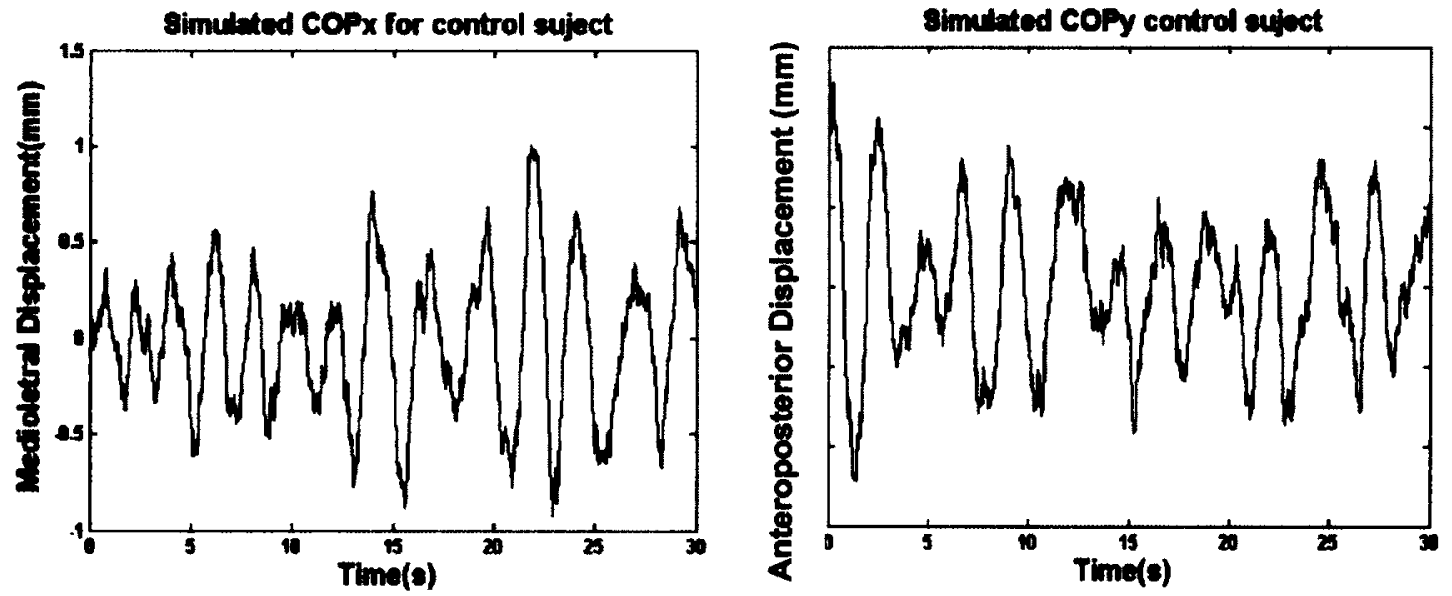

Figure B.2: Plots of COP time series of simulated data for control stability condition. 


\section{Appendix C: Statistical Analysis of Effect of Analysis Window Length}

\section{C.1 Slope Calculations}

The derivative $f^{\prime}\left(t_{i}\right)$ can be interpreted geometrically as the slope of the function $f$ at any point $t_{i}$ where the slope is defined as the slope of the tangent line at that point.

The numerical differentiation method was used to estimate the derivative of a function at a point $t_{i}$ by approximating the slope of the tangent line at $t_{i}$ using other known values of the function in the neighborhood of $t_{i}$. There are many methods to calculate the slope, in the present study the forward difference first degree approximation was used to calculate the slope. Then the slope is defined as follow:

$$
f^{\prime}\left(x_{i}\right)=\frac{f\left(x_{i+1}\right)-f\left(x_{i}\right)}{x_{i+1}-x_{i}} .
$$

Percentage drop in slope from its maximum value $f^{\prime}\left(x_{i}\right)_{\max }$ was calculated as follow

$$
\text { Percent decrease in slope }=\left(1-\frac{f^{\prime}\left(x_{i}\right)}{f^{\prime}\left(x_{i}\right)_{\max }}\right) * 100 .
$$


Table C.1: Pairwise comparison with Sidak correction for FT-EO of 11 trials for subjects 1.

\begin{tabular}{|c|c|c|c|c|c|c|}
\hline \multicolumn{7}{|c|}{ Pairwise comparison } \\
\hline \multirow{2}{*}{ Window Pair } & \multicolumn{5}{|c|}{ Sig. (2-tailed) for S1 FT-EO } \\
\cline { 2 - 7 } & RDavg & $V_{\text {avg }}$ & AREA & SD_RD & $\sigma_{x}$ & $\sigma_{y}$ \\
\hline $30 \mathrm{~s}-1.5 \mathrm{~s}$ & 0.001 & 1.000 & 0.002 & 0.005 & 0.057 & 0.001 \\
\hline $30 \mathrm{~s}-2.0 \mathrm{~s}$ & 0.071 & 1.000 & 0.005 & 0.002 & 0.109 & 0.003 \\
\hline $30 \mathrm{~s}-2.5 \mathrm{~s}$ & 0.160 & 1.000 & 0.094 & 0.009 & 0.141 & 0.001 \\
\hline $30 \mathrm{~s}-3.0 \mathrm{~s}$ & 0.075 & 1.000 & 0009 & 0.003 & 0.266 & 0.004 \\
\hline $30 \mathrm{~s}-3.5 \mathrm{~s}$ & 0.177 & 1.000 & 0.00 & 0.008 & 0.428 & 0.009 \\
\hline $30 \mathrm{~s}-4.0 \mathrm{~s}$ & 0.347 & 1.000 & 0.008 & 0.009 & 0.320 & 0.009 \\
\hline $30 \mathrm{~s}-4.5 \mathrm{~s}$ & 0.327 & 1.000 & 0.009 & 0.012 & 0.258 & 0.014 \\
\hline $30 \mathrm{~s}-5.0 \mathrm{~s}$ & 0.455 & 0.996 & 0.016 & 0.024 & 0.279 & 0.007 \\
\hline $30 \mathrm{~s}-10 \mathrm{~s}$ & 0.466 & 1.000 & 0.020 & 0.011 & 0.960 & 0.031 \\
\hline $30 \mathrm{~s}-15 \mathrm{~s}$ & 0.210 & 1.000 & 0.051 & 0.898 & 1.000 & 0.124 \\
\hline $30 \mathrm{~s}-20 \mathrm{~s}$ & 0.483 & 1.000 & 0.522 & 1.000 & 1.000 & 0.986 \\
\hline $30 \mathrm{~s}-25 \mathrm{~s}$ & 0.751 & 1.000 & 0.991 & 0.926 & 0.998 & 1.000 \\
\hline
\end{tabular}

Table C.2: Pairwise comparison with Sidak correction for FT-EC of 11 trials for subjects 1.

\begin{tabular}{|c|c|c|c|c|c|c|}
\hline \multicolumn{7}{|c|}{ Pairwise comparison } \\
\hline \multirow{2}{*}{ Window Pair } & \multicolumn{6}{|c|}{ Sig. (2-tailed) for S1 FT-EC } \\
\hline & RDavg & $V_{\text {avg }}$ & AREA & SD_RD & $\sigma_{x}$ & $\sigma_{y}$ \\
\hline $30 s-1.5 s$ & 0.019 & 1.000 & osos & 000 & opas & 0001 \\
\hline $30 s-2.0 s$ & $\$ 027$ & 1.000 & 0.008 & 0031 & 000 & 0.800 \\
\hline $30 \mathrm{~s}-2.5 \mathrm{~s}$ & 002 & 1.000 & 0.009 & ogis & otsi & 0.001 \\
\hline $30 \mathrm{~s} \cdot 3.0 \mathrm{~s}$ & 0023 & 1.000 & 0.010 & $010 \%$ & 020 & 0.694 \\
\hline $30 \mathrm{~s}-3.5 \mathrm{~s}$ & 8039 & 1.000 & 0.018 & eops & 002 & 000 \\
\hline $30 \mathrm{~s}-4.0 \mathrm{~s}$ & 0.074 & 1.000 & 0.021 & 0.008 & 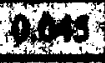 & 0.009 \\
\hline $30 s-4.5 s$ & 0.036 & 1.000 & 0.014 & 0009 & 0.023 & 0.014 \\
\hline $30 \mathrm{~s}-5.0 \mathrm{~s}$ & 0.013 & 1.000 & 0.005 & Oogs & 0,023 & 0.027 \\
\hline $30 s-10 s$ & 0.914 & 1.000 & 0.176 & 0.997 & 1.000 & 0,031 \\
\hline $30 s-15 s$ & 0.993 & 1.000 & 0.319 & 1.000 & 1.000 & 0.124 \\
\hline $30 s-20 s$ & 1.000 & 1.000 & 0.972 & 1.000 & 1.000 & 0.986 \\
\hline $30 s-25 s$ & 1.000 & 1.000 & 1.000 & 1.000 & 1.000 & 1.000 \\
\hline
\end{tabular}


Table C.3: Pairwise comparison with Sidak correction for SL-EO of 11 trials for subjects 1.

\begin{tabular}{|c|c|c|c|c|c|c|}
\hline \multicolumn{7}{|c|}{ Pairwise comparison } \\
\hline \multirow{2}{*}{ Window Pair } & \multicolumn{6}{|c|}{ Sig. (2-tailed) for S1 SL-EO } \\
\hline & RDavg & $V_{\text {avg }}$ & AREA & SD_RD & $\sigma_{x}$ & $\sigma_{y}$ \\
\hline $30 s-1.5 s$ & 0.000 & 0.996 & 0.996 & 0001 & 0.114 & 8001 \\
\hline $30 s-2.0 s$ & 0.000 & 0.866 & 0.866 & 0.001 & 0.183 & 8.031 \\
\hline $30 \mathrm{~s}-2.5 \mathrm{~s}$ & 0.000 & 1.000 & 1.000 & ao18 & 0.119 & 6PAI \\
\hline $30 \mathrm{~s}-3.0 \mathrm{~s}$ & 0.000 & 1.000 & 1.000 & 0010 & 0.173 & and \\
\hline $30 s-3.5 s$ & 0.000 & 1.000 & 1.000 & 0.009 & 0.160 & Hin \\
\hline $30 \mathrm{~s}-4.0 \mathrm{~s}$ & 0.000 & 1.000 & 1.000 & acos & 0.176 & $\infty 001$ \\
\hline $30 s-4.5 s$ & 0.000 & 1.000 & 1.000 & 0.003 & 0.978 & $\infty 0001$ \\
\hline $30 \mathrm{~s}-5.0 \mathrm{~s}$ & 0002 & 1.000 & 1.000 & 0006 & 0.986 & 0.001 \\
\hline $30 s-10 s$ & 0.050 & 1.000 & 1.000 & 0.997 & 0.965 & 0.034 \\
\hline $30 s-15 s$ & 0.359 & 1.000 & 1.000 & 1.000 & 1.000 & 0.203 \\
\hline $30 s-20 s$ & 1.000 & 1.000 & 1.000 & 1.000 & 1.000 & 1.000 \\
\hline $30 s-25 s$ & 1.000 & 1.000 & 1.000 & 1.000 & 0.905 & 1.000 \\
\hline
\end{tabular}

Table C.4: Pairwise comparison with Sidak correction for SL-EC of 11 trials for subjects 1.

\begin{tabular}{|c|c|c|c|c|c|c|}
\hline \multicolumn{7}{|c|}{ Pairwise comparison } \\
\hline \multirow{2}{*}{ Window Pair } & \multicolumn{5}{|c|}{ Sig-tailed) for S1 SL-EC } \\
\cline { 2 - 7 } & RDavg & $V_{\text {avg }}$ & AREA & SD_RD & $\sigma_{x}$ & $\sigma_{y}$ \\
\hline $30 \mathrm{~s}-1.5 \mathrm{~s}$ & $\mathbf{0 . 0 0 1}$ & 1.000 & 0.288 & 0.490 & .00 & 0.996 \\
\hline $30 \mathrm{~s}-2.0 \mathrm{~s}$ & 40.001 & 1.000 & 0.108 & 0.911 & .000 & 0.855 \\
\hline $30 \mathrm{~s}-2.5 \mathrm{~s}$ & 40.001 & 1.000 & 0.209 & 0.895 & .000 & 0.777 \\
\hline $30 \mathrm{~s}-3.0 \mathrm{~s}$ & $\mathbf{0 . 0 0 1}$ & 1.000 & 0.362 & 0.611 & .010 & 0.681 \\
\hline $30 \mathrm{~s}-3.5 \mathrm{~s}$ & $\$ 0.001$ & 1.000 & 0.302 & 0.635 & .065 & 0.575 \\
\hline $30 \mathrm{~s}-4.0 \mathrm{~s}$ & $\$ 0.001$ & 1.000 & 0.433 & 0.747 & .053 & 0.806 \\
\hline $30 \mathrm{~s}-4.5 \mathrm{~s}$ & 0.001 & 1.000 & 0.375 & 0.668 & .061 & 0.910 \\
\hline $30 \mathrm{~s}-5.0 \mathrm{~s}$ & 0.002 & 1.000 & 0.480 & 0.750 & 042 & 0.960 \\
\hline $30 \mathrm{~s}-10 \mathrm{~s}$ & 0.016 & 1.000 & 0.995 & 0.992 & .454 & 0.904 \\
\hline $30 \mathrm{~s}-15 \mathrm{~s}$ & 0.132 & 1.000 & 1.000 & 1.000 & .407 & 1.000 \\
\hline $30 \mathrm{~s}-20 \mathrm{~s}$ & 0.895 & 1.000 & 1.000 & 1.000 & .407 & 1.000 \\
\hline $30 \mathrm{~s}-25 \mathrm{~s}$ & 1.000 & 1.000 & 1.000 & 1.000 & .531 & 1.000 \\
\hline
\end{tabular}


Table C.5: Pairwise comparison with Sidak correction for FT-EO of 11 trials for subject 2.

\begin{tabular}{|c|c|c|c|c|c|c|}
\hline \multicolumn{7}{|c|}{ Pairwise comparison } \\
\hline \multirow{2}{*}{$\begin{array}{l}\text { Window } \\
\text { Pair }\end{array}$} & \multicolumn{6}{|c|}{ Sig. (2-tailed) for S2 FT-EO } \\
\hline & RDavg & $V_{\text {avg }}$ & AREA & SD_RD & $\sigma_{x}$ & $\sigma_{y}$ \\
\hline $30 \mathrm{~s}-1.5 \mathrm{~s}$ & o.00s & 1.000 & 0.007 & 000 & 0002 & 0.001 \\
\hline $30 \mathrm{~s}-2.0 \mathrm{~s}$ & 0.002 & 1.000 & 0.001 & 000 & & 6 \\
\hline $30 \mathrm{~s}-2.5 \mathrm{~s}$ & 0.001 & 0.991 & atoi & 6030 & 020 & \\
\hline $30 s-3.0 s$ & 0.001 & 1.000 & $0.00 \%$ & 0.601 & 401 & \\
\hline $30 \mathrm{~s}-3.5 \mathrm{~s}$ & 60.001 & 1.000 & $00 \%$ & 000 & Qns & \\
\hline $30 \mathrm{~s}-4.0 \mathrm{~s}$ & 0.001 & 1.000 & $60 \%$ & 002 & & \\
\hline $30 \mathrm{~s}-4.5 \mathrm{~s}$ & 60.001 & 1.000 & ato & 0.076 & $600 \%$ & 68 \\
\hline $30 \mathrm{~s}-5.0 \mathrm{~s}$ & 6.015 & 1.000 & 0000 & 0.051 & 0.051 & 0019 \\
\hline $30 s-10 s$ & 0.324 & 1.000 & 0.213 & 0.230 & 0.230 & 0.729 \\
\hline $30 s-15 s$ & 0.403 & 1.000 & 0.428 & 0.814 & 0.814 & 0.112 \\
\hline $30 s-20 s$ & 0.846 & 1.000 & 0.681 & 1.000 & 1.000 & 0.703 \\
\hline $30 s-25 s$ & 1.000 & 1.000 & 1.000 & 0.986 & 0.986 & 1.000 \\
\hline
\end{tabular}

Table C.6: Pairwise comparison with Sidak correction for FT-EC of 11 trials for subject 2.

\begin{tabular}{|c|c|c|c|c|c|c|}
\hline \multicolumn{7}{|c|}{ Pairwise comparison } \\
\hline \multirow{2}{*}{ Window Pair } & \multicolumn{6}{|c|}{ Sig. (2-tailed) for S2 FT-EC } \\
\hline & RDavg & $V_{\text {avg }}$ & AREA & SD_RD & $\sigma_{x}$ & $\sigma_{y}$ \\
\hline $30 s-1.5 s$ & 9019 & 1.000 & 0017 & 7015 & 0.001 & 0,02 \\
\hline $30 \mathrm{~s}-2.0 \mathrm{~s}$ & 0.177 & 1.000 & 0.01 & ares & $\$ 0001$ & 0.203 \\
\hline $30 \mathrm{~s}-2.5 \mathrm{~s}$ & 0.423 & 1.000 & 0.07 & 6019 & sant & 0.150 \\
\hline $30 \mathrm{~s}-3.0 \mathrm{~s}$ & 0.863 & 1.000 & 0.248 & 000 & 060 & 0.341 \\
\hline $30 \mathrm{~s}-3.5 \mathrm{~s}$ & 0.982 & 1.000 & 0.477 & 0006 & 6.003 & 0.717 \\
\hline $30 \mathrm{~s}-4.0 \mathrm{~s}$ & 1.000 & 1.000 & 0.822 & 0039 & 0.062 & 1.000 \\
\hline $30 \mathrm{~s}-4.5 \mathrm{~s}$ & 1.000 & 1.000 & 0.821 & 0.086 & 0.741 & 1.000 \\
\hline $30 \mathrm{~s}-5.0 \mathrm{~s}$ & 1.000 & 1.000 & 0.801 & 6032 & 0.999 & 1.000 \\
\hline $30 s-10 s$ & 0.558 & 1.000 & 0.332 & 0.085 & 0.997 & 0.797 \\
\hline $30 s-15 s$ & 0.139 & 1.000 & 0.224 & 0.443 & 1.000 & 0.405 \\
\hline $30 s-20 s$ & 0.257 & 1.000 & 0.459 & 0.610 & 1.000 & 0.798 \\
\hline $30 s-25 s$ & 0.992 & 1.000 & 0.996 & 0.980 & 1.000 & 1.000 \\
\hline
\end{tabular}


Table C.7: Pairwise comparison with Sidak correction for SL-EO of 11 trials for subject 2.

\begin{tabular}{|c|c|c|c|c|c|c|}
\hline \multicolumn{7}{|c|}{ Pairwise comparison } \\
\hline \multirow{2}{*}{ Window Pair } & \multicolumn{6}{|c|}{ Sig. (2-tailed) for S2 SL-EO } \\
\hline & RDavg & $V_{\text {avg }}$ & AREA & SD_RD & $\sigma_{x}$ & $\sigma_{y}$ \\
\hline $30 s-1.5 s$ & $\cos 0$ & 1.000 & ap: & ming & .357 & \\
\hline $30 \mathrm{~s}-2.0 \mathrm{~s}$ & Qtom & 1.000 & ofin: & 3 & .501 & \\
\hline $30 \mathrm{~s}-2.5 \mathrm{~s}$ & row & 1.000 & 603 & & .405 & \\
\hline $30 \mathrm{~s}-3.0 \mathrm{~s}$ & gon? & 1.000 & $0 x 0$ & a.2. & .193 & \\
\hline $30 \mathrm{~s}-3.5 \mathrm{~s}$ & 8008 & 1.000 & 260 & & .063 & \\
\hline $30 \mathrm{~s}-4.0 \mathrm{~s}$ & $6 x 02$ & 1.000 & $\operatorname{sen}$ & & & \\
\hline $30 \mathrm{~s}-4.5 \mathrm{~s}$ & 0.001 & 1.000 & Oapt & & & \\
\hline $30 \mathrm{~s}-5.0 \mathrm{~s}$ & 0.67 & 1.000 & Q64 & & & \\
\hline $30 s-10 s$ & 0.369 & 1.000 & 0.058 & 0.131 & .926 & 0.233 \\
\hline $30 s-15 s$ & 0.773 & 1.000 & 0.261 & 0.576 & 1.000 & 0.609 \\
\hline $30 s-20 s$ & 0.888 & 1.000 & 0.437 & 0.662 & 1.000 & 0.894 \\
\hline $30 s-25 s$ & 0.979 & 1.000 & 0.822 & 0.987 & 1.000 & 0.993 \\
\hline
\end{tabular}

Table C.8: Pairwise comparison with Sidak correction for SL-EC of 11 trials for subject 2.

\begin{tabular}{|c|c|c|c|c|c|c|}
\hline \multicolumn{7}{|c|}{ Pairwise comparison } \\
\hline \multirow{2}{*}{ Window Pair } & \multicolumn{6}{|c|}{ Sig. (2-tailed) for S2 SL-EC } \\
\hline & RDavg & $V_{\text {avg }}$ & AREA & SD_RD & $\sigma_{x}$ & $\sigma_{y}$ \\
\hline $30 \mathrm{~s}-1.5 \mathrm{~s}$ & 0.479 & 1.000 & 467 & .078 & .150 & .663 \\
\hline $30 \mathrm{~s}-2.0 \mathrm{~s}$ & 0.246 & 1.000 & 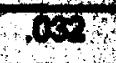 & 60 & .610 & .432 \\
\hline $30 \mathrm{~s}-2.5 \mathrm{~s}$ & 0.127 & 1.000 & wit & 5 & 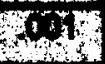 & .593 \\
\hline $30 \mathrm{~s}-3.0 \mathrm{~s}$ & 0.151 & 1.000 & 803 & & 40 & .710 \\
\hline $30 \mathrm{~s}-3.5 \mathrm{~s}$ & 0.199 & 1.000 & $6 \%$ & rops & .283 & .729 \\
\hline $30 \mathrm{~s}-4.0 \mathrm{~s}$ & 1.000 & 1.000 & .602 & .67 & 1.000 & .803 \\
\hline $30 \mathrm{~s}-4.5 \mathrm{~s}$ & 1.000 & 1.000 & .921 & 7010 & 1.000 & .957 \\
\hline $30 \mathrm{~s}-5.0 \mathrm{~s}$ & 1.000 & 1.000 & .880 & .053 & 1.000 & .774 \\
\hline $30 s-10 s$ & 0.999 & 1.000 & .812 & .523 & 1.000 & .959 \\
\hline $30 s-15 s$ & 0.982 & 1.000 & .963 & .927 & 1.000 & .996 \\
\hline $30 s-20 s$ & 1.000 & 1.000 & 1.000 & 1.000 & 1.000 & 1.000 \\
\hline $30 \mathrm{~s}-25 \mathrm{~s}$ & 1.000 & 1.000 & 1.000 & 1.000 & 1.000 & 1.000 \\
\hline
\end{tabular}


Table C.9: Pairwise comparison with Sidak correction for FT-EO of 11 trials for subject 3.

\begin{tabular}{|c|c|c|c|c|c|c|}
\hline \multicolumn{7}{|c|}{ Pairwise comparison } \\
\hline \multirow{2}{*}{ Window Pair } & \multicolumn{6}{|c|}{ Sig. (2-tailed) for S3 FT-EO } \\
\hline & RDavg & $V_{\text {avg }}$ & AREA & SD_RD & $\sigma_{x}$ & $\sigma_{y}$ \\
\hline $30 \mathrm{~s}-1.5 \mathrm{~s}$ & 0.010 & 1.000 & 0004 & 0.00 & 0.056 & \\
\hline $30 s-2.0 s$ & 0.008 & 1.000 & 908 & 0.00 & 695 & \\
\hline $30 \mathrm{~s}-2.5 \mathrm{~s}$ & 0016 & 1.000 & 040 & 0.058 & 0.371 & \\
\hline $30 \mathrm{~s}-3.0 \mathrm{~s}$ & 6,036 & 1.000 & 0.012 & 0.128 & 0.839 & \\
\hline $30 \mathrm{~s}-3.5 \mathrm{~s}$ & 0.651 & 1.000 & 0.012 & 0.149 & 0.938 & \\
\hline $30 \mathrm{~s}-4.0 \mathrm{~s}$ & 0.045 & 1.000 & 9.019 & 0.096 & 0.881 & oros \\
\hline $30 \mathrm{~s}-4.5 \mathrm{~s}$ & 0.046 & 1.000 & 0.623 & 0.053 & 0.758 & 0.03 \\
\hline $30 \mathrm{~s}-5.0 \mathrm{~s}$ & 0.036 & 1.000 & 0.030 & 0.055 & 0.745 & ago \\
\hline $30 s-10 s$ & 0.990 & 1.000 & 0.805 & 0.966 & 1.000 & 0.942 \\
\hline $30 s-15 s$ & 0.992 & 1.000 & 0.727 & 0.999 & 0.965 & 1.000 \\
\hline $30 s-20 s$ & 0.998 & 1.000 & 0.932 & 1.000 & 0.997 & 1.000 \\
\hline $30 s-25 s$ & 1.000 & 1.000 & 0.998 & 1.000 & 0.884 & 1.000 \\
\hline
\end{tabular}

Table C.10: Pairwise comparison with Sidak correction for FT-EC of 11 trials for subject 3.

\begin{tabular}{|c|c|c|c|c|c|c|}
\hline \multirow{7}{*}{ Window Pair } & \multicolumn{5}{|c|}{ Sig. (2-tailed) for S3 FT-EC } \\
\cline { 2 - 7 } & RDavg & $V_{\text {avg }}$ & AREA & SD_RD & $\sigma_{x}$ & $\sigma_{y}$ \\
\hline $30 \mathrm{~s}-1.5 \mathrm{~s}$ & 0.454 & 1.000 & 0.006 & 00.1 & 0.981 & 0.007 \\
\hline $30 \mathrm{~s}-2.0 \mathrm{~s}$ & 0.459 & 1.000 & 0.006 & 0.053 & 0.955 & 0.035 \\
\hline $30 \mathrm{~s}-2.5 \mathrm{~s}$ & 0.615 & 1.000 & 0.014 & 0.078 & 0.999 & 0.023 \\
\hline $30 \mathrm{~s}-3.0 \mathrm{~s}$ & 0.461 & 0.985 & 0.016 & 0.116 & 0.995 & 0.025 \\
\hline $30 \mathrm{~s}-3.5 \mathrm{~s}$ & 0.267 & 0.995 & 0.013 & 0.215 & 0.990 & 0.027 \\
\hline $30 \mathrm{~s}-4.0 \mathrm{~s}$ & 0.226 & 0.993 & 0.018 & 0.162 & 0.963 & 0.025 \\
\hline $30 \mathrm{~s}-4.5 \mathrm{~s}$ & 0.172 & 0.997 & 0.034 & 0.213 & 0.888 & 0.033 \\
\hline $30 \mathrm{~s}-5.0 \mathrm{~s}$ & 0.259 & 1.000 & 0.126 & 0.298 & 0.953 & 0.057 \\
\hline $30 \mathrm{~s}-10 \mathrm{~s}$ & 1.000 & 1.000 & 0.698 & 0.995 & 1.000 & 0.630 \\
\hline $30 \mathrm{~s}-15 \mathrm{~s}$ & 1.000 & 1.000 & 0.921 & 1.000 & 1.000 & 0.903 \\
\hline $30 \mathrm{~s}-20 \mathrm{~s}$ & 1.000 & 1.000 & 0.988 & 1.000 & 1.000 & 0.947 \\
\hline $30 \mathrm{~s}-25 \mathrm{~s}$ & 1.000 & 1.000 & 1.000 & 1.000 & 1.000 & 1.000 \\
\hline
\end{tabular}


Table C.11: Pairwise comparison with Sidak correction for SL-EO of 11 trials for subject 3.

\begin{tabular}{|c|c|c|c|c|c|c|}
\hline \multicolumn{7}{|c|}{ Pairwise comparison } \\
\hline \multirow{2}{*}{ Window Pair } & \multicolumn{6}{|c|}{ Sig. (2-tailed) for S3 SL-EO } \\
\hline & RDavg & $V_{\text {avg }}$ & AREA & SD_RD & $\sigma_{x}$ & $\sigma_{y}$ \\
\hline $30 \mathrm{~s}-1.5 \mathrm{~s}$ & 0.067 & 1.000 & 6017. & 0.332 & 0.730 & 0437 \\
\hline $30 \mathrm{~s}-2.0 \mathrm{~s}$ & 0.171 & 1.000 & 0.052 & and. & 0.991 & 0.68 \\
\hline $30 \mathrm{~s}-2.5 \mathrm{~s}$ & 0204 & 1.000 & ans & ory & 0.949 & 0 \\
\hline $30 \mathrm{~s}-3.0 \mathrm{~s}$ & 6027 & 1.000 & 69 & 0.055 & 0.932 & oris \\
\hline $30 \mathrm{~s}-3.5 \mathrm{~s}$ & 0.115 & 1.000 & 0.085 & 0.163 & 1.000 & $60+3$ \\
\hline $30 s-4.0 s$ & 0.319 & 0.999 & 0.234 & 0.171 & 1.000 & 0.055 \\
\hline $30 \mathrm{~s}-4.5 \mathrm{~s}$ & 0.427 & 0.918 & 0.260 & 0.133 & 1.000 & 0.092 \\
\hline $30 \mathrm{~s}-5.0 \mathrm{~s}$ & $\overline{0.382}$ & 0.951 & 0.278 & 0.224 & 1.000 & 0.065 \\
\hline $30 s-10 s$ & 0.826 & 0.802 & 0.212 & 0.998 & 1.000 & 0.806 \\
\hline $30 s-15 s$ & 1.000 & 0.995 & 0.988 & 0.981 & 1.000 & 1.000 \\
\hline $30 s-20 s$ & 0.999 & 1.000 & 0.953 & 0.996 & 1.000 & 0.998 \\
\hline $30 s-25 s$ & 0.995 & 1.000 & 0.972 & 1.000 & 1.000 & 0.943 \\
\hline
\end{tabular}

Table C.12: Pairwise comparison with Sidak correction for SL-EC of 11 trials for subject 3.

\begin{tabular}{|c|c|c|c|c|c|c|}
\hline \multicolumn{7}{|c|}{ Pairwise comparison } \\
\hline \multirow{2}{*}{ Window Pair } & \multicolumn{5}{|c|}{ Sig. (2-tailed) for S3 SL-EC } \\
\cline { 2 - 7 } & RDavg & $V_{\text {avg }}$ & AREA & SD_RD & $\sigma_{x}$ & $\sigma_{y}$ \\
\hline $30 \mathrm{~s}-1.5 \mathrm{~s}$ & 1.000 & 1.000 & 0.838 & 0.857 & 0.806 & 1.000 \\
\hline $30 \mathrm{~s}-2.0 \mathrm{~s}$ & 0.999 & 1.000 & 0.858 & 0.950 & 0.923 & 1.000 \\
\hline $30 \mathrm{~s}-2.5 \mathrm{~s}$ & 1.000 & 1.000 & 0.998 & 0.980 & 0.997 & 1.000 \\
\hline $30 \mathrm{~s}-3.0 \mathrm{~s}$ & 1.000 & 1.000 & 0.998 & 0.999 & 1.000 & 1.000 \\
\hline $30 \mathrm{~s}-3.5 \mathrm{~s}$ & 1.000 & 1.000 & 1.000 & 1.000 & 0.999 & 1.000 \\
\hline $30 \mathrm{~s}-4.0 \mathrm{~s}$ & 1.000 & 0.999 & 0.999 & 1.000 & 0.999 & 1.000 \\
\hline $30 \mathrm{~s}-4.5 \mathrm{~s}$ & 1.000 & 0.918 & 1.000 & 1.000 & 1.000 & 1.000 \\
\hline $30 \mathrm{~s}-5.0 \mathrm{~s}$ & 1.000 & 0.951 & 1.000 & 1.000 & 1.000 & 1.000 \\
\hline $30 \mathrm{~s}-10 \mathrm{~s}$ & 1.000 & 0.802 & 1.000 & 1.000 & 1.000 & 1.000 \\
\hline $30 \mathrm{~s}-15 \mathrm{~s}$ & 1.000 & 0.995 & 1.000 & 1.000 & 1.000 & 1.000 \\
\hline $30 \mathrm{~s}-20 \mathrm{~s}$ & 1.000 & 1.000 & 1.000 & 1.000 & 1.000 & 1.000 \\
\hline $30 \mathrm{~s}-25 \mathrm{~s}$ & 1.000 & 1.000 & 1.000 & 1.000 & 1.000 & 1.000 \\
\hline
\end{tabular}


Table C.13: Pairwise comparison with Sidak correction for FT-EO of 11 trials for subject 4.

\begin{tabular}{|c|c|c|c|c|c|c|}
\hline \multicolumn{7}{|c|}{ Pairwise comparison } \\
\hline \multirow{2}{*}{ Window Pair } & \multicolumn{6}{|c|}{ Sig. (2-tailed) for S4 FT-EO } \\
\hline & RDavg & $V_{\text {avg }}$ & AREA & SD_RD & $\sigma_{x}$ & $\sigma_{y}$ \\
\hline $30 \mathrm{~s}-1.5 \mathrm{~s}$ & 0.001 & 1.000 & 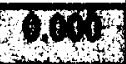 & $6 \times 02$ & 70 & 060 \\
\hline $30 \mathrm{~s}-2.0 \mathrm{~s}$ & 0.010 & 1.000 & 0.609 & 000 & 0.15: & 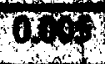 \\
\hline $30 \mathrm{~s}-2.5 \mathrm{~s}$ & 0.098 & 1.000 & $0003^{3}$ & Dros & 0.110 & $0 \mathrm{xp}$ \\
\hline $30 \mathrm{~s}-3.0 \mathrm{~s}$ & 0.476 & 1.000 & and & atot & 0.168 & 0.662 \\
\hline $30 \mathrm{~s}-3.5 \mathrm{~s}$ & 0.857 & 1.000 & 0.142 & 0.151 & 0.203 & 0.999 \\
\hline $30 \mathrm{~s}-4.0 \mathrm{~s}$ & 0.983 & 1.000 & 0.100 & 0.418 & 0.258 & 1.000 \\
\hline $30 \mathrm{~s}-4.5 \mathrm{~s}$ & 1.000 & 1.000 & 0.065 & 0.452 & 0.281 & 1.000 \\
\hline $30 \mathrm{~s}-5.0 \mathrm{~s}$ & 1.000 & 1.000 & 0.066 & 0.237 & 0.279 & 1.000 \\
\hline $30 s-10 s$ & 1.000 & 1.000 & 1.000 & 1.000 & 1.000 & 1.000 \\
\hline $30 s-15 s$ & 1.000 & 1.000 & 0.997 & 1.000 & 1.000 & 1.000 \\
\hline $30 s-20 s$ & 1.000 & 1.000 & 1.000 & 1.000 & 1.000 & 1.000 \\
\hline $30 s-25 s$ & 1.000 & 1.000 & 1.000 & 1.000 & 1.000 & 1.000 \\
\hline
\end{tabular}

Table C.14: Pairwise comparison with Sidak correction for FT-EC of 11 trials for subject 4.

\begin{tabular}{|c|c|c|c|c|c|c|}
\hline \multicolumn{7}{|c|}{ Pairwise comparison } \\
\hline \multirow{2}{*}{ Window Pair } & \multicolumn{6}{|c|}{ Sig. (2-tailed) for S4 FT-EC } \\
\hline & RDavg & $V_{\text {avg }}$ & AREA & SD_RD & $\sigma_{x}$ & $\sigma_{y}$ \\
\hline $30 \mathrm{~s}-1.5 \mathrm{~s}$ & 0.03 & 1.00 & 0.89 & 0.02 & and & 0.30 \\
\hline $30 \mathrm{~s}-2.0 \mathrm{~s}$ & 0.10 & 1.00 & 0.067 & 0.06 & 70,015 & 0.53 \\
\hline $30 \mathrm{~s}-2.5 \mathrm{~s}$ & 0.26 & 1.00 & 0.107 & 0.07 & 980 & 0.76 \\
\hline $30 \mathrm{~s}-3.0 \mathrm{~s}$ & 0.33 & 1.00 & 0.181 & 0.12 & 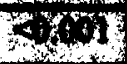 & 0.80 \\
\hline $30 \mathrm{~s}-3.5 \mathrm{~s}$ & 0.70 & 1.00 & 0.412 & 0.36 & 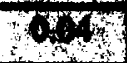 & 0.96 \\
\hline $30 \mathrm{~s}-4.0 \mathrm{~s}$ & 0.88 & 1.00 & 0.583 & 0.32 & 0.05 & 0.99 \\
\hline $30 \mathrm{~s}-4.5 \mathrm{~s}$ & 0.96 & 1.00 & 0.735 & 0.38 & 0.34 & 0.99 \\
\hline $30 \mathrm{~s}-5.0 \mathrm{~s}$ & 0.98 & 1.00 & 0.789 & 0.50 & 0.79 & 0.99 \\
\hline $30 s-10 s$ & 0.95 & 1.00 & 0.637 & 0.66 & 1.00 & 0.99 \\
\hline $30 s-15 s$ & 1.00 & 1.00 & 0.929 & 0.89 & 0.99 & 1.00 \\
\hline $30 s-20 s$ & 1.00 & 1.00 & 1.000 & 1.00 & 1.00 & 1.00 \\
\hline $30 s-25 s$ & 1.00 & 1.00 & 1.000 & 1.00 & 1.00 & 1.00 \\
\hline
\end{tabular}


Table C.15: Pairwise comparison with Sidak correction for SL-EO of 11 trials for subject 4.

\begin{tabular}{|c|c|c|c|c|c|c|}
\hline \multicolumn{7}{|c|}{ Pairwise comparison } \\
\hline \multirow{2}{*}{ Window Pair } & \multicolumn{6}{|c|}{ Sig. (2-tailed) for S4 SL-EO } \\
\hline & RDavg & $V_{\text {avg }}$ & AREA & SD_RD & $\sigma_{x}$ & $\sigma_{x}$ \\
\hline $30 \mathrm{~s}-1.5 \mathrm{~s}$ & 8001 & 1.000 & 804 & axp & $\operatorname{tas}$ & \\
\hline $30 \mathrm{~s}-2.0 \mathrm{~s}$ & $\$, 001$ & 1.000 & 8001 & $0 \times$ & onts & \\
\hline $30 \mathrm{~s}-2.5 \mathrm{~s}$ & 80.001 & 1.000 & 40001 & $0 \times 6 \%$ & axs & 0000 \\
\hline $30 \mathrm{~s}-3.0 \mathrm{~s}$ & 0.001 & 1.000 & 0901 & $0 \%$ & Q82 & 0012 \\
\hline $30 \mathrm{~s}-3.5 \mathrm{~s}$ & 0.601 & 1.000 & 0001 & & Qie2 & Q607 \\
\hline $30 \mathrm{~s}-4.0 \mathrm{~s}$ & 0.001 & 1.000 & orgex & & ast & 005 \\
\hline $30 \mathrm{~s}-4.5 \mathrm{~s}$ & 0.003 & 1.000 & 607 & 000 & oxet & 6068 \\
\hline $30 \mathrm{~s}-5.0 \mathrm{~s}$ & 0.014 & 1.000 & 6001 & 8013 & 0.256 & 0.104 \\
\hline $30 s-10 s$ & 1.000 & 0.908 & 1.000 & 0.507 & 1.000 & 1.000 \\
\hline $30 s-15 s$ & 1.000 & 0.647 & 1.000 & 0.923 & 1.000 & 1.000 \\
\hline $30 s-20 s$ & 1.000 & 0.999 & 1.000 & 1.000 & 1.000 & 1.000 \\
\hline $30 s-25 s$ & 1.000 & 0.602 & 1.000 & 1.000 & 1.000 & 1.000 \\
\hline
\end{tabular}

Table C.16: Pairwise comparison with Sidak correction for SL-EC of 11 trials for subject 4.

\begin{tabular}{|c|c|c|c|c|c|c|}
\hline \multicolumn{7}{|c|}{ Pairwise comparison } \\
\hline \multirow{2}{*}{ Window Pair } & \multicolumn{5}{|c|}{ Sig. (2-tailed) for S4 SL-EC } \\
\cline { 2 - 7 } & RDavg & $V_{\text {avg }}$ & AREA & SD_RD & $\sigma_{x}$ & $\sigma_{y}$ \\
\hline $30 \mathrm{~s}-1.5 \mathrm{~s}$ & 0.633 & 1.000 & 0.09 & 0.03 & 0.542 & 0.224 \\
\hline $30 \mathrm{~s}-2.0 \mathrm{~s}$ & 0.930 & 1.000 & 0003 & 0.099 & 0.999 & 0.183 \\
\hline $30 \mathrm{~s}-2.5 \mathrm{~s}$ & 1.000 & 1.000 & 0.905 & 0.264 & 1.000 & 0.136 \\
\hline $30 \mathrm{~s}-3.0 \mathrm{~s}$ & 1.000 & 1.000 & 0.727 & 0.311 & 1.000 & 0.070 \\
\hline $30 \mathrm{~s}-3.5 \mathrm{~s}$ & 1.000 & 1.000 & 0.540 & 0.258 & 1.000 & 0.075 \\
\hline $30 \mathrm{~s}-4.0 \mathrm{~s}$ & 1.000 & 1.000 & 1.000 & 0.972 & 1.000 & 0.995 \\
\hline $30 \mathrm{~s}-4.5 \mathrm{~s}$ & 1.000 & 1.000 & 1.000 & 1.000 & 1.000 & 0.999 \\
\hline $30 \mathrm{~s}-5.0 \mathrm{~s}$ & 1.000 & 1.000 & 1.000 & 1.000 & 1.000 & 1.000 \\
\hline $30 \mathrm{~s}-10 \mathrm{~s}$ & 1.000 & 0.993 & 1.000 & 1.000 & 1.000 & 1.000 \\
\hline $30 \mathrm{~s}-15 \mathrm{~s}$ & 1.000 & 1.000 & 1.000 & 1.000 & 1.000 & 1.000 \\
\hline $30 \mathrm{~s}-20 \mathrm{~s}$ & 1.000 & 1.000 & 1.000 & 1.000 & 1.000 & 0.984 \\
\hline $30 \mathrm{~s}-25 \mathrm{~s}$ & 1.000 & 1.000 & 1.000 & 1.000 & 1.000 & 0.218 \\
\hline
\end{tabular}


Table C.17: Pairwise comparison with Sidak correction for FT-EO of 11 trials for subject 5.

\begin{tabular}{|c|c|c|c|c|c|c|}
\hline \multicolumn{7}{|c|}{ Pairwise comparison } \\
\hline \multirow{2}{*}{ Window Pair } & \multicolumn{6}{|c|}{ Sig. (2-tailed) for S5 FT-EO } \\
\hline & RDavg & $V_{a v g}$ & AREA & SD_RD & $\sigma_{x}$ & $\sigma_{y}$ \\
\hline $30 \mathrm{~s}-1.5 \mathrm{~s}$ & 0,022 & 1.00 & $\$ .001$ & .065 & 6IX & 0.028 \\
\hline $30 \mathrm{~s}-2.0 \mathrm{~s}$ & 0.016 & 1.00 & $\$ .001$ & .001 & ara & 062 \\
\hline $30 \mathrm{~s}-2.5 \mathrm{~s}$ & 0,09 & 1.00 & 40.001 & $\cos$ & & \\
\hline $30 \mathrm{~s}-3.0 \mathrm{~s}$ & 0,005 & 1.00 & क.6.01 & 67 & Wis & OII \\
\hline $30 \mathrm{~s}-3.5 \mathrm{~s}$ & 0.011 & 1.00 & 20.001 & 5.00 & atro & 6916 \\
\hline $30 \mathrm{~s}-4.0 \mathrm{~s}$ & 0.008 & 0.99 & 0.001 & at7 & $00^{\circ}$ & ThI \\
\hline $30 \mathrm{~s}-4.5 \mathrm{~s}$ & 0.005 & 0.99 & 0.001 & . & & 000 \\
\hline $30 \mathrm{~s}-5.0 \mathrm{~s}$ & 0.003 & 0.86 & 0.002 & 7018 & $0.7 \mathrm{x}$ & 0.064 \\
\hline $30 s-10 s$ & 0.487 & 1.00 & 0.294 & .756 & 0.976 & 0.544 \\
\hline $30 s-15 s$ & 1.000 & 1.00 & 1.000 & 1.000 & 1.000 & 0.987 \\
\hline $30 s-20 s$ & 1.000 & 1.00 & 1.000 & 1.000 & 0.998 & 1.000 \\
\hline $30 s-25 s$ & 1.000 & 1.00 & 1.000 & 1.000 & 1.000 & 1.000 \\
\hline
\end{tabular}

Table C.18: Pairwise comparison with Sidak correction for FT-EC of 11 trials for subject 5.

\begin{tabular}{|c|c|c|c|c|c|c|}
\hline \multicolumn{7}{|c|}{ Pairwise comparison } \\
\hline \multirow{2}{*}{ Window Pair } & \multicolumn{6}{|c|}{ Sig. (2-tailed) for S5 FT-EC } \\
\hline & RDavg & $V_{\text {avg }}$ & AREA & SD_RD & $\sigma_{x}$ & $\sigma_{y}$ \\
\hline $30 s-1.5 s$ & 0.023 & 1.000 & 0011 & 0.601 & 0.110 & 0.018 \\
\hline $30 \mathrm{~s}-2.0 \mathrm{~s}$ & 0.115 & 1.000 & 0.028 & Dost & 0.790 & 0.019 \\
\hline $30 \mathrm{~s}-2.5 \mathrm{~s}$ & 0.193 & 1.000 & 6073 & 0.021 & 0.976 & 0.008 \\
\hline $30 \mathrm{~s}-3.0 \mathrm{~s}$ & 0.209 & 1.000 & 0.0 .8 & 0.015 & 0.939 & 0.076 \\
\hline $30 \mathrm{~s}-3.5 \mathrm{~s}$ & 0.357 & 1.000 & 0.249 & 0.033: & 0.897 & 0.156 \\
\hline $30 s-4.0 s$ & 0.409 & 1.000 & 0.301 & 0.038 & 0.748 & 0.193 \\
\hline $30 \mathrm{~s} \cdot 4.5 \mathrm{~s}$ & 0.472 & 1.000 & 0.344 & 0.197 & 0.816 & 0.269 \\
\hline $30 \mathrm{~s}-5.0 \mathrm{~s}$ & 0.407 & 1.000 & 0.301 & 0.372 & 0.680 & 0.294 \\
\hline $30 s-10 s$ & 0.474 & 0.978 & 0.478 & 0.464 & 0.976 & 0.279 \\
\hline $30 s-15 s$ & 1.000 & 0.988 & 0.907 & 1.000 & 0.991 & 0.928 \\
\hline $30 s-20 s$ & 1.000 & 1.000 & 1.000 & 1.000 & 0.944 & 1.000 \\
\hline $30 s-25 s$ & 1.000 & 1.000 & 1.000 & 1.000 & 0.943 & 1.000 \\
\hline
\end{tabular}


Table C.19: Pairwise comparison with Sidak correction for SLEO of 11 trials for subject 5.

\begin{tabular}{|c|c|c|c|c|c|c|}
\hline \multicolumn{7}{|c|}{ Pairwise comparison } \\
\hline \multirow{2}{*}{ Window Pair } & \multicolumn{5}{|c|}{ Sig. (2-tailed) for SS SL-EO } \\
\cline { 2 - 7 } & RDavg & $V_{\text {avg }}$ & AREA & SD_RD & $\sigma_{x}$ & $\sigma_{y}$ \\
\hline $30 \mathrm{~s}-1.5 \mathrm{~s}$ & 0.777 & 1.000 & 0.142 & 0.64 & 0.583 & 0.919 \\
\hline $30 \mathrm{~s}-2.0 \mathrm{~s}$ & 0.959 & 1.000 & 0.168 & 0.6 & 0.829 & 0.990 \\
\hline $30 \mathrm{~s}-2.5 \mathrm{~s}$ & 1.000 & 1.000 & 0.689 & 0.01 & 0.685 & 1.000 \\
\hline $30 \mathrm{~s}-3.0 \mathrm{~s}$ & 1.000 & 1.000 & 0.979 & 0.064 & 0.968 & 1.000 \\
\hline $30 \mathrm{~s}-3.5 \mathrm{~s}$ & 1.000 & 1.000 & 0.983 & 0.129 & 0.989 & 1.000 \\
\hline $30 \mathrm{~s}-4.0 \mathrm{~s}$ & 1.000 & 1.000 & 0.958 & 0.067 & 0.986 & 1.000 \\
\hline $30 \mathrm{~s}-4.5 \mathrm{~s}$ & 1.000 & 1.000 & 0.979 & 0.079 & 0.988 & 1.000 \\
\hline $30 \mathrm{~s}-5.0 \mathrm{~s}$ & 1.000 & 1.000 & 0.998 & 0.023 & 0.980 & 1.000 \\
\hline $30 \mathrm{~s}-10 \mathrm{~s}$ & 1.000 & 1.000 & 0.986 & 0.154 & 1.000 & 1.000 \\
\hline $30 \mathrm{~s}-15 \mathrm{~s}$ & 1.000 & 1.000 & 0.964 & 0.206 & 0.998 & 1.000 \\
\hline $30 \mathrm{~s}-20 \mathrm{~s}$ & 1.000 & 1.000 & 1.000 & 0.999 & 1.000 & 1.000 \\
\hline $30 \mathrm{~s}-25 \mathrm{~s}$ & 1.000 & 1.000 & 1.000 & 1.000 & 1.000 & 1.000 \\
\hline
\end{tabular}

Table C.20: Pairwise comparison with Sidak correction for SL-EC of 11 trials for subject 5.

\begin{tabular}{|c|c|c|c|c|c|c|}
\hline \multicolumn{7}{|c|}{ Pairwise comparison } \\
\hline \multirow{2}{*}{ Window Pair } & \multicolumn{6}{|c|}{ Sig. (2-tailed) for S5 SL-EC } \\
\hline & RDavg & $V_{a v g}$ & AREA & SD_RD & $\sigma_{x}$ & $\sigma_{y}$ \\
\hline $30 \mathrm{~s}-1.5 \mathrm{~s}$ & $<0,9$ & 0.916 & 240I & $\$ 001$ & $6 \%$ & af \\
\hline $30 \mathrm{~s}-2.0 \mathrm{~s}$ & 4063 & 0.626 & 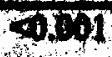 & ODI & & \\
\hline $30 \mathrm{~s}-2.5 \mathrm{~s}$ & 20001 & 0.865 & 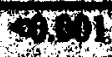 & & & \\
\hline $30 \mathrm{~s}-3.0 \mathrm{~s}$ & 0.001 & 0.981 & & & 9191 & Wwa \\
\hline $30 \mathrm{~s}-3.5 \mathrm{~s}$ & 0.011 & 1.000 & & & 4 & 092 \\
\hline $30 \mathrm{~s}-4.0 \mathrm{~s}$ & oxplo & 1.000 & 10 & arots: & 0.337 & 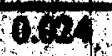 \\
\hline $30 \mathrm{~s}-4.5 \mathrm{~s}$ & Oxts: & 1.000 & roses & $\$ 201$ & 0.328 & 0,021 \\
\hline $30 \mathrm{~s}-5.0 \mathrm{~s}$ & 0.015 & 1.000 & 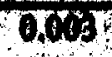 & $0 \times 014$ & 0.365 & OATH: \\
\hline $30 s-10 s$ & 0.120 & 1.000 & 0.024 & 0.581 & 0.972 & 0.367 \\
\hline $30 s-15 s$ & 0.884 & 1.000 & 0.670 & 0.986 & 0.823 & 0.983 \\
\hline $30 s-20 s$ & 1.000 & 1.000 & 0.992 & 1.000 & 1.000 & 1.000 \\
\hline $30 s-25 s$ & 1.000 & 1.000 & 1.000 & 1.000 & 1.000 & 1.000 \\
\hline
\end{tabular}


Table C.21: Pairwise comparison with Sidak correction for FT-EO of 11 trials for subject 6.

\begin{tabular}{|c|c|c|c|c|c|c|}
\hline \multicolumn{7}{|c|}{ Pairwise comparison } \\
\hline \multirow{2}{*}{ Window Pair } & \multicolumn{6}{|c|}{ Sig. (2-tailed) for S6 FT-EO } \\
\hline & RDavg & $V_{\text {avg }}$ & AREA & SD_RD & $\sigma_{x}$ & $\sigma_{y}$ \\
\hline $30 \mathrm{~s}-1.5 \mathrm{~s}$ & .001 & 1.000 & 30.001 & 0019 & 0010 & 0.009 \\
\hline $30 s-2.0 s$ & .071 & 1.000 & $\$, 001$ & 0.099 & 0.272 & 0.166 \\
\hline $30 \mathrm{~s}-2.5 \mathrm{~s}$ & .160 & 1.000 & 0.001 & 0.101 & 0.586 & 0.120 \\
\hline $30 \mathrm{~s}-3.0 \mathrm{~s}$ & .075 & 1.000 & 40.001 & 0.106 & 0.517 & 0.026 \\
\hline $30 \mathrm{~s}-3.5 \mathrm{~s}$ & .177 & 1.000 & 0.001 & 0.067 & 0.679 & $0.01 \%$ \\
\hline $30 \mathrm{~s}-4.0 \mathrm{~s}$ & .347 & 1.000 & 0.038 & 0.051 & 0.754 & 0.017 \\
\hline $30 \mathrm{~s}-4.5 \mathrm{~s}$ & .327 & 1.000 & 0.007 & 0.073 & 0.630 & 0.111 \\
\hline $30 \mathrm{~s}-5.0 \mathrm{~s}$ & .455 & 1.000 & 0.015 & 0.085 & 0.816 & 0.073 \\
\hline $30 s-10 s$ & .466 & 1.000 & 0.215 & 0.104 & 0.628 & 0.971 \\
\hline $30 s-15 s$ & .210 & 1.000 & 0.315 & 0.354 & 0.277 & 1.000 \\
\hline $30 s-20 s$ & .483 & 1.000 & 0.840 & 0.593 & 0.111 & 1.000 \\
\hline $30 s-25 s$ & .751 & 1.000 & 0.881 & 0.744 & 0.645 & 1.000 \\
\hline
\end{tabular}

Table C.22: Pairwise comparison with Sidak correction for FT-EC of 11 trials for subject 6.

\begin{tabular}{|c|c|c|c|c|c|c|}
\hline \multicolumn{7}{|c|}{ Pairwise comparison } \\
\hline \multirow{2}{*}{ Window Pair } & \multicolumn{5}{|c|}{ Sig-tailed) for S6 FT-EC } \\
\cline { 2 - 7 } & RDavg & $V_{\text {avg }}$ & AREA & SD_RD & $\sigma_{x}$ & $\sigma_{y}$ \\
\hline $30 \mathrm{~s}-1.5 \mathrm{~s}$ & 0.023 & 1.000 & 0.011 & 0.004 & 0.110 & 0.018 \\
\hline $30 \mathrm{~s}-2.0 \mathrm{~s}$ & 0.109 & 1.000 & 0.026 & 0.006 & 0.790 & 0.019 \\
\hline $30 \mathrm{~s}-2.5 \mathrm{~s}$ & 0.176 & 1.000 & 0.043 & 0.004 & 0.976 & 0.038 \\
\hline $30 \mathrm{~s}-3.0 \mathrm{~s}$ & 0.189 & 1.000 & 0.086 & 0.015 & 0.939 & 0.076 \\
\hline $30 \mathrm{~s}-3.5 \mathrm{~s}$ & 0.300 & 1.000 & 0.249 & 0.033 & 0.897 & 0.156 \\
\hline $30 \mathrm{~s}-4.0 \mathrm{~s}$ & 0.336 & 1.000 & 0.301 & 0.038 & 0.748 & 0.193 \\
\hline $30 \mathrm{~s}-4.5 \mathrm{~s}$ & 0.377 & 1.000 & 0.344 & 0.179 & 0.816 & 0.269 \\
\hline $30 \mathrm{~s}-5.0 \mathrm{~s}$ & 0.335 & 1.000 & 0.301 & 0.311 & 0.680 & 0.294 \\
\hline $30 \mathrm{~s}-10 \mathrm{~s}$ & 0.378 & 0.978 & 0.478 & 0.372 & 0.976 & 0.279 \\
\hline $30 \mathrm{~s}-15 \mathrm{~s}$ & 0.914 & 0.988 & 0.907 & 0.678 & 0.991 & 0.928 \\
\hline $30 \mathrm{~s}-20 \mathrm{~s}$ & 1.000 & 1.000 & 1.000 & 0.997 & 0.944 & 1.000 \\
\hline $30 \mathrm{~s}-25 \mathrm{~s}$ & 1.000 & 1.000 & 1.000 & 1.000 & 0.943 & 1.000 \\
\hline
\end{tabular}


Table C.23: Pairwise comparison with Sidak correction for SL-EO of 11 trials for subject 6.

\begin{tabular}{|c|c|c|c|c|c|c|}
\hline \multicolumn{7}{|c|}{ Pairwise comparison } \\
\hline \multirow{2}{*}{ Window Pair } & \multicolumn{5}{|c|}{ Sig-tailed) for S6 SL-EO } \\
\cline { 2 - 7 } & RDavg & $V_{\text {avg }}$ & AREA & SD_RD & $\sigma_{\boldsymbol{x}}$ & $\sigma_{\boldsymbol{y}}$ \\
\hline $30 \mathrm{~s}-1.5 \mathrm{~s}$ & 0.034 & 1.000 & $\mathbf{0 0 6 5}$ & 0.555 & 0.943 & 0.3 \\
\hline $30 \mathrm{~s}-2.0 \mathrm{~s}$ & 0.07 & 1.000 & 0.016 & 0.915 & 0.999 & 0.080 \\
\hline $30 \mathrm{~s}-2.5 \mathrm{~s}$ & 0.776 & 1.000 & 0.268 & 0.949 & 1.000 & 0.218 \\
\hline $30 \mathrm{~s}-3.0 \mathrm{~s}$ & 0.911 & 1.000 & 0.400 & 0.916 & 1.000 & 0.299 \\
\hline $30 \mathrm{~s}-3.5 \mathrm{~s}$ & 0.963 & 1.000 & 0.601 & 0.987 & 1.000 & 0.661 \\
\hline $30 \mathrm{~s}-4.0 \mathrm{~s}$ & 0.945 & 1.000 & 0.611 & 0.989 & 1.000 & 0.733 \\
\hline $30 \mathrm{~s}-4.5 \mathrm{~s}$ & 0.818 & 1.000 & 0.534 & 0.990 & 1.000 & 0.496 \\
\hline $30 \mathrm{~s}-5.0 \mathrm{~s}$ & 0.812 & 1.000 & 0.561 & 0.983 & 1.000 & 0.348 \\
\hline $30 \mathrm{~s}-10 \mathrm{~s}$ & 1.000 & 1.000 & 0.987 & 0.998 & 1.000 & 0.388 \\
\hline $30 \mathrm{~s}-15 \mathrm{~s}$ & 0.998 & 1.000 & 0.993 & 1.000 & 1.000 & 0.747 \\
\hline $30 \mathrm{~s}-20 \mathrm{~s}$ & 0.999 & 1.000 & 1.000 & 1.000 & 1.000 & 0.703 \\
\hline $30 \mathrm{~s}-25 \mathrm{~s}$ & 1.000 & 1.000 & 1.000 & 1.000 & 1.000 & 0.998 \\
\hline
\end{tabular}

Table C.24: Pairwise comparison with Sidak correction for SL-EC of 11 trials for subject 6.

\begin{tabular}{|c|c|c|c|c|c|c|}
\hline \multicolumn{7}{|c|}{ Pairwise comparison } \\
\hline \multirow{2}{*}{ Window Pair } & \multicolumn{6}{|c|}{ Sig. (2-tailed) for S6 SL-EC } \\
\hline & RDavg & $V_{\text {avg }}$ & AREA & SD_RD & $\sigma_{x}$ & $\sigma_{y}$ \\
\hline $30 s-1.5 s$ & 0.097 & 1.000 & 0002 & guse & 0.981 & 0.002 \\
\hline $30 \mathrm{~s}-2.0 \mathrm{~s}$ & 0.098 & 1.000 & ons & ons & 0.955 & aspo \\
\hline $30 \mathrm{~s}-2.5 \mathrm{~s}$ & 0.218 & 1.000 & 0.015 & ones. & 0.999 & 0.005 \\
\hline $30 \mathrm{~s}-3.0 \mathrm{~s}$ & 0.210 & 1.000 & 043 & 0.109 & 0.996 & 0.015 \\
\hline $30 \mathrm{~s}-3.5 \mathrm{~s}$ & 0.118 & 1.000 & oogs & 0.134 & 0.967 & 0.013 \\
\hline $30 s-4.0 s$ & 0.093 & 1.000 & 0006 & 0.123 & 0.946 & 0.012 \\
\hline $30 \mathrm{~s}-4.5 \mathrm{~s}$ & 0.041 & 1.000 & 0.015 & 0.158 & 0.902 & 0005 \\
\hline $30 s-5.0 s$ & 0,034 & 1.000 & 0.02 & 0.598 & 0.994 & 000 \\
\hline $30 s-10 s$ & 0.844 & 1.000 & 0.988 & 1.000 & 1.000 & 0.920 \\
\hline $30 s-15 s$ & 1.000 & 1.000 & 1.000 & 1.000 & 1.000 & 1.000 \\
\hline $30 s-20 s$ & 1.000 & 1.000 & 1.000 & 1.000 & 1.000 & 1.000 \\
\hline $30 s-25 s$ & 1.000 & 1.000 & 1.000 & 1.000 & 1.000 & 1.000 \\
\hline
\end{tabular}


Table C.25: Pairwise comparison with Sidak correction for FT-EO of 11 trials for subject 7.

\begin{tabular}{|c|c|c|c|c|c|c|}
\hline \multicolumn{7}{|c|}{ Pairwise comparison } \\
\hline \multirow{2}{*}{ Window Pair } & \multicolumn{5}{|c|}{ Sig. (2-tailed) for S7 FT-EO } \\
\cline { 2 - 7 } & RDavg & $V_{\text {avg }}$ & AREA & SD_RD & $\sigma_{x}$ & $\sigma_{y}$ \\
\hline $30 \mathrm{~s}-1.5 \mathrm{~s}$ & 0.004 & 1.000 & 0.007 & $\mathbf{6 0 0 1}$ & $\mathbf{0 0 0 1}$ & 0.056 \\
\hline $30 \mathrm{~s}-2.0 \mathrm{~s}$ & 0.070 & 1.000 & 0.054 & 0.004 & 0.101 & 0.03 \\
\hline $30 \mathrm{~s}-2.5 \mathrm{~s}$ & 0.520 & 1.000 & 0.383 & 0.034 & 0.670 & 0.345 \\
\hline $30 \mathrm{~s}-3.0 \mathrm{~s}$ & 0.608 & 1.000 & 0.504 & 0.026 & 0.483 & 0.557 \\
\hline $30 \mathrm{~s}-3.5 \mathrm{~s}$ & 0.510 & 1.000 & 0.414 & 0.013 & 0.415 & 0.524 \\
\hline $30 \mathrm{~s}-4.0 \mathrm{~s}$ & 0.432 & 1.000 & 0.366 & 0.054 & 0.473 & 0.536 \\
\hline $30 \mathrm{~s}-4.5 \mathrm{~s}$ & 0.375 & 1.000 & 0.302 & 0.109 & 0.239 & 0.747 \\
\hline $30 \mathrm{~s}-5.0 \mathrm{~s}$ & 0.481 & 1.000 & 0.241 & 0.062 & 0.135 & 0.853 \\
\hline $30 \mathrm{~s}-10 \mathrm{~s}$ & 0.824 & 1.000 & 0.645 & 0.533 & 0.770 & 0.983 \\
\hline $30 \mathrm{~s}-15 \mathrm{~s}$ & 0.993 & 1.000 & 0.994 & 1.000 & 1.000 & 1.000 \\
\hline $30 \mathrm{~s}-20 \mathrm{~s}$ & 1.000 & 0.997 & 1.000 & 1.000 & 1.000 & 1.000 \\
\hline $30 \mathrm{~s}-25 \mathrm{~s}$ & 1.000 & 0.991 & 1.000 & 1.000 & 1.000 & 1.000 \\
\hline & & & & & & \\
\hline
\end{tabular}

Table C.26: Pairwise comparison with Sidak correction for FT-EC of 11 trials for subject 7.

\begin{tabular}{|c|c|c|c|c|c|c|}
\hline \multicolumn{7}{|c|}{ Pairwise comparison } \\
\hline \multirow{2}{*}{ Window Pair } & \multicolumn{6}{|c|}{ Sig. (2-tailed) for S7 FT-EC } \\
\hline & RDavg & $V_{a v g}$ & AREA & SD_RD & $\sigma_{x}$ & $\sigma_{y}$ \\
\hline $30 \mathrm{~s}-1.5 \mathrm{~s}$ & 0.023 & 1.000 & 0011 & 0.004 & 0.110 & 0018 \\
\hline $30 \mathrm{~s}-2.0 \mathrm{~s}$ & 0.109 & 1.000 & apo: & Oeas: & 0.790 & 0019 \\
\hline $30 \mathrm{~s}-2.5 \mathrm{~s}$ & 0.176 & 1.000 & ars. & 801 & 0.976 & 0.038 \\
\hline $30 \mathrm{~s}-3.0 \mathrm{~s}$ & 0.189 & 1.000 & 0.086 & 0015 & 0.939 & 0.076 \\
\hline $30 \mathrm{~s}-3.5 \mathrm{~s}$ & 0.300 & 1.000 & 0.249 & 0108 & 0.897 & 0.156 \\
\hline $30 s-4.0 s$ & 0.336 & 1.000 & 0.301 & 608 & 0.748 & 0.193 \\
\hline $30 s-4.5 s$ & 0.377 & 1.000 & 0.344 & 0.179 & 0.816 & 0.269 \\
\hline $30 \mathrm{~s}-5.0 \mathrm{~s}$ & 0.335 & 1.000 & 0.301 & 0.311 & 0.680 & 0.294 \\
\hline $30 s-10 s$ & 0.378 & 0.978 & 0.478 & 0.372 & 0.976 & 0.279 \\
\hline $30 s-15 s$ & 0.914 & 0.988 & 0.907 & 0.678 & 0.991 & 0.928 \\
\hline $30 s-20 s$ & 1.000 & 1.000 & 1.000 & 0.997 & 0.944 & 1.000 \\
\hline $30 s-25 s$ & 1.000 & 1.000 & 1.000 & 1.000 & 0.943 & 1.000 \\
\hline
\end{tabular}


Table C.27: Pairwise comparison with Sidak correction for SL-EO of 11 trials for subject 7.

\begin{tabular}{|c|c|c|c|c|c|c|}
\hline \multicolumn{7}{|c|}{ Pairwise comparison } \\
\hline \multirow{2}{*}{ Window Pair } & \multicolumn{7}{|c|}{ (2-tailed) for S7 SL-EO } \\
\cline { 2 - 7 } & RDavg & $V_{\text {avg }}$ & AREA & SD_RD & $\sigma_{x}$ & $\sigma_{y}$ \\
\hline $30 \mathrm{~s}-1.5 \mathrm{~s}$ & 0.987 & 1.000 & 0.407 & 0.138 & 0.996 & 0.949 \\
\hline $30 \mathrm{~s}-2.0 \mathrm{~s}$ & 0.997 & 1.000 & 0.615 & 0.766 & 0.321 & 1.000 \\
\hline $30 \mathrm{~s}-2.5 \mathrm{~s}$ & 0.990 & 1.000 & 0.694 & 1.000 & 0.545 & 1.000 \\
\hline $30 \mathrm{~s}-3.0 \mathrm{~s}$ & 0.825 & 1.000 & 0.454 & 1.000 & 0.316 & 0.992 \\
\hline $30 \mathrm{~s}-3.5 \mathrm{~s}$ & 0.525 & 1.000 & 0.301 & 1.000 & 0.166 & 0.968 \\
\hline $30 \mathrm{~s}-4.0 \mathrm{~s}$ & 0.784 & 1.000 & 0.451 & 1.000 & 0.916 & 0.970 \\
\hline $30 \mathrm{~s}-4.5 \mathrm{~s}$ & 0.851 & 1.000 & 0.564 & 1.000 & 0.860 & 0.982 \\
\hline $30 \mathrm{~s}-5.0 \mathrm{~s}$ & 0.899 & 1.000 & 0.524 & 1.000 & 0.488 & 1.000 \\
\hline $30 \mathrm{~s}-10 \mathrm{~s}$ & 0.976 & 1.000 & 0.827 & 1.000 & 0.543 & 1.000 \\
\hline $30 \mathrm{~s}-15 \mathrm{~s}$ & 0.870 & 1.000 & 0.964 & 1.000 & 0.677 & 1.000 \\
\hline $30 \mathrm{~s}-20 \mathrm{~s}$ & 0.777 & 1.000 & 0.996 & 1.000 & 0.955 & 1.000 \\
\hline $30 \mathrm{~s}-25 \mathrm{~s}$ & 1.000 & 1.000 & 1.000 & 1.000 & 1.000 & 1.000 \\
\hline
\end{tabular}

Table C.28: Pairwise comparison with Sidak correction for SL-EC of 11 trials for subject 7.

\begin{tabular}{|c|c|c|c|c|c|c|}
\hline \multicolumn{7}{|c|}{ Pairwise comparison } \\
\hline \multirow{2}{*}{ Window Pair } & \multicolumn{5}{|c|}{ Sig. (2-tailed) for S7 SL-EC } \\
\cline { 2 - 7 } & RDavg & $V_{\text {avg }}$ & AREA & SD_RD & $\sigma_{x}$ & $\sigma_{y}$ \\
\hline $30 \mathrm{~s}-1.5 \mathrm{~s}$ & 0.003 & 1.000 & 0.001 & 0.003 & 0.004 & 0.003 \\
\hline $30 \mathrm{~s}-2.0 \mathrm{~s}$ & 0.018 & 1.000 & 0.003 & 0.016 & 0.246 & 0.095 \\
\hline $30 \mathrm{~s}-2.5 \mathrm{~s}$ & 0.073 & 1.000 & 0.022 & 0.033 & 0.928 & 0.009 \\
\hline $30 \mathrm{~s}-3.0 \mathrm{~s}$ & 0.073 & 1.000 & 0.031 & 0.024 & 0.921 & 0.011 \\
\hline $30 \mathrm{~s}-3.5 \mathrm{~s}$ & 0.116 & 1.000 & 0.056 & 0.030 & 0.932 & 0.027 \\
\hline $30 \mathrm{~s}-4.0 \mathrm{~s}$ & 0.116 & 1.000 & 0.065 & 0.026 & 0.968 & 0.037 \\
\hline $30 \mathrm{~s}-4.5 \mathrm{~s}$ & 0.097 & 1.000 & 0.048 & 0.054 & 0.634 & 0.068 \\
\hline $30 \mathrm{~s}-5.0 \mathrm{~s}$ & 0.128 & 0.997 & 0.055 & 0.027 & 0.781 & 0.076 \\
\hline $30 \mathrm{~s}-10 \mathrm{~s}$ & 0.844 & 0.911 & 0.623 & 0.416 & 0.110 & 0.877 \\
\hline $30 \mathrm{~s}-15 \mathrm{~s}$ & 1.000 & 1.000 & 0.966 & 0.996 & 1.000 & 1.000 \\
\hline $30 \mathrm{~s}-20 \mathrm{~s}$ & 1.000 & 1.000 & 0.999 & 1.000 & 1.000 & 1.000 \\
\hline $30 \mathrm{~s}-25 \mathrm{~s}$ & 0.999 & 1.000 & 0.995 & 1.000 & 1.000 & 1.000 \\
\hline
\end{tabular}


Table C.29: Pairwise comparison with Sidak correction for FT-EO of 11 trials for subject 8.

\begin{tabular}{|c|c|c|c|c|c|c|}
\hline \multicolumn{7}{|c|}{ Pairwise comparison } \\
\hline \multirow{2}{*}{ Window Pair } & \multicolumn{6}{|c|}{ Sig. (2-tailed) for S8 FT-EO } \\
\hline & RDavg & $V_{\text {avg }}$ & AREA & SD_RD & $\sigma_{x}$ & $\sigma_{y}$ \\
\hline $30 \mathrm{~s}-1.5 \mathrm{~s}$ & 0.010 & 1.000 & 0010 & 0.001 & 0.030 & 0.009 \\
\hline $30 \mathrm{~s}-2.0 \mathrm{~s}$ & 0.046 & 1.000 & 002 & Q001 & 0.164 & 0.00 \\
\hline $30 \mathrm{~s}-2.5 \mathrm{~s}$ & 0.114 & 1.000 & 0.056 & 0.001 & 0.474 & 0,0 \\
\hline $30 s-3.0 s$ & 0.110 & 1.000 & 0.074 & 0.004 & 0.486 & 0.60 \\
\hline $30 \mathrm{~s}-3.5 \mathrm{~s}$ & 0.135 & 1.000 & 0.088 & 0015 & 0.679 & 0.005 \\
\hline $30 s-4.0 s$ & 0.102 & 1.000 & 0.080 & 0.017 & 0.677 & 0.009 \\
\hline $30 \mathrm{~s}-4.5 \mathrm{~s}$ & 0.071 & 1.000 & 0.077 & 0.015 & 0.591 & 0,005 \\
\hline $30 \mathrm{~s}-5.0 \mathrm{~s}$ & 0.055 & 1.000 & 0.088 & 0.086 & 0.471 & 0.004 \\
\hline $30 s-10 s$ & 0.367 & 1.000 & 0.383 & 0.061 & 0.583 & 0.182 \\
\hline $30 s-15 s$ & 0.963 & 1.000 & 0.628 & 0.310 & 0.983 & 0.922 \\
\hline $30 s-20 s$ & 1.000 & 1.000 & 0.938 & 0.983 & 1.000 & 1.000 \\
\hline $30 s-25 s$ & 1.000 & 1.000 & 1.000 & 1.000 & 1.000 & 1.000 \\
\hline
\end{tabular}

Table C.30: Pairwise comparison with Sidak correction for FT-EC of 11 trials for subject 8.

\begin{tabular}{|c|c|c|c|c|c|c|}
\hline \multicolumn{7}{|c|}{ Pairwise comparison } \\
\hline \multirow{2}{*}{ Window Pair } & \multicolumn{5}{|c|}{ Sig. (2-tailed) for S8 FT-EC } \\
\cline { 2 - 7 } & RDavg & $V_{\text {avg }}$ & AREA & SD_RD & $\sigma_{x}$ & $\sigma_{y}$ \\
\hline $30 \mathrm{~s}-1.5 \mathrm{~s}$ & 0.023 & 1.000 & 0.011 & 0.004 & 0.110 & 0.014 \\
\hline $30 \mathrm{~s}-2.0 \mathrm{~s}$ & 0.109 & 1.000 & 0.026 & 000 & 0.790 & 0.019 \\
\hline $30 \mathrm{~s}-2.5 \mathrm{~s}$ & 0.176 & 1.000 & 0.043 & 0.021 & 0.976 & 0.038 \\
\hline $30 \mathrm{~s}-3.0 \mathrm{~s}$ & 0.189 & 1.000 & 0.069 & 0.015 & 0.939 & 0.076 \\
\hline $30 \mathrm{~s}-3.5 \mathrm{~s}$ & 0.300 & 1.000 & 0.249 & 0.033 & 0.897 & 0.156 \\
\hline $30 \mathrm{~s}-4.0 \mathrm{~s}$ & 0.336 & 1.000 & 0.301 & 0.038 & 0.748 & 0.193 \\
\hline $30 \mathrm{~s}-4.5 \mathrm{~s}$ & 0.377 & 1.000 & 0.344 & 0.179 & 0.816 & 0.269 \\
\hline $30 \mathrm{~s}-5.0 \mathrm{~s}$ & 0.335 & 1.000 & 0.301 & 0.311 & 0.680 & 0.294 \\
\hline $30 \mathrm{~s}-10 \mathrm{~s}$ & 0.378 & 0.978 & 0.478 & 0.372 & 0.976 & 0.279 \\
\hline $30 \mathrm{~s}-15 \mathrm{~s}$ & 0.914 & 0.988 & 0.907 & 0.678 & 0.991 & 0.928 \\
\hline $30 \mathrm{~s}-20 \mathrm{~s}$ & 1.000 & 1.000 & 1.000 & 0.997 & 0.944 & 1.000 \\
\hline $30 \mathrm{~s}-25 \mathrm{~s}$ & 1.000 & 1.000 & 1.000 & 1.000 & 0.943 & 1.000 \\
\hline
\end{tabular}


Table C.31: Pairwise comparison with Sidak correction for SL-EO of 11 trials for subject 8.

\begin{tabular}{|c|c|c|c|c|c|c|}
\hline \multicolumn{7}{|c|}{ Pairwise comparison } \\
\hline \multirow{2}{*}{ Window Pair } & \multicolumn{6}{|c|}{ Sig. (2-tailed) for S8 SL-EO } \\
\hline & RDavg & $V_{\text {avg }}$ & AREA & SD_RD & $\sigma_{x}$ & $\sigma_{y}$ \\
\hline $30 s-1.5 s$ & 0.002 & 1.000 & $000 \%$ & 0.003 & $00 \%$ & \\
\hline $30 s-2.0 s$ & 0.035 & 1.000 & ad1 & 0 otw & 0.548 & \\
\hline $30 \mathrm{~s}-2.5 \mathrm{~s}$ & 0.042 & 1.000 & $00 \%$ & 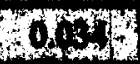 & 0.832 & \\
\hline $30 \mathrm{~s}-3.0 \mathrm{~s}$ & 0.072 & 1.000 & 0.086 & 0.061 & 0.987 & \\
\hline $30 \mathrm{~s}-3.5 \mathrm{~s}$ & 0.064 & 1.000 & 0.079 & 0.082 & 0.998 & \\
\hline $30 \mathrm{~s}-4.0 \mathrm{~s}$ & 0.081 & 1.000 & 0.111 & 0.125 & 0.998 & \\
\hline $30 \mathrm{~s}-4.5 \mathrm{~s}$ & 0.051 & 1.000 & 0.075 & 0.160 & 0.990 & \\
\hline $30 \mathrm{~s}-5.0 \mathrm{~s}$ & 0.038 & 1.000 & oas & 0.208 & 0.975 & $\mathbf{6 0}$ \\
\hline $30 s-10 s$ & 0.011 & 1.000 & 0.013 & 0.373 & 0.936 & 0.012 \\
\hline $30 s-15 s$ & 0.081 & 1.000 & 0.052 & 0.559 & 0.971 & 0.186 \\
\hline $30 s-20 s$ & 0.423 & 1.000 & 0.249 & 0.894 & 1.000 & 0.605 \\
\hline $30 s-25 s$ & 0.486 & 1.000 & 0.675 & 1.000 & 0.998 & 0.902 \\
\hline
\end{tabular}

Table C.32: Pairwise comparison with Sidak correction for SL-EC of 11 trials for subject 8.

\begin{tabular}{|c|c|c|c|c|c|c|}
\hline \multicolumn{7}{|c|}{ Pairwise comparison } \\
\hline \multirow{2}{*}{ Window Pair } & \multicolumn{6}{|c|}{ Sig. (2-tailed) for S8 SL-EC } \\
\hline & RDavg & $V_{\text {avg }}$ & AREA & SD_RD & $\sigma_{x}$ & $\sigma_{y}$ \\
\hline $30 \mathrm{~s}-1.5 \mathrm{~s}$ & 0005 & 1.000 & 0.010 & o67 & 0.494 & 0,038 \\
\hline $30 \mathrm{~s}-2.0 \mathrm{~s}$ & ton: & 1.000 & ooce: & 0.097 & 0.991 & (x.06) \\
\hline $30 \mathrm{~s}-2.5 \mathrm{~s}$ & 0.051 & 1.000 & 0.056 & 0.059 & 0.859 & 0038 \\
\hline $30 \mathrm{~s}-3.0 \mathrm{~s}$ & dose & 1.000 & 0.074 & $0.6 \%$ & 0.655 & 0.161 \\
\hline $30 \mathrm{~s}-3.5 \mathrm{~s}$ & 0.038 & 1.000 & 0.088 & 2043 & 0.611 & 0.121 \\
\hline $30 \mathrm{~s}-4.0 \mathrm{~s}$ & 0.007 & 1.000 & 0.080 & $00 \%$ & 0.321 & 0.042 \\
\hline $30 \mathrm{~s}-4.5 \mathrm{~s}$ & 0.004 & 0.860 & 0.077 & 600 & 0.451 & $60 \mathrm{xi}$ \\
\hline $30 \mathrm{~s}-5.0 \mathrm{~s}$ & 0009 & 0.950 & 0.088 & 0.119 & 0.722 & 0.026 \\
\hline $30 s-10 s$ & 0.191 & 1.000 & 0.383 & 0.314 & 0.999 & 0.632 \\
\hline $30 s-15 s$ & 0.451 & 1.000 & 0.628 & 0.228 & 0.954 & 0.724 \\
\hline $30 s-20 s$ & 0.749 & 1.000 & 0.938 & 0.573 & 1.000 & 0.420 \\
\hline $30 s-25 s$ & 0.999 & 1.000 & 1.000 & 1.000 & 1.000 & 0.999 \\
\hline
\end{tabular}




\section{References}

Abarbanel, H. D. I., Gills, Z., Liu, C., \& Roy, R. (1996). Nonlinear-time-series analysis of chaotic laser dynamics. Physical review. A, 53(1), 440-453.

Advanced Mechanical Technology, Inc. (AMTI). (2012).Force Platform Mounting Information. Retrieved October 6, 2012, from http://amti.biz/fps-mounting.aspx

American Geriatrics Society. (2001). Guideline for the Prevention of Falls in Older Persons. Journal of the American Geriatrics Society, 49(5), 664-672. doi:10.1046/j.1532-5415.2001.49115.x

Askvik, B. (2010). Effects of exercise in elderly women with osteopenia or osteoporosis. Master Thesis in Sport Sciences, Department of Sports Medicine, Norwegian School of Sports Sciences.

Baloh, R. W., Jacobson, K. M., Beykirch, K., \& Honrubia, V. (1998). Static and dynamic posturography in patients with vestibular and cerebellar lesions. Archives of neurology, 55(5), 649-54.

Baratto, L., Morasso, P. G., Re, C., \& Spada, G. (2002). A new look at posturographic analysis in the clinical context: sway-density versus other parameterization techniques. Motor control, 6(3), 246-70.

Barrett, R., Hyde, S. A., \& Hark, W. B. (1987). The design of a force platform for clinical use: a feasibility study of stabilograpy in evaluating the effect of orthotic intervention in Duchenne muscular dystrophy. Journal of Medical Engineering \& Technology, 11(2), 68-73.

Berg, K. O., Maki, B. E., Williams, J. I., Holliday, P. J., \& Wood-Dauphinee, S. L. (1992). Clinical and laboratory measures of postural balance in an elderly population. Archives of physical medicine and rehabilitation, 73(11), 1073-80.

Berger, W., Horstmann, G., \& Dietz, V. (1984). Tension development and muscle activation in the leg during gait in spastic hemiparesis: independence of muscle hypertonia and exaggerated stretch reflexes. Journal of neurology, neurosurgery, and psychiatry, 47(9), 1029-33.

Bickerstaffe, A., Beelen, A., \& Nollet, F. (2010). Circumstances and consequences of falls in polio survivors. Journal of rehabilitation medicine, 42(10), 908-15. doi: $10.2340 / 16501977-0620$

BioAnalysis, V2.2. (2004). 176 Waltham St., Watertown, Massachusetts 02472-4800. 
Bizzo, G., Guillet, N., Patat, A., \& Gagey, P, M. (1985). Specification for building a vertical force platform designed for clinical stabilometry. Medical \& biological engineering \& computing, 23(September), 474-476.

Bobbert, M. F., \& Schamhardt, H. C. (1990). Accuracy of Determining the Point of Force Application with Piezoelectric Force Plates. Journal of Biomechanics, 23, 705-710.

Boes, M. K. (2011). Postural control in persons with multiple sclerosis: An investigation of dual task cost and physical modeling. Master Thesis, Master of Science in Bioengineering in the Graduate College of the University of Illinois at UrbanaChampaign, Urbana, IL.

Braga B., A., Rodrigue, C. deMello A., Lima, G. V., Larissa Rabello DE Melo, L., Rodrigo De Carvalho, A., \& Bertolini, G. R. F. B. (2012). compaRison of static postuRal balance between healthy subJects and those with low bacK pain, 20(4), 2010-2012.

Brenière, Y. (1996). Why we walk the way we do. Journal of motor behavior, 28(4), 291-298.

Browne, J., \& O'Hare, N. (2000a). A quality control procedure for force platforms. Physiological measurement, 21, 515-524.

Browne, J., \& O'Hare, N. (2000b). Development of a novel method for assessing balance: the quantitative posturography system. Physiological measurement, 21(4), $525-34$.

Browne, J., \& O'Hare, N. J. (2001). Review of the Different Methods for Assessing Standing Balance. Physiotherapy, 87(9), 489-495. doi:10.1016/S00319406(05)60696-7

Buckley, F. J. (1989). Establishing a standard metrics program, (July).

Bustamante Valles, K. D., Long, J. T., Riedel, S. a, Graf, A., Krzak, J., Hassani, S., Smith, P. a, et al. (2008). Application of a bi-planar postural stability model in children with cerebral palsy. Conference proceedings: Annual International Conference of the IEEE Engineering in Medicine and Biology Society., 2008(3), 4535-8. doi:10.1109/IEMBS.2008.4650221

CDC. (2012). Costs of Falls Among Older Adults. 4770 Buford Hwy, NE MS F-63 Atlanta, GA 30341-3717. Retrieved from http://www.cdc.gov/HomeandRecreationalSafety/Falls/fallcost.html 
Carpenter, M. G., Frank, J. S., Winter, D. a, \& Peysar, G. W. (2001). Sampling duration effects on centre of pressure summary measures. Gait \& posture, 13(1), 35-40. Retrieved from http://www.ncbi.nlm.nih.gov/pubmed/11166552

Cavalheiro, G. L., Almeida, M. F. S., Pereira, A. A., \& Andrade, A. O. (2009). Study of age-related changes in postural control during quiet standing through linear discriminant analysis. BioMedical Engineering onLine, 8, 35. doi:10.1186/1475925X-8-35

Cavanaugh, J. T., Guskiewicz, K. M., Giuliani, C., Marshall, S., Mercer, V., \& Stergiou, N. (2005). Detecting altered postural control after cerebral concussion in athletes with normal postural stability. British journal of sports medicine, 39(11), 805-811. doi:10.1136/bjsm.2004.015909

Clair, K. L., \& Riach, C. (1996). Postural stability measures: what to measure and for how long. Clinical biomechanics, II(3), 176-178.

Collins, J. J., \& De Luca, C. J. (1993). Open-loop and closed-loop control of posture: a random-walk analysis of center-of-pressure trajectories. Experimental brain research, 95(2), 308-318.

Corbeil, P., Blouin, J.-S., Bégin, F., Nougier, V., \& Teasdale, N. (2003). Perturbation of the postural control system induced by muscular fatigue. Gait \& Posture, 18(2), 92100. doi:10.1016/S0966-6362(02)00198-4

Curcio, C.-L., Gomez, F., \& Reyes-Ortiz, C. A. (2009a). Activity restriction related to fear of falling among older people in the Colombian Andes mountains: are functional or psychosocial risk factors more important? Journal of Aging and Health, 21(3), 460-79. doi:10.1177/0898264308329024

Curcio, C.-L., Gomez, F., \& Reyes-Ortiz, C. a. (2009b). Activity restriction related to fear of falling among older people in the Colombian Andes mountains: are functional or psychosocial risk factors more important? Journal of aging and health, 21(3), 460-79. doi:10.1177/0898264308329024

Davies, L. D., \& Bouldin, D. W. (1979). A Cluster Separation measure. IEEE transactions on pattern analysis and Machine intelligence, 1(2), 224-227.

Dietz, V. (1992). Human neuronal control of automatic functional movements: interaction between central programs and afferent input. Physiological reviews, 72(1), 33-69.

Donker, S. F., Roerdink, M., Greven, A. J., \& Beek, P. J. (2007). Regularity of center-ofpressure trajectories depends on the amount of attention invested in postural control. 
Experimental brain research. Experimentelle Hirnforschung. Expérimentation cérébrale, 181(1), 1-11. doi:10.1007/s00221-007-0905-4

Doyle, R. J., Hsiao-Wecksler, E. T., Ragan, B. G., \& Rosengren, K. S. (2007). Generalizability of center of pressure measures of quiet standing. Gait \& posture, 25(2), 166-171. doi:10.1016/j.gaitpost.2006.03.004

Duncan, P. W., Weiner, D. K., Chandler, J., \& Studenski, S. (1990). Functional reach: a new clinical measure of balance. Journal of gerontology, 45(6), M192-7.

Dunn, J. C. (1974). Well separated clusters and optimal fuzzy partitions. J Cybern, 4, 95104.

Fioretti, S., Guidi, M., Ladislao, L., \& Ghetti, G. (2004). Analysis and reliability of posturographic parameters in Parkinson patients at an early stage. Conference proceedings: Annual International Conference of the IEEE Engineering in Medicine and Biology Society., 1, 651-4. doi:10.1109/IEMBS.2004.1403242

Fletcher, G. F., Balady, G., Blair, S. N., Caspersen, C., Chaitman, B., Epstein, S., \& Pollock, M. L. (1996). Statement on Exercise : Benefits and Recommendations for Physical Activity Programs for All Americans.

Gage, W. H., Winter, D. A., Frank, J. S., \& Adkin, A. L. (2004). Kinematic and kinetic validity of the inverted pendulum model in quiet standing. Gait \& posture, 19(2), 124-32. doi:10.1016/S0966-6362(03)00037-7

Gill, H. S., \& O'Connor, J. J. (1997). A new testing rig for force platform calibration and accuracy tests. Gait \& Posture, 5(3), 228-232. doi:10.1016/S0966-6362(96)01090-9

Gosselin, G., Rassoulian, H., \& Brown, I. (2004). Effects of neck extensor muscles fatigue on balance. Clinical biomechanics (Bristol, Avon), 19(5), 473-9. doi:10.1016/j.clinbiomech.2004.02.001

Gurfinkel, V. (1994). The mechanisms of postural regulation in man. Soviet Scientific Reviews F Phys Gen Biol, 7, 59-89.

Hall, M. G., Fleming, H. E., Donal, M. J., Millbank, S. F. D., \& Paul, J. P. (1996). Static in situ calibration of force plates. Journal of Biomechanics, 29(5), 659-665.

Horak, F. B. (1987). Clinical measurement of postural control in adults. Physical therapy, 67(12), 1881-5.

Jacobson, G. P., Newman, C. W., \& Kartush, J. M. (1997). Handbook of Balance Function Testing (p. 439). 
Jbabdi, M., Boissy, P., \& Hamel, M. (2008). Assessing control of postural stability in community-living older adults using performance-based limits of stability. $B M C$ geriatrics, 8, 8. doi:10.1186/1471-2318-8-8

Jensen, J., Nyberg, L., Gustafson, Y., \& Lundin-Olsson, L. (2003). Fall and injury prevention in residential care--effects in residents with higher and lower levels of cognition. Journal of the American Geriatrics Society, 51(5), 627-35.

Johansson, R., Magnusson, M., \& Akesson, M. (1988). Identification of human postural dynamics. IEEE transactions on bio-medical engineering, 35(10), 858-69. doi:10.1109/10.7293

Lafond, D., Corriveau, H., Hébert, R., \& Prince, F. (2004). Intrasession reliability of center of pressure measures of postural steadiness in healthy elderly people. Archives of Physical Medicine and Rehabilitation, 85(6), 896-901. doi:10.1016/j.apmr.2003.08.089

Lin, D., Seol, H., Nussbaum, M. a, \& Madigan, M. L. (2008). Reliability of COP-based postural sway measures and age-related differences. Gait \& posture, 28(2), 337-42. doi:10.1016/j.gaitpost.2008.01.005

Loram, I. D., \& Lakie, M. (2002). Human balancing of an inverted pendulum: position control by small, ballistic-like, throw and catch movements. The Journal of Physiology, 540(3), 1111-1124. doi:10.1113/jphysiol.2001.013077

Lord, S. R., Menz, H. B., \& Tiedemann, A. (2003). A physiological profile approach to falls risk assessment and prevention. Physical therapy, 83(3), 237-52.

Luoto S, Aalto H, Taimela S, Hurri H, Pyykkö I, A. H. (1998). One-footed and externally disturbed two-footed postural control in patients with chronic low back pain and healthy control subjects: A controlled study with follow-up. Spine, 23(19), 2081 2089.

Massion, J. (1994). Postural control system. Current opinion in neurobiology, 4(6), 87787.

Maurer, C., \& Peterka, R. J. (2005). A New Interpretation of Spontaneous Sway Measures Based on a Simple Model of Human Postural Control. J Neurophysiol, 93, 189-200. doi:10.1152/jn.00221.2004.

Mcclenaghan, B. A., Williamsb, H. G., Dickersonc, J., Dowdaa, M., Thombsd, L., \& Eleazere, P. (1996). Spectral characteristics of aging postural control. Gait \& posture, 4, 112-121. 
Mita, K., Akataki, K., Itoh, K., Nogami, H., Katoh, R., Ninomi, S., Watakabe, M., et al. (1993). An investigation of the accuracy in measuring the body center of pressure in a standing posture with a force plate. Frontiers of Medical Biological Engineering, 5(3), 201-213.

Moghadam, M., Ashayeri, H., Salavati, M., Sarafzadeh, J., Taghipoor, K. D., Saeedi, A., \& Salehi, R. (2011). Reliability of center of pressure measures of postural stability in healthy older adults: effects of postural task difficulty and cognitive load. Gait \& posture, 33(4), 651-5. Elsevier B.V. doi:10.1016/j.gaitpost.2011.02.016

Nichols, D. S. (1997). Balance retraining after stroke using force platform biofeedback. Physical therapy, 77(5), 553-8.

Nist-traceability, B. (2010). Beyond NIST-Traceability: What really creates Accuracy?, 13(9).

Norris, J. A., Marsh, A. P., Smith, I. J., Kohut, R. I., \& Miller, M. E. (2005). Ability of static and statistical mechanics posturographic measures to distinguish between age and fall risk. Journal of biomechanics, 38(6), 1263-72.

doi:10.1016/j.jbiomech.2004.06.014

Pellecchia, G. L., \& Shockley, K. (2005). Application of Recurrence Quantification Analysis: Influence of Cognitive Activity on Postural Fluctuations. In M. A. Riley \& G. C. Van Orden (Eds.), Tutorials in contemporary nonlinear methods for the behavioral sciences (pp. 95-141).

Peterka, R. J. (2000). Postural control model interpretation of stabilogram diffusion analysis. Biological cybernetics, 82(4), 335-43.

Peterka, R. J., \& Loughlin, P. J. (2004). Dynamic regulation of sensorimotor integration in human postural control. Journal of neurophysiology, 91(1), 410-23. doi:10.1152/jn.00516.2003

Pieterse, A. J., Luttikhold, T. B., de Laat, K., Bloem, B. R., van Engelen, B. G., \& Munneke, M. (2006). Falls in patients with neuromuscular disorders. Journal of the neurological sciences, 251(1-2), 87-90. doi:10.1016/j.jns.2006.09.008

Pincus, S. M. (1991). Approximate entropy as a measure of system complexity. Proceedings of the National Academy of Sciences of the United States of America, 88(6), 2297-2301.

Pivnickova, L., Dolinay, V., \& Vasek, V. (2012). Processing of the balance examination results. Proceedings of the 13th International Carpathian Control Conference (ICCC), 559-563. Ieee. doi:10.1109/CarpathianCC.2012.6228707 
Prieto, T. E., Myklebust, J. B., Hoffmann, R. G., Lovett, E. G., \& Myklebust, B. M. (1996). Measures of postural steadiness: differences between healthy young and elderly adults. IEEE transactions on bio-medical engineering, 43(9), 956-66. doi: $10.1109 / 10.532130$

Raymakers, J. a, Samson, M. M., \& Verhaar, H. J. J. (2005). The assessment of body sway and the choice of the stability parameter(s). Gait \& posture, 21(1), 48-58. doi:10.1016/j.gaitpost.2003.11.006

Richman, J. S., \& Moorman, J. R. (2000). Physiological time-series analysis using approximate entropy and sample entropy. American Journal of Physiology-Heart and Circulatory Physiology, 278(6), H2039-H2049.

Rousseeuw, P. J. (1987). Silhouettes: a graphical aid to the interpretation and validation of cluster analysis.pdf. Journal of Computational and Applied Mathematics, 20, 5365 .

Ruhe, A., Fejer, R., \& Walker, B. (2010). The test-retest reliability of centre of pressure measures in bipedal static task conditions--a systematic review of the literature. Gait \& posture, 32(4), 436-45. doi:10.1016/j.gaitpost.2010.09.012

Ruhe, A., Fejer, R., \& Walker, B. (2011). Center of pressure excursion as a measure of balance performance in patients with non-specific low back pain compared to healthy controls: a systematic review of the literature. European spine journal, 20(3), 358-68. doi:10.1007/s00586-010-1543-2

Salavati, M., Hadian, M. R., Mazaheri, M., Negahban, H., Ebrahimi, I., Talebian, S., Jafari, A. H., et al. (2009). Test-retest reliability [corrected] of center of pressure measures of postural stability during quiet standing in a group with musculoskeletal disorders consisting of low back pain, anterior cruciate ligament injury and functional ankle instability. Gait \& posture, 29(3), 460-4. doi:10.1016/j.gaitpost.2008.11.016

Salminen, M., Vahlberg, T., Sihvonen, S., Sjösten, N., Piirtola, M., Isoaho, R., Aarnio, P., et al. (2009). Effects of risk-based multifactorial fall prevention on postural balance in the community-dwelling aged: A randomized controlled trial. Archives of Gerontology and Geriatrics, 48(1), 22-27. doi:10.1016/j.archger.2007.09.006

Satcher, D. (1999). Physical activity and health: a report of the Surgeon General (p. 306). Jones \& Bartlett Publishers.

Schmit, J. M., Riley, M. a, Dalvi, A., Sahay, A., Shear, P. K., Shockley, K. D., \& Pun, R. Y. K. (2006). Deterministic center of pressure patterns characterize postural instability in Parkinson's disease. Experimental brain research, 168(3), 357-367. doi:10.1007/s00221-005-0094-y 
Shepard, N. T., \& Janky, K. (2010). Computerized postural control assessment 1, 9, 238251. doi:10.1016/S1567-4231(10)09019-2

Shimada, H., Suzukawa, M., Ishizaki, T., Kobayashi, K., Kim, H., \& Suzuki, T. (2011). Relationship between subjective fall risk assessment and falls and fall-related fractures in frail elderly people. BMC geriatrics, 11(1), 40. BioMed Central Ltd. doi:10.1186/1471-2318-11-40

Tanaka, H., Nakashizuka, M., Uetake, T., \& Itoh, T. (2000). The effects of visual input on postural control mechanisms: an analysis of center-of-pressure trajectories using the auto-regressive model. Journal of human ergology, 29(1-2), 15-25. Retrieved from http://www.ncbi.nlm.nih.gov/pubmed/12696318

Tinetti, M. E., Williams, T. F., \& Mayewski, R. (1986). Fall risk index for elderly patients based on number of chronic disabilities. The American journal of medicine, $80(3), 429-34$.

Valles, K. D. B., Schneider, J. M., Long, J. T., Riedel, S. a, Johnson, M. J., \& Harris, G. F. (2006). Combined sagittal and coronal plane postural stability model. Conference proceedings: Annual International Conference of the IEEE Engineering in Medicine and Biology Society., 1, 4576-9. doi:10.1109/IEMBS.2006.259225

Winter, D. A. (1995). Human balance and posture control during standing and walking. Gait \& posture, 3, 193-214.

Wolff, D. R., Rose, J., Jones, V. K., Bloch, D. a, Oehlert, J. W., \& Gamble, J. G. (1998). Postural balance measurements for children and adolescents. Journal of orthopaedic research : official publication of the Orthopaedic Research Society, 16(2), 271-5. doi:10.1002/jor.1100160215

Žalik, K. R., \& Žalik, B. (2011). Validity index for clusters of different sizes and densities. Pattern Recognition Letters, 32(2), 221-234.

doi:10.1016/j.patrec.2010.08.007 